\title{
Catalysis with Colloidal Ruthenium Nanoparticles
}

\section{Rosa Axet and Karine Philippot*}

CNRS, LCC (Laboratoire de Chimie de Coordination), UPR8241, Université de Toulouse, UPS,

$$
\text { INPT, F-31077 Toulouse cedex 4, France }
$$

\section{AUTHOR INFORMATION}

LCC-CNRS (Laboratoire de Chimie de Coordination du CNRS)

205 route de Narbonne - BP 44099

31077 TOULOUSE CEDEX 4 - FRANCE

*E-mail: karine.philippot@Icc-toulouse.fr

\section{ORCID numbers}

Karine Philippot: 0000-0002-8965-825X

M. Rosa Axet: 0000-0002-2483-1533

Notes

The authors declare no competing financial interest. 


\section{ABSTRACT:}

This review provides a synthetic overview of the recent research advancements addressing the topic of catalysis with colloidal ruthenium metal nanoparticles through the last five years. The aim is to enlighten the interest of ruthenium metal at the nanoscale for a selection of catalytic reactions performed in solution condition. The recent progress in nanochemistry allowed providing well-controlled ruthenium nanoparticles which served as models and allowed to study how their characteristics influence their catalytic properties. Although this parameter is not enough often taken into consideration the surface chemistry of ruthenium nanoparticles starts to be better understood. This offers thus a strong basis to better apprehend catalytic processes on the metal surface and also, explore how these can be affected by the stabilizing molecules as well as the ruthenium crystallographic structure. Ruthenium nanoparticles have been reported for their application as catalysts in solution for diverse reactions. The main ones are reduction, oxidation, Fischer-Tropsch, $\mathrm{C}-\mathrm{H}$ activation, $\mathrm{CO}_{2}$ transformation, hydrogen production through amine borane dehydrogenation or watersplitting reactions, which will be here reviewed. Results obtained showed that ruthenium nanoparticles can be highly performant in these reactions but efforts are still required in order to be able to rationalize the results. Beside their catalytic performance, ruthenium nanocatalysts are very good models in order to investigate key-parameters for a better controlled nanocatalysis. This is a challenging but fundamental task in order to develop more efficient catalytic systems, namely more active and more selective catalysts able to work in mild conditions.

\section{CONTENTS}

\section{Introduction}


2. Interests of ruthenium and of metal nanoparticles

2.1 Physicochemical properties and interests of ruthenium

2.2 Interests of metal nanoparticles in catalysis

2.3 Present challenges in nanocatalysis and place of ruthenium nanocatalysts

3. Synthesis methods of ruthenium nanoparticles

3.1. Reduction of ruthenium(III) chloride hydrate

3.2. Polyol method

3.3. Use of an organometallic precursor

3.4. Supported nanoparticles

4. Ruthenium nanoparticles as catalysts

4.1. Reduction reactions

4.2. Oxidation reactions

4.3. Fischer-Tropsch reaction

4.4. C-H activation and other reactions

4.5. Transformation of $\mathrm{CO}_{2}$

4.6. Dehydrogenation of amine boranes

4.7. Water splitting

5. Concluding remarks and outlook

\section{INTRODUCTION}

With symbol Ru and the $44^{\text {th }}$ position in the periodic table of elements, ruthenium is part of the transition metals group. It is considered as a scarce metal with limited availability. This may be hindering wider commercial applications involving ruthenium due to its high price (even if still the least expensive precious metal) and wide fluctuations in the market. The 
applications of ruthenium mainly concern technological devices and catalysis sectors. In 2018, ruthenium consumption has achieved 42 tons for industrial applications concerning electronics (33\%), electrochemistry $(17 \%)$ and chemistry $(37 \%) .{ }^{1}$ For instance ruthenium is commonly added at a small quantity in alloys given its ability to harden them. This is the case of super alloys used for the manufacture of turbine blades of jet engines. It reinforces the rhodium, palladium and platinum-based alloys used for wear-resistant electrical contacts (high-end spark plugs have electrodes coated with a Pt-Ru alloy; pen tips are made with alloys containing ruthenium). Ruthenium dioxide, $\mathrm{RuO}_{2}$, and ruthenates of lead and bismuth are involved in resistive chips. In electronics, ruthenium is used in the manufacture of hard disks as a coating between two magnetic layers.

Regarding catalysis, ruthenium is a polyvalent metal because it can easily adopt formal oxidation states in a wide range (from - II to VIII) leading to a multitude of complexes that display interesting and often unique properties. These properties can be tuned by an appropriate choice of the stabilizing ligands because ligands strongly affect the reactivity as well as stability of ruthenium complexes. A molecular level understanding of structure-activity relationships in complexes is a key-parameter for the development of better catalysts. For instance bipyridines- and terpyridine-containing ruthenium complexes are known for their luminescent and photoredox properties. Such properties are at the basis of the photodissociation of water into $\mathrm{O}_{2}$ and $\mathrm{H}_{2}$ (water splitting) ${ }^{2}$ and of the development of new generation photovoltaic cells. ${ }^{3}$ Another important application of ruthenium is the catalytic production of added-value chemicals like acetic acid. ${ }^{4}$ Carbene-based ruthenium complexes are well-known for their central role in olefin metathesis that provides active molecules or functionalized polymers among others. Ru complexes with phosphorus-containing ligands (for example phosphines, diphosphines as the so-called BINAP, or phosphites) are active for 
hydrogenation reactions such as hydrogenation of $\mathrm{C}=\mathrm{C}$ and $\mathrm{C}=\mathrm{O}$ double bonds among others, including the enantioselective version. ${ }^{5}$ Ru complexes are also known for their catalytic performance in the synthesis of formic acid and its decomposition into $\mathrm{H}_{2}$ and $\mathrm{CO}_{2}$ or also the dehydrogenation of alcohols, two important reactions regarding hydrogen storage. ${ }^{6}$ Finally Ru species are also catalysts of oxidation reactions. ${ }^{7}$ In heterogeneous condition ruthenium is the most active catalyst for the production of ammonia. ${ }^{8}$ It is also active in the hydrogenation of diverse substrates. As ligands in molecular catalysis, supports play a key-role in the properties of supported ruthenium catalysts due to metal-support interactions. The fine understanding of microscopic properties of the heterogeneous catalysts, in particular the nature of surface active sites and their chemical or sterical environment is of utmost importance in order to improve catalytic performances. Finally, the oxidized form of ruthenium, $\mathrm{RuO}_{2}$, is known for its performance in heterogeneous oxidation catalysis and in electrocatalysis.

The exaltation of properties at the nanoscale regime can increase the relevance of ruthenium for catalysis. The recent progress in nanochemistry allowed having at disposal better controlled Ru NPs in terms of size, dispersion, shape, composition and surface state, etc. All these characteristics may influence strongly their surface properties and consequently their catalytic performance (both reactivity and selectivity) and numerous efforts are presently made in this sense. Using a molecular approach, namely studying the interface between surface atoms and stabilizers (ligands) by a combination of techniques from molecular chemistry (like nuclear magnetic resonance) to theoretical studies allows a better understanding of the surface chemistry of ruthenium nanoparticles. As it will be seen in the next parts, these findings give thus a strong basis to better apprehend catalytic processes on the metal surface as well as how these can be affected by the presence of stabilizing molecules 
or by the crystallographic structure of the ruthenium cores, eventually by taking benefit of these parameters.

This review will start by summarizing the physicochemical properties and interests of ruthenium together with those of metal nanoparticles (section 2) and following, the main synthesis methods to produce ruthenium metal nanoparticles in solution (section 3 ). Then, the purpose is to provide a synthetic overview of the recent advancements in research that address the investigation of ruthenium metal nanoparticles (Ru NPs) in catalysis in solution (or suspension) conditions in the period 2014-2019 (section 4). The aim is to highlight the potential of ruthenium metal when it is divided at the nanoscale in a controlled manner, namely under the form of well-defined Ru NPs, in colloidal catalysis. Ru NPs have been reported for their application as catalysts in diverse reactions. The reactions reviewed here include reduction, oxidation, Fischer-Tropsch, $\mathrm{C}-\mathrm{H}$ activation and amine borane dehydrogenation reactions where Ru NPs show to be very performant. Even if at a lesser extent, Ru NPs have been also investigated for the reduction of carbon dioxide and water splitting process. Relevant works involving Ru NPs in these catalytic reactions will be described. Selection of examples was governed by the degree of control of the characteristics of the described Ru NPs that was made possible by solution synthesis methods, thus allowing precise catalytic investigations. Heterogeneous catalysts are not considered due to the fact the metal nanoparticles they contain are generally poorly controlled due to drastic conditions applied for their preparation. However, a few examples of supported Ru NP-based catalysts are presented. This is justified either by their initial preparation method, which enabled to obtain well-controlled nanostructures thus providing complementary information to the discussed subjects or by the relevant or pioneering character of the contribution to the field 
of catalysis. Also a few papers from earlier years are included due to their high input. Finally concluding remarks and perspectives will be given for each type of reaction treated.

\section{INTERESTS OF RUTHENIUM AND METAL NANOPARTICLES}

\subsection{Physicochemical properties and interests of ruthenium}

Identified and isolated by Karl Karlovich Klaus in $1844,{ }^{9}$ ruthenium has as symbol Ru and the $44^{\text {th }}$ position in the periodic table of elements. Ruthenium is the $74^{\text {th }}$ most abundant metal, a rare element, and is part of the precious metals, being the first of the series beside rhodium, palladium, osmium, iridium and platinum. With a current price of ca. $7000 € / \mathrm{kg},{ }^{10}$ ruthenium is still the least expensive precious metal.

Ruthenium is a hard, silvery white metal which is unalterable in the ambiant air and does not tarnish at room temperature (r.t.). Ruthenium is a transition metal with electronic configuration $[\mathrm{Kr}] 4 \mathrm{~d}^{7} 5 \mathrm{~s}^{1}$ for the isolated atom in ground state. The oxidation states of ruthenium range from - II to VIII, the most common ones being II, III and IV. These different oxidation states provide a large number of stable ruthenium catalysts (at 16 or 18 electrons). Ruthenium is not easily oxidized at atmospheric condition but $\mathrm{RuO}_{2}$, a stable oxide, may be formed under oxygen pressure. Ruthenium tetroxide $\left(\mathrm{RuO}_{4}\right)$, a volatile compound, is a powerful oxidizing and very toxic. ${ }^{9}$ The dissolution of ruthenium is not easy and requires to use aqua regia in heating conditions. Crystalline structure of bulk ruthenium is hexagonal closed-packed (hcp) but at the nanoscale, face-centered cubic (fcc) structure is also known. ${ }^{11-}$

${ }^{13}$ Ruthenium is the only noble metal that can crystallize in the nanometer scale with the hcp structure or the fcc one. The anisotropy of the hexagonal system is expected to lead more easily to anisotropic crystals but there are only a few papers reporting anisotropic Ru NPs, and none with a high aspect ratio. ${ }^{14}$ 
The applications of ruthenium mainly concern technological devices and catalysis sectors. ${ }^{15}$ In catalysis, ruthenium is a polyvalent metal which proved to be active in both homogeneous and heterogeneous conditions. $\mathrm{RuCl}_{3} .3 \mathrm{H}_{2} \mathrm{O}$ is often the starting point of a rich coordination and organometallic chemistry thus leading to a wide variety of ruthenium complexes of high interest for homogeneous catalysis. Ruthenium complexes are able to activate unique and multiple bonds and make possible selective $\mathrm{C}-\mathrm{C}, \mathrm{C}-\mathrm{H}$ or $\mathrm{C}$-heteroatom bond formation and cleavage ${ }^{16}$ Ruthenium catalysts are thus involved in a great variety of organic reactions, such as alkylation, allylation, arylation, cyclization, cyclopropanation, hydrogenation, hydroformylation, hydrosilylation, hydroxylation, isomerization, olefin metathesis, oxidation, transfer hydrogenation, tandem reactions, water splitting, etc. Ru-catalysis is effectively exploited in the synthesis of natural and biologically active organic compounds, to access recognized chemotherapeutic agents, supramolecular assemblies, smart materials, specialty polymers, biopolymers, agrochemicals, and, increasingly, in valorization of renewable resources as platform chemicals for polymers. Presently, intensive research efforts are devoted in $\mathrm{C}-\mathrm{H}$ and $\mathrm{C}-\mathrm{X}$ bond activation, olefin metathesis, and newest trends of green chemistry, such as water oxidation and hydrogen production, reduction of $\mathrm{CO}_{2}$ to $\mathrm{CO}$, oleochemistry and reactions in eco-friendly media. ${ }^{17}$ Due to their matter state, heterogeneous transition metal catalysts are also of high interest in catalysis, and largely exploited at the industrial level. Heterogeneous catalysts are extended inorganic solids where the $d$ orbitals play a key-role in the adsorption and transformation of substrates. The catalytic activity of transition metals shows a strong periodic effect with a maximum of reactivity for group-8 transition metals among which ruthenium. Ruthenium is able to chemisorb diverse small molecules such as $\mathrm{O}_{2}, \mathrm{C}_{2} \mathrm{H}_{2}, \mathrm{CO}, \mathrm{H}_{2}, \mathrm{~N}_{2}$ and $\mathrm{CO}_{2}$. In heterogeneous and colloidal conditions, ruthenium is reputed to be active in hydrogenation of nitrogen for ammonia synthesis, 
hydrogenation of diverse substrates like olefins and carbonylated molecules but also of aromatics for which molecular ruthenium is not known, as well as for dehydrogenation of amine boranes and hydrogen evolution reactions. Interestingly, it is not very known for hydrogenation of $\mathrm{CO}_{2}$ and dehydrogenation of formic acid. $\mathrm{RuO}_{2}$ turned out to be an excellent oxidation catalyst in heterogeneous catalysis (mainly oxidation of $\mathrm{CO}$ ) and electrocatalysis (oxidation of water). ${ }^{18}$

\subsection{Interests of metal nanoparticles in catalysis}

Heterogeneous transition metal catalysts are extended inorganic solids where the $d$ orbitals play a key-role in the adsorption of substrates due to their ability to donate and accept electron density to and from the substrates. This is particularly true for the degenerate states in band structures. The electronic flexibility provided by the $d$ electrons of the metal surface has to be such that the bond with the substrate atoms is intermediate between weak and strong. The metal surface must be able to bind the substrate atoms strongly enough to provoke their dissociation in the chemisorption process. But the surface-atom bond created has to be not too strong, for the bonded substrate atom to be able to further react with other surface-bonded atoms and form the products that can rapidly desorb. If the surface-atom bond is too strong, further reaction will be precluded. The catalytic activity of transition metals shows a strong periodic effect with a maximum of reactivity for group- 8 transition metals where ruthenium is located. ${ }^{19}$

Being part of heterogeneous catalysts, metal nanoparticles (MNPs) have been known for a long time, but a renewed interest emerged in the last three decades for the design of better defined systems. ${ }^{20}$ Numerous research efforts are devoted to the design of well-controlled MNPs and even at an atomic precision level. ${ }^{21-22}$ This keen interest for MNPs derives from the particular matter state (finely divided metals) and exalted electronic properties, influencing 
physical and chemical properties that they present in comparison to bulk metals and molecular complexes. Besides fundamental aspects of research, this interest is also governed by the specific properties and the potential applications that MNPs may find in various domains including optoelectronics, sensing, biomedicine, catalysis, energy conversion and storage, as non-exhaustive examples. ${ }^{23-26}$ Several books focus specifically on nanocatalysis. ${ }^{27-}$ ${ }^{37}$ For catalysis, MNPs are attractive species due to the high surface to volume ratio they display. This ratio is even more pronounced when MNPs are at a size as close as one nanometer, or even below, since the number of surface atoms can be $>90 \%$ thus providing a vast number of potential active sites. It is thus of prime importance to have synthesis tools that enable to get ultra-small NPs in order to promote high surface area. Besides the size, other key-parameters need also to be controlled. The crystalline structure is important because depending on it, different types of crystalline plans can be exposed at the nanoparticle surface, which can lead to different catalytic properties. Controlling the shape of MNPs is another way to orientate the crystalline plans exposed. ${ }^{38-40}$ The last key-parameter but not the least is the composition of MNPs. The composition has to be adjusted depending on the catalysis target. Apart from the nature of the metallic core that may govern the reactivity (some metals are well-known for certain catalyses but not for others), the surrounding stabilizer for colloidal catalysis (ionic liquids (IL), polymers, surfactants, polyols, ligands, etc.) or the support for supported catalysis (metal oxides, metal organic frameworks (MOFs), carbon derivatives, etc.) may also influence or even orientate the catalytic performance. If calcination is usually applied in heterogeneous catalysis in order to suppress any organics and liberate the active sites, such treatment on small nanoparticles can be critical because of sintering. Moreover, naked MNPs are not always optimal catalysts. In modern nanocatalysis, the presence of organic ligands at the NP surface is not seen as detrimental but 
instead is a way to improve or even modify the chemoselectivity. ${ }^{41}$ Using ligands as stabilizers allows to make a parallel with molecular catalysis; the ligand interaction with surface metal atoms of the nanoparticles can be compared to ligand interactions with the metal centers in homogeneous catalysts, which is of paramount importance for stability and catalytic properties (activity and selectivity). Ligands can be chosen in order to tune the surface properties of MNPs through steric or electronic effects. ${ }^{42-43}$ The challenge is to find ligands able to stabilize well-defined MNPs while controlling accessibility at the metal surface and reactivity. ${ }^{41,44}$ Strongly bound capping ligands (like thiols or phosphines) can result in the poisoning of a nanocatalyst at high surface coverage. But a limited amount of ligand can be beneficial. The coordination of a ligand at a metal surface can also be a way to block selectively some active sites in order to orientate the catalysis evolution. Compared to the investigation of facet dependency, ${ }^{40,45}$ the ligand influence on the catalytic activity has been less intensively studied but recent results illustrate well the interest to do so. ${ }^{46-50}$ Ligand-stabilized MNPs can be applied to catalysis as stable colloidal suspensions but also in heterogeneous conditions when deposited on the surface or confined in the pores of a solid support. ${ }^{51}$ Ionic liquids ${ }^{52}$ are also very efficient to stabilize metal NPs and colloidal suspensions in ionic liquids can even be deposited onto inorganic supports. ${ }^{53}$

\subsection{Present challenges in nanocatalysis and place of ruthenium nanocatalysts}

Have at disposal synthesis strategies that allow access, in a reproducible manner, to welldefined MNPs in terms of size, crystalline structure, composition (metal cores and stabilizing agents), chemical order (bimetallic or multimetallic systems), shape and dispersion is a beneficial condition to investigate finely their catalytic properties and define structure/properties relationships. Taking advantage of recent developments in nanochemistry in solution, and in particular of the use of molecular chemistry tools, 
nanocatalysis is now well-established as a borderline domain between homogeneous and heterogeneous catalysis. Nanocatalysts can be seen as assemblies of individual active sites where metal-metal and metal-stabilizer bonds will both have influence. ${ }^{54}$ Precisely designed MNPs are expected to present benefits from both homogeneous and heterogeneous catalysts, namely high reactivity and better selectivity together with high stability. ${ }^{55}$ The understanding of structure-properties relationships is required for the design of more performant nanocatalysts in order to develop more efficient and eco-compatible chemical production. ${ }^{56}$ If a certain progress has been done in the last decade, this topic remains very challenging. Model nanocatalysts are needed in order to better understand the link between the characteristics of MNPs and their catalytic performance and thus bridge the gap between model surfaces and real catalysts. Each progress that contributes to reduce the gap of knowledge between nanocatalysts and homogeneous catalysts constitutes a step forward the development of more efficient and selective catalytic systems. Intensive efforts in this direction are needed in order to one day be able to anticipate the design of suitable catalysts for a given reaction.

Various metals are investigated in nanocatalysis towards these principles, with a huge number of studies dedicated to gold which is highly reputed for $\mathrm{CO}$ oxidation and emerges now in hydrogenation catalysis, ${ }^{57-58}$ or palladium which intervenes in various C-C coupling reactions and also in hydrogenation catalysis. ${ }^{59-60}$ Other metals like rhodium, platinum, iridium, nickel, cobalt, and iron among others, are also the object of numerous studies. Compared to all these metals, the number of works focusing on the use of Ru metal NPs in nanocatalysis may appear to be lower. This may be quite surprising given the large and successful application of this metal in homogeneous catalysis but can be explained by the fact it is an expensive metal. However, as it will be seen hereafter, ruthenium proved to be an interesting metal to carry 
out precise studies in order to establish structure/properties relationships in diverse catalytic reactions, mainly hydrogenation, hydrodeoxygenation, Fischer-Tropsch, $\mathrm{C}-\mathrm{H}$ activation, amine borane dehydrogenation, water splitting and carbon dioxide reduction.

\section{SYNTHESIS METHODS OF RUTHENIUM NANOPARTICLES}

Being part of heterogeneous catalysts, metal NPs have been known for a long time, but a renewed interest emerged in the last three decades for the design of better defined systems, studies in which Ru NPs stand at a good place. ${ }^{33}$ This arises from fundamental hurdles met in scientific research with badly defined NPs such as the common issue of size dispersity (e.g. $5 \%$ in even highly monodispersed samples), the unascertained surfaces of NPs, the unknown core/ligand interfaces, the defects and elusive edge structures in 2D materials, and the still missing information on alloy patterns in bi- and multimetallic NPs. Such imprecisions preclude deep understandings of many fundamental aspects of NPs, including the atomic-level mechanism of surface catalysis. ${ }^{22}$ Developing synthesis strategies that allow preparing, in a reproducible manner, well-defined MNPs in terms of size, crystalline structure, composition (metal cores and stabilizing agents), chemical order, shape and dispersion is a prerequisite in order to investigate finely their catalytic properties and determine the links between structural features and catalytic properties. For this purpose, bottom-up liquid-phase techniques are very attractive because they are versatile and easy to use, necessitating straightforward equipment than physic routes. Recent developments in nanochemistry offer efficient tools to reach these objectives and make nanocatalysis to be a recognized domain at the frontier between homogeneous and heterogeneous catalyses, thanks to better-controlled NPs that allow progressively to take benefit of advantages of both types of catalysts. ${ }^{33}$ Metal NPs stabilized by ligands allow performing fine surface studies as done with homogeneous 
catalysts. Indeed such NPs display a metal surface with an interface close to that of molecular complexes (isolated surface atoms can be seen like metal centers with their coordination sphere) while benefiting from the influence of neighbouring metal atoms. It is also worth to mention that recent developments of theoretical tools allow to bring computational chemistry applied to small NPs to the same level of accuracy and relevance as in molecular chemistry. ${ }^{61}$ All together nanochemistry and computational chemistry enable to have precise mapping of the surface properties of MNPs.

At the nanoscale level, ruthenium showed to be of interest in diverse catalytic reactions and different synthesis tools have been developed to access well-defined Ru NPs. The synthesis of ruthenium $\mathrm{NPs}^{62}$ is often performed by chemical reduction of ruthenium(III) chloride hydrate because of its availability, using various reagents such as amines, carbon monoxide, hydride salts $\left(\mathrm{NaBH}_{4}, \mathrm{LiAlH}_{4}\right)$, hydrazine, alcohols, citrate salts or hydrogen. The drawback of these methods is the presence of surface contaminants resulting from the reaction conditions, such as water, salts, organic residues, or even an oxide shell, which can alter the NP properties and limit access to their surface. An elegant approach to circumvent these difficulties is the use of organometallic (or metal-organic) complexes as metal sources which are generally decomposed under hydrogen atmosphere in mild conditions (low temperature and pressure) in organic solution. ${ }^{63}$ The main disadvantages of this approach is the access to the metal precursors and the need to handle them in inert conditions and in degassed organic solvents in order to preserve their initial properties. The gain is the high quality of the obtained NPs which display well-controlled characteristics and allow precise surface studies. In between, the polyol method allows the access to MNPs starting from metal complexes, similarly to the organometallic approach, but usually using harsher synthesis conditions. ${ }^{14}$ Whatever the preparation method followed, the particles are generally stabilized by a polymer, an ionic 
liquid, a surfactant or a ligand added to the reaction mixture for preventing undesired metal agglomeration and precipitation. A large interest is presently devoted to ligand-protected particles due to the intrinsic physicochemical properties of these ligands which can contribute to tune those of the particles. ${ }^{41}$ Before describing the catalytic applications of Ru NPs, we will summarize in the next sub-parts the main strategies developped in order to access Ru NPs in colloidal solutions, namely the reduction of ruthenium trichloride, polyol method and the use of an organometallic precursor. It is important to note that apart from these very often used methods, others are reported in the literature, such as the usage of ultrasounds or microwaves, microemulsion systems, co-precipitation techniques, sol-gel method, hydrothermal/solvothermal processing. These synthesis approaches will not be here described because they are not applied for the preparation of the Ru nanocatalysts cited in the following parts of this review.

\subsection{Reduction of ruthenium(III) chloride hydrate}

The reduction of ruthenium(III) chloride hydrate in water is the most used method to prepare Ru NPs because of its low cost, ease of implementation and scalability. This method (Figure 1) consists in treating an aqueous solution of commercial $\mathrm{RuCl}_{3} . \mathrm{xH}_{2} \mathrm{O}$ (with $\mathrm{x} \sim 3$ depending on purity; hereafter referred as $\mathrm{RuCl}_{3}$ ) by a reducing agent in the presence of a stabilizer, at ambient conditions (room temperature; r.t.) and without taking specific cautions. ${ }^{64}$ Diverse reductants can be used among which alcohols $(\mathrm{EtOH}),{ }^{65}$ hydrides $\left(\mathrm{NaBH}_{4}, \mathrm{KBH}_{4}\right.$ or other amine boranes, $\left.\mathrm{LiAlH}_{4}\right),{ }^{66}$ as well as hydrogen at low pressure (1-3 bar) ${ }^{67}$ are very common. Concerning the stabilizers whose role is to avoid the agglomeration of Ru NPs and to control their growth (size, shape), they need to be water-soluble. It can be an organic polymer like polyvinylpyrrolidone (PVP), a sugar derivative like cyclodextrins or chitosans, a surfactant like 
quaternary ammoniums, an ionic liquid (like imidazolium salts) or organic ligands (sulfonated phosphines, phosphonates, etc.) among others. By this way, stable aqueous colloidal suspensions of Ru NPs are fastly obtained that can be directly used for in catalysis in neat water or biphasic media without any purification. However, if no purification, one drawback can be the presence of by-products resulting from the reactants which can act as pollutants at the metal surface. Another inconvenient can be the (partial) oxidation of the metal surface which is often circumvented by treating the colloidal suspension under hydrogen pressure (low pressure: 1-20 bar) before catalysis. Nevertheless, the so-obtained Ru NPs can be isolated and purified, in particular to have a characterization reference before involving them in catalytic reactions, for comparison purposes.

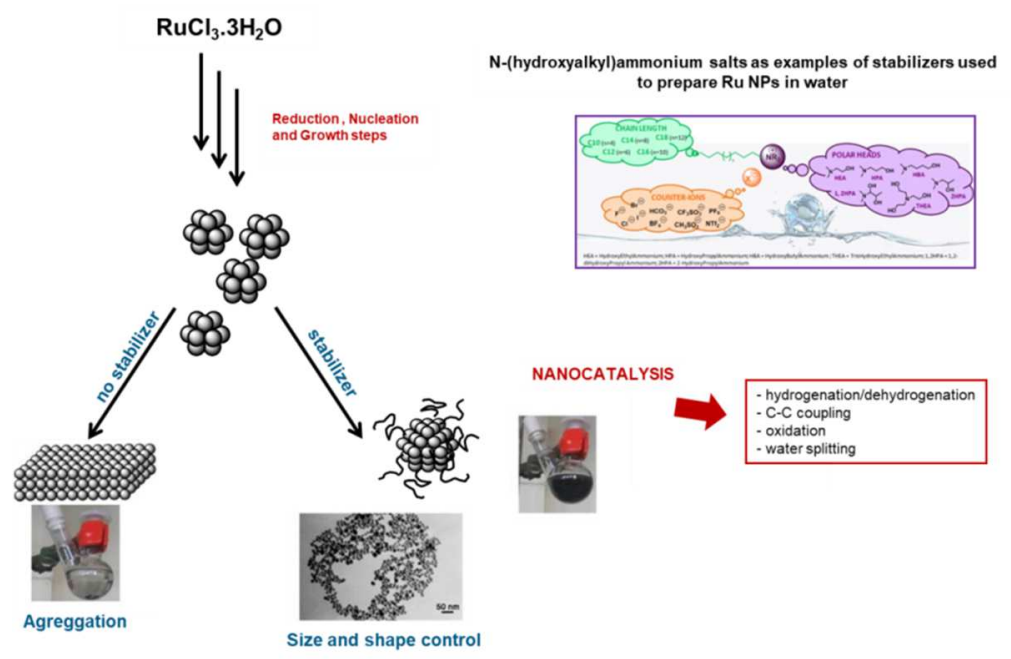

Figure 1 Synthesis of Ru nanocatalysts by reduction of ruthenium(III) chloride. Adapted with permission from ref ${ }^{64}$. Copyright 2016 Wiley.

\subsection{Polyol method}

In a recent review, Fiévet, Piquemal and coworkers recently described into detail the polyol process and its interests (Figure 2) to prepare MNPs with tailored sizes, shapes, compositions and architectures. ${ }^{14}$ 


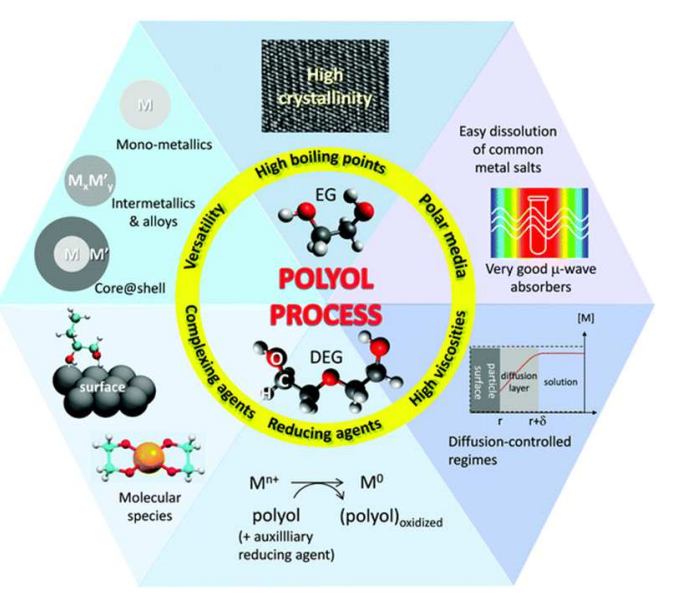

Figure 2. General view of the advantages of the polyol process. Reprinted with permission from ref ${ }^{14}$. Copyright 2016 Royal Society of Chemistry.

It is also a low cost and facile process, where a polyol (including 1,2-diols and ether glycols) is used as the liquid organic compound, acting as both as a solvent of the metal precursor and reducing agent as well as sometimes as colloidal stabilizer. The high boiling point of the polyols allows working at high temperature that assures the formation of well-crystallized NPs and enlarges the possibilities of syntheses. The polyol coordination ability to metal precursors and to NP surface via -OH groups both facilitates the dissolution of the metal sources and minimizes the NP coalescence. The high viscosity of polyols favours a diffusion-controlled regime for the NP growth resulting in controlled structures and morphologies. Despite the intrinsic properties of polyols, reducing agents (like acetates or hydrogen) and stabilizers (like polymers or surfactants) are often added to improve the characteristics of the NPs. Concerning Ru NPs, only a few papers describe their formation by the polyol process, mostly from $\mathrm{RuCl}_{3} .{ }^{14}$ But ruthenium complexes like $\left[\mathrm{Ru}(\mathrm{acac})_{3}\right]$ have been also described. In the presence of a protecting agent $\left(\mathrm{PVP},{ }^{68-69}\right.$ thiol, $^{70} \mathrm{or} \mathrm{NaOH}^{71}$ ) the formation of isotropic NPs in a size range 1- $6 \mathrm{~nm}$ has been reported. An example of anisotropic Ru NPs ${ }^{69}$ and others of fcc Ru NPs (active in CO oxidation, ${ }^{72}$ reduction of nitrophenol and dehydrogenation of 
aminoboranes, ${ }^{73}$ nitrogen reduction for ammonia synthesis ${ }^{74}$ or oxygen evolution reaction ${ }^{11}$ ) prepared in a polyol have also been reported.

\subsection{Use of an organometallic precursor}

First inspired by Bradley and coworkers, ${ }^{75-78}$ and then mainly developed by Chaudret and collaborators, ${ }^{79}$ the use of an organometallic complex is nowadays a well-established method to access model nanocatalysts. It allows getting well-defined soluble MNPs and exploring their surface properties. The key point of this strategy is the use of an organometallic complex (and in some extent metal-organic complex) as the source of metal atoms together with adequate stabilizers. It allows building diverse nano-objects with modulable sizes including ultra-small size (ca. 1-10 nm) and a metallic surface free of contaminants, which can be tuned at will. An advantageous benefit from organometallic or metal-organic complexes is their easy decomposition in mild conditions (1-3 bar $\mathrm{H}_{2} ;$ r. t. or $\mathrm{T} \leq 423 \mathrm{~K}$ ) through reduction or ligand displacement from the metal coordination sphere in an organic solvent and in the presence of a stabilizer. ${ }^{63}$ When accessible, olefinic complexes are preferred as they provide clean metal surfaces as treatment by $\mathrm{H}_{2}$ releases alkanes that are inert towards the NP surface and easily eliminated. Using this method, monodisperse assemblies of NPs with an efficient control of size, shape and surface state can be synthesized and then isolated and purified for a fine determination of their characteristics before application in catalysis. $[\operatorname{Ru}(C O D)(2-$ methylallyl) $\left.{ }_{2}\right]$ and $[\mathrm{Ru}(\mathrm{COD})(\mathrm{COT})]$ (where 1,5-cyclooctadiene (COD) and 1,3,5cyclooctatriene (COT)) are particularly relevant precursors to access well-defined Ru NPs (Figure 3). $\left[\mathrm{Ru}(\mathrm{acac})_{3}\right]$ and $\left[\mathrm{Ru}_{3}(\mathrm{CO})_{12}\right]$ can also be used but their decomposition requires higher temperatures and in the case of the latter, CO can remain at the metal surface. However, $\left[\mathrm{Ru}_{3}(\mathrm{CO})_{12}\right]$ complex allowed to access shape-controlled $\mathrm{Ru}$ NPs which is uncommon. ${ }^{80}$ 


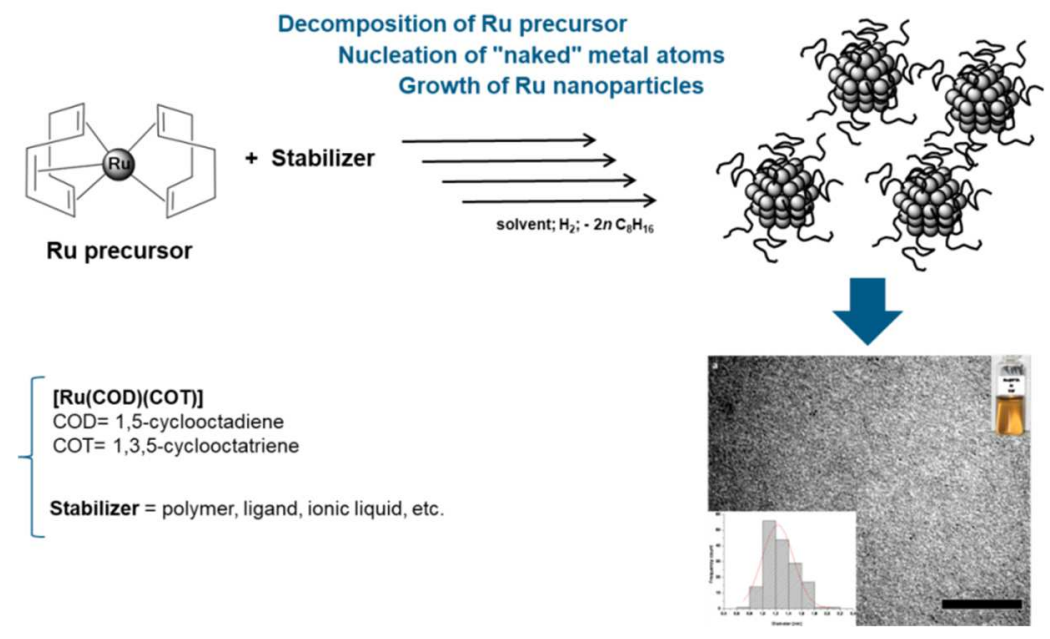

Figure 3. Synthesis of Ru NPs from an organometallic complex. Adapted with permission

$$
\text { from ref }{ }^{81} \text {. Copyright } 2014 \text { Springer. }
$$

The choice of the stabilizer is also fundamental as it governs the growth, stability, solubility properties and catalytic performance of the NPs. Besides organic polymers, like PVP, that provide steric stabilization and weak interaction with the metal surface, a plethora of organic ligands coordinating via $\mathrm{N}, \mathrm{S}, \mathrm{Si}, \mathrm{P}$ or $\mathrm{C}$ atoms to the metal surface have been used leading to fine-tuned surface properties. ${ }^{82}$ Ionic liquids can also be used. ${ }^{83-84}$ The employment of watersoluble stabilizers, namely polymers like PVP, ${ }^{85}$ ligands like 1,3,5-triaza-7phosphaadamantane (PTA), ${ }^{86}$ or sulfonated phosphines ${ }^{87}$ and also cyclodextrins ${ }^{88}$ allowed to produce aqueous suspensions of Ru NPs that are stable and active in C-H activation ${ }^{89}$ or hydrogenation catalysis, ${ }^{90}$ thus offering other opportunities in catalysis.

If a major inconvenient of this synthesis process is the access to the metal precursors which are costly, in some cases difficult to prepare and most often need to be handled under inert atmosphere, the quality of the obtained MNPs is a real plus for fundamental studies. Indeed, a good control over the particle formation process is achieved, due to the mild reaction conditions. Moreover, except the stabilizer voluntary added or traces of solvent, no contaminant, such as halides or other ions, is introduced. This makes this method powerful to 
have suitable NP models for performing fundamental studies on surface properties and also for following catalytic reactions, and numerous studies have been done with ruthenium (Figure 4). 81,91

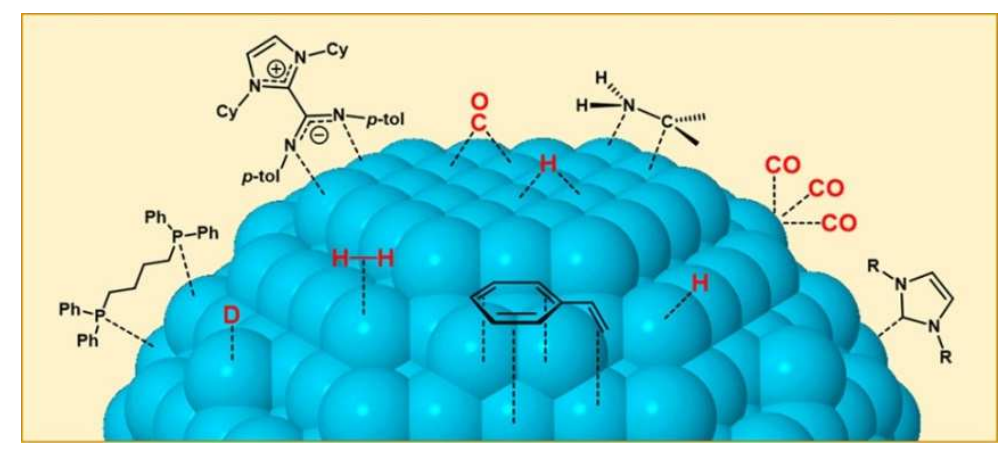

Figure 4. Schematic representation of some surface studies performed with Ru NPs prepared from an organometallic complex. Reprinted with permission from ref ${ }^{91}$. Copyright 2018 American Chemical Society.

The use of $\mathrm{H}_{2}$ as reducing agent to synthesize MNPs leads to hydrogen atoms at the metal surface, a clear advantage for reduction catalysis (vide infra). Computational chemistry performed onto ethanoic acid-stabilized Ru NPs indicated that ruthenium atoms present a positive charge density and hydrogen atoms a negative one, thus showing that hydrogen atoms are likely hydrides. ${ }^{92}$ The presence of hydrides has been experimentally supported by ${ }^{1} \mathrm{H}$ MAS NMR on PTA-stabilized Ru NPs which presented a signal at - $14 \mathrm{ppm}$, a typical value for hydrides on ruthenium complexes. ${ }^{90}$ The surface hydrides content has been shown to vary depending on the surface state of Ru NPs but is generally high ( $>1$ /surface Ru atom) even after $\mathrm{Np}$ transfer into water. ${ }^{81}$ Though this value can be also modulated with the species present on the surface; in Ru NPs stabilized by carboxylates the number of hydrides per surface Ru atom was found to be significantly lower (ca. $0.4 \mathrm{H} /$ surface Ru atom) by both experimental and theoretical techniques, as the result of the coordination mode of the stabilizer. ${ }^{92}$ The 
surface hydrides can be displaced by coordination of $\mathrm{CO}$ at the surface. NMR methods, in particular solid-state ${ }^{2} \mathrm{H}$ NMR, evidenced H-D exchange between Ru NPs surface and ligand sites: incorporation of ${ }^{2} \mathrm{H}$ atoms in the alkylchains of HDA used as capping ligand was observed, as the result of a $\mathrm{C}-\mathrm{H}$ activation phenomenon. ${ }^{93-94}$ This was further exploited in order to perform the deuteration of different substrates (vide infra). Using ${ }^{13} \mathrm{CO}$ as a probe molecule and IR (Infrared) and MAS NMR (magic angle spinning nuclear magnetic resonance) techniques provided indirect information on location and mobility of ligands at metal surface and helped to understand the surface properties and catalytic reactivity of NPs. ${ }^{95}$ For instance, it has been demonstrated that the strong coordination of phosphine ligands at a Ru NP surface blocks CO mobility contrarily to the few, weak bonds involved when a polymer is used as stabilizer. Similar strategies allowed localizing carbene ${ }^{96}$ or betaine adduct of NHC-carbene and carbodiimide ${ }^{95}$ ligands at Ru NP surface. CO oxidation was used to compare the reactivity of phosphine- and PVP-stabilized Ru NPs by FTIR (Fourier-Transform Infrared Spectroscopy), NMR (Nuclear magnetic resonance) and WAXS (Wide-angle X-Ray Scattering): CO oxidation proceeds at r.t. in each case but a rapid deactivation occurred for PVP-stabilized NPs due to the formation of $\mathrm{RuO}_{2}$ while phosphine effectively protects the NPs against bulk oxidation. Reduction of ${ }^{13} \mathrm{CO}_{2}$ by $\mathrm{H}_{2}$ was studied on PVP- and phosphine-stabilized Ru NPs by solid-state MAS NMR spectroscopy. Formation of ${ }^{13} \mathrm{CO}$ was observed in mild conditions ( 3 bar $\left.\mathrm{H}_{2}, 393 \mathrm{~K}\right)^{97}$ which was reduced upon heating into $\mathrm{CH}_{4}$ or hydrocarbons in a Fischer-Tropsch process as observed also when studying reduction of $\mathrm{CO}$ at the surface of the same Ru NPs. ${ }^{98}$

\subsection{Supported nanoparticles}

As the main purpose of this review is to discuss on the application of Ru NPs into colloidal (or suspension) condition, the synthesis of supported Ru NPs is here only briefly discussed. From the synthesis methods described above, it is quite easy to access supported Ru NPs using 
different types of supports (most often oxide-type and carbon-based supports). The most simple strategy is certainly the immobilization of pre-formed Ru NPs following an impregnation method, meaning mix a chosen support (eventually previously treated by treatment in temperature or vacuum) with a colloidal suspension of Ru NPs. If any, the porosity of the support will enable the NPs to diffuse inside the pores of the matrix and thus to be dispersed. An important point in this approach is the size of the pores which needs to be compatible with the NP size in order to get a high dispersion level. A favourable advantage deals with the presence of anchoring groups at the surface or in the pores of the support. The anchoring groups are generally chosen in order to provide interaction with the metal NPs and thus retain them more firmly than with simple physical adsorption. This interaction can be electrostatic, $\pi-\pi$ stacking or even covalent in nature.

For example, immobilization of Ru NPs, previously prepared from an organometallic precursor, into alumina, silica or carbon materials ${ }^{99}$ was carried out by this way in order to improve stability and recovery of the nanomaterials and also take advantage of the support properties during catalysis. Aqueous suspensions of Ru NPs prepared by reduction of $\mathrm{RuCl}_{3}{ }^{64}$ as well as by polyol suspensions ${ }^{14}$ can also be used to disperse NPs onto a support. The main advantage of this route is that the control of the NP growth is previously performed in solution and is generally kept after their deposition on the support. This makes possible to carry out comparison catalytic studies from NPs displaying similar characteristics in terms of size, shape and stabilizer nature, either being in suspension or supported conditions. But it is a two-steps synthesis process. Another strategy consists in the direct synthesis of NPs in the presence of the chosen support, keeping all the reaction conditions equal otherwise. Functionalized supports bearing chemical groups similar to those present in the stabilizers can improve the grafting of the NPs and their stability. Ionic liquids can be used also as stabilizing layer in the 
presence of an extra ligand or not. ${ }^{83}$ If this strategy is a one-step process, the structural characteristics of the growing NPs can be strongly influenced by the support properties which make comparison studies more complicated or even impossible.

\section{RUTHENIUM NANOPARTICLES AS CATALYSTS}

In the next sections, the use of Ru colloidal NPs as catalysts is described. Reduction reactions are mainly focused on arene hydrogenations, which have been extensively studied using Ru NPs as catalysts. Other reduction reactions like of nitrobenzene and azo compounds with $\mathrm{NaBH}_{4}$ are reported as well. Ru based catalysts are outstanding for this kind of reductions, but the intensive work in these reactions is also due to the fact that the properties of Ru NPs can be easily evaluated, namely, electronic and steric effects of the surface ligands, the crystalline structure, or the addition of a second metal, among others. Similarly, $\mathrm{CO}$ oxidation with $\mathrm{O}_{2}$ can be used as a model reaction to evaluate such parameters. Hydrodeoxygenation, a valuable procedure to upgrade biomass, is also studied with Ru NPs catalysts. Remarkably, bimetallic systems such as RuNi and RuFe NPs gave interesting results which pave the way to new applications of hydrodeoxygenation. An objective beyond is its application directly to biomass compounds and not only limited to oxygen containing model compounds. More recently, $\mathrm{C}-\mathrm{H}$ activation has been described with Ru NPs allowing to selectively deuterate organic compounds in mild conditions. Colloidal Ru NPs have found less application in other types of catalytic reactions such as oxidations or Fischer-Tropsch, and a few others, which are also described thereafter. Contrarily to Ru complexes, Ru NPs are not commonly reported for the transformation of $\mathrm{CO}_{2}$, but recent papers provide promising results. In the opposite, Ru NPs are largely studied in the dehydrogenation of amine boranes. If often in supported conditions, but Ru NPs in colloidal suspensions are also highly performant and ruthenium is among the 
best catalysts for this reaction. Ru-based NPs are presently the object of a renewed interest in water-splitting catalysis, with some catalysts showing a performance approaching that of $\mathrm{Pt}$ in the hydrogen evolution reaction.

\subsection{Reduction reactions}

$\mathrm{Rh}, \mathrm{Ir}$ and Ru compounds are very well-known as effective homogeneous catalysts. ${ }^{100}$ Similarly, the emerging single atom catalysts for reduction reactions are based in these metals. ${ }^{101}$ It is not surprising that Ru NPs have found applications as catalysts for a large panel of reduction reactions, mainly $\mathrm{C}=\mathrm{C}$ and $\mathrm{C}=\mathrm{O}$ bonds, in a broad range of reaction conditions. $\mathrm{Ru}$ NPs used as catalysts in reduction reactions are synthesised by one of the methodologies described above using a large variety of stabilizing agents, such as polymers, ${ }^{73-74,}$ 102-111 phosphines, ${ }^{112-116} \mathrm{~N}$-donor ligands, ${ }^{50,} 117-118$ ILs, $^{83-84, ~ 119-131} \mathrm{NHC},{ }^{96,}$ 132-139 alkynes, $^{140}$ chitin, ${ }^{141}$ fullerene, ${ }^{50,142-143}$ cyclodextrines, ${ }^{144-145}$ dendrimers, ${ }^{146-148}$ and others. The stabilizing agents not only allow to synthesize and maintain the Ru NPs stable, but also modulate their surface chemistry in a way which can be beneficial to obtain more efficient catalysts. The modulation of the surface properties is of major interest for catalysis, as the presence, or lack, of surface stabilizers can improve both the activity and selectivity on a given reaction. The non-innocent role of surface compounds in catalysis is nowadays well accepted and therefore, more efforts are devoted to this topic. ${ }^{91}$ Due to the accessibility and the surface sensitivity towards the metal surface of reduction reactions, they have also been used as an indirect characterization method to understand the surface of Ru-based NPs. ${ }^{113}$ Also, the addition of a second metal has been successfully used to improve the catalytic performances of Ru NPs catalysts. ${ }^{26,41,149-}$ 152 In this case, not only the nature of the second metal, but also the composition, the crystalline structure or the chemical order of the associated metals (alloy, core-shell, among others), play an important role in the results. More complex systems, based in the 
combination of three $\mathrm{e}^{153-154}$ or four ${ }^{155}$ different metals, have been also described as catalysts for reduction reactions.

\subsubsection{Reduction of $\mathrm{C}=\mathrm{C}$ and $\mathrm{C}=\mathrm{O}$ bonds}

Reduction of $\mathrm{C}=\mathrm{C}$ and $\mathrm{C}=\mathrm{O}$ double bonds have been extensively studied using Ru colloidal NPs as catalysts. Table 1 and 3 summarize Ru catalysed hydrogenation reactions of substrates containing these double bonds. By far styrene has been the most studied substrate, but also a plethora of other arene-type compounds, ketones, aldehydes, among others, is also described.

Table 1. Ru NPs as hydrogenation catalysts of arenes and carbonyl compounds

\begin{tabular}{|c|c|c|c|c|c|}
\hline $\begin{array}{l}\text { Stabilizing } \\
\text { agent }\end{array}$ & Synthetic methodology & Characterization & $\begin{array}{l}\text { Catalytic reaction } \\
\text { conditions }\end{array}$ & Comments & Ref. \\
\hline $\begin{array}{c}\text { Terminal and } \\
\text { internal alkynes }\end{array}$ & $\begin{array}{c}\text { Reduction of } \mathrm{RuCl}_{3} \\
\text { in 1,2-propanediol } \\
\mathrm{RuCl}_{3}(0.28 \mathrm{mmol}) \\
\text { sodium acetate (2 } \\
\mathrm{mmol}), 1,2- \\
\text { propanediol (100 } \\
\mathrm{mL}), 438 \mathrm{~K}, 30 \mathrm{~min}, \\
\text { alkyne }(0.84 \mathrm{mmol}) \\
\text { toluene }(100 \mathrm{~mL})\end{array}$ & $\begin{array}{l}\text { TGA, ICPS NMR, } \\
\text { IR, XPS, } \\
\text { photoluminescen } \\
\text { ce } \\
\text { measurements, } \\
\text { DFT }\end{array}$ & $\begin{array}{l}\text { Hydrogenation of } \\
\text { styrene by } \mathrm{H}_{2} \\
\text { Catalyst, styrene (1 } \\
\text { mL), THF, } \mathrm{H}_{2}(10 \\
\text { bar), } 298 \mathrm{~K}\end{array}$ & $\begin{array}{l}\text { Full hydrogenation of } \\
\text { styrene to } \\
\text { ethylcyclohexane using } \\
\text { terminal alkyne capped } \\
\text { Ru NPs; selective } \\
\text { hydrogenation to } \\
\text { ethylbenzene using } \\
\text { internal alkyne capped Ru } \\
\text { NPs; TOFs and quantity of } \\
\text { catalyst not given; } \\
\text { recycling tests not } \\
\text { reported }\end{array}$ & 140 \\
\hline $\begin{array}{l}\text { Cholesterol- } \\
\text { derived NHC }\end{array}$ & $\begin{array}{c}\text { Reduction of } \\
\text { [Ru(COD)(COT)] with } \\
\mathrm{H}_{2} \\
{[\mathrm{Ru}(\mathrm{COD})(\mathrm{COT})]} \\
\mathrm{NHC}\left(0.2 \text { eq.) } \mathrm{H}_{2}(3\right. \\
\text { bar), THF, } 298 \mathrm{~K}\end{array}$ & TEM, AAS, NMR & $\begin{array}{l}\text { Hydrogenation of } \\
\text { arenes by } \mathrm{H}_{2} \\
\text { Catalyst }(2 \mathrm{mg}, 0.01 \\
\mathrm{mmol} \mathrm{Ru}) \text {, arene } \\
(0.2 \mathrm{mmol}), \mathrm{THF}(1 \\
\mathrm{mL}), \mathrm{H}_{2}(5 \text { bar), r.t., } \\
20 \mathrm{~h}\end{array}$ & $\begin{array}{l}\text { Ligand backbone governs } \\
\text { selectivity and activity } \\
\text { bulky ligand displaying } \\
\text { higher selectivity; TEM } \\
\text { analysis after catalysis; } \\
\text { recycling and leaching } \\
\text { tests not reported }\end{array}$ & 138 \\
\hline Long-chain NHC & $\begin{array}{c}\text { Reduction of } \\
{[\mathrm{Ru}(\mathrm{COD})(\mathrm{COT})] \text { with }} \\
\mathrm{H}_{2} \\
{[\mathrm{Ru}(\mathrm{COD})(\mathrm{COT})](100} \\
\mathrm{mg}), \mathrm{NHC}(0.1-0.3 \\
\text { eq.), } \mathrm{H}_{2}(3 \mathrm{bar}), \mathrm{THF} \\
(50 \mathrm{~mL}), 298 \mathrm{~K}, 20 \mathrm{~h}\end{array}$ & $\begin{array}{l}\text { TEM, WAXS, } \\
\text { SSNMR, IR }\end{array}$ & $\begin{array}{c}\text { Hydrogenation of } \\
\text { arenes and alkenes } \\
\text { by } \mathrm{H}_{2} \\
\text { Catalyst }(1 \mathrm{mg}) \text {, } \\
\text { substrate }(0.2 \\
\mathrm{mmol}) \text {, solvent ( } 1 \\
\mathrm{~mL}), \mathrm{H}_{2}(3.5-5 \text { bar), } \\
298-303 \mathrm{~K}\end{array}$ & $\begin{array}{l}\text { Selectivity modulated } \\
\text { with surface ligand }\end{array}$ & 135 \\
\hline
\end{tabular}




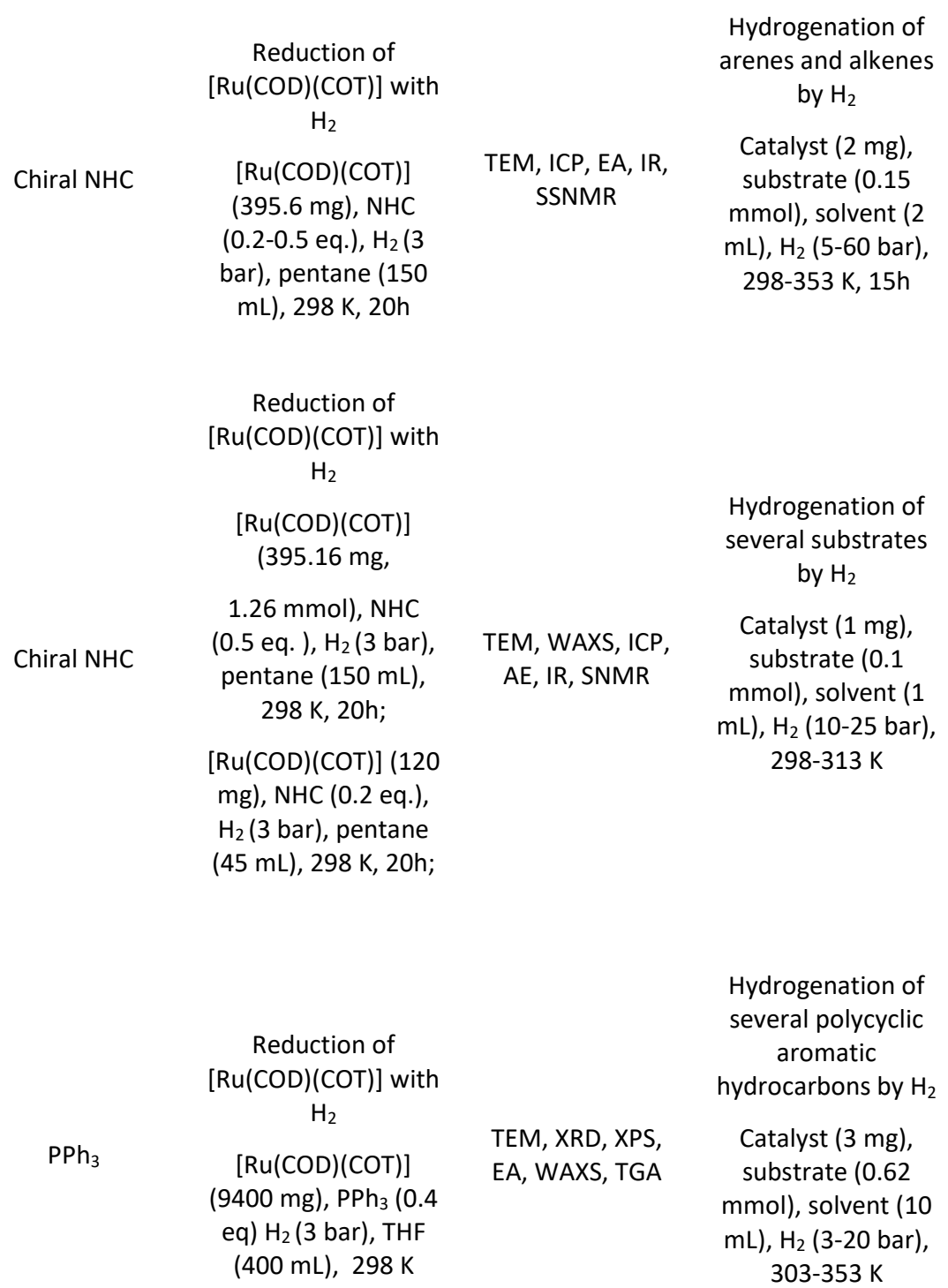

Reduction of [Ru(COD)(COT)] with $\mathrm{H}_{2}$

Phosphines $\quad[\mathrm{Ru}(\mathrm{COD})(\mathrm{COT})](400$ $\mathrm{mg}), \mathrm{PPh}_{3}$ or dppb (0.4 eq) $\mathrm{H}_{2}$ (3 bar), THF (400 mL), $298 \mathrm{~K}$

Reduction of $\mathrm{RuCl}_{3}$ with $\mathrm{NaBH}_{4}$.

Chitin

Hydrogenation of aromatic ketones by $\mathrm{H}_{2}$

TEM, XRD, XPS, EA, WAXS, TGA

Catalyst (2 mol\%), substrate (1.24 $\mathrm{mmol})$, solvent (10 $\mathrm{mL}), \mathrm{H}_{2}$ (3-20 bar), $303 \mathrm{~K}$

TEM, XRD, ICP

Hydrogenation of benzyl glycidyl ether and other arenes by $\mathrm{H}_{2}$ Catalyst $(0.8 \mathrm{~mol} \%$ $\mathrm{Ru})$, substrate (1
$\mathrm{RuCl}_{3}$ (71.6 mg), chitin (2.97 g), $\mathrm{NaBH}_{4}$ (30.6 mg), $\mathrm{H}_{2} \mathrm{O}(9 \mathrm{~mL}), 303 \mathrm{~K}$, $3.5 \mathrm{~h}$
Hydrogenation of by $\mathrm{H}_{2}$

Catalyst (2 mg), substrate $(0.15$ $\mathrm{mmol})$, solvent (2 298-353 K, 15h

Negligible enantiomeric excess observed; no recycling test or characterization of the spent catalysts
Negligible enantiomeric excess observed; no recycling test; TEM of the spent catalysts

Good activities and selectivities under mild reaction conditions; rate and selectivity depend on number of cycles on the substrate; selectivity depend on the number and nature of substrate substituents; no recycling test; no characterization of the spent catalyst

reduction of the arene favoured against ketone group; selectivity modulated by the surface ligand; catalytic reaction profile; $\mathrm{mmol}), \mathrm{H}_{2} \mathrm{O}(5 \mathrm{~mL})$, $\mathrm{H}_{2}$ (20bar), $323 \mathrm{~K}$, $1.5 \mathrm{~h}$

No hydrogenolysis side products; no Ru leaching as ascertained by ICP; TEM after catalysis show a slightly increase of NP size 


\begin{tabular}{|c|c|}
\hline & $\begin{array}{c}\text { Reduction of } \\
{[\mathrm{Ru}(\mathrm{COD})(\mathrm{COT})] \text { with }} \\
\mathrm{H}_{2}\end{array}$ \\
\hline Fullerene $\mathrm{C}_{60}$ & $\begin{array}{c}\text { [Ru(COD)(COT)], } \mathrm{C}_{60} \\
\text { (0.03-1 eq. ) }, \mathrm{H}_{2}(3 \\
\text { bar), } \mathrm{CH}_{2} \mathrm{Cl}_{2}, 298 \mathrm{~K}\end{array}$ \\
\hline
\end{tabular}

Polysiloxane matrix

Phosphinefunctionalized IL
Cyclodextrin polymer

NHC

\section{Reduction of \\ [Ru(COD)(2-} methylallyl) ${ }_{2}$ ] with $\mathrm{H}_{2}$ in a fused-silica coated column.

[Ru(COD)(2methylallyl) ${ }_{2}$ ] (0.1 $\mathrm{mg}), \mathrm{H}_{2}$ (0.1 bar), 313-463 K (0.5K/min), $10 \mathrm{~h}$

Reduction of $\mathrm{RuO}_{2}$ or [Ru(COD)(2methylallyl) ${ }_{2}$ ] with $\mathrm{H}_{2}$

$\mathrm{RuO}_{2}$ or

[Ru(COD)(2methylallyl) $)_{2}$ (0.018 mmol), phosphinefunctionalized ionic liquids (0.018 $\mathrm{mmol}),\left[\mathrm{BMIM} \mathrm{BF}_{4}\right.$ (1 $\mathrm{mL}), \mathrm{H}_{2}$ (10 bar), $348 \mathrm{~K}, 4 \mathrm{~h}$

Reduction of $\mathrm{RuCl}_{3}$ with $\mathrm{NaBH}_{4}$.

$\mathrm{RuCl}_{3}\left(3.6 \times 10^{-3}\right.$ $\mathrm{mmol})$, cyclodextrin polymer $(0.5 \mathrm{~g})$, $\mathrm{NaBH}_{4}(0.5 \mathrm{~mL}, 0.1$ $\mathrm{M}), \mathrm{H}_{2} \mathrm{O}(1.5 \mathrm{~mL})$, $273 \mathrm{~K}$

Reduction in situ of Ru-NHC complex during
TEM, IR, NMR, WAXS, Raman, EXAFS, XPS
Hydrogenation of trans-

cinnamaldehyde by $\mathrm{H}_{2}$

Catalyst $(5 \mathrm{mg})$, trans-

cinnamaldehyde (4 $\mathrm{mmol}$ ), IPrOH (30 $\mathrm{mL})$, pyridine (4.5 eq.), $\mathrm{H}_{2}$ (20 bar), $343 \mathrm{~K}, 20 \mathrm{~h}, 1000$ rpm hydrogenation reaction using $\mathrm{H}_{2}$
TEM, XRD, XPS, NMR, IR

TEM, IR, XRD, TGA, UV-vis, NMR
Hydrogenation of various carbonyl compounds oncolumn reaction by $\mathrm{H}_{2}$ chromatography

Catalyst (0.3 mol\%), substrate, $\mathrm{H}_{2}(0.5$ bar), 363K, retention time (5.2 s)

Hydrogenation of various substrates by $\mathrm{H}_{2}$

Catalyst (substrate/Ru = $100)$, substrate (1 $\mathrm{ml}$ solution at

1.8 M), $\mathrm{H}_{2}$ (50 bar), $303 \mathrm{~K}, 15 \mathrm{~h}$

Hydrogenation of cellulose-derived platform molecules by $\mathrm{H}_{2}$ Catalyst $\left(3.6 \times 10^{-3}\right.$ $\mathrm{mmol})$, substrate (5 mmol), $\mathrm{H}_{2} \mathrm{O}$ (1 $\mathrm{mL}), \mathrm{H}_{2}$ (40 bar), 353-403 K, 2-4 h

Hydrogenation of levulinic acid by $\mathrm{H}_{2}$ Catalyst (0.1 (4.31 mmol), $\mathrm{H}_{2} \mathrm{O}$ $(10 \mathrm{~mL}), \mathrm{H}_{2}(12$ mol\%), substrate
Selectivity to transcinnamyl alcohol of $77 \%$ TOF $=128 \mathrm{~h}^{-1}$

Recycling tests

Selectivity tuned with reaction conditions; poison test with $\mathrm{Hg}$; recycling test and leaching of $9 \mathrm{ppm}$ of Ru in the hydrogenation of styrene
Recycled 5 consecutive runs; TEM after catalysis showed a slight Ru NP aggregation and a slight increase of NP size
Ru NP formed during Ru homogeneous catalysed hydrogenation reaction
157

143 , 156

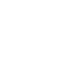<smiles>CCC</smiles>

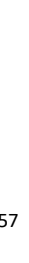

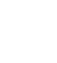


bar), $433 \mathrm{~K}, 160$ $\min$

Reduction of $[\mathrm{Ru}(\mathrm{COD})(\mathrm{COT})]$ with $\mathrm{H}_{2}$

$\begin{array}{cc}\begin{array}{c}\text { Chiral N-donor } \\ \text { ligands }\end{array} & {[\mathrm{Ru}(\mathrm{COD})(\mathrm{COT})](30} \\ & \mathrm{mg}, 0.1 \mathrm{mmol}), \\ & \text { chiral ligand }(0.02 \\ & \mathrm{mmol}), \mathrm{H}_{2}(3 \mathrm{bar}), \\ & \operatorname{THF}(80 \mathrm{~mL}), 298 \mathrm{~K}\end{array}$

IL

Thermal decomposition of $[\mathrm{Ru}(\mathrm{COD})(2$ methylallyl $)_{2}$ ]

$[\mathrm{Ru}(\mathrm{COD})(2$ methylallyl) $)_{2}$ (10-20 $\mathrm{mg})$, IL (1.4-2.8 g), $348 \mathrm{~K}, 18 \mathrm{~h}$

Stepwise reduction of [Ru(COD)(COT)] and $\left.\left[\mathrm{Pt}\left(\mathrm{CH}_{3}\right)_{2}(\mathrm{COD})\right]\right)$ or $\left[\mathrm{Pt}_{2}(\mathrm{dba})_{3}\right]$ with $\mathrm{H}_{2}$.

[Ru(COD)(COT)] (57$142 \mathrm{mg}$ ), [Pt $\left.\left.\left(\mathrm{CH}_{3}\right)_{2}(\mathrm{COD})\right]\right)$

RuPt/PPP (150-240 mg), PPP (0.24 mmol), THF, $\mathrm{H}_{2}$ (3 bar), $343 \mathrm{~K}, 18 \mathrm{~h}$; $\left[\mathrm{Pt}_{2}(\mathrm{dba})_{3}\right]$ (98-246 $\mathrm{mg})$, [Ru(COD)(COT)] (142-227 mg), PPP (0.22 mmol), THF, $\mathrm{H}_{2}$ (3 bar), r. t., $18 \mathrm{~h}$

Reduction of $\left[\mathrm{Fe}\left[\mathrm{N}\left(\mathrm{Si}\left(\mathrm{CH}_{3}\right)_{3}\right)_{2}\right]_{2}\right]_{2}$ and $[\mathrm{Ru}(\mathrm{COD})(\mathrm{COT})]$ with $\mathrm{H}_{2}$

RuFe/SILP
TEM

Hydrogenation of
acetophenone
derivatives by $\mathrm{H}_{2}$

Catalyst (0.01 $\mathrm{mmol})$, substrate (1 $\mathrm{mmol}$ ), heptane ( 25 $\mathrm{mL}$ ), $\mathrm{H}_{2}$ (40 bar), $323 \mathrm{~K}, 16 \mathrm{~h}$

Hydrogenation of the aldehyde intermediate originated from the acid-catalysed cleavage of lignin $\beta$ O-4 model by $\mathrm{H}_{2}$

TEM

Catalyst (5-30

mol\%), substrate (0.05 mmol, $0.1 \mathrm{M}$ ), $\mathrm{H}_{2}$ (10 bar), $453 \mathrm{~K}$, 5-20 min or $373 \mathrm{~K}$ 1-3h

TEM, WAXS, IR
Hydrogenation of trans-

cinnamaldehyde by $\mathrm{H}_{2}$ trans-

(7.5 mmol), nonane

(3.5 mmol), 2-PrOH

(50 mL), $\mathrm{H}_{2}$ (20 bar), $343 \mathrm{~K}$
Catalyst $(2.5 \mathrm{mg})$,

cinnamaldehyde

TEM, XAFS,
Low enantiomeric excesses; no recycling test; no characterization of the spent catalyst

Ru NPs on IL are active in arene and ketone hydrogenation; bifunctional reaction media containing both a Brønsted acid catalyst and Ru NPs lead to good yields of 2-phenylalcohol

Core-shell structure, selectivity tuned by structure and composition of the catalyst; synergistic effects observed

TEM after catalysis showed that shell rich NPs agglomerated and coalesced after catalysis while rich Ru or shell-Ru NPs were stable

$$
\begin{aligned}
& \text { Hydrogenation of } \\
& \text { substituted } \\
& \text { aromatic substrates } \\
& \text { Catalyst }(0.016 \\
& \text { mmol of metal), } \\
& \text { furfuralacetone }(0.4 \\
& \mathrm{mmol}), \mathrm{BMI}^{\mathrm{P}} \cdot \mathrm{PF}_{6}(1 \\
& \mathrm{mL}), \text { mesitylene }(0.5
\end{aligned}
$$

$\mathrm{Fe}_{25} \mathrm{Ru}_{75} / \mathrm{SILP}$ highly selective for ketone hydrogenation, while $\mathrm{Ru} / \mathrm{SILP}$ proceed to the full hydrogenation of the furfuralacetone molecule; hot filtration test recycled 
(500 mg),

mesitlyene $(5 \mathrm{~mL})$,

$\mathrm{H}_{2}$ (3 bar), $423 \mathrm{~K}$,

$18 \mathrm{~h}$

Reduction of

$\left[\mathrm{Fe}\left[\mathrm{N}\left(\mathrm{Si}\left(\mathrm{CH}_{3}\right)_{3}\right)_{2}\right]_{2}\right]_{2}$

and $[\mathrm{Ru}(\mathrm{COD})(\mathrm{COT})]$

with $\mathrm{H}_{2}$

$\left.\mathrm{Fe}\left[\mathrm{N}\left(\mathrm{Si}\left(\mathrm{CH}_{3}\right)_{3}\right)_{2}\right]_{2}\right]_{2}$

(0.5 mmol, 188.3

RuFe/HDA

RuSn/phosphine

Ru-PdCu yolkshell nanocrystals
$\mathrm{mg}),[\mathrm{Ru}(\mathrm{COD})(\mathrm{COT})]$

(0.5 mmol, 157.7

$\mathrm{mg}$ ), HDA (1.5 mmol, $362.2 \mathrm{mg})$,

mesitlyene $(10 \mathrm{~mL})$,

$\mathrm{H}_{2}$ (3 bar), $423 \mathrm{~K}$,

$18 \mathrm{~h}$

TEM, ICP, WAXS,

IR, magnetic

mesuarements

Reduction of

[Ru(COD)(COT)] with

$\mathrm{H}_{2}$ followed by

reaction with

tributyltin hydride

[Ru(COD)(COT)] (157

$\mathrm{mg}, 0.50 \mathrm{mmol}), \mathrm{PVP}$

(1 g) or dppb (20.8

$\mathrm{mg}, 0.049 \mathrm{mmol}, 0.1$

equiv.), THF $(60 \mathrm{~mL})$,

$\mathrm{H}_{2}$ (3 bar), r. t., 68h;

tri-n-butyltin

hydride $(13.5 \mu \mathrm{L}$,

$0.05 \mathrm{mmol}, 0.1$

equiv.), THF (10 mL),

$$
\text { r. t., } 18 \mathrm{~h} \text {. }
$$

Stepwise reduction

$$
\text { of }
$$

$\left[\mathrm{Pd}(\mathrm{acac})_{2}\right] / \mathrm{CuCl}_{2} \cdot 2 \mathrm{H}$ ${ }_{2} \mathrm{O}$ and $\mathrm{RuCl}_{3}$

[Pd(acac) $)_{2}$ (7.5 mg), $\mathrm{CuCl}_{2} .2 \mathrm{H}_{2} \mathrm{O}(0-40$

$\mathrm{mg}$ ), oleylamine (3

$\mathrm{mL})$, 1-octadecylene

(3 mL), EtOH, (1 mL),

$393 \mathrm{~K}, 10 \mathrm{~min} ; \mathrm{RuCl}_{3}$

(15.6 mg), EtOH (1

$\mathrm{mL}), 473 \mathrm{~K}, 12 \mathrm{~h}$

TEM, XRD, ICP,
$\mathrm{mL}), \mathrm{H}_{2}$ (20 bar),

$373 \mathrm{~K}, 18 \mathrm{~h}$

twice without loss of activity
Selectivity tuned by $\mathrm{Ru} /$ Fe ratio; no recycling test; no characterization of the spent catalyst
Hydrogenation of styrene by $\mathrm{H}_{2}$

TEM, HRTEM, WAXS, IR, NMR

Catalyst $(0.03 \mathrm{mmol}$ $\mathrm{Ru})$, styrene $(1 \mathrm{~mL})$, THF (5 mL), $\mathrm{H}_{2}$ (3 bar), r.t.
Synthesis of tin-

decorated nanoparticles; reactivity tuned by $\mathrm{Sn}$ surface species
Hydrogenation of styrene,

diphenylacetylene, 4-

nitrochlorobenzene

Catalyst $(0.005$

$\mathrm{mmol})$, styrene

( $0.17 \mathrm{mmol}$ ) or

diphenylacetylene

(0.056 mmol),

toluene $(1.5 \mathrm{~mL})$, $\mathrm{H}_{2}, 353 \mathrm{~K}$

- catalyst $(0.005$ $\mathrm{mmol}), 4-$

nitrochlorobenzene

(6 mg), toluene $(0.5$

$\mathrm{mL}), \mathrm{DMF}(1.5 \mathrm{~mL})$

$\mathrm{H}_{2}$ (ballon), $368 \mathrm{~K}$ fcc character of Ru depends on \%Pd; the reduction of nitro group was more performant when using fcc NPs compared to hcp NPs; the opposite trend was observed in styrene hydrogenation; no recycling tests; no characterization of the spent catalyst; no recycling test 
Selective hydrogenation reactions can provide useful information about the surface chemistry of the nanoparticles. For example, in the case of the hydrogenation of styrene, as Ru is very active in the hydrogenation of the arene moiety, the obtention of the partially hydrogenated product (ethylbenzene) is challenging and can give information about the role of the stabilizing surface compounds, such as their steric hindrance, or electronic properties, or the potential blockage of active sites. Ru NPs capped with terminal and internal alkynes showed different activity and selectivity in the selective hydrogenation of styrene; NPs capped with internal alkynes were highly selective towards the hydrogenation of the vinyl group. ${ }^{140}$ The characterization of the Ru NPs combined with theoretical calculations suggested that internal and terminal alkynes coordinate differently to the Ru surface; $\eta^{2}$ side-on configuration and $\mathrm{Ru}=\mathrm{C}=\mathrm{CH}-$, respectively; which could explain the different reactivity of both systems. Likewise, the deposition of Sn atoms onto the surface or Ru/PVP or Ru/dppb NPs modulated the reactivity of these systems when used as catalysts in the styrene hydrogenation. ${ }^{113}$ Indeed, the amount of Sn able to be accommodated onto the Ru NPs surface was dependent of the capping agent; Ru/PVP was able to integrate more Sn on the surface, when compared to $\mathrm{Ru} / \mathrm{dppb}$, in which the reaction with tin-precursor is limited due to the presence of the bulky ligand. Then, the nature of the stabilizing agent together with the amount of Sn deposited on the ruthenium surface tuned the catalytic activity of the Ru NPs (Table 2). Introducing 0.2 eq of $\mathrm{Sn}$ onto the Ru/PVP catalyst led to a highly selective catalyst, as $95 \%$ of styrene was obtained at $100 \%$ of conversion. The same selectivity was reached by only introducing 0.05 eq of $\mathrm{Sn}$ onto the $\mathrm{Ru} / \mathrm{dppb}$ surface. Both the presence of a bulky ligand and of a small amount of tin onto the surface led to a highly selective catalyst. The increase of the amount of tin on the NP surface was in detrimental of the activity in both catalysts used, Ru/PVP and Ru/dppb, indicating that the control of the selectivity is more likely due to a decrease on the reaction 
rate, than to a specific reactivity. This later has not being checked for instance by following the reaction over time.

Table 2. Hydrogenation of styrene with Ru/PVP/Sn or Ru/dppb/Sn NPs as catalysts. Conversion determined by GC. $(\mathrm{A}=$ styrene; $\mathrm{B}=$ ethylbenzene; $\mathrm{C}=$ ethylcyclohexane. Reprinted with permission from ref ${ }^{113}$. Copyright 2014 The Royal Society of Chemistry.

\begin{tabular}{ccc}
\hline & \multicolumn{2}{l}{ Product ratio A : B : C (\%) } \\
\cline { 2 - 3 } Sn eq. & Ru/PVP/Sn & Ru/dppb/Sn \\
\hline 0 & $0: 0: 100$ & $0: 0: 100$ \\
0.05 & $0: 1: 99$ & $0: 95: 5$ \\
0.1 & $0: 5: 95$ & $0: 88: 12$ \\
0.2 & $0: 95: 5$ & $0: 99: 1$ \\
0.5 & $15: 85: 0$ & $52: 47: 1$ \\
\hline
\end{tabular}

Similarly, styrene and 2-butanone hydrogenation selectivity was modulated by the Fe content in RuFe NPs stabilized with HDA. ${ }^{118}$ The same synthesis procedure allowed to prepare a series of RuFe NPs displaying several Ru/Fe ratios, in this case using a supported ionic liquid phase $(\mathrm{SILP})^{131}$ as a stabilizer. $\mathrm{Fe}_{25} \mathrm{Ru}_{75} / \mathrm{SILP}$ was highly selective for ketone hydrogenation in furanbased substrates, while Ru/SILP promoted the full hydrogenation of the substrates. The reduction of furfuralacetone was found highly sensitive to the amount of iron in the catalyst. Best compromise in terms of activity and selectivity was obtained for a $\mathrm{Fe}_{25} \mathrm{Ru}_{75}$ composition. Reaction rates for the $\mathrm{C}=\mathrm{O}$ hydrogenation of intermediates in furfuralacetone reduction were calculated to be 0.107 and $0.025 \mathrm{M} / \mathrm{h}$ for $\mathrm{Fe}_{25} \mathrm{Ru}_{75}$ and $\mathrm{Ru}_{100}$, respectively. These data and also reaction profiles over time supported that by adding a second metal to the ruthenium catalyst 
the hydrogenation of the heteroarene can be suppressed, but also that the hydrogenation of the ketone group can be enhanced, leading to a highly selective catalyst.

The crystalline structure of the metal cores has been found to also influence the reactivity of Ru nanocatalysts in hydrogenation reactions. The crystalline structure of Ru NPs synthesised by epitaxial growth on PdCu alloyed NPs could be controlled in a way to obtain Ru NPs presenting a fcc or a hcp structure. ${ }^{154}$ The crystal structure of the nanoparticles affected the catalytic activity of the hydrogenation of 4-chloronitrobenzene; fcc Ru NPs had a superior activity when compared to the hcp ones. In opposition, fcc Ru NPs were less efficient in the hydrogenation of styrene. The reported conversion of styrene towards ethylbenzene at $4 \mathrm{~h}$ of reaction was over $98 \%$ catalysed by hcp Ru NPs compared with $53 \%$ conversion with fcc Ru NPs catalyst. The different reactivity towards the reduction of the two different functional groups was attributed to a different adsorption of the substrates over Ru surface but no further evidence is reported.

Styrene hydrogenation activity and selectivity were also tuned with Ru NPs bearing two different rigid and bulky NHC ligands derived from cholesterol. ${ }^{138}$ The different performances observed were related to the flexibility of the NHC backbones; while ligands with higher steric hindrance lower the amount of ligand on the NP surface, higher quantities of free faces are accessible at the metallic surface, which are needed for the hydrogenation of aromatic rings, and therefore reduces the selectivity towards partially hydrogenated product. Differences on activity were also reported for substrates like acetophenone, biphenyl and naphthalene. Other NHC ligands displaying different backbones and substituents at the $\mathrm{N}$ atoms have been also used as stabilizers for Ru NPs. ${ }^{133-135,138}$ The reactivity of these species in catalysed hydrogenation reactions was governed by the bulkiness of the ligand, nevertheless, the use of 
slightly different synthetic and catalytic reaction conditions make the comparison difficult among them.

In Ru NPs stabilized with phosphines, $\mathrm{PPh}_{3}$ or $\mathrm{dppb}$, both arene and carbonyl group of the acetophenone coordinate to the NPs surface competitively, giving predominantly the fully hydrogenated product. It was pointed out that the steric hindrance of the phosphine ligand governed the selectivity in several reduction reactions. ${ }^{116}$ The reported TON for $\mathrm{Ru} / \mathrm{PPh}_{3}$ are superior to those for Ru/dppb system in the hydrogenation of acetophenone, but not being a general rule, which indicates that the activity and selectivity depend on the reaction conditions too. In contrast to ruthenium systems, for Rh NPs stabilized by the same phosphine ligands, no ligand effect was observed.

Polycyclic aromatic hydrocarbons were also hydrogenated with $\mathrm{Ru} / \mathrm{PPh}_{3} \mathrm{NPs}$ under mild reaction conditions. ${ }^{112}$ The selectivity in the hydrogenation reaction of naphthalene, phenanthrene, triphenylene, and pyrene was mainly governed by experimental conditions, and the nature and number of substituents of the substrates (Figure 5).

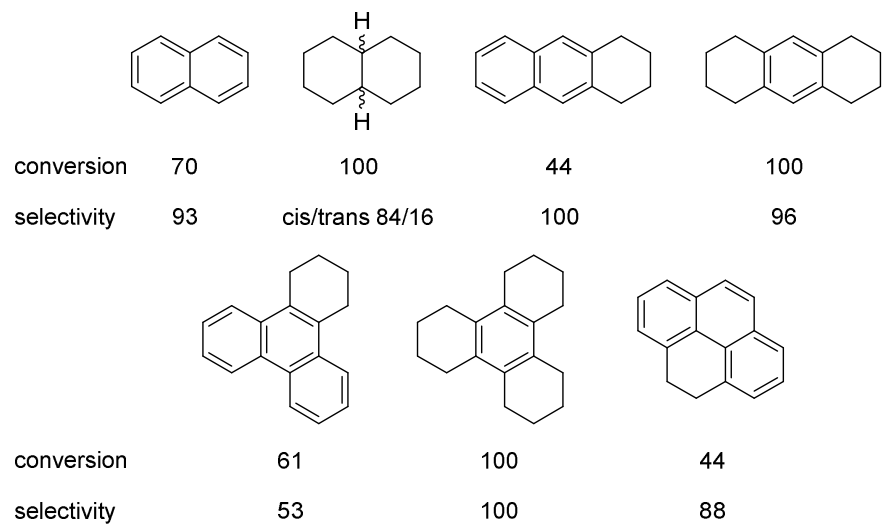

Figure 5. Conversion and selectivity of reduction using $\mathrm{Ru} / \mathrm{PPh}_{3} \mathrm{NPs}$. Reprinted with permission from ref ${ }^{112}$. Copyright 2015 The Royal Society of Chemistry.

Ru NPs are able to hydrogenate non-conjugated $C=C$ double bonds in very mild reaction conditions. In the case of $\alpha$-pinene (Figure 6), Ru NPs have proven to be very efficient among 
other metals, such as Pd or Ni. Also, the reaction is more selective when performed in water. ${ }^{159}$ This explains than mainly Ru NPs stabilized with water-soluble polymers are described for this application, and also that water-soluble Ru salts are the preferred starting precursors to synthesise them (Table 3). ${ }^{107,}$ 109, $159-162$ Usually high selectivities towards cis-pinane are reported, and the catalytic systems can be recycled several times without significative loss of activity. Interesting enough, Ru NPs synthesised in the presence of a $\beta$-cyclodextrin polymer ${ }^{145}$ were able to selectively convert phenylacethylene to styrene in water under mild conditions (1 bar $\mathrm{H}_{2}, 323 \mathrm{~K}$ ).

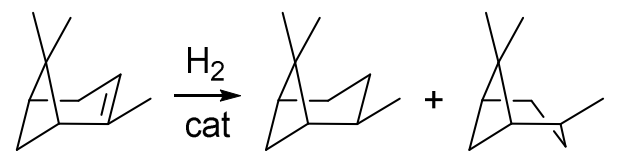

Figure 6. Hydrogenation of $\alpha$-pinene

Table 3. Ru NPs as hydrogenation catalysts of alkenes

\begin{tabular}{|c|c|c|c|c|c|}
\hline $\begin{array}{l}\text { Stabilizing } \\
\text { agent }\end{array}$ & Synthetic methodology & $\begin{array}{l}\text { Characterizati } \\
\text { on }\end{array}$ & $\begin{array}{l}\text { Catalytic reaction } \\
\text { conditions }\end{array}$ & Comments & Ref. \\
\hline $\begin{array}{l}\text { Polyvinyl } \\
\text { alcohol } \\
\text { (PVA) }\end{array}$ & $\begin{array}{l}\text { Reduction of } \mathrm{RuCl}_{3} \text { with } \mathrm{H}_{2} \\
\mathrm{RuCl}_{3}(2.1 \mathrm{mg}, 0.01 \mathrm{mmol}) \text {, } \\
\text { PVA (Mw: 78,000,15 mg), } \\
\mathrm{H}_{2} \mathrm{O}(\mathrm{mL}), \mathrm{H}_{2}(50 \text { bar }), 323 \mathrm{~K}\end{array}$ & $\begin{array}{l}\text { TEM, XPS, ICP, } \\
\text { confocal laser } \\
\text { scanning } \\
\text { microscope } \\
\text { (CLSM) }\end{array}$ & $\begin{array}{l}\text { Hydrogenation of } \alpha \text { - } \\
\text { pinene and other } \\
\text { alkenes by } \mathrm{H}_{2} \\
\text { Catalyst/ } \alpha \text {-pinene } \\
1000 / 1, \alpha \text {-pinene ( } 10 \\
\text { mmol), water, } \mathrm{H}_{2}(20 \\
\text { bar), } 343 \mathrm{~K}\end{array}$ & $\begin{array}{l}\text { Recycled eight times } \\
\text { without loss in the } \\
\text { catalytic activity and } \\
\text { selectivity }\end{array}$ & 159 \\
\hline $\begin{array}{l}\text { Methyl } \\
\text { laurate- } \\
\text { modified } \\
\text { carboxym } \\
\text { ethyl } \\
\text { cellulose } \\
\text { (HM-CMC) }\end{array}$ & $\begin{array}{l}\text { Reduction of } \mathrm{RuCl}_{3} \text { with } \mathrm{H}_{2} \\
\begin{array}{c}\mathrm{RuCl}_{3}(0.008 \mathrm{mmol}), \mathrm{HM}-\mathrm{CMC} \\
(2 \mathrm{mg}), \mathrm{H}_{2} \mathrm{O}(2 \mathrm{~mL}), \mathrm{H}_{2}(20 \\
\text { bar) }, 333 \mathrm{~K}\end{array}\end{array}$ & $\begin{array}{c}\text { TEM, XRD, } \\
\text { CLSM, DLS, IR }\end{array}$ & $\begin{array}{l}\text { Hydrogenation of } \alpha \text { - } \\
\text { pinene by } \mathrm{H}_{2} \\
\text { Catalyst }(2 \mathrm{mg}), \alpha- \\
\text { pinene }(5 \mathrm{mmol}), 2 \\
\mathrm{mg} \mathrm{Na}_{2} \mathrm{CO}_{3}, \text { water, } \mathrm{H}_{2} \\
(15 \text { bar), } 348 \mathrm{~K}, 5 \mathrm{~h}\end{array}$ & $\begin{array}{c}96.6 \% \text { conv. with } 98.4 \% \\
\text { conv.; recycled } 20 \text { times } \\
\text { with loss of activity due } \\
\text { to catalysts } \\
\text { agglomeration and Ru } \\
\text { leaching (measured by } \\
\text { ICP) }\end{array}$ & 160 \\
\hline $\begin{array}{l}\text { TPGS- } \\
1000\end{array}$ & $\begin{array}{l}\text { Reduction of } \mathrm{RuCl}_{3} \text { with } \mathrm{H}_{2} \\
\mathrm{RuCl}_{3}(2 \mathrm{mg}), \mathrm{TPGS}-1000 \text { (2 } \\
\left.\mathrm{mL} 0.5 \% \text { in } \mathrm{H}_{2} \mathrm{O}\right),(2 \mathrm{~mL}), \mathrm{H}_{2}(5 \\
\text { bar), } 323 \mathrm{~K}\end{array}$ & $\begin{array}{c}\text { TEM, XPS, } \\
\text { XRD, DLS, ICP }\end{array}$ & $\begin{array}{l}\text { Hydrogenation of } \alpha \text { - } \\
\text { pinene by } \mathrm{H}_{2} \\
\text { Catalyst }(0.01 \mathrm{mmol}), \\
\alpha \text {-pinene }(2 \mathrm{mmol}), \\
\mathrm{Na}_{2} \mathrm{CO}_{3}(2 \mathrm{mg}), \mathrm{H}_{2}(15 \\
\text { bar), r. t.-323 K }\end{array}$ & $\begin{array}{l}\text { Recycled at } 100 \% \\
\text { conversion up to } 14 \\
\text { times, then abrupt } \\
\text { decrease of conversion; } \\
\text { TEM of the spent } \\
\text { catalysts indicates NP } \\
\text { agglomeration }\end{array}$ & 107 \\
\hline
\end{tabular}




$$
\begin{array}{cc}
\text { triblock } & \text { Reduction of } \mathrm{RuCl}_{3} \text { with } \mathrm{H}_{2} \\
\text { copolyme } & \mathrm{RuCl}_{3}(2 \mathrm{mg}), \mathrm{TPGS}-1000(2 \\
r & \left.\mathrm{~mL} 0.5 \% \text { in } \mathrm{H}_{2} \mathrm{O}\right),(2 \mathrm{~mL}), \mathrm{H}_{2}(5 \\
& \text { bar), } 323 \mathrm{~K}
\end{array}
$$

TEM, XRD, XPS, UV-vis

Reduction of $\left[\mathrm{Ru}(\mathrm{NO})\left(\mathrm{NO}_{3}\right)_{3}\right]$ with $\mathrm{NaBH}_{4}$.

B- $\quad\left[\mathrm{Ru}(\mathrm{NO})\left(\mathrm{NO}_{3}\right)_{3}\right](269 \mathrm{mg}, 40$ cyclodextr $\quad \mu \mathrm{mol},),(7.8 \mathrm{mg}, 0.03 \mathrm{mmol})$, in $\quad$ CTAB (235 mg of the polymer polymer

(0.4 mmol of ammonium group), $\mathrm{NaBH}_{4}(4 \mathrm{~mL}, 0.1 \mathrm{M})$, $\mathrm{H}_{2} \mathrm{O}(8 \mathrm{~mL}), 298 \mathrm{~K}$

TEM, DLS, TGA
Hydrogenation of $\alpha$ pinene by $\mathrm{H}_{2}$

Catalyst $(0.01 \mathrm{mmol})$, $\alpha$-pinene (273 mg), $\mathrm{H}_{2} \mathrm{O}(2 \mathrm{~mL}), \mathrm{H}_{2}$ (3 bar), $313 \mathrm{~K}, 2 \mathrm{~h}$

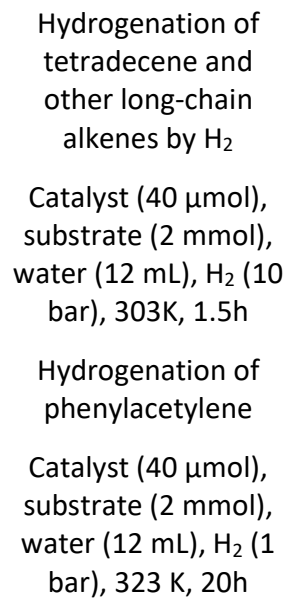

Hydrogenation of tetradecene and other long-chain alkenes by $\mathrm{H}_{2}$

Catalyst $(40 \mu \mathrm{mol})$, substrate $(2 \mathrm{mmol})$, water $(12 \mathrm{~mL}), \mathrm{H}_{2}(10$ bar), 303K, $1.5 \mathrm{~h}$

Hydrogenation of phenylacetylene

Catalyst $(40 \mu \mathrm{mol})$, substrate $(2 \mathrm{mmol})$, water $(12 \mathrm{~mL}), \mathrm{H}_{2}$ (1 bar), $323 \mathrm{~K}, 20 \mathrm{~h}$ NMR, IR, XPS,

Hydrogenation of alkenes by $\mathrm{H}_{2}$

Montmori Ilonite clay

$$
\text { with } \mathrm{NaBH}_{4} \text {. }
$$

$\left[\mathrm{Ru}\left(\mathrm{NH}_{3}\right)_{6}\right] \mathrm{Cl}_{3}$

montmorillonite clay, $\mathrm{NaBH}_{4}$ (4 mL, $0.1 \mathrm{M}), \mathrm{H}_{2} \mathrm{O}(40 \mathrm{~mL}), \mathrm{r}$.
TEM, SAXS, ICP, BET
Catalyst $(0.1 \mathrm{~g})$, substrate $(2 \mathrm{~mL})$, water (12 mL), $\mathrm{H}_{2}$ (520 bar), 313-373 K
Recycled at $100 \%$ conversion up to 5 times, then abrupt decrease of conversion; TEM of the spent catalysts indicates NP agglomeration
Ru NPs organized into small worm-like microdomains

of size-controlled nanoparticles; catalyst recycled and reused 10 times without loss of activity

Semi-hydrogenation of phenylacetylene with $100 \%$ selectivity towards styrene

Recycled 9 times with a slightly loss of activity

.


and hydrazo derivatives, among others. ${ }^{166-168}$ Reactions performed in the liquid phase have used a variety of metal catalysts $(\mathrm{Ni}, \mathrm{Pt}$, and $\mathrm{Pd})$, but $\mathrm{Ru}$, due to its excellent ability to hydrogenate aromatic rings, is an interesting alternative to obtain selectively cyclohexylamine, or if modified conveniently, aniline. ${ }^{169-170} \mathrm{Ru} / \mathrm{C}_{60}$ system has demonstrated to be highly selective for the reduction of nitrobenzene, being able to hydrogenate the nitro group in first place, and successively after the aromatic ring (Figure 7). ${ }^{164}$ This behaviour is in contrast with that of other Ru-based heterogeneous catalysts. ${ }^{171}$ Theoretical calculations have shown that the coordination of the arene on $\mathrm{Ru} / \mathrm{C}_{60} \mathrm{NPs}$ is favoured over the nitro group in terms of adsorption energy, but the addition of hydrides onto the Ru NP surface, which are likely to be present on the surface during the hydrogenation reaction, favours the coordination through the nitro group (Figure 7).
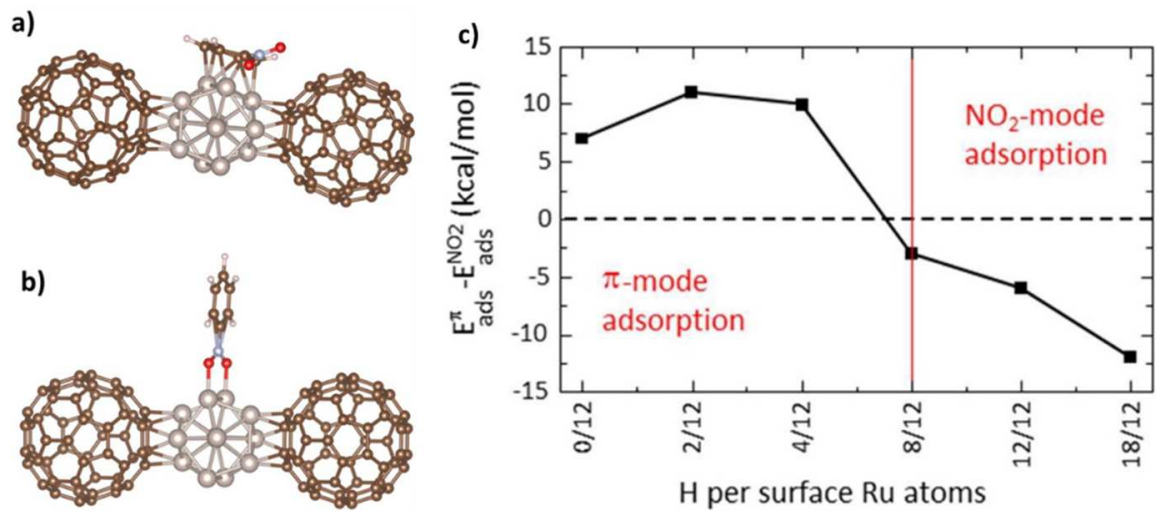

Figure 7. a) $\pi$-mode coordination of a nitrobenzene molecule on a facet of a naked $2 C_{60}-R u_{13}$ molecular complex; b) $\mathrm{NO}_{2}$-mode coordination of a nitrobenzene molecule on the edge of a naked $2 \mathrm{C}_{60}-\mathrm{Ru}_{13}$ molecular complex; c) evolution of the energy difference between the two adsorption modes with respect to the ratio of $\mathrm{H}$ per Ru surface atoms present on the metallic cluster. Reprinted with permission from ref ${ }^{164}$. Copyright 2016 American Chemical Society. Ligand effects on the selective hydrogenation of nitrobenzene to cyclohexylamine were further studied by introducing several stabilizing ligands onto the surface of the Ru NPs. ${ }^{50}$ 
$\mathrm{Ru} / \mathrm{C}_{60}, \mathrm{Ru} / \mathrm{PVP}$ and $\mathrm{Ru} / \mathrm{NHC}$ proceeded in a stepwise manner (Figure 8), producing aniline first and then cyclohexylamine. This agrees with the fact that the reaction selectivity is mainly governed by surface hydrides present onto the Ru NPs surface. Ru/HDA showed a slightly different behaviour which can be explained by the lability of the ligand. Even if the selectivity was mainly dominated by the intrinsic nature of the small Ru NPs a clear influence of the ligands was also noticed. Less donor ligands promoted the hydrogenation of the $\mathrm{N}$ phenylhydroxylamine intermediate, leading to more active and selective catalysts. Reported TOFs at $1 \mathrm{~h}$ of reaction were $136.9,129.2,82.8,64.8 \mathrm{~h}-1 \mathrm{Ru} / \mathrm{C}_{60}, \mathrm{Ru} / \mathrm{HDA}, \mathrm{Ru} / \mathrm{PVP}$ and Ru/NHC, respectively.

a)

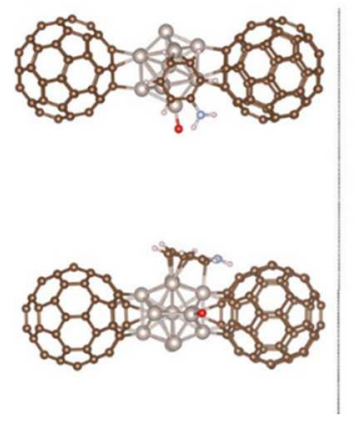

b)

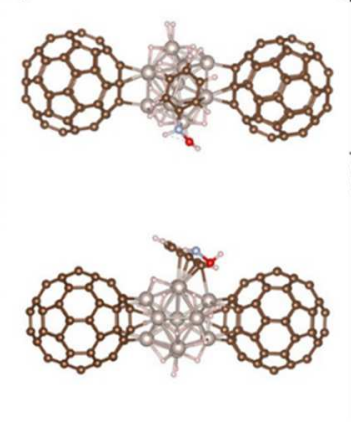

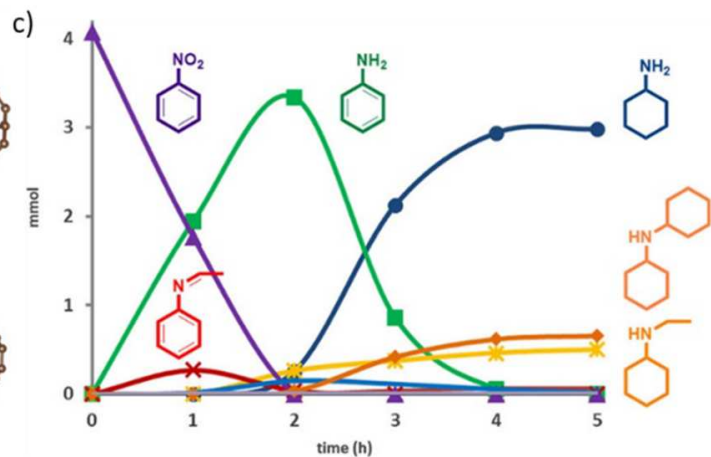

Figure 8. Most stable states after $\mathrm{N}$-phenylhydroxylamine adsorption on a) $\operatorname{Ru}_{13}-\left(\mathrm{C}_{60}\right)_{2}$ and $\left.\mathrm{b}\right)$

$\left.\mathrm{Ru}_{13} \mathrm{H}_{18}-\left(\mathrm{C}_{60}\right)_{2} ; \mathrm{c}\right)$ time-concentration curve for nitrobenzene hydrogenation with $\mathrm{Ru}-\mathrm{C}_{60}$.

Reprinted with permission from ref ${ }^{50}$. Copyright 2018 American Chemical Society.

Table 4. Ru NPs as hydrogenation catalysts of nitrobenzene derivatives

\begin{tabular}{|c|c|c|c|c|c|}
\hline $\begin{array}{l}\text { Stabilizing } \\
\text { agent }\end{array}$ & Synthetic methodology & $\begin{array}{c}\text { Characterizati } \\
\text { on }\end{array}$ & $\begin{array}{l}\text { Catalytic reaction } \\
\text { conditions }\end{array}$ & Comments & Ref. \\
\hline $\begin{array}{l}\text { Fullerene } \\
\mathrm{C}_{60}\end{array}$ & $\begin{array}{c}\text { Reduction of }[\mathrm{Ru}(\mathrm{COD})(\mathrm{COT})] \\
\text { with } \mathrm{H}_{2} \\
{[\mathrm{Ru}(\mathrm{COD})(\mathrm{COT})](30-250 \mathrm{mg})} \\
\mathrm{C}_{60}(0.10-0.16 \mathrm{mmol} \text { or } 0.18 \\
\mathrm{mmol}) \mathrm{H}_{2}(3 \mathrm{bar}), \mathrm{CH}_{2} \mathrm{Cl}_{2}(50- \\
400 \mathrm{~mL}), 298 \mathrm{~K}\end{array}$ & $\begin{array}{l}\text { TEM, WAXS, } \\
\text { ICP, IR, } \\
\text { Raman, } \\
\text { EXAFS, XPS, } \\
\text { DFT }\end{array}$ & $\begin{array}{c}\text { Reduction of } \\
\text { nitrobenzene by } \mathrm{H}_{2} \\
\text { Catalyst ( } 5 \mathrm{mg}) \\
\text { nitrobenzene (4 } \\
\text { mmol), dodecane (1 } \\
\mathrm{mmol}), \mathrm{H}_{2},(30 \text { bar), } \\
\text { EtOH }(30 \mathrm{~mL}), 353 \mathrm{~K}\end{array}$ & $\begin{array}{l}\text { Chemoselective and } \\
\text { stepwise hydrogenation; } \\
\text { DFT } \\
\text { Calculations show that } \\
\text { the coordination mode of } \\
\text { nitrobenzene changes } \\
\text { with the hydride } \\
\text { coverage; recycling test } \\
\text { with slightly decrease of } \\
\text { activity; TEM }\end{array}$ & 164 \\
\hline
\end{tabular}


PVP, HDA Fullerene $\mathrm{C}_{60}, \mathrm{NHC}$

$\begin{array}{cc} & \begin{array}{c}\text { Reduction of }[\mathrm{Ru}(\mathrm{COD})(\mathrm{COT})] \\ \text { with } \mathrm{H}_{2}\end{array} \\ \mathrm{C}_{66}(\mathrm{COOH}) & {[\mathrm{Ru}(\mathrm{COD})(\mathrm{COT})](0.13-0.36} \\ 12 & \mathrm{mmol}), \mathrm{C}_{66}(\mathrm{COOH})_{12}(0.02-0.2 \\ & \text { eq), } \mathrm{H}_{2}(3 \mathrm{bar}), \mathrm{THF}(10-150 \\ & \mathrm{mL}), 298 \mathrm{~K}\end{array}$

$\begin{array}{cc}\text { phosphine } & \text { Reduction of } \mathrm{RuO}_{2} \text { with } \mathrm{H}_{2} \\ - & \\ \text { functional } & \mathrm{RuO}_{2}(3 \mathrm{mg}, 0.0225 \mathrm{mmol}), \\ \text { ized } & {\left[\mathrm{BMMIM}_{3}[\mathrm{tppt}](16.3 \mathrm{mg},\right.} \\ \begin{array}{c}\text { [BMMIM }]_{3} \\ \text { [tppt }]\end{array} & \begin{array}{c}0.0225 \mathrm{mmol}), \mathrm{IL}(1 \mathrm{~mL}), \mathrm{H}_{2}(4 \\ \text { bar), } 343 \mathrm{~K}\end{array}\end{array}$
Reduction of [Ru(COD)(COT)] with $\mathrm{H}_{2}$

[Ru(COD)(COT)] (90-250 mg), stabilizer $\left(0.04 \mathrm{mmol}_{60}\right.$, or $0.18 \mathrm{mmol} H D A$, or 0.38

$\mathrm{mmol} \mathrm{NHC}, 100 \mathrm{mg}$, or 1000 mg of PVP)) $\mathrm{H}_{2}$ (3 bar), THF, $298 \mathrm{~K}$

TEM, ICP, IR, SSNMR, SAXS, WAXS, XPS, Tomographie $\mathrm{mL}), 298 \mathrm{~K}$
Reduction of nitrobenzene by $\mathrm{H}_{2}$

Catalyst $(0.025 \mathrm{mmol}$ of $\mathrm{Ru}$ ) nitrobenzene (4 mmol), dodecane (1 mmol), $\mathrm{H}_{2}$, (30 bar), EtOH (30 mL), $353 \mathrm{~K}$

Reduction of nitrobenzene by $\mathrm{H}_{2}$

\section{Catalyst (5 mg)} nitrobenzene (4 $\mathrm{mmol})$, dodecane (1 $\mathrm{mmol}$ ), $\mathrm{H}_{2}$, (30 bar), EtOH (30 mL), $353 \mathrm{~K}$

Reduction of nitrobenzene by $\mathrm{H}_{2}$

Catalyst (17.75.10-3 $\mathrm{mmol}), \mathrm{IL}(1 \mathrm{~mL})$, nitrobenzene

TEM, XRD, XPS derivative (substrate/Ru = 200), dodecane (1 $\mathrm{mmol})$, $\mathrm{H}_{2}$, (50 bar), EtOH (30 $\mathrm{mL}), 333 \mathrm{~K}$

Stepwise reaction; reduction of $\left[\mathrm{Ru}(\mathrm{acac})_{3}\right]$ over preformed iron oxide NPs

$\mathrm{RuRuO}_{2}$ /PVP

Iron oxide NPs (15 mg), dioctyl ether $(7 \mathrm{ml}), 1,2$ hexadecane diol $(0.05 \mathrm{~g}), \mathrm{OA}$ $(10 \mu \mathrm{L}),\left[\mathrm{Ru}(\mathrm{acac})_{3}\right](0.025 \mathrm{~g})$, $558 \mathrm{~K}, 45 \mathrm{~min}$

Reduction of $\left[\mathrm{Ru}_{3}(\mathrm{CO})_{12}\right]$ and [Co(acac) $)_{2}$ in heptanol.

RuCo/OA

$\left[\mathrm{Ru}_{3}(\mathrm{CO})_{12}\right](8 \mathrm{mg})$, [Co(acac)2] (6.6 mg), glucose (10 mg), heptanol (2 mL), OAm (4 mL), $423 \mathrm{~K}, 2 \mathrm{~h}$
TEM, XRD,

XPS, XRF, DLS, $I C P, I R$

EM, XAFS, XRD, ICP, XANES, EXAFS,
Reduction of nitrobenzene by $\mathrm{H}_{2}$

Catalyst ( 3 g. $\mathrm{L}^{-1}$ ) nitrobenzene $(0.06$ $\mu \mathrm{M}), \mathrm{H}_{2}$, (30 bar), 423 $\mathrm{K}$

Hydrogenation of 4nitrostyrene

catalyst (0.3 mol\% 4nitrostyrene $(0.5$ $\mathrm{mmol}$ ), $\mathrm{CMeOH}$ (3 $\mathrm{mL}), \mathrm{H}_{2}$ (ballon), 298 $\mathrm{K}$

Chemoselective and stepwise hydrogenation; DFT

Calculations point out that hydride coverage is crucial for adsorption of the phenylhidroxylamine intermediate; surface ligands modulate the activity and selectivity

Assemblies of Ru NP. selectivity towards aniline up to $90 \%$; no significative change on the size of NP after catalysis (by TEM); no recycling tests

Better activity than commercial Ru/C; the addition of [BMMIM] $]_{3}[$ tppt] is in detriment of the activity; no characterization of the spent catalyst; no recycling tests

Catalysts displays a $\mathrm{Ru}^{+4} / \mathrm{Ru}^{0}$ mixture; some synthesis lead to a mixture of monometallic NPs; selective hydrogenation towards aniline; recycling test

Dumbbell-shaped Co-Ru nanostructure

composed of a Co nanorod with two ends capped with Ru

nanoplates; tuning metal lattice strain

Ru with 3\% lattice compression exhibits high selectivity for

hydrogenation of 4- 
nitrostyrene to 4aminostyrene; recycled 4 times; DFT calculations

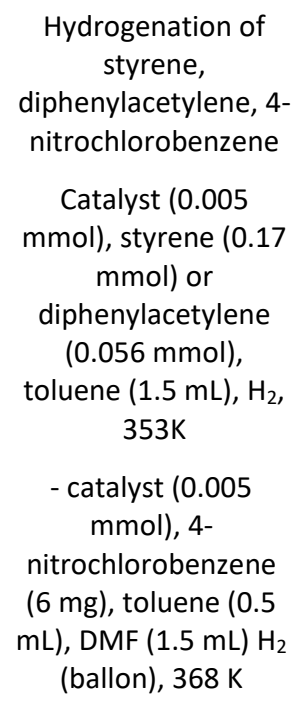

$$
\begin{gathered}
\text { Catalyst }(0.005 \\
\mathrm{mmol}), \text { styrene }(0.17 \\
\text { mmol) or } \\
\text { diphenylacetylene } \\
(0.056 \mathrm{mmol}), \\
\text { toluene }(1.5 \mathrm{~mL}), \mathrm{H}_{2} \text {, } \\
353 \mathrm{~K} \\
\text { - catalyst }(0.005 \\
\text { mmol), } 4- \\
\text { nitrochlorobenzene } \\
(6 \mathrm{mg}), \text { toluene }(0.5 \\
\mathrm{mL}), \mathrm{DMF}(1.5 \mathrm{~mL}) \mathrm{H}_{2}
\end{gathered}
$$

(ballon), $368 \mathrm{~K}$

fcc character of Ru depends on \%Pd; the reduction of nitro group was more performant when using fcc NPs compared to hcp NPs; the opposite trend was observed in styrene hydrogenation; no recycling tests; no characterization of the spent catalyst; no recycling test

The evaluation of the catalytic properties and the reaction kinetics in the reduction of nitroarenes or azo dyes with $\mathrm{NaBH}_{4}$ is widely used to obtain information about the performances of a catalyst because it can be easily implemented and conveniently measured by UV-vis spectrophotometry (Table 5). These reactions have been reported to be sensitive to the size and structure of Ru NPs. Ru nanocages or nanoframes displaying a fcc structure have been synthesised through the chemical etching of a sacrificial seed, ${ }^{73-74}$ and tested as catalysts in the reduction of 4-nitrophenol, in order to demonstrate the higher reactivity of this crystallographic structure. Ru fcc icosahedral nanocages, which are very stable against temperature retaining their structure up to $573 \mathrm{~K}$, were active in this reaction and displayed higher activities than Ru hcp NPs. ${ }^{74}$ Ru cubic, octahedral, and icosahedral nanocages were tested as catalysts displaying rate constants of $17.62,20.64$, and $41.21 \mathrm{~s}^{-1} \mathrm{mg}^{-1}$, respectively. Likewise, Ru fcc nanoframes, synthesized as well by chemical etching of a nanosized template, performed better in this reaction than Ru nanowires displaying a hcp structure. ${ }^{73}$ In this case the rate constants of Ru fcc nanoframes were reported to be $0.022 \mathrm{~min}^{-1}$ in opposition to 0.005 
$\mathrm{min}^{-1}$ displayed by the hcp Ru nanowires. Nevertheless, no recycling test or characterization of the spent catalysts are reported. The reaction is also sensitive to the size of the Ru NPs. ${ }^{106}$ Ru NPs ranging from 2.6 to $51.5 \mathrm{~nm}$ were synthesized by a polyol reduction (using $\mathrm{RuCl}_{3}$ as $\mathrm{Ru}$ source and PVP as capping agent) where the size of the as-synthesised NPs was controlled mainly by the reaction temperature, but also with the $\mathrm{pH}$ of the solution. Catalytic activity of the different sized Ru NPs was compared with that of other reported noble metal NPs. Rubased catalysts were more active for the nitrophenol reduction than other nanosized metals (Ag, Au, Ir and Pt). The reactivity of Ru NPs was dependent on their size and displayed a volcano trend, where $8 \mathrm{~nm}$ sized NPs were observed to be the most performant. The degradation of azo dyes was also successfully achieved using this Ru-based catalytic system. A multidentate bulky ligand with weak interactions with the metal NPs but strong enough to stabilize them has been described. ${ }^{104}$ The amphiphilic tripodal ligand tris(1,2,3-triazolyl)polyethylene glycol (tristrz-PEG) (Figure 9), allowed to stabilize several metal NPs (Fe, Co, Ni, $\mathrm{Cu}, \mathrm{Ru}, \mathrm{Ag}, \mathrm{Pt}, \mathrm{Pd}$, and $\mathrm{Au})$. Ru NPs displayed a high catalytic activity in the reduction of nitrophenol and was recycled three times.

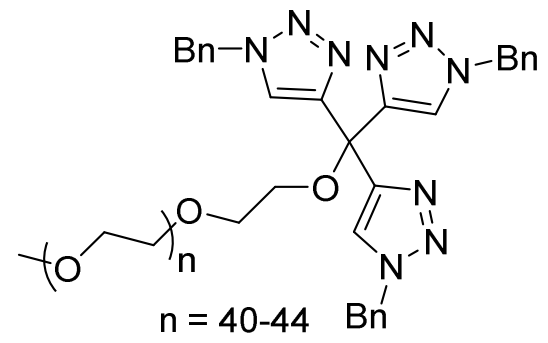

Figure 9. Amphiphilic tripodal ligand tris(1,2,3-triazolyl)-polyethylene glycol (tristrz-PEG). Lattice strain can modify the electronic structure of catalysts and therefore affect the adsorption of reactants. The reduction of $\left[\mathrm{Ru}_{3}(\mathrm{CO})_{12}\right]$ and $\left[\mathrm{Co}(\mathrm{acac})_{2}\right]$ in heptanol using oleylamine as stabilizer allowed preparing dumbbell-shaped CoRu nanostructures, where a Co nanorod is capped with a Ru plate. NPs of several $\mathrm{Ru} / \mathrm{Co}$ ratios were synthesised, and $\mathrm{Co}_{0.23^{-}}$ 
$\mathrm{Ru} 0.77$ catalyst was shown to be highly selective towards $-\mathrm{NO}_{2}$ hydrogenation $(99 \%)$ in the

hydrogenation of 4-nitrostyrene to 4-aminostyrene. The selectivity of RuCo NPs follows a volcano-type curve with increasing the Ru compressive lattice strain. ${ }^{172}$

Table 5. Ru NPs as reduction catalysts of nitrobenzene and azo derivatives using $\mathrm{NaBH}_{4}$ or $\mathrm{N}_{2} \mathrm{H}_{4}$ as reducing agents

\begin{tabular}{|c|c|c|c|c|c|}
\hline $\begin{array}{l}\text { Stabilizing } \\
\text { agent }\end{array}$ & Synthetic methodology & $\begin{array}{l}\text { Characterizati } \\
\text { on }\end{array}$ & $\begin{array}{l}\text { Catalytic reaction } \\
\text { conditions }\end{array}$ & Comments & Ref. \\
\hline PVP & $\begin{array}{c}\text { Ru fcc icosahedral } \\
\text { nanocages. Chemical } \\
\text { etching of PdRu core-shell } \\
\mathrm{NPs} \text { RuPd NP }(0.1 \mathrm{mg}), \\
\mathrm{FeCl}_{3}(30 \mathrm{mg}), \mathrm{KBr}(300 \\
\mathrm{mg}), \mathrm{PVP} \\
(50 \mathrm{mg}), \mathrm{HCl}(0.18 \mathrm{~mL}) \\
\mathrm{H}_{2} \mathrm{O}(4.82 \mathrm{~mL})\end{array}$ & $\begin{array}{l}\text { TEM, XRD, } \\
\text { thermal } \\
\text { stability } \\
\text { followed by } \\
\text { using in situ } \\
\text { XRD }\end{array}$ & $\begin{array}{c}\text { Reduction of } 4- \\
\text { nitrophenol by } \mathrm{NaBH}_{4} \\
\text { Catalyst }(0.2 \mathrm{mM}, 0.5 \\
\mathrm{mL}), \mathrm{NaBH}_{4} \\
(20 \mathrm{mM}, 1 \mathrm{~mL}) 4- \\
\text { nitrophenol }(0.2 \mathrm{mM}, \\
1 \mathrm{~mL}), \mathrm{H}_{2} \mathrm{O}, 298 \mathrm{~K}\end{array}$ & $\begin{array}{l}\text { Ru fcc structure enhances } \\
\text { catalytic properties; Ru } \\
\text { cubic, octahedral, and } \\
\text { icosahedral nanocages } \\
\text { rate constants: } 17.62, \\
20.64 \text {, and } 41.21 \mathrm{~s}^{-1} \mathrm{mg}^{-1} \\
\text { respectively }\end{array}$ & 74 \\
\hline PVP & $\begin{array}{c}\text { Ru fcc nanoframes. } \\
\text { Chemical etching of PdRu } \\
\text { core-shell NPs. RuPd NP, } \\
\mathrm{FeCl}_{3}(25 \mathrm{mg}), \mathrm{KBr}(150 \\
\mathrm{mg}), \mathrm{PVP} \\
(25 \mathrm{mg}), \mathrm{HCl}(0.15 \mathrm{~mL}) \\
\mathrm{H}_{2} \mathrm{O}(2.85 \mathrm{~mL})\end{array}$ & TEM, XRD, ICP & $\begin{array}{c}\text { Reduction of } 4- \\
\text { nitrophenol by } \mathrm{NaBH}_{4} \\
\text { Catalyst }(10 \mu \mathrm{L} 0.218 \\
\mathrm{mM}), \mathrm{NaBH}_{4} \\
(5 \mu \mathrm{L}, 2 \mathrm{M})) 4- \\
\text { nitrophenol }(29.5 \mu \mathrm{L}, \\
0.5 \mathrm{mM}), \mathrm{H}_{2} \mathrm{O}(0.69 \\
\mathrm{mL}), 298 \mathrm{~K}\end{array}$ & $\begin{array}{l}\text { Ru fcc nanoframes active } \\
\text { in this reaction; no } \\
\text { recyclability or stability } \\
\text { tests after catalysis }\end{array}$ & 73 \\
\hline PVP & $\begin{array}{c}\text { Reduction of } \mathrm{RuCl}_{3} \text { in } \mathrm{n}- \\
\text { propanol, } \\
\mathrm{RuCl}_{3}(500 \mu \mathrm{L}, 100 \mathrm{mM}) \\
\text { PVP }(50 \mathrm{mM}), \mathrm{n} \text {-propanol } \\
(10 \mathrm{~mL}), 303-371 \mathrm{~K}, 10 \mathrm{~h}\end{array}$ & $\begin{array}{l}\text { TEM, XRD, } \\
\text { UV-Vis, DLS, } \\
\text { XPS }\end{array}$ & $\begin{array}{c}\text { Reduction of } 4- \\
\text { nitrophenol and other } \\
\text { nitrobenzene } \\
\text { derivatives by } \mathrm{NaBH}_{4} \\
\text { Catalyst }(4 \mu \mathrm{L}, 10 \\
\mathrm{nM}), \mathrm{NaBH}_{4} \\
(2 \mathrm{~mL} \mathrm{mM}, 0.1 \mathrm{M}), \\
\text { nitroarene }(20 \mu \mathrm{L}, 10 \\
\mathrm{mM}), 298 \mathrm{~K}\end{array}$ & $\begin{array}{l}\text { Ru NPs sizes from } 2.6 \text { to } \\
51.5 \text { nm by adjusting the } \\
\text { pH and temperature; size } \\
\text { dependent catalytic } \\
\text { activity; better } \\
\text { performances than Pt and } \\
\text { Ir NPs; loss of activity } \\
\text { after seven recycling } \\
\text { cycles; few information } \\
\text { about the spent catalyst }\end{array}$ & 106 \\
\hline \multirow[t]{2}{*}{$\begin{array}{l}\text { Amphiphilic } \\
\text { tripodal ligand } \\
\text { tris(1,2,3- } \\
\text { triazolyl)- } \\
\text { polyethylene } \\
\text { glycol }\end{array}$} & $\begin{array}{c}\mathrm{RuCl}_{3}(1 \mathrm{eq}) \text {, stabilizer (1 } \\
\text { eq), } \mathrm{NaBH}_{4}(10 \mathrm{eq}), \mathrm{H}_{2} \mathrm{O}(6 \\
\mathrm{mL}), 298 \mathrm{~K}\end{array}$ & $\begin{array}{l}\text { TEM, XPS, UV- } \\
\text { vis }\end{array}$ & $\begin{array}{c}\text { Reduction of } \\
\text { nitrobenzene by } \\
\mathrm{NaBH}_{4} \text { and transfer } \\
\text { hydrogenation } \\
\text { Catalyst }(0.2-2 \mathrm{~mol} \%), \\
\mathrm{NaBH}_{4}(10 \mathrm{eq}), \\
\text { nitroarene }(1 \mathrm{eq}), \\
298 \mathrm{~K}\end{array}$ & \multirow[t]{2}{*}{$\begin{array}{c}\text { Ru NP active in reduction } \\
\text { reactions in water; Ru NP } \\
\text { recycled } 3 \text { times without } \\
\text { significant loss of activity; } \\
\text { TEM of the spent catalysis } \\
\text { indicates a slightly } \\
\text { increase of the NP size }\end{array}$} & \multirow[t]{2}{*}{104} \\
\hline & & & $\begin{array}{c}\text { Catalyst (0.2-2 mol\%), } \\
\mathrm{NaOH}(0.2 \mathrm{mmol})\end{array}$ & & \\
\hline
\end{tabular}


nitroarene $(0.1$

$\mathrm{mmol}), \mathrm{H} 2 \mathrm{O} / \mathrm{i}$ -

propanol $(1 / 4,5 \mathrm{~mL})$,

$353 \mathrm{~K}, 24 \mathrm{~h}$

Reduction of $\mathrm{RuCl}_{3}$ with $\mathrm{NaBH}_{4}$

Dendrimer

Porous polymer

PVP

$\mathrm{RuCl}_{3}$ (12.3 mg), PVP (55.5 $\mathrm{mg}$ ), ethylene glycol (10 $\mathrm{mL}), 443 \mathrm{~K}, 6 \mathrm{~h}$

Reduction of $\mathrm{RuCl}_{3}$ in ethylene glycol at $443 \mathrm{~K}$ $\left.1.63 \times 10^{-3} \mathrm{M}\right)$, dendrimer (4. $\left.2 \times 10^{-5} \mathrm{M}\right), \mathrm{NaBH}_{4}(5$ $\mathrm{mL}, 1 \mathrm{M}), \mathrm{MeOH}(65 \mathrm{~mL})$, $\mathrm{H}_{2} \mathrm{O}(100 \mathrm{~mL})$, r. t., $24 \mathrm{~h}$

Reduction of $\mathrm{RuCl}_{3}$ with $\mathrm{NaBH}_{4}$ or ethylene glycol

$\mathrm{RuCl}_{3} \cdot 3 \mathrm{H}_{2} \mathrm{O}(15 \mathrm{mg})$, polymer $(50 \mathrm{mg}), \mathrm{NaBH}_{4}$ $\left(4 \mathrm{~mL}, 1.63 \times 10^{-2} \mathrm{M}\right)$, $\mathrm{MeOH}(20 \mathrm{~mL})$, r. t., 24;

$\mathrm{RuCl}_{3} \cdot 3 \mathrm{H}_{2} \mathrm{O}(15 \mathrm{mg})$, polymer (50 mg), ethylene glycol $(50 \mathrm{~mL})$, $453 \mathrm{~K}, 3$ or $4 \mathrm{~h}$

Reduction of $\mathrm{RuCl}_{3}$ in $\mathrm{n}$ propanol,

PVP

$\mathrm{RuCl}_{3}(500 \mu \mathrm{L}, 100 \mathrm{mM})$, PVP (50 mM), n-propanol (10 mL), 303-371 K, 10h

Reduction of $\mathrm{RuCl}_{3}$ with $\mathrm{NaBH}_{4}$.

4-

sulfocalix[4]ar

ene

RuPd nanosheets

$\mathrm{RuCl}_{3}(0.402 \mathrm{mmol})$, stabilizer (0.201 $\mathrm{mmol})$, $\mathrm{NaBH}_{4}(2.4 \mathrm{mmol}), \mathrm{H}_{2} \mathrm{O}$ $(100 \mathrm{~mL}), 298 \mathrm{~K}, 12 \mathrm{~h}$

Stepwise reduction of $\left[\mathrm{Pd}(\mathrm{acac})_{2}\right]$ and
TEM, XRD, XPS, UV-Vis, IR, cyclic voltammogra $\mathrm{ms}$

Reduction of $\mathrm{p}$ nitrophenol by $\mathrm{NaBH}_{4}$

Catalyst $(100 \mu \mathrm{L})$, $\mathrm{NaBH}_{4}(0.25 \mathrm{~mL}, 100$ $\mathrm{mM})$, p-nitrophenol (0.25 mL, $1 \mathrm{mM}$ ), 298 $\mathrm{K}$

TEM, DRX, ICP, XPS, BET, NMR $\left[\mathrm{Ru}(\mathrm{acac})_{3}\right]$
TEM, XRD, UV-Vis, XPS

TEM, XRD, UV-Vis, DLS, XPS

Hydrogenation of Orange I (azo dye) by $\mathrm{N}_{2} \mathrm{H}_{4}$

Catalyst (8 nM), orange I $(4 \mu \mathrm{L}, 10$ $\mathrm{mM}), \mathrm{N}_{2} \mathrm{H}_{4}(2 \mathrm{~mL}$, $0.8 \mathrm{M})$

Hydrogenation of azo dyes by $\mathrm{NaBH}_{4}$

Catalyst $(4 \mu \mathrm{L}, 10$ $\mathrm{mM})$, azo dye $(20 \mu \mathrm{L}$, $10 \mathrm{mM}), \mathrm{NaBH}_{4}$

(2 mL mM, 0.1 M)

Hydrogenation of azo dye by $\mathrm{N}_{2} \mathrm{H}_{4}$

TEM, SEM, $X R D, T G A, I R$, DLS

Catalyst $(0.5 \mathrm{mg})$, azo dye $(0.05 \mathrm{mM}), \mathrm{N}_{2} \mathrm{H}_{4}$ $(15 \mu \mathrm{L}), \mathrm{H}_{2} \mathrm{O}(3 \mathrm{~mL})$

TEM, XRD, $X P S, I C P$

Reduction of 4nitrophenol by $\mathrm{NaBH}_{4}$
No recycling test; no characterization of the spent catalyst
Reduction of nitroarenes

Catalyst $(5 \mathrm{mg})$, $\mathrm{NaBH}_{4}(2.5 \mathrm{mmol})$, nitroarene $(0.5$ $\mathrm{mmol}), \mathrm{THF} / \mathrm{H}_{2} \mathrm{O}(1 / 3$, $\mathrm{mL}), 298 \mathrm{~K}$

Ru NPs more efficient when stabilized with the polymer compared to other standard supports; best catalyst recycled 11 times with loss of activity; TEM, NMR, XPS, ICP of the spent catalysts indicate that is stable

Degradation kinetic curves measured by absorbance intensities of orange I at $512 \mathrm{~nm}$; Ru

NPs showed better performances than $\mathrm{Pt}$ and Ir NPs; Ru Nps are poisoned with $\mathrm{H}_{2} \mathrm{~S}$, this particularity is exploited to prepare paper strips for $\mathrm{H}_{2} \mathrm{~S}$ gas detection

Ru NPs decomposes azo dyes in seconds; no recyclability test; no information about the spent catalyst

Recycled 9 times; leaching test; spent catalyst characterized by SEM, IR, XRD

Submonolayered $\mathrm{Ru}$ deposited on ultrathin $\mathrm{Pd}$

173 
[Pd(acac) $)_{2}$ (16 mg), PVP (30mg), citric acid (170 $\mathrm{mg})$, СТAB (60 mg), [W(CO) $)_{6}$ (100 mg), DMF, $(10 \mathrm{~mL}), 353 \mathrm{~K}, 1 \mathrm{~h}$; [Ru(acac) 3 ] (4 mg), PVP (50 mg), ascorbic acid (50 $\mathrm{mg}$ ), ethylene glycol (10 $\mathrm{mL}), 433 \mathrm{~K}, 1 \mathrm{~h}$
Catalyst (Pd: $7.6 \mathrm{mM}$, $\mathrm{Ru}: 1.0 \mathrm{mM}), \mathrm{NaBH}_{4}$ (25 $\mu \mathrm{L}, 2 \mathrm{M}), 4-$ nitrophenol $(4.95 \mathrm{~mL}$, $0.15 \mathrm{mM}), \mathrm{H}_{2} \mathrm{O}, 298 \mathrm{~K}$

Reduction of 1-octyne

Catalyst (Pd: $7.6 \mathrm{mM}$, Ru: $1.0 \mathrm{mM}), 1-$ octyne $(73.5 \mu \mathrm{L}, 0.05$ $\mathrm{mmol}), \mathrm{n}$-decane (10 $\mu \mathrm{L}, 0.05 \mathrm{mmol}), \mathrm{EtOH}$ (6 mL), $\mathrm{H}_{2}$ (1 bar), 298 performances in terms of activity than monometalic Ru and Pd NPs in both reactions
Stepwise procedure using galvanic replacement

$\mathrm{CoCl}_{2}(1 \mathrm{~mL}, 0.4 \mathrm{M})$,

$\mathrm{NaBH}_{4}(100 \mathrm{~mL}, 8 \mathrm{mM})$,

AuPdRu

$\mathrm{HAuCl}_{4}(60 \mathrm{~mL}, 0.44 \mathrm{mM})$ PVP (1\%), $323 \mathrm{~K} 2 \mathrm{~h}$;

$\mathrm{NaBH}_{4}(0.4 \mathrm{~mL}, 0.5$

M), $0.31 \mathrm{~mL}, 20 \mathrm{mM}), 323$

$\mathrm{K}, 2 \mathrm{~h} ; \mathrm{RuCl}_{3}(0.166 \mathrm{mM})$

Reduction of 4nitrophenol and azo dye by $\mathrm{NaBH}_{4}$

Catalyst $(100 \mu \mathrm{L}$, $5 \mathrm{pM}), \mathrm{NaBH}_{4}(100 \mu \mathrm{L}$, $100 \mathrm{mM} \mathrm{M}$ ), 4nitrophenol $(100 \mu \mathrm{L}, 1$ $m M)$, buffer $(700 \mu \mathrm{L})$, $298 \mathrm{~K}$
No recycling test; no characterization of the 153 spent catalyst

\subsubsection{Hydrodeoxygenation}

In order to produce basic chemicals and renewable fuels from biomass feedstocks it is needed

to remove oxygen from these materials due to the high amount of oxygenated moieties present in their structure. Hydrodeoxygenation is a metal catalyzed reaction, which allows to remove oxygen from oxygen-containing compounds in the presence of $\mathrm{H}_{2} \cdot{ }^{174-176} \mathrm{Ni}$, Co, Mo, $\mathrm{Pt}, \mathrm{Rh}, \mathrm{Ru}$, among other supported metals have been used to upgrade biomass model compounds. ${ }^{175}$ Lignin, one of the components of biomass, requires tobe depolymerizated through $\mathrm{C}-\mathrm{O}$ cleavage followed by hydrodeoxygenation. Likewise, cellulose requires the same procedure to produce polyols. Also, hydrodeoxygenation of vegetable oils can produce longchain alkanes, a renewable fuel from biomass. ${ }^{174}$ Unsupported Ru NPs have found applications in hydrodeoxygenation of long-chain fatty acids, ${ }^{177}$ lignin monomeric and dimeric model 
substrates, ${ }^{130}$ including bimetallic RuNi NPs, ${ }^{102,178}$ eucalyptol ${ }^{179}$ and carbonyl compounds by a bimetallic RuFe bifunctional catalyst ${ }^{119}$ (Table 6).

Lignin monomeric and dimeric model compounds, such as phenol, guaiacol, diphenyl ether (4O-5), benzyl phenyl ether ( $\alpha-0-4)$, 2-phenylethyl phenyl ether ( $\beta-0-4)$, and benzofuran $(\beta-5)$ have been hydrodeoxygenated using several metallic NPs ( $\mathrm{Pt}, \mathrm{Rh}, \mathrm{Ru}$ and $\mathrm{Pd}$ ) stabilized in different ILs. ${ }^{130}$ In general, Pt/IL systems were more active and selective with all substrates while Rh and Ru displayed similar behaviour; the nature of the IL slightly modifying the selectivity. Ru NPs synthesised over a porous organic network exhibited high catalytic performance in stearic acid hydrogenation reaction with $95.6 \%$ conversion of stearic acid. ${ }^{177}$ The alcohol-hydrogenated product was then hydrodeoxygenated to produce C18 alkane or decarbonylated to $\mathrm{C} 17$ alkane. The ratio between $\mathrm{C} 17 / \mathrm{C} 18$ could be modulated by the temperature and pressure of the catalytic reaction. The Ru NPs stabilized with the porous organic network were more performant than other Ru-supported heterogeneous catalysts. Bifunctional $\mathrm{Ru}^{120,179}$ or RuFe ${ }^{119}$ NPs stabilized in IL or SILP have been used as catalysts in the hydrodeoxygenation of eucalyptol, hydrogenation of the aldehyde intermediate originated from the acid-catalysed cleavage of lignin $\beta-0-4$ model, and the hydrodeoxygenation of carbonyl-substituted aromatic substrates. Hydrodeoxygenation is often carried out with bifunctional catalysts that contain both metal and acid sites, and are generally prepared by dispersing the metal NPs in a solid acidic support. ${ }^{174}$ Ru/SILP NPs were highly active and selective to the formation of $p$-menthane from eucalyptol, and the reaction selectivity was dependent of the acidity of the SILP. ${ }^{179}$ Acid cleavage of lignin $\beta-0-4$ model in the presence of Ru NPs allowed to hydrogenate the aldehyde intermediate product into 2-phenylalcohol in good yields. ${ }^{120}$ Bimetallic RuFe/SILP+IL-SO ${ }_{3} \mathrm{H}^{119}$ showed to be a very efficient system in the hydrodeoxygenation of carbonyl groups contained in aromatic substrates, the presence of Fe 
in small amounts (25\%) preventing the hydrogenation of the aromatic ring, ${ }^{131}$ and leading to

the production of the aromatic dehydrodeoxygenated product in a very selective manner. The catalyst had a large substrate scope and could be easily recycled four times without loss of activity.

Table 6. Ru NPs as hydrodeoxygenation catalysts

\begin{tabular}{|c|c|c|c|c|c|}
\hline Stabilizing agent & Methodology & Characterization & Reaction conditions & Comments & Ref. \\
\hline PVP & $\begin{array}{c}\text { Reduction of } \mathrm{RuCl}_{3} \text { in } \\
\text { ethanol/ } \mathrm{H}_{2 \mathrm{O}} \\
\mathrm{RuCl}_{3}(0.10 \mathrm{~g}, 0.5 \\
\mathrm{mmol}), \operatorname{PVP}(0.55 \mathrm{~g}, 5 \\
\mathrm{mmol}), \text { ethanol }(100 \\
\mathrm{mL}), \mathrm{H}_{2} \mathrm{O}(100 \mathrm{~mL}), \\
353,2 \mathrm{~h}\end{array}$ & TEM & $\begin{array}{c}\text { Dehydrogenation of } \\
\text { cellobiose } \\
\text { Catalyst }(1.67 \times 10- \\
3 \mathrm{~mol} \mathrm{Ru} / \mathrm{L}), \text { cellobiose } \\
(7.31 \mathrm{mmol}), \mathrm{H}_{2} \mathrm{O}(30 \\
\mathrm{mL}), \mathrm{H}_{2}(40 \text { bar), } 393 \mathrm{~K} \\
12 \mathrm{~h}\end{array}$ & $\begin{array}{l}\text { Selectivity towards } \\
\text { sorbitol depends on } \\
\text { reaction } \mathrm{pH} \text { and } \\
\text { metal used; no } \\
\text { recyclability test; no } \\
\text { information about } \\
\text { the spent catalyst }\end{array}$ & 180 \\
\hline $\begin{array}{c}\text { Porous } \\
\text { organic network }\end{array}$ & $\begin{array}{c}\text { Reduction of } \mathrm{RuCl}_{3} \\
\text { with } \mathrm{NaBH}_{4} \\
\mathrm{RuCl}_{3}(60 \mathrm{mg}) \text {, } \\
\text { polymer }(200 \mathrm{mg}), \\
\mathrm{MeOH}^{(130 \mathrm{~mL}),} \\
\mathrm{NaBH}_{4}(10 \mathrm{~mL}, 1 \mathrm{M}), \\
298 \mathrm{~K}\end{array}$ & $\begin{array}{c}\text { TEM, XRD, TGA, } \\
\text { NMR, IR, XPS, } N_{2} \\
\text { sorption, DFT, ICP } \\
\mathrm{NH}_{3}-\mathrm{TPD} \text { analysis }\end{array}$ & $\begin{array}{l}\text { Dehydrogenation of } \\
\text { long-chain fatty acids } \\
\text { Catalyst }(20 \mathrm{mg}) \text {, } \\
\text { substrate }(0.350 \\
\mathrm{mmol}), \text { water }(70 \mathrm{~mL}), \\
\mathrm{H}_{2} \text { (30 bar), } 453 \mathrm{~K}\end{array}$ & $\begin{array}{l}\text { Better activity and } \\
\text { selectivity than Ru } \\
\text { over inorganic } \\
\text { supports; recycled } 6 \\
\text { times without loss } \\
\text { of activity; spent } \\
\text { catalyst analysed by } \\
\text { TEM, XRD and XPS } \\
\text { showing no change } \\
\text { respect the as- } \\
\text { synthesised material }\end{array}$ & 177 \\
\hline IL & $\begin{array}{l}\text { Reduction in situ of } \\
\text { metal salts during } \\
\text { hydrogenation } \\
\text { reaction using } \mathrm{H}_{2}\end{array}$ & TEM, XPS, XRD & $\begin{array}{l}\mathrm{C}-\mathrm{O} \text { cleavage and } \\
\text { hydrodeoxygenation } \\
\text { lignin monomeric and } \\
\text { dimeric model } \\
\text { compounds by } \mathrm{H}_{2} \\
\text { Catalyst }(0.01 \mathrm{mmol} \\
\text { metal), IL ( } 2 \mathrm{~g}, \\
\text { substrate }(1 \mathrm{mmol}) \\
\mathrm{H}_{3} \mathrm{PO}_{4}(0.15 \mathrm{~g}), \mathrm{H}_{2}(5 \\
\text { bar), } 403 \mathrm{~K}, 10 \mathrm{~h}\end{array}$ & $\begin{array}{l}\text { Catalyst recycling } \\
\text { for diphenyl ether } \\
\text { using Pt based } \\
\text { catalys; loss of } \\
\text { catalytic activity } \\
\text { after } 3 \text { runs }\end{array}$ & 130 \\
\hline SILP & $\begin{array}{c}\text { Decomposition of } \\
\left.\text { [Ru(cod(methylallyl })_{2}\right] \\
\text { by } \mathrm{H}_{2} \\
\text { [Ru(cod(methylallyl) } 2] \\
(40.8 \mathrm{mg}), \mathrm{SILP}(4 \mathrm{~g}), \\
\mathrm{CH}_{2} \mathrm{Cl}_{2}(40 \mathrm{~mL}), \mathrm{H}_{2} \\
(120 \text { bar }), 373 \mathrm{~K}, 16 \mathrm{~h}\end{array}$ & TEM, ICP & $\begin{array}{c}\text { Hydrodeoxygenation of } \\
\text { eucalyptol } \\
\text { Batch: catalyst }(75 \mathrm{mg}) \text {, } \\
\text { eucalyptol ( } 2.4 \mathrm{mmol}) \text {, } \\
\mathrm{H}_{2} \text { ( } 120 \text { bar), } 423 \mathrm{~K} \\
\text { Flow: catalyst ( } 547 \\
\text { mg), eucalyptol ( } 0.05 \\
\text { M eucalyptol in } \\
\text { heptane, } 0.3-0.9 \\
\mathrm{~mL} / \mathrm{min}), \mathrm{H}_{2}(80 \text { bar, }\end{array}$ & $\begin{array}{l}\text { Integration of both } \\
\text { a metal and acid } \\
\text { catalyst onto a } \\
\text { single support; } \\
\text { selective catalysts } \\
\text { for the } \\
\text { hydrodeoxygenation } \\
\text { of eucalyptol to p- } \\
\text { menthane; } \\
\text { selectivity depends } \\
\text { on the acidity of the } \\
\text { SILP }\end{array}$ & 179 \\
\hline
\end{tabular}


$\mathrm{RuFe} / \mathrm{SILP}+\mathrm{IL}-\mathrm{SO}_{3} \mathrm{H}$

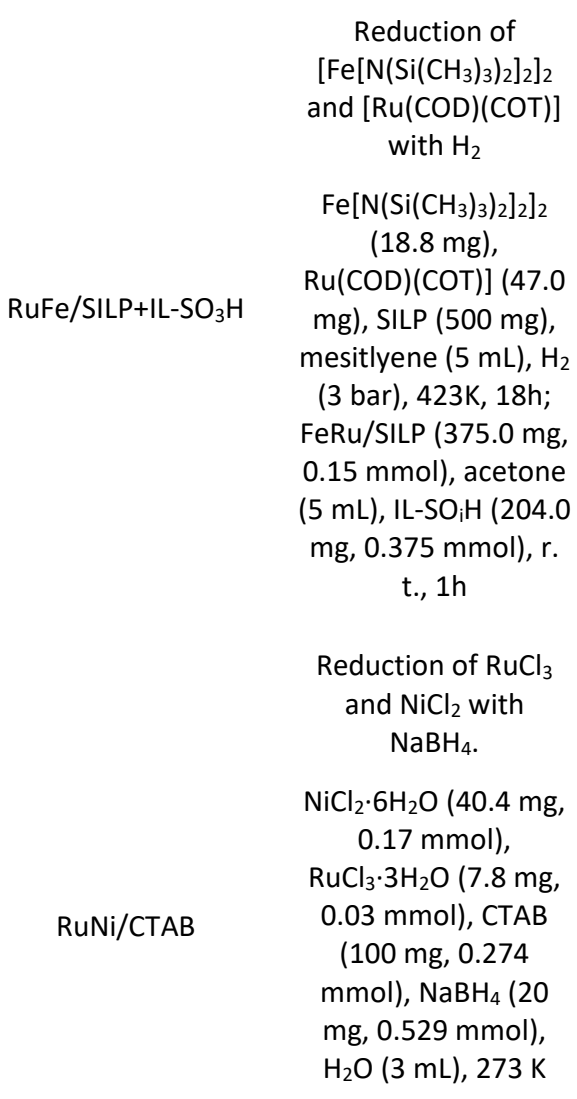

Reduction of $\mathrm{RuCl}_{3}$ and $\mathrm{NiCl}_{2}$ with

$\mathrm{NaBH}_{4}$.

$\mathrm{NiCl}_{2} \cdot 6 \mathrm{H}_{2} \mathrm{O}(4.4 \mathrm{mg}$, $0.0187 \mathrm{mmol})$,

RuNi/PVP
$0.0033 \mathrm{mmol}$, CTAB

(48.8 mg, 0.44

$\mathrm{mmol}), \mathrm{NaBH}_{4}(4 \mathrm{mg}$,

$0.11 \mathrm{mmol}), \mathrm{H}_{2} \mathrm{O}$ (3

$\mathrm{mL}), 273 \mathrm{~K}$
TEM, XRD, XPS

Hydrodeoxygenation of carbonyl-substituted aromatic substrates

Catalyst $(58 \mathrm{mg}$,

TEM, SEM, BET containing $0.015 \mathrm{mmol}$ metal and $0.038 \mathrm{mmol}$ (2.50 equiv.) IL-SO3H), substrate $(0.38 \mathrm{mmol})$, mesitylene $(0.5 \mathrm{~mL}), \mathrm{H}_{2}$ (50 bar), $448 \mathrm{~K}, 10 \mathrm{~h}$

Highly selective; no hydrogenation of aromatic moieties; catalyst recycled 4 times without loss of activity; no leaching

Hydrogenolysis of three lignin model substrates

Catalyst $\left(9.45 \times 10^{-3}\right.$ $\mathrm{mmol})$,

aromatic ether $(0.189$ $\mathrm{mmol}), \mathrm{H}_{2} \mathrm{O}(1 \mathrm{~mL}), \mathrm{H}_{2}$

(1 bar), $368 \mathrm{~K}, 16 \mathrm{~h}$

TEM, XRD, XAS, XANES, EXAFS, UV-Vis

Ni responsible for the hydrogenolysis; Ru and Rh are active in the hydrogenation of the aromatic rings; hydrogenation rete depends on $\mathrm{RH}$ and Ru loading; hydrogenolysis of $\mathrm{C}(\mathrm{sp} 3)-\mathrm{O}$ bonds is preferred over $\mathrm{C}(\mathrm{sp} 2)-\mathrm{O}$ bonds
Hydrogenolysis of three lignin model substrates

Catalyst $(0.022 \mathrm{mmol}$ metal and $0.44 \mathrm{mmol}$ PVP in $3 \mathrm{~mL} \mathrm{H}_{2} \mathrm{O}$ ),

substrate $(0.22 \mathrm{mmol})$, $\mathrm{H}_{2} \mathrm{O}$ (1 mL), $\mathrm{H}_{2}$ (10 bar), $368 \mathrm{~K}, 16 \mathrm{~h}$

-depolymerisation of organosolv lignin

- catalyst $(0.022 \mathrm{mmol}$ metal and $0.44 \mathrm{mmol}$ PVP in $3 \mathrm{~mL} \mathrm{H}_{2} \mathrm{O}$ ),

substrate $(50 \mathrm{mg}), \mathrm{H}_{2} \mathrm{O}$ (1 mL), $\mathrm{H}_{2}$ (10 bar), 368 $\mathrm{K}, 16 \mathrm{~h}$
$\mathrm{NiRu}(85 \% \mathrm{Ni}$ and $15 \%$ Ru, Ni surface enriched) best catalyst ; bimetallic systems better performances than monometallic counterparts; low $\mathrm{H}_{2}$ pressure enanhces hydrogenolysis over hydrogenation 
$\mathrm{Ni}_{x} \mathrm{Ru}_{100-\mathrm{x}}$ catalysts $(\mathrm{x}=0,75,80,85,90,95,100$, where $\mathrm{x}$ represents the molar percentage of $\mathrm{Ni}$ ), were prepared by reduction of $\mathrm{RuCl}_{3}$ and $\mathrm{NiCl}_{2}$ with $\mathrm{NaBH}_{4},{ }^{102}$ and later, tested as catalysts in the dehydrodeoxygenation of $\beta-0-4$ model compound. The yield and selectivity were correlated to the $\mathrm{Ru} / \mathrm{Ni}$ ratio following a volcano-type curve (Figure 10). Ru NPs were able to hydrogenate the aromatic ring, while the increasing amount of $\mathrm{Ni}$ enhanced the $\mathrm{C}-\mathrm{O}$ cleavage, being $\mathrm{Ni}_{85} \mathrm{Ru}_{15}$ the catalyst giving higher amounts of monomeric species. In addition, under the catalytic conditions studied, fully hydrogenated dimeric compounds did not undergo further C-O hydrogenolysis (Figure 11).
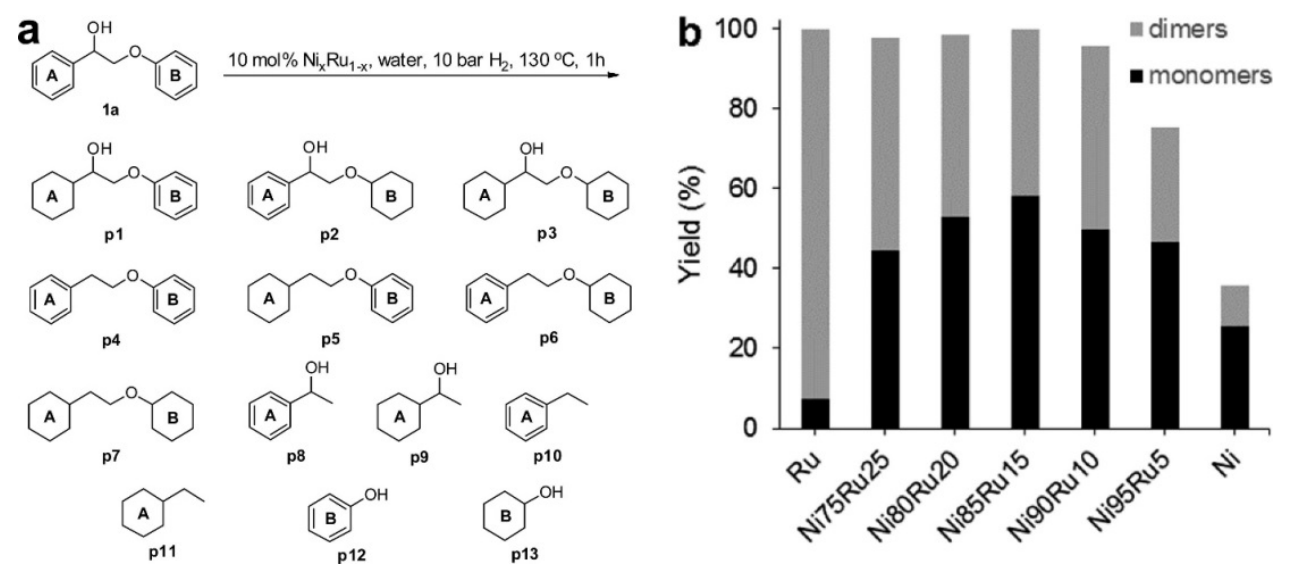

Figure 10. (a) Thirteen products identified after $\beta-0-4$ hydrogenolysis; (b) yields of monomers and dimers over $\mathrm{Ni}, \mathrm{Ru}$, and $\mathrm{NiRu}$ with varying $\mathrm{Ni} / \mathrm{Ru}$ ratio. Reaction conditions: $0.22 \mathrm{mmol} \beta$ $0-4,3 \mathrm{~mL}$ of freshly prepared aqueous solution containing $0.022 \mathrm{mmol}$ of metal and 0.44 mmol of PVP, 10 bar H2, 403 K, 1h. Adapted with permission from ref ${ }^{102}$. Copyright 2014 American Chemical Society. 

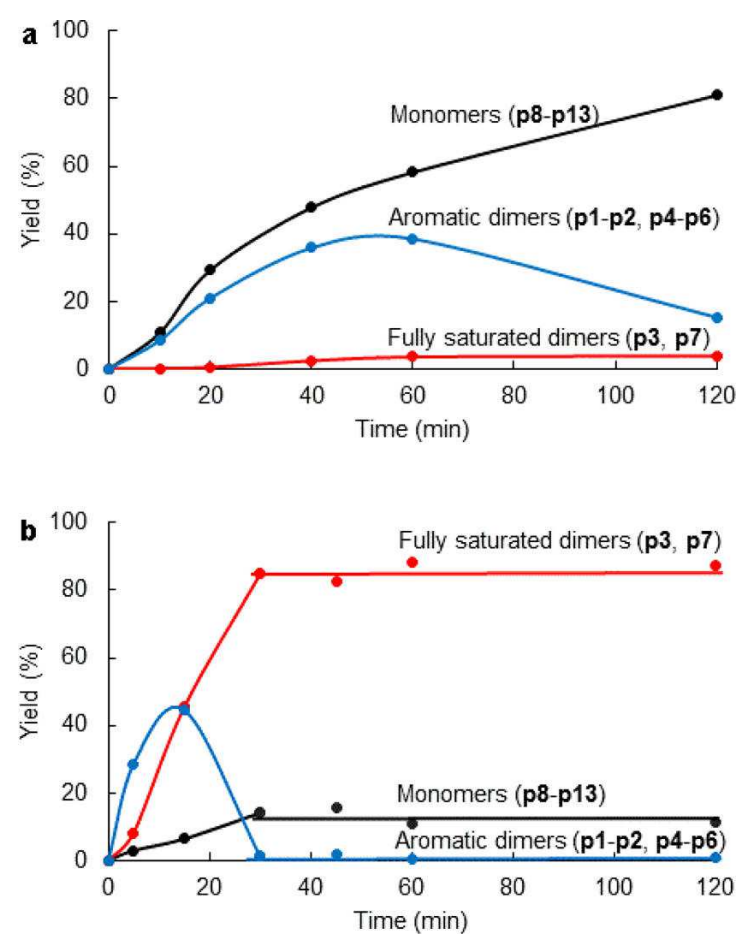

Figure 11. Kinetic study on hydrogenolysis of $\beta-O-4$ over (a) $\mathrm{Ni}_{85} \mathrm{Ru}_{15}$ and (b) Ru. Reaction conditions: $0.22 \mathrm{mmol}$ of $\beta-0-4,3 \mathrm{~mL}$ of freshly prepared aqueous solution containing 0.022 mmol of metal and $0.44 \mathrm{mmol}$ of PVP, $10 \mathrm{bar} \mathrm{H}_{2}, 403 \mathrm{~K}$. Adapted with permission from ref 102. Copyright 2014 American Chemical Society.

More recently, it has been reported the application of the same procedure to synthesize RuNi NPs but in the presence of the surfactant cetyltrimethylammonium bromide (CTAB) instead of PVP. ${ }^{178}$ Similar results were found, i. e. $\mathrm{Ni}_{x} \mathrm{Ru}_{100-x}$ catalysts were efficient towards $\mathrm{C}-\mathrm{O}$ cleavage, while Ru NPs were mainly active in the arene hydrogenation (Figure 12). 

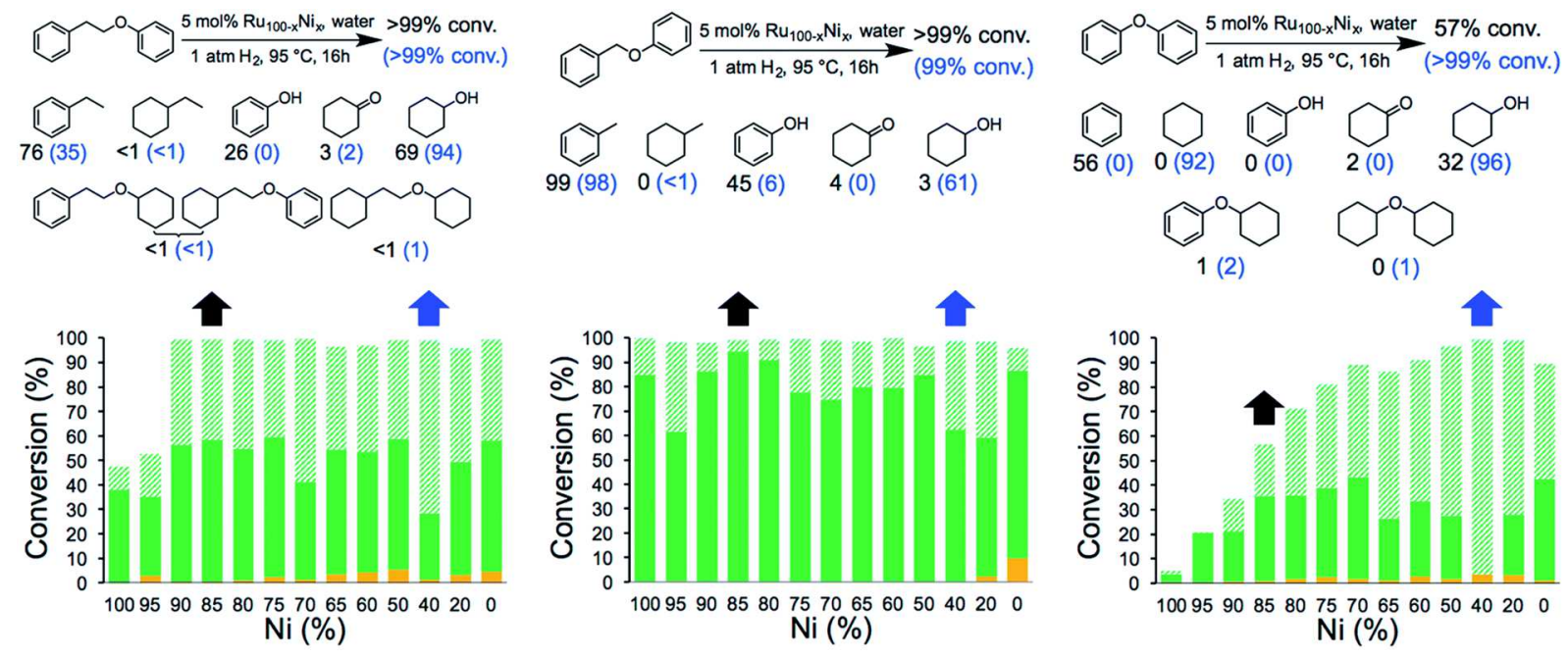

Figure 12. Hydrogenolysis/hydrogenation of (left) 1-phenoxy-2-phenylethane ( $\beta$-O-4 linkage), (middle) benzyl phenyl ether ( $\alpha-0-4$ linkage), (right) diphenyl ether (4-0-5 linkage) and product yield for selected metal combinations catalysed by $\mathrm{Ru}_{100-x} \mathrm{Ni}_{x} \mathrm{NCs}$. The black arrows refer to the $\mathrm{M}_{15} \mathrm{Ni}_{85} \mathrm{NCs}$ and the corresponding yields are in black. The blue arrows refer to the $\mathrm{M}_{60} \mathrm{Ni}_{40} \mathrm{NCs}$ and the corresponding yields are in blue in parenthesis. The fractions comprise partially/fully hydrogenated dimers $(\square)$, non-hydrogenated monomers $(\square)$ and hydrogenated monomers ( $/$ ). Adapted with permission from ref ${ }^{178}$. Copyright 2018 The Royal Society of Chemistry.

Cellulose can be converted to polyols through hydrodeoxygenation reaction catalysed by Ru based nanocatalysts. ${ }^{180-185}$ In a pioneering work, ${ }^{180}$ water soluble Ru NPs were used to conduct hydrogenation and hydrogenolysis reactions of cellobiose into monomeric polyols, thus opening a new route for the valorization of cellulose, the world most abundant biopolymer. In this work, $2.4 \mathrm{~nm}$ Ru NPs were obtained by reduction of $\mathrm{RuCl}_{3}$ in the presence of PVP in an ethanol/water mixture at $353 \mathrm{~K}$. The catalytic reduction of cellobiose was conducted at $393 \mathrm{~K}$ at 40 bar of $\mathrm{H}_{2}$. Ru over performed other metals such as Pd, Pt and Rh, in terms of selectivity to produce sorbitol (100\% conversion and selectivity). Subsequently, Ru supported catalysts have been used to upgrade cellulose, mainly using carbonaceous supports. ${ }^{181-182,184-185}$ 
Interesting enough support effects were reported for this reaction by using the transfer hydrogenation methodology instead of molecular $\mathrm{H}_{2} \cdot{ }^{182} \mathrm{Ru}$ over several carbon supports was reported to be active using isopropanol as reduction agent, but, Ru over alumina was not active to produce sugar alcohols from cellulose.

\subsubsection{Reductive amination of carbonyl compounds, amination of alcohols and other miscellaneous reduction reactions}

In order to obtain primary amines several methodologies have been developed, including hydroaminomethylation/hydroamination, ${ }^{186-187}$ alcohol amination, ${ }^{188-189}$ and reductive amination of carbonyl compounds. ${ }^{189-190}$ Colloidal Ru based catalysts have found applications in these later reactions for the production of primary amines from ammonia. ${ }^{191}$ This could open new opportunities, for instance, to upgrade biomass-derived oxygen-rich materials. ${ }^{191-}$ ${ }^{193}$ Heterogeneous catalysts for alcohol amination are scarce, ${ }^{191,193-202}$ but include the use of Ru based materials. ${ }^{191,193-194,199,} 201$ These later are mainly supported catalysts, which often display better performances than other metals for this reaction, ${ }^{193-194}$ although, Ni based catalysts also displaying high performances. ${ }^{197-198}$ Amino acids were obtained from $\alpha$-hydroxyl acids derived from biomass and ammonia in high yields in the presence of Ru/CNT trough the amination reaction. ${ }^{193} \mathrm{Ru} / \mathrm{CNT}$ catalyst surpassed other metal based catalysts, including Pd, Pt, Rh, Ir over CNT and Ni Raney, in terms of activity; and also other Ru based catalysts supported in oxides such as $\mathrm{SiO}_{2}, \mathrm{Al}_{2} \mathrm{O}_{3}, \mathrm{ZrO}_{2}, \mathrm{CeO}_{2}$ and $\mathrm{MgO}$. As mentioned before, colloidal based catalysts allow a fine-tuning of their properties, if compared to supported catalysts, which permits to access to more detailed information about the impact of certain characteristics in a given reaction. Recently, non-supported Ru NPs stabilized with CTAB (ca. 2- $9 \mathrm{~nm}$ ) were investigated in direct amination of octanol and other alcohols into primary amines in the presence of ammonia. ${ }^{191}$ This work revealed that the amination of alcohol 
towards octylamine is insensitive to the size of the nanoparticles, but the selectivity is not at high conversions. The self-coupling of the amine, leading to less selective systems because of the formation of secondary and tertiary amines, is almost supressed for small NPs therefore leading to highly selective catalyst ( $89 \%$ conversion, $90 \%$ selectivity). Electronic and steric properties of the NPs and the substrates are claimed to be plausible explanations of the size sensitive of this reactions but without any further evidence.

Ru-based catalysts have found applications in the reductive amination of carbonyl compounds in order to obtain amines selectively. ${ }^{189,192,199,203-208}$ Special focus is given to primary amines using $\mathrm{NH}_{3}$ and $\mathrm{H}_{2}$. Similarly to the amination of alcohols, the reductive amination of carbonyl compounds allows to upgrade efficiently oxygen-rich biomass derivatives. ${ }^{189,} 192,199$ Other metal-based heterogeneous catalysts have been successfully used in this catalytic reaction, ${ }^{205}$, 209-217 but Ru seems to be highly efficient to produce primary amines. ${ }^{189,} 205$ Up to now, Rubased catalysts used in this reaction consist mainly in supported materials. It has been evidenced a support effect on the performances of supported Ru catalysts. ${ }^{199,}{ }^{204} \mathrm{Ru} / \mathrm{Nb}_{2} \mathrm{O}_{5}$, $\mathrm{Ru} / \mathrm{TiO}_{2}$ and $\mathrm{Ru} / \mathrm{SiO}_{2}$ catalysts displayed a different behaviour in the reductive amination of furfural. ${ }^{199} \mathrm{Ru} / \mathrm{Nb}_{2} \mathrm{O}_{5}$ was very efficient for this reaction, and this fact was attributed to the lower electron density of Ru NPs deposited on $\mathrm{Nb}_{2} \mathrm{O}_{5}$ when compared to those of $\mathrm{Ru} / \mathrm{TiO}_{2}$ and $\mathrm{Ru} / \mathrm{SiO}_{2}$, which gave more electron-rich Ru surfaces. Support effects were also evidenced elsewhere, ${ }^{189}$ but in this case the control of the reactivity was related to the mixture of Ru and $\mathrm{RuO}_{2}$ on the surface. Recently, unsupported Ru NPs displaying a fcc structure proved to be an extremely efficient catalyst for the reductive amination of furfural and other substrates. ${ }^{192}$ The fcc Ru NPs (TOF $=1850 \mathrm{~h}^{-1}$, at $363 \mathrm{~K}$ ) outperformed Ru/ $/ \mathrm{Nb}_{2} \mathrm{O}_{5}\left(\mathrm{TOF}=520 \mathrm{~h}^{-1}\right.$, at $363 \mathrm{~K}$ ) and $\mathrm{Rh} / \mathrm{Al}_{2} \mathrm{O}_{3}\left(\mathrm{TOF}=990 \mathrm{~h}^{-1}\right.$, at $353 \mathrm{~K}$ ) catalysts in terms of activity, but displaying similar selectivity 
towards the primary amine (99\%, 99\%, and $92 \%$, respectively). This catalyst was reused four

times and was highly active and selective for other substrates.

Other reduction reactions have been studied using Ru NPs as catalysts, such as transfer

hydrogenation reactions, ${ }^{155,218}$ or reduction of $\mathrm{NOx}^{105}$ which are summarized in Table 7.

Table 7. Ru NPs as catalysts in miscellaneous reduction reactions

\begin{tabular}{|c|c|c|c|c|c|}
\hline Stabilizing agent & Methodology & Characterization & Reaction conditions & Comments & Ref. \\
\hline & $\begin{array}{l}\text { Reduction of } \mathrm{RuCl}_{3} \\
\text { with } \mathrm{NaBH}_{4} \text {. }\end{array}$ & & Amination of Octanol & & \\
\hline CTAB & $\begin{array}{c}\mathrm{RuCl}_{3}(0.22 \mathrm{~g}), \mathrm{CTAB} \\
(2.9-5 \mathrm{eq}), \mathrm{NaBH}_{4} \\
(0.13 \mathrm{~g}), \text { hexanol }(2.6- \\
4.5 \mathrm{eq}), \mathrm{H}_{2} \mathrm{O}(0.5-4.5 \\
\text { eq), } 273 \mathrm{~K}\end{array}$ & $\begin{array}{c}\text { TEM, } \mathrm{O}_{2} \text { titration, } \\
\text { XRD, XPS }\end{array}$ & $\begin{array}{l}\text { Catalyst }(10-200 \mathrm{mg}), \\
\text { substrate }(1 \mathrm{~mL}), \\
\text { decane }(1 \mathrm{mmol}), \mathrm{NH}_{3} \\
\text { gas, } \mathrm{H}_{2}(2 \mathrm{bar}), 453 \mathrm{~K}, \\
1-24 \mathrm{~h}\end{array}$ & $\begin{array}{c}\text { NPs size effect; } \\
\text { three recycling tests; } \\
\text { no leaching }\end{array}$ & 191 \\
\hline none & $\begin{array}{c}\text { Acidic treatment of } \\
\mathrm{Ru} / \mathrm{Ca}\left(\mathrm{NH}_{2}\right)_{2} \\
\mathrm{Ru} / \mathrm{Ca}\left(\mathrm{NH}_{2}\right)_{2}(2 \mathrm{~g}), 2- \\
\text { propanol }(15 \mathrm{~mL}), \\
\mathrm{HNO}_{3}(2 \mathrm{M} \text { until } \mathrm{pH}=4), \\
\mathrm{H}^{2} \mathrm{O}(20 \mathrm{~mL}), 333 \mathrm{~K}, 2- \\
4 \mathrm{~h}\end{array}$ & $\begin{array}{c}\text { TEM, XRD, } \mathrm{N}_{2} \\
\text { adsorption- } \\
\text { desorption } \\
\text { isotherms, CO } \\
\text { chemisorption, } \\
\text { XPS, IR }\end{array}$ & $\begin{array}{l}\text { Reductive amination } \\
\text { Catalyst (0.2 mg), } \\
\text { substrate }(0.5 \mathrm{mmol}), \\
\mathrm{NH}_{3} \text {-methanol ( } 4 \mathrm{~mL}, 8 \\
\mathrm{mmol}), \mathrm{H}_{2}(20 \mathrm{bar}), \\
363 \mathrm{~K}, 0-6 \mathrm{~h}\end{array}$ & $\begin{array}{l}\text { Recycling test, no } \\
\text { further } \\
\text { characterization of } \\
\text { the spent catalyst }\end{array}$ & 192 \\
\hline RuFe & $\begin{array}{c}\text { Stepwise reaction; } \\
\mathrm{FeSO}_{4} \text { reduction with } \\
\mathrm{NaBH}_{4} \text { followed by } \\
\text { galvanic reduction. } \\
\mathrm{FeSO}_{4}(4.5 \mathrm{~g}), \mathrm{NaBH}_{4} \\
(0.8 \mathrm{~g}), \mathrm{MeOH}(60 \mathrm{~mL}), \\
\mathrm{H}_{2} \mathrm{O}(360 \mathrm{~mL}) ; \\
\mathrm{RuCl}_{3}(10 \mathrm{mg}), \mathrm{Fe} \mathrm{NPs} \\
(100 \mathrm{mg}), \mathrm{MeOH}\end{array}$ & TEM, ICP, XPS & $\begin{array}{c}\text { Transfer } \\
\text { hydrogenation } \\
\text { Catalyst (50 mg, } 1.3 \\
\text { mol\%), substrate (1 } \\
\mathrm{mmol}) \text {, decane (1 } \\
\mathrm{mmol}), \mathrm{KOH}(15 \\
\mathrm{mol} \%), 2-\mathrm{PrOH}(5 \mathrm{~mL}), \\
373 \mathrm{~K}\end{array}$ & $\begin{array}{l}\text { Hot filtration test; } \\
\text { metal leaching (Ru } \\
\text { (12 ppm), Fe (4 } \\
\text { ppm); recycled } 5 \\
\text { times with a slightly } \\
\text { loss of activity }\end{array}$ & 218 \\
\hline $\mathrm{Ni} / \mathrm{Ru} / \mathrm{Pt} / \mathrm{Au}$ & $\begin{array}{c}\begin{array}{c}\text { Reduction of metal } \\
\text { precursors with } \\
\text { lithium }\end{array} \\
\text { triethylborohydride. } \\
\mathrm{NiCl} 2, \\
\left.\mathrm{RuCl}_{3}, \mathrm{KAuCl}_{4}\right) \mathrm{H}_{2} \mathrm{PtCl}_{6}, \\
\left(0.50 \mathrm{mmol}_{\text {in total), }}\right. \\
\text { trioctylphosphine } \\
\text { oxide }(0.50 \mathrm{mmol}) \\
\mathrm{THF}(10 \mathrm{~mL}) \text { lithium } \\
\text { triethylborohydride } \\
(7.5 \mathrm{~mL}, 1 \mathrm{M}), \text { r. t., } 2 \mathrm{~h}\end{array}$ & TEM, ICP & $\begin{array}{c}\text { Transfer } \\
\text { hydrogenation } \\
\text { Catalyst }(0.3-0.7 \\
\text { mol\%), 4-phenyl-1- } \\
\text { butene }(1 \mathrm{mmol}), \\
\mathrm{H}_{2} \mathrm{O} / 2-\mathrm{PrOH}(3 / 10,3.3 \\
\mathrm{mL}), 373 \mathrm{~K}, 24 \mathrm{~h}\end{array}$ & $\begin{array}{c}\text { Tetrametallic } \\
\text { catalyst displayed } \\
\text { higher conversion to } \\
\text { the desired product } \\
\text { than mono-, bi-, or } \\
\text { trimetallic } \\
\text { counterparts; no } \\
\text { recycling tests; no } \\
\text { characterization of } \\
\text { the spent catalysts }\end{array}$ & 155 \\
\hline
\end{tabular}




$\begin{array}{ccc} & \text { Reduction of } \mathrm{K}_{2}\left[\mathrm{PdCl}_{4}\right] & \\ \text { and } \mathrm{RuCl}_{3} \text { in } & \\ \text { triethylene glycol } & \\ & & \\ \text { RuPd/PVP } & \mathrm{K}_{2}\left[\mathrm{PdCl}_{4}\right](163.4 \mathrm{mg}), & \text { TEM, XRD, XPS, } \\ \mathrm{RuCl}_{3}(131.1), \mathrm{PVP} & \text { SSNMR } \\ (444 \mathrm{mg}), \text { triethylene } & \\ \text { glycol }(100 \mathrm{~mL}), \mathrm{H}_{2} \mathrm{O} & \\ (40 \mathrm{~mL}), 473 \mathrm{~K}, & \end{array}$

RuPd NP displays better NOx reduction activity than Rh; theoretical calculations show Reduction of NOx that the electronic

Tubular quartz reactor with catalyst, mixture simulating automotive exhaust, 293-873K $\mathrm{Pd}_{0.5} \mathrm{Ru}_{0.5}$ is similar to that of $\mathrm{Rh}$

inverse volcano-type behaviour in reduction activity with respect the atomic ratio of $\mathrm{Pd}$ and Ru

\subsection{Oxidation reactions}

Ru NPs have been successfully used as catalysts in oxidation reactions. Thus, the oxidation of several substrates with oxidation agents such as tert-butyl hydroperoxide (TBHP), ${ }^{219} \mathrm{H}_{2} \mathrm{O}_{2},{ }^{220}$ or aerobic conditions ${ }^{135}$ is described in the literature (Table 8 ). Water-soluble Ru NPs were used in the allylic oxidation of $\alpha$-pinene by TBHP to produce verbenone with $39 \%$ yield. ${ }^{219}$ Also, Ru NPs catalyzed the oxidation of substrates such as 3,3,5,5-tetramethylbenzidine, ophenylenediamine, and dopamine hydrochloride by $\mathrm{H}_{2} \mathrm{O}_{2}$. Ru/PVP NPs converted ethanol to acetaldehyde with molecular $\mathrm{O}_{2}\left(30\right.$ bar). ${ }^{221}$ Milder conditions $\left(1\right.$ bar $\mathrm{O}_{2}$ ) were applied in the oxidation of alcohol and amine derivatives, using aerobic conditions by Ru/NHC NPs. ${ }^{135}$ The oxidation with Ru/NHC NPs proceeded smoothly, and it was also possible to perform consecutive oxidation/hydrogenation reactions. WAXS analyses of the Ru/NHC catalysts exposed to air showed that amorphous ruthenium oxide was formed only at the surface of the nanoparticles providing an unoxidazed Ru core, thus indicating the stability of the Ru nanosystem in the applied conditions.

Table 8. Ru NPs as oxidation catalysts

\begin{tabular}{lllll}
\hline Stabilizing agent & Methodology & Characterization & Reaction conditions & Comments \\
\hline
\end{tabular}




\begin{tabular}{|c|c|c|c|c|c|}
\hline $\begin{array}{c}\text { ammonium } \\
\text { surfactants } \\
\left(\mathrm{HEA}_{16} \mathrm{Cl}, \mathrm{HEA}_{16} \mathrm{Br} \text {, }\right. \\
\left.\mathrm{HEA}_{16} \mathrm{BF}_{4}, \mathrm{THEA}_{16} \mathrm{Cl}\right)\end{array}$ & $\begin{array}{c}\text { Reduction of } \\
\mathrm{RuCl}_{3} \text { and } \mathrm{NiCl}_{2} \\
\text { with } \mathrm{NaBH}_{4} \text {. } \\
\mathrm{RuCl}_{3} \cdot 3 \mathrm{H}_{2} \mathrm{O}(10 \\
\mathrm{mg}, 3.8 \times 10^{-5} \\
\mathrm{~mol}, 1 \mathrm{eq}) \text {, } \\
\text { ammonium } \\
\text { surfactant } \\
\left(7.6 \times 10^{-5} \mathrm{~mol} \text {, }\right. \\
2 \text { eq.), } \mathrm{NaBH}_{4} \\
\text { (3.6 } \mathrm{mg}, 2.5 \\
\text { eq.), } \mathrm{H}_{2} \mathrm{O}(10 \\
\mathrm{mL}), 273 \mathrm{~K}\end{array}$ & TEM, DLS, & $\begin{array}{c}\text { Oxidation of } \alpha \text {-pinene } \\
\text { Catalyst }\left(1.9 \times 10^{-5} \mathrm{~mol}\right) \text {, } \\
\alpha \text {-pinene }\left(1.9 \times 10^{-3} \mathrm{~mol}\right) \text {, } \\
\text { t-BHP }\left(5.7 \times 10^{-3}\right. \\
\text { mol), water }(5 \mathrm{~mL}), 3 \mathrm{~h}, \\
293 \mathrm{~K}\end{array}$ & $\begin{array}{l}39 \% \text { yield of } \\
\text { verbenone from } \alpha \text { - } \\
\text { pinene; Ru NPs } \\
\text { with ammonium } \\
\text { surfactants HEA } \\
\text { perform better } \\
\text { than other Ru NPs; } \\
\text { counter-ion (X=Cl, } \\
\left.\mathrm{Br}_{\text {, }} \mathrm{BF}_{4}\right) \text { slightly } \\
\text { influences the } \\
\text { ketone selectivity; } \\
\text { recycling test; TEM } \\
\text { after catalysis }\end{array}$ & 219 \\
\hline- & commercial & $\begin{array}{l}\text { TEM, SEM, DLS, zeta } \\
\text { potential, UV-Vis }\end{array}$ & $\begin{array}{l}\text { Oxidation of several } \\
3,3,5,5- \\
\text { tetramethylbenzidine, o- } \\
\text { phenylenediamine, and } \\
\text { dopamine } \\
\text { hydrochloride) } \\
\text { Catalyst }(2.5-20 \mu \mathrm{gg} / \mathrm{mL}) \text {, } \\
\text { substrate }(0.1 \mathrm{mM}), \mathrm{H}_{2} \mathrm{O}_{2} \\
(0.1 \mathrm{mM})\end{array}$ & $\begin{array}{c}\text { Some test using } \mathrm{O}_{2} \\
\text { as oxidizing agent; } \\
\text { no recycling test or } \\
\text { characterization of } \\
\text { the catalysts after } \\
\text { reaction }\end{array}$ & 220 \\
\hline Long-chain NHC & $\begin{array}{c}\text { Reduction of } \\
{[\mathrm{Ru}(\mathrm{COD})(\mathrm{COT})]} \\
\text { with } \mathrm{H}_{2} \\
{[\mathrm{Ru}(\mathrm{COD})(\mathrm{COT})]} \\
(100 \mathrm{mg}), \mathrm{NHC} \\
(0.1-0.3 \text { eq. }), \mathrm{H}_{2} \\
\text { (3 bar), THF (50 } \\
\mathrm{mL}), 298 \mathrm{~K}, 20 \mathrm{~h}\end{array}$ & $\begin{array}{c}\text { TEM, WAXS, SSNMR, } \\
\text { IR }\end{array}$ & $\begin{array}{c}\text { Oxidation of several } \\
\text { substrates with } \mathrm{O}_{2} \\
\text { Catalyst }(1 \mathrm{mg}), \\
\text { substrate }(0.2 \mathrm{mmol}) \text {, } \\
\text { trifluorotoluene }(1 \mathrm{~mL}) \text {, } \\
\mathrm{O}_{2}(1 \text { bar), } 298 \mathrm{~K}, 16 \mathrm{~h} \\
\text { Oxidation/hydrogenation } \\
\text { of several substrates } \\
\text { with } \mathrm{O}_{2} \text {, then } \mathrm{H}_{2} \\
\text { Catalyst }(1-1.5 \mathrm{mg}), \\
\text { substrate }(0.2 \mathrm{mmol}), \\
\text { trifluorotoluene }(1 \mathrm{~mL}), \\
\mathrm{O}_{2}\left(1 \text { bar), } 298 \mathrm{~K}, 16 \mathrm{~h} ; \mathrm{H}_{2}\right. \\
(5 \text { bar), r.t. or } 318 \mathrm{~K}, 4 \text { or } \\
16 \mathrm{~h}\end{array}$ & $\begin{array}{l}\text { Selectivity } \\
\text { modulated with } \\
\text { surface ligand; } \\
\text { oxidized NP } \\
\text { characterized by } \\
\text { TEM and WAXS; no } \\
\text { recycling test }\end{array}$ & 135 \\
\hline
\end{tabular}

Because of the importance of CO removal from car exhaust or fuel-cell systems, $\mathrm{CO}$ oxidation

has been studied thoughtfully, both theoretically and experimentally. ${ }^{222}$ CO oxidation can be seen also as a model reaction, similar to the case of styrene hydrogenation as previously mentioned, which can bring further information about metal NPs nature and characteristics. ${ }^{223}$ Mono- and bimetallic Ru-based catalysts synthesized by wet procedures 
have been investigated for $\mathrm{CO}$ oxidation (Table 9). The influence of parameters such as $\mathrm{Ru}$ crystal structure, size, and in bimetallic systems, the ratio of the two metals, on the activity of the reaction has been underlined. Ru NPs displaying fcc or hcp crystalline structures were prepared selectively from $\left[\mathrm{Ru}(\mathrm{acac})_{3}\right]$ and $\mathrm{RuCl}_{3}$, respectively, with controllable sizes ranging from 2 to $5.5 \mathrm{~nm} \cdot{ }^{13,224}$ The crystalline structure was controlled by the choice of the Ru source and the solvent, ethylene glycol or triethylene glycol, and the size was adjusted by varying the concentration of reagents and the stabilizer (PVP). TEM and XRD analyses pointed out the fcC character of the Ru NPs. In situ XRD probed the high thermal stability of the Ru fcc NPs, which were stable up to $723 \mathrm{~K}$. The CO oxidation was dependent on both crystalline phase and size; small Ru fcc NPs outperformed hcp ones when displaying small sizes, while hcp Ru NPs were more performant at larger sizes (Figure 13). Ru nanochains were synthesized in water from Ru seeds with cetyl trimethylammonium bromide as capping agent. The self-assembled nanochains were more efficient as $\mathrm{CO}$ oxidation catalysts than Ru nanoseeds ( $3.5 \mathrm{~nm}$ ) and Ru spheres $(6 \mathrm{~nm}) .^{225}$

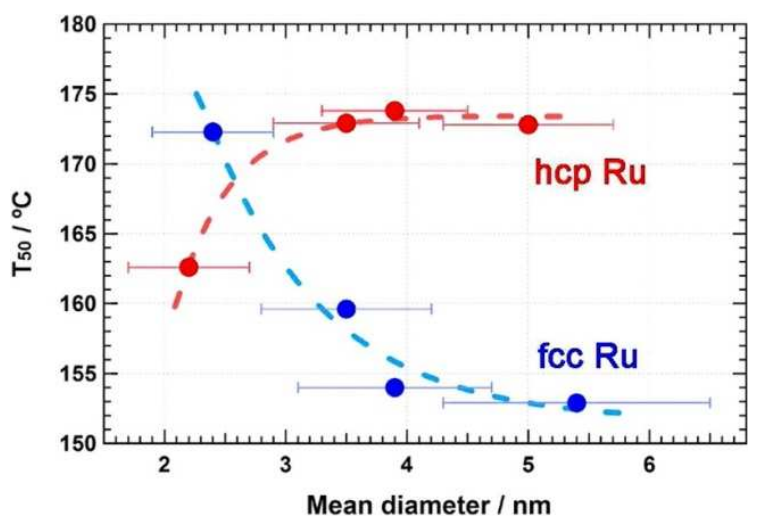

Figure 13. Size dependence of the temperature for $50 \%$ conversion of $\mathrm{CO}$ to $\mathrm{CO}_{2}\left(T_{50}\right)$ for fcc (blue) and hcp (red) Ru NPs. Adapted with permission from ref ${ }^{13}$. Copyright 2013 American Chemical Society. 
Bimetallic RuPd, ${ }^{226} \mathrm{RuCu}^{227-228}$ and $\mathrm{RuCO}_{3} \mathrm{O}_{4}{ }^{229}$ catalysts have been described, as well. $\mathrm{Ru}$ deposited onto Co-rods and further thermally treated gave $\mathrm{RuCo}_{3} \mathrm{O}_{4}$ species which were active towards the CO-oxidation reaction and outperformed the corresponding monometallic NPs (Figure 14). ${ }^{229}$ DFT calculations attributed the enhancement of the catalytic activity of $\mathrm{RuCO}_{3} \mathrm{O}_{4}$ species to the charge transfer from ruthenium to $\mathrm{Co}_{3} \mathrm{O}_{4}$; which activated more efficiently $\mathrm{O}_{2}$ and lowered the activation energy.

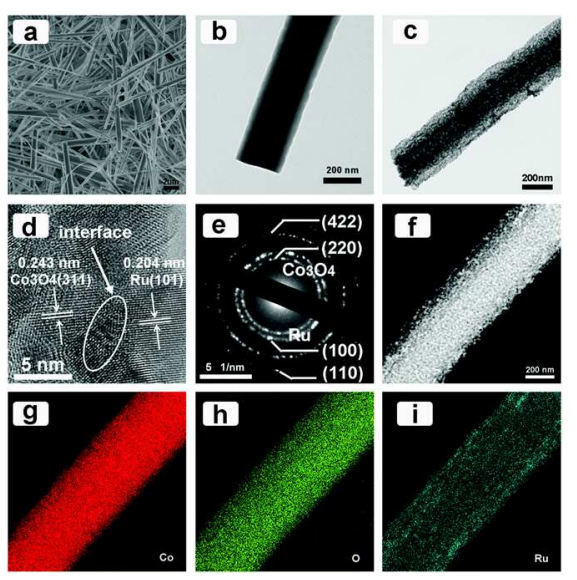

Figure 14. (a) FESEM and (b) TEM images of the as-prepared Co-MOF precursor; (c) TEM, (d) HRTEM and (e) SAED images of the $\mathrm{Ru}-\mathrm{CO}_{3} \mathrm{O}_{4}$ interfacial structure; ( $\mathrm{f}-\mathrm{i}$ ) EDS mapping images of the $\mathrm{Ru}-\mathrm{CO}_{3} \mathrm{O}_{4}$ interfacial structure. Adapted with permission from ref ${ }^{229}$. Copyright 2018 The Royal Society of Chemistry.

A series of RuPd NPs have been synthesised from $\mathrm{RuCl}_{3}$ and $\mathrm{K}_{2}\left[\mathrm{PdCl}_{4}\right]$ by tunning the $\mathrm{Ru} / \mathrm{Pd}$ ratio. ${ }^{226}$ The crystallographic structure of the bimetallic NPs changed from fcc to hcp when increasing the Ru content. Surface characterization was performed using solid state- ${ }^{2} \mathrm{H}-\mathrm{NMR}$; ${ }^{2} \mathrm{H}$ NMR spectra after ${ }^{2} \mathrm{H}$ adsorption showed that the chemical shift of the hydrides on the surface of the NPs depends on their composition (Figure 15). $\mathrm{Ru}_{0.5} \mathrm{Pd}_{0.5}$ was the most active catalyst, performing better than other RuPd mixtures and also than monometallic $\mathrm{Ru}, \mathrm{Pd}$ and Rh based catalysts (Figure 15). 
(a)

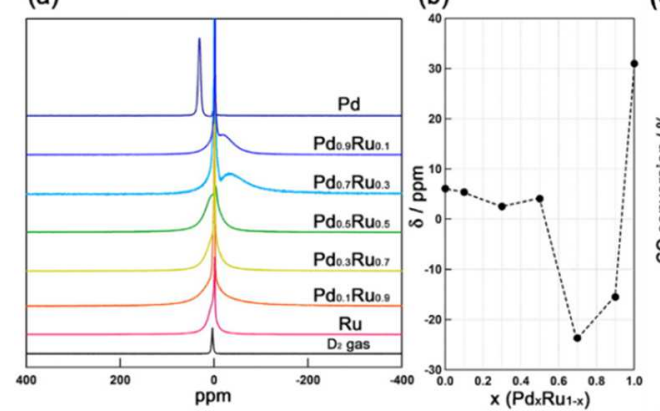

(c)

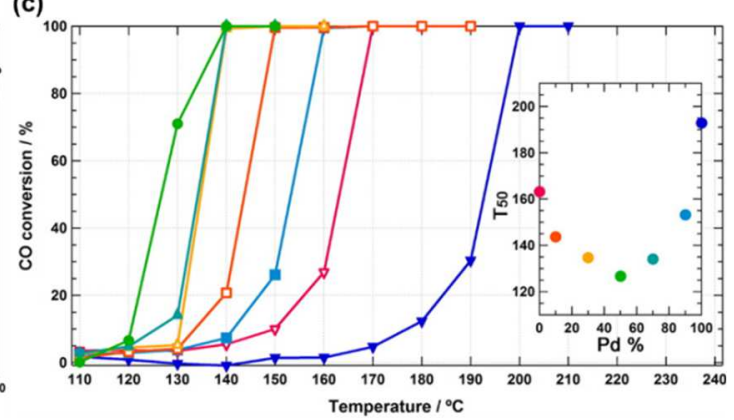

Figure 15. (a) The solid-state ${ }^{2} \mathrm{H}$ NMR spectra for $\mathrm{Pd}_{x} \mathrm{Ru}_{1-x}$ nanoparticles and ${ }^{2} \mathrm{H}_{2}$ gas. All of the samples were measured under $101.3 \mathrm{kPa}$ of ${ }^{2} \mathrm{H}_{2}$ gas at $303 \mathrm{~K}$. (b) The chemical shift position of the broad absorption lines in $\mathrm{Pd}_{x} \mathrm{Ru}_{1-x}$. (c) Temperature dependence of $\mathrm{CO}$ conversion in PdxRu1-x nanoparticles supported on $\gamma$-Al2O3; $x=0$ ( $\nabla$ red), 0.1 ( $\square$ orange), 0.3 ( $\Delta$ yellow), 0.5 ( $\bullet$ green), 0.7 ( $\boldsymbol{\Delta}$ blue-green), 0.9 ( $\mathbf{~ l i g h t ~ b l u e ) , ~ a n d ~ 1 . 0 ~ ( ~} \boldsymbol{\nabla}$ blue). The inset is the metal composition dependence of T50. Adapted with permission from ref ${ }^{226}$. Copyright 2014 American Chemical Society.

Following a similar procedure, nanosized $\mathrm{Ru}_{x} \mathrm{Cu}_{1-x}$ alloys were synthesised, which is remarkable since $\mathrm{Ru}$ and $\mathrm{Cu}$ are completely immiscible in bulk phase. ${ }^{227-228} \mathrm{XRD}, \mathrm{TEM}$ and EDX suggest that $\mathrm{Cu}$ and $\mathrm{Ru}$ atoms are randomly mixed to form alloy structures. As observed with the close RuPd NPs system described above, the catalytic activity of $\mathrm{Ru}_{x} \mathrm{Cu}_{1-\mathrm{x}}$ alloys in the CO oxidation reaction depends on the $\mathrm{Ru} / \mathrm{Cu}$ ratio; $\mathrm{Cu}_{0.2} \mathrm{Ru}_{0.8}$ nanoparticles demonstrated the best catalytic activity. IR studies provided better insights on the catalytic system. $\mathrm{CO}$ adsorbed onto the NPs surface was observed by IR; pure Ru NPs, displayed a CO band at $1986 \mathrm{~cm}^{-1}$ along with those of free $\mathrm{CO}$ gas at 2200 to $2050 \mathrm{~cm}^{-1}$. A blue shift was observed when increasing the $\mathrm{Cu}$ content in the samples. After further exposure to $\mathrm{O}_{2}$, only $\mathrm{CO}$ bands corresponding to the $\mathrm{CO}$ adsorbed onto Ru atoms remained, indicating that probably $\mathrm{CO}$ is activated on this metal. DFT calculations suggested that the Ru atoms are responsible for the $\mathrm{CO}$ activation as well, 
and that the presence of $\mathrm{Cu}$ lowers the $\mathrm{CO}$ adsorption energy. The decrease of the $\mathrm{CO}$ adsorption energy was originated by a site exchange from Ru hollow sites to Ru top sites. ${ }^{228}$

Table 9. Ru NPs as oxidation catalysts of CO

\begin{tabular}{|c|c|c|c|c|c|}
\hline Stabilizing agent & Methodology & Characterization & Reaction conditions & Comments & Ref. \\
\hline PVP & $\begin{array}{l}\text { Reduction of } \\
{\left[\mathrm{Ru}(\mathrm{acac})_{3}\right] \text { or }} \\
\mathrm{RuCl}_{3} \text { in } \\
\text { ethylene glycol } \\
\text { or triethylene } \\
\text { glycol } \\
\text { [Ru(acac) })_{3} \text { or } \\
\mathrm{RuCl}_{3}(2.1 \\
\mathrm{mmol}, \mathrm{PVP}(1- \\
10 \mathrm{mmol}), \\
\text { solvent }(25-500 \\
\mathrm{mL}), 473 \mathrm{~K}, 3 \mathrm{~h}\end{array}$ & TEM, XRD & $\begin{array}{c}\text { CO oxidation } \\
\text { Tubular quartz reactor } \\
\text { with quartz wool, } \\
\text { catalyst }(150 \mathrm{mg}) \text {, gas } \\
\text { mixture of } \mathrm{CO} / \mathrm{O}_{2} / \mathrm{He} \\
\left(\mathrm{CO} / \mathrm{O}_{2} / \mathrm{He}: 0.5 / 0.5 / 49\right. \\
\left.\mathrm{ml} \cdot \mathrm{min}^{-1}\right), 373 \mathrm{~K}\end{array}$ & $\begin{array}{l}\text { Synthesis of Ru fcc } \\
\left.\left(\left[\mathrm{Ru}_{(\mathrm{acac}}\right)_{3}\right]\right) \text { or hcp } \\
\left(\mathrm{RuCl}_{3}\right) \text { depending } \\
\text { on the metal } \\
\text { precursor used; } \mathrm{CO} \\
\text { oxidation size- and } \\
\text { structure- } \\
\text { dependent; higher } \\
\text { CO oxidation } \\
\text { activity of fcc Ru } \\
\text { NP compared with } \\
\text { that of hcp Ru NPs, } \\
\text { for sizes larger than } \\
3 \mathrm{~nm} \text {. }\end{array}$ & $\begin{array}{l}13, \\
224\end{array}$ \\
\hline CTAB & $\begin{array}{c}\text { Reduction of } \\
{\left[\mathrm{Ru}(\mathrm{NO})(\mathrm{NO})_{3}\right]} \\
\text { with } \mathrm{NaBH}_{4} \\
\\
{\left[\mathrm{Ru}(\mathrm{NO})(\mathrm{NO})_{3}\right]} \\
(125 \mu \mathrm{L}, 1.5 \\
\text { wt\%), } \mathrm{NaBH}_{4} \\
(50 \mu \mathrm{L}, 0.25 \mathrm{M}) ; \\
\mathrm{CTAB}(4 \mathrm{~mL} \text { of } \\
22 \mathrm{mM}), \\
\text { ascorbic acid } \\
(300 \mathrm{~mL}, 0.1 \mathrm{M}) \\
\text { and } \\
{\left[\mathrm{Ru}(\mathrm{NO})(\mathrm{NO})_{3}\right]} \\
(50 \mathrm{~mL}, \\
1.5 \mathrm{wt} \% \mathrm{w}), 343 \\
\mathrm{~K}, 0.5 \mathrm{~h}, \mathrm{r} . \mathrm{t.} 12 \mathrm{~h}\end{array}$ & $\begin{array}{c}\text { TEM, XRD, UV-Vis, } \\
\text { DLS }\end{array}$ & 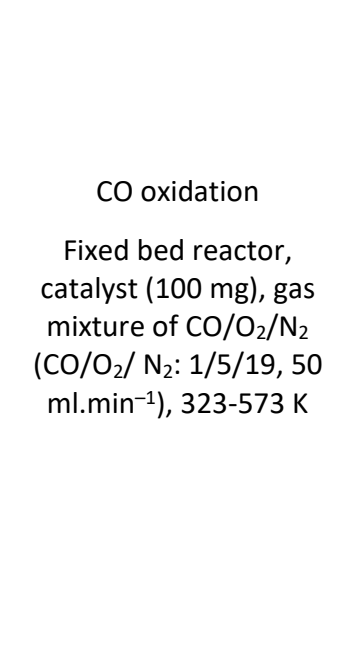 & $\begin{array}{l}\text { Ru nanochains } \\
\text { synthesised in a } \\
\text { two stes procedure } \\
\text { are more } \\
\text { performant in CO } \\
\text { oxidation than Ru } \\
\text { spherical NPS; } \\
\text { catalytic activity } \\
\text { depends also on } \\
\text { the support used } \\
\text { Ru nanochains can } \\
\text { be recycled while } \\
\text { Ru NPs tend to } \\
\text { increase the size } \\
\text { during time and } \\
\text { loss some activity }\end{array}$ & 225 \\
\hline $\mathrm{Ru}-\mathrm{CO}_{3} \mathrm{O}_{4}$ & $\begin{array}{l}\text { Annealing of Ru } \\
\text { incorporated } \\
\text { Co-MOFs in } \mathrm{N}_{2} \\
\text { (873K) and then } \\
\text { in air (523 K) }\end{array}$ & $\begin{array}{c}\text { TEM, XRD, specific } \\
\text { surface area and pore } \\
\text { volume, TGA, XPS, } \\
\text { DFT }\end{array}$ & $\begin{array}{c}\text { CO oxidation } \\
\text { Fixed-bed flow reactor. } \\
\text { Catalyst }(50 \mathrm{mg}) \text {, feed } \\
\text { gas }(1 \% \mathrm{CO}, 99 \% \text { air, flow } \\
\text { rate } 30 \mathrm{ml} / \mathrm{min}), 323 \mathrm{~K}\end{array}$ & $\begin{array}{l}\text { Catalyst stable and } \\
\text { active after } 30 \mathrm{~h} \text { of } \\
\text { use; TEM and XRD } \\
\text { analyses after } \\
\text { catalysis showing } \\
\text { no appreciable } \\
\text { change }\end{array}$ & 229 \\
\hline $\mathrm{Ru}_{x} \mathrm{Cu}_{1-x}$ & $\begin{array}{c}\text { Polyol synthesis } \\
\left.\text { [Ru(acac })_{3}\right] \\
(318.7 \mathrm{mg}, 0.8 \\
\mathrm{mmol}) \\
{\left[\mathrm{Cu}(\mathrm{OAc})_{2} \cdot \mathrm{H}_{2} \mathrm{O}\right]} \\
(239.6 \mathrm{mg}, 1.2 \\
\mathrm{mmol}),\end{array}$ & $\begin{array}{l}\text { TEM, XRD, XRF, in situ } \\
\text { IR, thermal stability } \\
\text { investigated by in situ } \\
\text { synchrotron XRD } \\
\text { measurements }\end{array}$ & $\begin{array}{c}\text { CO oxidation } \\
\text { Tubular quartz reactor } \\
\text { with quartz wool, } \\
\text { catalyst }(150 \mathrm{mg}) \text {, gas } \\
\text { mixture of } \mathrm{CO} / \mathrm{O}_{2} / \mathrm{N}_{2} \\
\left(\mathrm{CO} / \mathrm{O}_{2} / \mathrm{N}_{2}: 0.5 / 0.5 / 49\right.\end{array}$ & $\begin{array}{l}\mathrm{Ru}_{0.8} \mathrm{Cu}_{0.2} \text { displayed } \\
\text { higher catalytic } \\
\text { activity than other } \\
\text { bimetallic mixtures } \\
\text { and monometallic } \\
\text { Ru and Cu NPs }\end{array}$ & 228 \\
\hline
\end{tabular}




\begin{tabular}{|c|c|c|c|c|c|}
\hline & $\begin{array}{c}\text { diethylene } \\
\text { glycol (200 mL), } \\
\text { PVP (440 mg, } 4 \\
\text { mmol), } 493 \mathrm{~K}\end{array}$ & & $\left.\mathrm{ml} \cdot \mathrm{min}^{-1}\right), 433 \mathrm{~K}$ & & \\
\hline \multirow[b]{2}{*}{$\mathrm{Cu}_{0.5} \mathrm{Ru}_{0.5}$} & Polyol synthesis & & & \multirow[b]{2}{*}{$\begin{array}{c}\text { fcc structure, alloy } \\
\text { NP } \mathrm{Cu}_{0.5} \mathrm{Ru}_{0.5} \text { better } \\
\text { catalytic } \\
\text { performances in } \\
\text { CO oxidation that } \\
\text { fcc } \mathrm{Ru} N \mathrm{NP}\end{array}$} & \multirow[b]{2}{*}{227} \\
\hline & $\begin{array}{c}{\left[\mathrm{Ru}(\mathrm{acac})_{3}\right]} \\
(796.8 \mathrm{mg}, 2.0 \\
\mathrm{mmol})) \\
{\left[\mathrm{Cu}(\mathrm{OAc})_{2} \cdot \mathrm{H}_{2} \mathrm{O}\right],} \\
(399.4 \mathrm{mg}, 2.0 \\
\mathrm{mmol})), \\
\text { diethylene } \\
\text { glycol }(330 \mathrm{~mL}), \\
\text { PVP }(880 \mathrm{mg}, 4 \\
\mathrm{mmol}), 493 \mathrm{~K}\end{array}$ & $\begin{array}{l}\text { TEM, XRD, XRF, in situ } \\
\text { IR, thermal stability } \\
\text { investigated by in situ } \\
\text { synchrotron XRD } \\
\text { measurements }\end{array}$ & $\begin{array}{c}\text { CO oxidation } \\
\text { Tubular quartz reactor } \\
\text { with quartz wool, } \\
\text { catalyst }(150 \mathrm{mg}) \text {, gas } \\
\text { mixture of } \mathrm{CO} / \mathrm{O}_{2} / \mathrm{He} \\
\left(\mathrm{CO} / \mathrm{O}_{2} / \mathrm{He}: 0.5 / 0.5 / 49\right. \\
\left.\mathrm{ml} \cdot \mathrm{min}^{-1}\right), 433 \mathrm{~K}\end{array}$ & & \\
\hline & Polyol synthesis & \multirow[b]{2}{*}{$\begin{array}{l}\text { TEM, XRD, hydrogen- } \\
\text { absorption by } \\
\text { pressure-composition } \\
\text { isotherms, SSNMR, } \\
\text { XPS }\end{array}$} & & \multirow[b]{2}{*}{$\begin{array}{l}\text { Increasing the } \mathrm{Ru} \\
\text { content changes } \\
\text { the crystallographic } \\
\text { structure from } \mathrm{fcc} \\
\text { to hcp; } \mathrm{Ru}_{0.5} \mathrm{Pd}_{0.5} \\
\text { best catalyst; }\end{array}$} & \multirow[b]{2}{*}{226} \\
\hline$R u_{x} P d_{1-x}$ & $\begin{array}{c}\mathrm{RuCl}_{3},(25.9- \\
235.6 \mathrm{mg}) \\
\mathrm{K}_{2}\left[\mathrm{PdCl}_{4}\right],(32.6- \\
293.8 \mathrm{mg}) \\
\text { triethylene } \\
\text { glycol } \\
(100 \mathrm{~mL}), \mathrm{H} 20 \\
(40 \mathrm{~mL}), \mathrm{PVP} \\
(444 \mathrm{mg}, 4 \\
\mathrm{mmol}), 473 \mathrm{~K}\end{array}$ & & $\begin{array}{c}\text { CO oxidation } \\
\text { Tubular quartz reactor } \\
\text { with quartz wool, } \\
\text { catalyst }(150 \mathrm{mg}) \text {, gas } \\
\text { mixture of } \mathrm{CO} / \mathrm{O}_{2} / \mathrm{He} \\
\left(\mathrm{CO} / \mathrm{O}_{2} / \mathrm{He}: 0.5 / 0.5 / 49\right. \\
\left.\mathrm{ml} \cdot \mathrm{min}^{-1}\right)\end{array}$ & & \\
\hline
\end{tabular}

\subsection{Fischer-Tropsch reaction}

Ru-based compounds are very active catalysts for Fischer-Tropsch reaction. But the limitation of their use in industry probably arises from their price even if they are active under milder temperatures and are less sensitive to $\mathrm{H}_{2} \mathrm{O}$ in comparison to $\mathrm{Fe}$ and $\mathrm{Co}$ based catalysts, which are greatly exploited. ${ }^{230}$ This reaction is largely studied in gas phase, but it can be achieved in liquid phase by using Ru NPs. ${ }^{231-232}$ Fischer-Tropsch reaction with Ru catalysts is a size $233-235$ and structure ${ }^{236}$ sensitive reaction (Table 11). Fischer-Tropsch reaction catalyzed by fcc and hcp Ru NPs was studied experimentally and theoretically. ${ }^{236}$ The main conclusion of the DFT study points out that fcc Ru displays some open facets with low CO dissociation barriers, which is in contrast with the fact that only few edges with low CO dissociation barriers are available 
in hcp Ru catalyst. Experimentally, synthesised Ru NPS with fcc structure and a size of $6.8 \mathrm{~nm}$ showed a high mass specificity towards the reaction, as predicted, and superior to hcp Ru NPs (Figure 16).
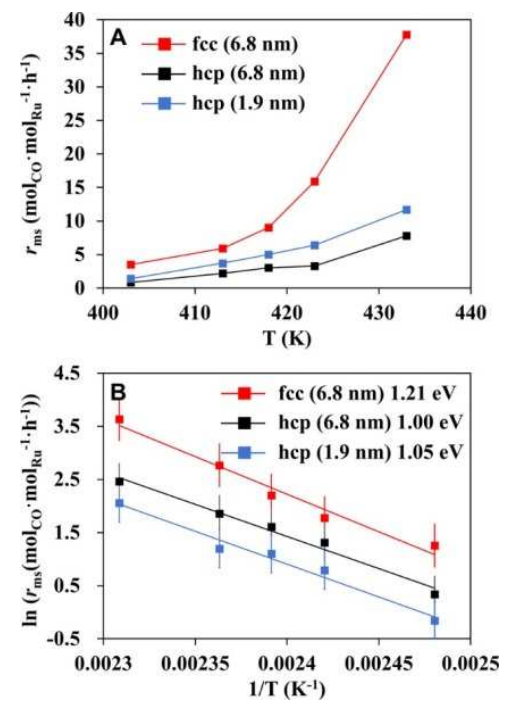

Figure 16. Reaction performance of Ru catalysts. (A) Activity of fcc NCs (6.8 nm), hcp NCs (6.8 and $1.9 \mathrm{~nm}$ ) at 413 and $433 \mathrm{~K}$. (B) The Arrhenius plot and the extracted apparent FTS barriers are indicated. The reaction was conducted at 3.0 MPa syngas ( $\mathrm{CO} / \mathrm{H} 2=1: 2 \mathrm{~mol}$ ratio), 0.2 mmol catalyst, 800 rpm stirring. Adapted with permission from ref ${ }^{236}$. Copyright 2017 American Chemical Society.

To obtain better insights of the size-effect in Ru NPs-catalysed Fischer-Tropsch catalysis, theoretical calculations on the electronic structure of CO adsorbed in Ru step-edge sites have been carried out (Figure 17). ${ }^{234}$ It has been demonstrated that step-edge sites are more reactive towards $\mathrm{CO}$ activation than flat surfaces by using theoretical Ru NPs models of 1 and $2 \mathrm{~nm}$ diameter in size. The CO cleavage is easier in step-edge sites in larger NPs; this is due to the smaller extent of the Ru-O interaction in the $\eta^{2}$ adsorption mode on smaller NPs, which destabilizes the transition-state for direct CO cleavage. 
(a)

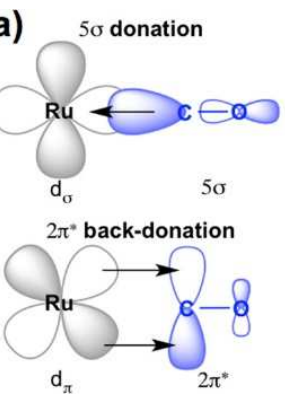

(b)

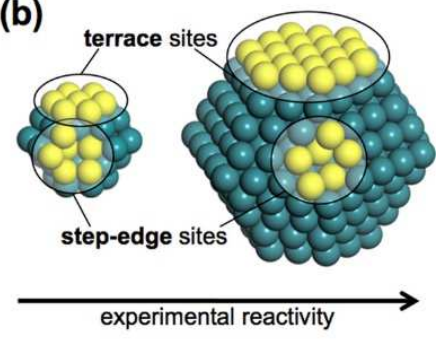

Figure 17. (a) Blyholder model for CO adsorption on Ru surface sites. (b) Different types of terrace and step-edge sites on metal NPs (marked in yellow) of different sizes and experimental NP size effect on reactivity. Adapted with permission from ref ${ }^{234}$. Copyright 2016 American Chemical Society

Experimentally, the size effect was investigated by using Ru NPs synthesised from $\mathrm{RuCl}_{3}$ and $\left[\mathrm{Ru}(\mathrm{acac})_{3}\right]$ which allowed to obtain Ru NPs ranging from 1.2 to $5.2 \mathrm{~nm}$. Ru NPs catalysts showed a maximum of activity around $2.3 \mathrm{~nm}$ for nanoparticles between 1.2 and $3.7 \mathrm{~nm}$. With a further increase of the Ru NPs size the conversion rate increased strongly. Also, it was observed that the nanoparticle size affected the selectivity; increasing the size a decrease on the oxygenate products selectivity was observed. ${ }^{237}$ Later on, the study was extended in order to understand the size-effect observed ${ }^{235}$ by combining high-energy XRD with theoretical calculations. Using high-energy XRD technique the core and surface atomic-scale structure of real Ru NPs smaller than $6 \mathrm{~nm}$ was determined in good detail, allowing to identify and quantify step-edge and terrace sites on the surface of Ru NPs. DFT calculations confirmed that CO dissociation proceeds easily on these surface atoms; and it has been observed that CO hydrogenation correlates with $\mathrm{Ru}$ surface atoms with coordination numbers of $10-11$. In previous studies by the same authors, ${ }^{238-240}$ stepped Ru (1121) surfaces, which display low barrier for $\mathrm{CO}$ activation and bind reaction intermediates strongly, were compared to $\mathrm{Ru}$ (0001) dense surfaces, with a high barrier for $\mathrm{CO}$ activation and a high selectivity for methane production. It was pointed out that the sites with low barrier for CO dissociation were 
responsible for the Fischer-Tropsch reaction with low production of methane; on the opposite, the dense surfaces were the preferred sites for CO hydrogenation to produce methane.

Size and surface ligands effects on the Fischer-Tropsch reaction were also investigated. ${ }^{98}$ Ru/PVP (1.3 nm size) and Ru/dppb (1.9 and $3.1 \mathrm{~nm}$ size) were synthesised from $[R u(C O D)(C O T)]$ in the presence of the respective stabilizing agents. This study did not evidence a clear effect of the Ru NPs size on catalysis performance in terms of activity or selectivity. Nevertheless, the dppb ligands on the surface were shown to play a key role on the activity. Ru/PVP NPs were not active at $393 \mathrm{~K}$ and slightly active at $423 \mathrm{~K}$, while the $\mathrm{Ru} / \mathrm{dppb}$ NPs were active in both cases, with high selectivity towards alkenes and alkanes (Table 10).

Table 10. Fischer-Tropsh activities ${ }^{a}$ and selectivities ${ }^{b}$ of Ru NPs as a function of the stabilizer, size, and reaction temperature. Adapted with permission from ref ${ }^{98}$. Copyright 2014 American Chemical Society.

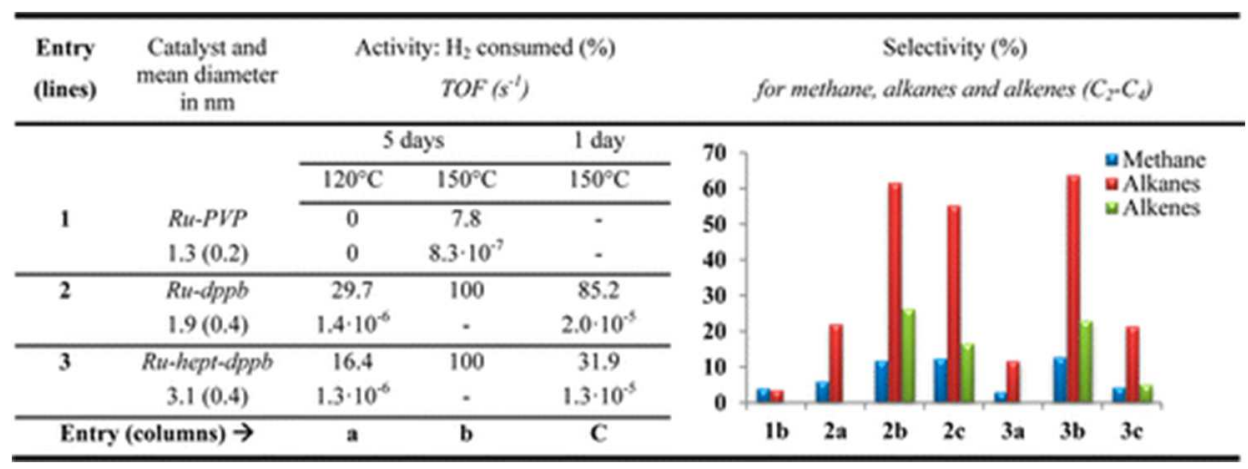

${ }^{a}$ Activity evaluated from the consumption of $\mathrm{H}_{2}$. TOFs normalized per number of Ru surface atoms. ${ }^{\text {B }}$ Selectivity calculated only for methane, alkanes, and alkenes as products (water and remaining $\mathrm{H}_{2}$ and $\mathrm{CO}$ omitted for the sake of clarity).

Table 11. Ru NPs as Fischer-Tropsch catalysts

\begin{tabular}{|c|c|c|c|c|c|}
\hline Stabilizing agent & Methodology & Characterization & $\begin{array}{l}\text { Reaction } \\
\text { conditions }\end{array}$ & Comments & Ref. \\
\hline oleic acid & $\begin{array}{c}\text { Thermal } \\
\text { decomposition } \\
(508 \mathrm{~K}) \text { of } \\
{\left[\mathrm{CO}_{2}(\mathrm{CO})_{8}\right] \text { and }}\end{array}$ & $\begin{array}{l}\text { TEM, AP-XPS, XAS } \\
\text { (under oxidizing, } \\
\text { reducing, and reactive } \\
\text { gas environments) }\end{array}$ & $\begin{array}{c}\text { Catalyst ( } 70 \mathrm{mg}) \\
\text { feed gas mixture } \\
\text { of } \mathrm{H}_{2} / \mathrm{CO} / \mathrm{Ar}(20 \\
\text { bar, } \mathrm{H}_{2} / \mathrm{CO} / \mathrm{Ar} \text { : } \\
2 / 1 / 0.08)\end{array}$ & $\begin{array}{l}\text { synthesis of a variety } \\
\text { of Co-M bimetallic } \\
\text { catalysts; slight } \\
\text { differences to that of } \\
\text { pure Co }\end{array}$ & 241 \\
\hline
\end{tabular}


$\left[\mathrm{Ru}_{3}(\mathrm{CO})_{12}\right]$ in diphenyl ether

Hydrothermal synthesis $\mathrm{K}_{2} \mathrm{PtCl}_{4}(0.024$

$\mathrm{mmol}$ ),

$\mathrm{RuCl}_{3} \cdot \mathrm{xH}_{2} \mathrm{O}$

$(0.216 \mathrm{mmol})$, PVP (100 mg), $\mathrm{HCHO}(0.1 \mathrm{~mL})$, $\mathrm{HCl}(0.062 \mathrm{~mL}$, 1M), $\mathrm{H}_{2} \mathrm{O}$ (15 $\mathrm{mL}$ ), formaldehyde (0.1 mL, 40 wt.\%), 433K, $8 \mathrm{~h}$

Reduction of $\left[\mathrm{Ru}(\mathrm{acac})_{3}\right]$ in 1,4-butanediol

$\left[\mathrm{Ru}(\mathrm{acac})_{3}\right]$ (30 $\mathrm{mg}), \mathrm{PVP}(170$ $\mathrm{mg})$, THF (2 $\mathrm{mL})$, 1,4-butanediol $(30 \mathrm{~mL}),(25-$ PVP $500 \mathrm{~mL}), 498 \mathrm{~K}$, $2 \mathrm{~h}$

Reduction of $\mathrm{RuCl}_{3}$ with $\mathrm{H}_{2}$

$\mathrm{RuCl}_{3}$ (40 mg), PVP (220 mg), $\mathrm{H} 20$ (1 mL), H2 (20 bar), $423 \mathrm{~K}$, $2 \mathrm{~h}$

PVP; dppb
TEM, ICP, XRD, XANES, EXAFS

Catalyst (0.2 $\mathrm{mmol})$, syngas (CO: $\mathrm{H}_{2}=1: 230$ bar), $423 \mathrm{~K}$.

$\mathrm{Ru}(50 \mu \mathrm{mol}), \mathrm{H}_{2} \mathrm{O}$ (3 mL), $\mathrm{CO} / \mathrm{H}_{2}$ (30 bar, $\mathrm{H}_{2} / \mathrm{CO}=2$ ), 403-503 K, 3-24 h

TEM, ICP, IR, EXAFS,
Ru fcc higher activity in FTS higher selectivity towards $\mathrm{C} 5+$ compounds than hcp NP; recycling

experiments at $423 \mathrm{~K}$ show shlighlty decrease of activity in first runs and remained contant after 10 cycles; DFT calculation points out that $\mathrm{CO}$

dissociation is more favourable is fcc Ru NP

Ru NPs ranging from 1.2 to $5.2 \mathrm{~nm}$; selectivity and activity depend on 235, 237 Ru NPs size
Reaction done on a quick pressure

Reduction of [Ru(COD)(COT)] with $\mathrm{H}_{2}$

[Ru(COD)(COT)], PVP or dppb, $\mathrm{H}_{2}$

(3 bar), 298K
TEM, SSNMR, in situ ambient-pressure XPS valve NMR tube.

$$
\mathrm{Ru} \text { (0.02-0.05 }
$$$$
\mathrm{mmol} \mathrm{Ru} \text { ), }
$$

${ }^{13} \mathrm{CO} / \mathrm{H}_{2}$ (3 bar,

$\left.{ }^{13} \mathrm{CO} / \mathrm{H}_{2} 1 / 1\right)$,

393-423 K1-5 days.
No size effect; ligand effect on the activity of the reaction 


\section{4 $\mathrm{C}-\mathrm{H}$ activation and other reactions}

$\mathrm{H} / \mathrm{D}$ (or T) exchange through $\mathrm{C}-\mathrm{H}$ activation has been achieved with Ru NPs for several compounds in mild reaction conditions. Nitrogen, ${ }^{85,} 89,242-243$ phosphorus ${ }^{163,244}$ and sulphur ${ }^{245}$ containing compounds, or alkanes ${ }^{163246}$ have been selectively deuterated using Ru NPs as catalysts, stabilized with PVP, phosphines or NHC ligands, and in some cases by supported Ru catalysts (Table 12). First study by Chaudret and coworkers on deuteration ${ }^{247}$ demonstrated that Ru/PVP NPs were able to deuterate pyridines, quinolones, indoles, and alkyl amines with $D_{2}$ with high chemo- and regioselectivity; this methodology was also successful for the enantiospecific $\mathrm{C}-\mathrm{H}$ activation/deuteration of amino acids and peptides. Experimental evidence and theoretical calculations showed that the labelling is governed by the coordination of the substrate to the ruthenium surface, and that the surface ligands modulate the efficiency of the labelling procedure.

Table 12. Ru NPs as C-H activation catalysts for labelling applications

\begin{tabular}{|c|c|c|c|c|c|}
\hline Stabilizing agent & $\begin{array}{l}\text { Synthetic } \\
\text { methodology }\end{array}$ & Characterization & $\begin{array}{l}\text { Catalytic reaction } \\
\text { conditions }\end{array}$ & Comments & Ref. \\
\hline $\begin{array}{l}\mathrm{Ru} / \mathrm{dppb} \\
\mathrm{RuPt} / \mathrm{dppb} \\
\mathrm{Pt} / \mathrm{dppb}\end{array}$ & $\begin{array}{c}\text { Reduction of } \\
{[\mathrm{Ru}(\mathrm{COD})(\mathrm{COT})]} \\
{\left[\mathrm{Pt}\left(\mathrm{CH}_{3}\right)_{2}(\mathrm{COD})\right] ;} \\
{\left[\mathrm{Pt}(\mathrm{dba})_{2}\right] \text { with } \mathrm{H}_{2}}\end{array}$ & & $\begin{array}{l}\text { Deuteration of alkanes } D_{2} \text { ( } 6 \\
\text { bar), } 333 \mathrm{~K}, 24 \mathrm{~h}\end{array}$ & $\begin{array}{l}\text { Isotope exchange } \\
\text { and } \mathrm{P}-\mathrm{C} \text { bond } \\
\text { cleavage }\end{array}$ & 94 \\
\hline PVP; NHC & $\begin{array}{c}\text { Reduction of } \\
{[\mathrm{Ru}(\mathrm{COD})(\mathrm{COT})]} \\
\text { with } \mathrm{H}_{2} \\
{[\mathrm{Ru}(\mathrm{COD})(\mathrm{COT})]} \\
\mathrm{PVP} \text { or } \mathrm{NHC}, \mathrm{H}_{2}(3 \\
\text { bar), } \mathrm{THF}, 298 \mathrm{~K}\end{array}$ & & $\begin{array}{l}\text { Deuterium and tritium } \\
\text { labelling of purine } \\
\text { derivatives and } \\
\text { pharmaceuticals } \mathrm{D}_{2}(2 \mathrm{bar}) \text {, } \\
328-353 \mathrm{~K}, 36 \mathrm{~h}\end{array}$ & $\begin{array}{l}\text { Hydrogen-isotope } \\
\text { labelling of } \\
\text { nucleobase } \\
\text { derivatives in mild } \\
\text { conditions; broad } \\
\text { scope; modification } \\
\text { of the surface } \\
\text { stabilizer could } \\
\text { increase the } \\
\text { efficiency of the } \\
\text { labelling }\end{array}$ & 242 \\
\hline
\end{tabular}




\begin{abstract}
Reduction of
[Ru(COD)(COT)]

with $\mathrm{H}_{2}$
\end{abstract}

$\mathrm{dppb}$

[Ru(COD)(COT)], dppb, $\mathrm{H}_{2}$ (3 bar), THF, 298K

$\mathrm{Ru} / \mathrm{C}$

Commercial

catalyst

Reduction of
$[\mathrm{Ru}(\mathrm{COD})(\mathrm{COT})]$
with $\mathrm{H}_{2}$

[Ru(COD)(COT)]

( $250 \mathrm{mg}, 0.8 \mathrm{mmol}$ ), sulfonated $\mathrm{NHC}(0.2$

eq), KOtBu (19.7

$\mathrm{mg}, 0.176 \mathrm{mmol}$,

Sulfonated NHC 0.22 eq.), $\mathrm{H}_{2}$ (3 bar), THF (30 mL), 298K, $20 \mathrm{~h}$

[Ru(COD)(COT)], PVP, $\mathrm{H}_{2}$ (3 bar), THF, $298 \mathrm{~K}$

PVP

$$
\begin{gathered}
\text { [Ru(COD)(COT)] } \\
\text { with } \mathrm{H}_{2}
\end{gathered}
$$$$
\text { Reduction of }
$$

[Ru(COD)(COT)], PVP, $\mathrm{H}_{2}$ (3 bar), THF, $298 \mathrm{~K}$

\section{Reduction of \\ [Ru(COD)(COT)] with $\mathrm{H}_{2}$}

PVP
Deuteration of alkanes $\mathrm{Ru} / \mathrm{dppb}$, substrate $(1 \mathrm{~mL})$, THF (1 mL), D2 (6 bar), 333

$$
\mathrm{K}, 24 \mathrm{~h}
$$

\section{Deuterium and tritium labelling of thioether substructures in complex molecules}

$\mathrm{Ru} / \mathrm{C}$ (5 wt\%, 121.2 mg, 30 $\mathrm{mol} \%)$, substrate $(0.2$ $\mathrm{mmol}$ ), $\mathrm{D}_{2}$ (2 bar), solvent ( 2 $\mathrm{mL}), 333 \mathrm{~K}, 2^{\prime}$ or $72 \mathrm{~h}$

TEM, WAXS, IR, TGA, NMR

Deuteration of L-Lysine

Catalyst ( $2 \mathrm{mg}, 8 \%$ ), L-lysine (21.92 mg, $0.15 \mathrm{mmol}$ ), D2 (2 bar), $\mathrm{D}_{2} \mathrm{O}(2 \mathrm{~mL}), 328 \mathrm{~K}$, $42 \mathrm{~h}$

\section{Deuteration of chiral amines}

Catalyst (8 mg, 3.3\%), substrate $(0.15 \mathrm{mmol}), \mathrm{D} 2$ (2 bar), THF or $\mathrm{D}_{2} \mathrm{O}(2 \mathrm{~mL})$, $328 \mathrm{~K}, 36 \mathrm{~h}$

Deuteration of phosphine, phosphine oxide and phosphite

Catalyst (8 mg, 3.3\%), substrate $(0.15 \mathrm{mmol}), \mathrm{D} 2$ ( 2 bar), THF (1 mL)
$\mathrm{C}-\mathrm{H}$ activation of alkanes was structure dependent; only cyclopentane was smoothly deuterated

$\mathrm{C}\left(\mathrm{sp}^{3}\right)-\mathrm{H}$ activation directed

by a sulfur atom; labelling of complex structures in mild conditions

Enantiospecific H/D exchange of the amino acid L-lysine; influence of $\mathrm{pH}$ on the activity and selectivity: low $\mathrm{pH}$ $H / D$ is reduced or negligible; high $\mathrm{pH}$ increases activity and changes selectivity

\section{Deuterium} incorporation at stereogenic centers; high selectivity towards heteroatom $\alpha$ position;mechanistic studies suggest that a dimetallacycle is the key intermediate

Phenyl rings in phenyl- or phenylalkylphosphines are selectively deuterated at the ortho position; indication of ligand coordination 
trhougth the $\mathrm{P}$

atom; no

deuteration of

triphenylphosphite

Reduction of

[Ru(COD)(COT)]

with $\mathrm{H}_{2}$

PVP

[Ru(COD)(COT)],

PVP, $\mathrm{H}_{2}$ (3 bar), THF,

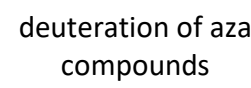

Catalyst (3\%), D2 (1 or 2

bar), THF, r. t. or $328 \mathrm{~K}, 36 \mathrm{~h}$
Mild reaction

conditions; good

labelling yields with 243

high chemo- and

regioselectivities

Unsupported Ru NPs have been applied as catalysts to other reactions such as Wittig

olefination, ${ }^{163,249}$ selenylation ${ }^{245}$ or isomerization. ${ }^{250}$ The synthetic procedure and the catalytic

reaction conditions, together with the main features of the catalytic system are summarized

in Table 13.

Table 13. Ru NPs as catalysts in other reactions

\begin{tabular}{|c|c|c|c|c|c|}
\hline $\begin{array}{l}\text { Stabilizing } \\
\text { agent }\end{array}$ & Methodology & Characterization & Reaction conditions & Comments & Ref. \\
\hline PVP & $\begin{array}{c}\text { Hydrothermal } \\
\text { synthesis } \\
\mathrm{RuCl}_{3} \cdot x \mathrm{H}_{2} \mathrm{O}(0.24 \\
\mathrm{mmol}, \mathrm{PVP}(100 \mathrm{mg}), \\
\mathrm{Na}_{2} \mathrm{C}_{3} \mathrm{H}_{2} \mathrm{O}_{4} \cdot \mathrm{H}_{2} \mathrm{O}(80 \\
\mathrm{mg}), \mathrm{HCl}(0.062 \mathrm{~mL}, \\
1 \mathrm{M}), \mathrm{H}_{2} \mathrm{O}(25 \mathrm{~mL}), \\
\text { formaldehyde }(0.1 \mathrm{~mL}, \\
40 \text { wt. } \%), 433 \mathrm{~K}, 8 \mathrm{~h}, 1- \\
\text { h or } 24 \mathrm{~h}\end{array}$ & $\begin{array}{l}\text { TEM, ICP, XPS, } \\
\text { EXAFS, EPR }\end{array}$ & $\begin{array}{c}\text { Aerobic cross- } \\
\text { dehydrogenative coupling } \\
(\mathrm{C}-\mathrm{H}) \text { activation } \\
\text { Catalyst }(8 \mathrm{~mol} \% \mathrm{Ru}), \\
\text { tetrahydroisoquinoline } \\
\text { derivatives }(0.1 \mathrm{mmol}), \\
\text { indoles (4 eq), } \mathrm{H}_{2} \mathrm{O} / \mathrm{MeOH} \\
\text { (1/1), AcOH (10-48 mL), } 298 \\
K\end{array}$ & $\begin{array}{l}\text { Ru nanocatalyst } \\
\text { with a different } \\
\text { oxidation level; loss } \\
\text { of activity after } 6 \\
\text { catalytic cycles }\end{array}$ & 246 \\
\hline IL & $\begin{array}{c}\text { Reduction of several } \\
\text { Ru complexes with } \mathrm{H}_{2} \text {. } \\
\text { Ru complex ( } 1.16 \mathrm{wt} \text {. } \\
\% \text { Ru), IL ( } 0.85 \mathrm{~mL}), \mathrm{H}_{2} \\
\text { (4 bar), 3h, } 323 \mathrm{~K}\end{array}$ & $\begin{array}{c}\text { TEM, ICP, XRD, } \\
\text { XPS }\end{array}$ & $\begin{array}{c}\text { Wittig olefination } \\
\text { Catalyst ( } 250 \mathrm{mg}) \text {, alcohol } \\
(0.1 \mathrm{~mol}), \text { phosphorus ylide } \\
(0.11 \mathrm{~mol}), \text { water }(5 \mathrm{~mL}), 1 \mathrm{~h} \text {, } \\
343 \mathrm{~K}\end{array}$ & $\begin{array}{c}\text { Good yields in } \\
\text { stilbene products, } \\
\text { but low } \mathrm{E} / \mathrm{Z} \\
\text { selectivity; } \\
{\left[\mathrm{RuCl}_{2}\left(\mathrm{C}_{6} \mathrm{H}_{6}\right)\right]_{2}} \\
\text { precursor produced } \\
\text { the most active } \\
\text { catalyst; recycled } 5 \\
\text { times without } \\
\text { appreciable loss of } \\
\text { activity }\end{array}$ & 249 \\
\hline $\begin{array}{l}\text { Montmorillonite } \\
\text { clay }\end{array}$ & $\begin{array}{c}\text { Reduction of } \\
{\left[\mathrm{Ru}\left(\mathrm{NH}_{3}\right)_{6}\right] \mathrm{Cl}_{3} \text { with }} \\
\mathrm{NaBH}_{4} .\end{array}$ & $\begin{array}{c}\text { TEM, SAXS, ICP, } \\
\text { BET }\end{array}$ & $\begin{array}{l}\text { Wittig-type reaction of } \\
\text { benzyl alcohols and } \\
\text { phosphorus ylides }\end{array}$ & $\begin{array}{l}\text { moderate yield and } \\
\text { low } \\
\text { diastereoselectivity; } \\
\text { no recycling test; }\end{array}$ & 163 \\
\hline
\end{tabular}


$\left[\mathrm{Ru}\left(\mathrm{NH}_{3}\right)_{6}\right] \mathrm{Cl}_{3}$, montmorillonite clay, $\mathrm{NaBH}_{4}(4 \mathrm{~mL}, 0.1 \mathrm{M})$, $\mathrm{H}_{2} \mathrm{O}(40 \mathrm{~mL})$, r. t.

Hydrothermal synthesis $\mathrm{RuCl}_{3} \cdot x \mathrm{H}_{2} \mathrm{O}$ (0.24 mmol), PVP (100 $\mathrm{mg}, \mathrm{Na}_{2} \mathrm{C}_{3} \mathrm{H}_{2} \mathrm{O}_{4} \cdot \mathrm{H}_{2} \mathrm{O}$ (140 mg), $\mathrm{H}_{2} \mathrm{O}(25 \mathrm{~mL})$ formaldehyde $(400 \mu \mathrm{L}$,

$\mathrm{Ru} / \mathrm{RuO}_{\mathrm{x}} / \mathrm{PVP}$ $40 \mathrm{wt} . \%), 433 \mathrm{~K}, 8 \mathrm{~h}$

One set post-reduced by $\mathrm{H}_{2}(1,4,12 \mathrm{~h})$

One set post-oxidized by $\mathrm{O}_{2}(1,4 \mathrm{~h})$

Reduction of $[\mathrm{Ru}(\mathrm{COD})(\mathrm{COT})]$ with $\mathrm{H}_{2}$

Phosphines [Ru(COD)(COT)] (60.0 $\mathrm{mg}, 0.19 \mathrm{mmol}$ ), phosphine (0.1 eq), $\mathrm{H}_{2}$ (3 bar), THF (60 mL), $298 \mathrm{~K}$

Reduction of [Ru(COD)(COT)] with $\mathrm{H}_{2}$

$\mathrm{NHC}$ [Ru(COD)(COT)], NHC, $\mathrm{H}_{2}$ (10 bar), pentane, $298 \mathrm{~K}$
Catalyst (0.1 g), (3,4,5trimethoxyphenyl) methanol (1 mmol), methoxylated benzyltriphenylphosphonium halide (1.5 mmol), n-BuLi (6.25 mL, $1.0 \mathrm{mmol})$, THF (2 $\mathrm{mL}), 353 \mathrm{~K}, 1 \mathrm{~h}$

TEM, ICP, XRD, XPS, XAFS)

TEM, TGA Synthesis of pyrazines from
a-diketones

Catalyst (1 mol \%), $(\alpha-$ diketone $(1.0 \mathrm{mmol})$, ammonium formate (5.0 $\mathrm{mmol}), \mathrm{DMF}(3.0 \mathrm{~mL}), 358 \mathrm{~K}$, 1-12 $\mathrm{h}$

Isomerization of estragole

TEM, SEM, ICP, XPS

Catalyst (1 mol\%), estragol $(2 \mathrm{mmol})$, toluene $(9.3 \mathrm{~mL})$, $\mathrm{H}_{2}$ (12 bar), $433 \mathrm{~K}, 160 \mathrm{~min}$ no characterization of the spent catalyst
Activity related to the ratio $\mathrm{Ru} / \mathrm{RuO}_{\mathrm{x}}$ volcano-shaped relationship

DFT

Ru NP act as hydrogen borrowing and as dehydrogenation catalysts; Xantphos stabilized Ru NP performs better than other phosphine stabilized Ru NP; no recycling

Ru NP formed during Ru homogeneous catalysed olefin methatesis are active in alkene isomerization reaction; isolated Ru Nps bearing the same NHC ligand are very active for isomerization of estragol; poison test using $\mathrm{Hg}$ or phosphorus ligands

\subsection{Transformation of $\mathrm{CO}_{2}$}

Because it is a cheap, non-toxic, abundant, renewable feedstock, $\mathrm{CO}_{2}$ appears as an attractive building block in order to produce fuels and value-added products that are currently issued 
from non-renewable resources (see Figure 18 for chemicals that may be obtained from $\left.\mathrm{CO}_{2}\right) .{ }^{252}, 253$ But intensive efforts are still required in order to develop technologies for its valorisation as a "raw material". 254

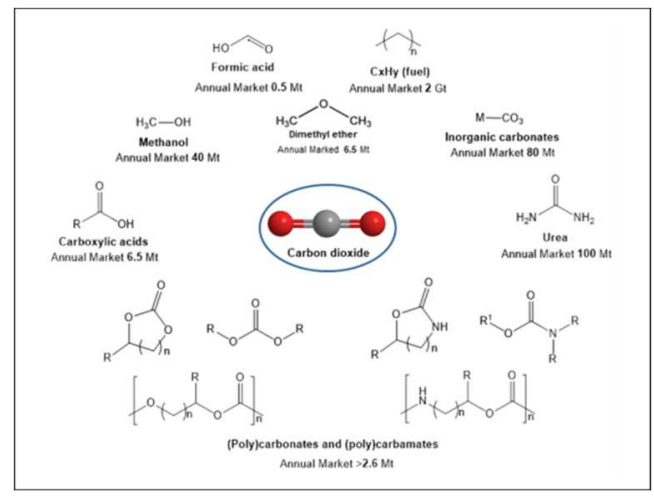

Figure 18. Potential chemicals from $\mathrm{CO}_{2}$ transformation. Reprinted with permission from ref 253. Copyright 2018 Elsevier.

Chemical production based on $\mathrm{CO}_{2}$ is not a facile task due to several technical challenges. It requires major scientific breakthroughs since only highly efficient technologies can make it economically viable while aiming at more sustainable chemical production. The main difficulty to transform $\mathrm{CO}_{2}$ derives from its high thermodynamic stability. Large scale $\mathrm{CO}_{2}$ transformation requires to develop very effective and selective catalytic systems ${ }^{255}$ wich present a good balance between the energy needed and the gain obtained (Figure 19).

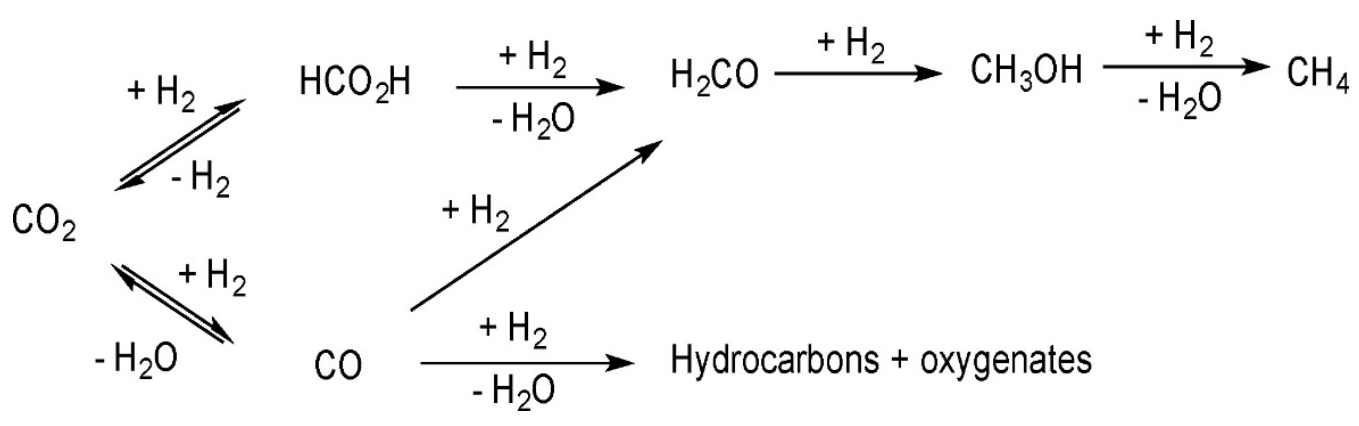

Figure 19. Reaction pathways for the $\mathrm{CO}_{2}$ hydrogenation. Reprinted with permission from ref ${ }^{256}$. Copyright 2018 American Chemical Society. 
Chemical transformation of $\mathrm{CO}_{2}$ has been largely investigated with homogeneous catalysts. ${ }^{6}$ 257-258 Heterogeneous (bulk) catalysts are also explored, ${ }^{259}$ with good performance towards the formation of formic acid, methanol and dimethylether ${ }^{260}$ or methane. ${ }^{261}$ More recently, encouraging results were achieved with metal catalysts at the nanoscale prepared by a molecular approach, thus evidencing the relevance of this class of materials for this catalysis. ${ }^{260}$ As it will be seen hereafter, to our best knowledge only a few papers describe ruthenium catalysts based on well-defined Ru NPs or bimetallic RuM NPs for the challenging chemical transformation of $\mathrm{CO}_{2}$. Products obtained are mainly $\mathrm{HCOOH}, \mathrm{CO}$ and $\mathrm{CH}_{4}$ but also $\mathrm{C}_{2+}$ hydrocarbons.

\subsubsection{Transformation of $\mathrm{CO}_{2}$ into $\mathrm{HCOOH}$}

Formic acid $(\mathrm{FA} ; \mathrm{HCOOH})$ is a valuable basic chemical with different uses (preservative agent, antibacterial, insecticide, or de-icing) and plays also a major role in synthetic chemistry (as an acid, reductant and precursor) for syntheses. ${ }^{262}$ Despite a relatively small hydrogen content (4.4 wt\%; 53 g.L L $^{-1}$ hydrogen at r.t. and ambient pressure), FA provides also an alternative for chemical energy storage, being one of the best among liquid storage and transport media for $\mathrm{H}_{2} \cdot{ }^{263}$ If the chemical reduction of $\mathrm{CO}_{2}$ by using hydrogen is a highly attractive route to produce FA, it remains a significant challenge. This process is thermodynamically unfavourable, due to the strong entropic contribution $\left(\Delta \mathrm{G}_{298}^{0}=32.9 \mathrm{~kJ} \mathrm{~mol}^{-1}\right)$ and thus necessitates appropriate catalysts.

Direct hydrogenation of $\mathrm{CO}_{2}$ into $\mathrm{FA}$ has been extensively studied using homogeneous catalysts (mainly based on $\mathrm{Ru}, \mathrm{Rh}$ and Ir but also on non-noble metals like $\mathrm{Fe}, \mathrm{Co}, \mathrm{Ni}$ and $\mathrm{Cu}$ ) using various conditions and temperatures in the range r. t.-393 K). ${ }^{6,257,262,264-265}$ Efficient complexes display electron-rich metal centers by using electron-donating ligands and are able to activate $\mathrm{H}_{2}$ under the form of hydrides and to transfer these hydrides to $\mathrm{CO}_{2}$, for some of 
them under mild conditions. But despite excellent catalytic performances (both in terms of activity and selectivity) and heterogenization (mainly on silica- and polymer-based materials or porous organic polymers) to solve separation and recovery concerns, homogeneous catalysts are still far from the industrial expectation. ${ }^{260,266}$

In the opposite, despite the early works involving Pd black ${ }^{267}$ and Ni-Raney ${ }^{268}$ and their advantages for continuous operation and product separation, the development of heterogeneous catalysts for this reaction lags significantly. ${ }^{260,266}$ But presently, the number of supported nanoparticulate metal catalysts tends to increase, mainly based on $\mathrm{Pd}$ or $\mathrm{Au} .{ }^{253}$ Very surprisingly, only a few examples of Ru-based heterogeneous catalysts or nanocatalysts are reported although $\mathrm{Ru}$ complexes (including heterogenized and isolated single-atomic systems ${ }^{269}$ ) are known to be efficient for the synthesis of FA. ${ }^{270}$ If low to moderate catalytic performances are observed in comparison to the TON or TOF values achieved by ruthenium molecular catalysts encouraging results are reported, as it will be described hereafter.

An interesting bridge between homogeneous Ru catalysts and nanocatalysts has been made by Dupont and coworkers who reported excellent results in the hydrogenation of $\mathrm{CO}_{2}$ using a ruthenium cluster. It is worth to mention that "nanocluster" is usually used for metal NPs that are very small and well-controlled. They studied the behavior of $\left[\mathrm{Ru}_{3}(\mathrm{CO})_{12}\right]$ dispersed in ionic liquids (ILS). ${ }^{271}$ They observed remarkable activity and selectivity for the formation of HCOOH with high TON (17000) and TOF values at mild pressure (total pressure 40 bar; $\mathrm{H}_{2} / \mathrm{CO}_{2}=1 / 1$ ) and temperature $(333 \mathrm{~K})$. Among the ILs tested, they observed that the imidazolium-based IL associated with the acetate anion acts as a precursor for the formation of the catalytically active Ru-H species, as a catalyst stabilizer, and as an acid buffer, shifting the equilibrium toward free formic acid. Moreover, the immobilization of this catalytic system onto a solid support facilitated the separation of FA. What is important to note here is the multiple role of 
the IL that enhances the catalytic activity of the $\left[\operatorname{Ru}_{3}(C O)_{12}\right]$ cluster. Second, even if it contains only three ruthenium atoms, the catalytic performance of this Ru cluster strongly encourages to study more Ru NPs since higher activity can be expected due to the multiple active sites they expose.

As a first example of Ru NPs, Kojima and coworkers reported on the use of metallic RuNPs (primary particles of ca. 3-5 nm and agregates of ca. 200-240 nm) prepared by reduction of $\mathrm{RuCl}_{3}$ in a methyl alcohol solution under solvothermal conditions for the hydrogenation of supercritical $\mathrm{CO}_{2}$ to formic acid in the presence of triethylamine as a base (total pressure 13 $\left.\mathrm{MPa} ; \mathrm{H}_{2} / \mathrm{CO}_{2}=5 / 8 ; \mathrm{T}=353 \mathrm{~K}\right) .{ }^{272}$ The activity was drastically improved by using a prereduction procedure and adding an appropriate quantity of water to the colloidal suspension in methyl alcohol. The most active nanocatalyst was obtained with $4 \mathrm{~mL}$ of water providing a TON (expressed as the number of moles of FA produced per mole of Ru) of 6351 in $3 \mathrm{~h}$. When adding $\mathrm{PPh}_{3}$ a negligible activity was observed, indicating the presence of a negligible amount of $\mathrm{Ru}$ ions in solution and discarding the role of molecular species in the catalytic act. Describing the first performance of pure ruthenium colloidal catalyst, this work opened the door towards the use of solution Ru NPs for the hydrogenation of $\mathrm{CO}_{2}$.

Srivastava and coworkers published a comparative study on the reactivity of nanocatalysts made of Ru NPs (ca. 6-22 nm from TEM analysis depending on the Ru loading in the range 1-6 wt\%) dispersed onto $\mathrm{TiO}_{2}$ as a support for the hydrogenation of $\mathrm{CO}_{2}$ to $\mathrm{FA}$ in the presence or not of an ionic liquid (IL). ${ }^{273} \mathrm{Ru}-\mathrm{TiO}_{2}$ nanocatalysts were prepared by a micro-emulsion protocol from a suspension of $\mathrm{TiO}_{2}$ (ca. $30 \mathrm{~nm}$ ) and a suspension of $\mathrm{RuCl}_{3}$ and citric acid followed by a reduction treatment of the final solids at $573 \mathrm{~K}$ for $2 \mathrm{~h}$. The effects of pressure (total pressure of $30-60$ bar with $\left.\mathrm{H}_{2} / \mathrm{CO}_{2}=1 / 1\right)$, temperature $(313-353 \mathrm{~K}$ ), reaction time and presence of water in the absence of IL were first studied. This allowed to determine the best 
$\mathrm{Ru}-\mathrm{TiO}_{2}$ nanocatalyst to be that with the smallest size of Ru NPs (ca. $6.0 \mathrm{~nm}$ as determined by TEM for a Ru loading of $3 \mathrm{wt} \%$ ) with a TOF (expressed as the number of moles of FA produced per mole of Ru per hour) of ca. $28 \mathrm{~h}^{-1}$ at $353 \mathrm{~K}$ and a total pressure of 40 bar $\left(\mathrm{H}_{2} / \mathrm{CO}_{2}=1 / 1\right)$. Then, the influence of the addition of an IL on the catalytic conversion was studied from the most promising $\mathrm{Ru}-\mathrm{TiO}_{2}$ system just cited (Figure 20). ILs are known to absorb gases and can be expected to improve catalysis involving gaseous reactants. ${ }^{274}$ Catalytic experiments were performed in 1,3-di(N,N-dimethylaminoethyl)-2-methylimidazolium bis(trifuoromethylsulfonyl)imide ([DAMI] $\left.\left[\mathrm{CF}_{3} \mathrm{CF}_{2} \mathrm{CF}_{2} \mathrm{CF}_{2} \mathrm{SO}_{3}\right]\right)$ at different pressures, temperatures and water contents. TOF values up to ca. $47 \mathrm{~h}^{-1}$ evidenced the IL positive effect on the $\mathrm{CO}_{2}$ hydrogenation into FA. Recyclability studies led to a slight loss of catalytic activity after ten runs attributed to a Ru leaching into the product phase (ICP analysis of the filtrates). Thus, the use of an IL was clearly beneficial to the catalytic transformation of $\mathrm{CO}_{2}$ into $\mathrm{FA}$ by small $\mathrm{Ru}$ NPs deposited onto $\mathrm{TiO}_{2}$, this being attributed to the fact IL can act as both as a solvent for the reaction and enabled to capture $\mathrm{CO}_{2}$. But, ILs are also known to be suitable media to stabilize Ru NPs, ${ }^{83,129}$ being excellent alternatives to surfactants or solid supports. Thus, the IL probably increased the stability of the Ru NPs while favouring exchange at the metal surface.

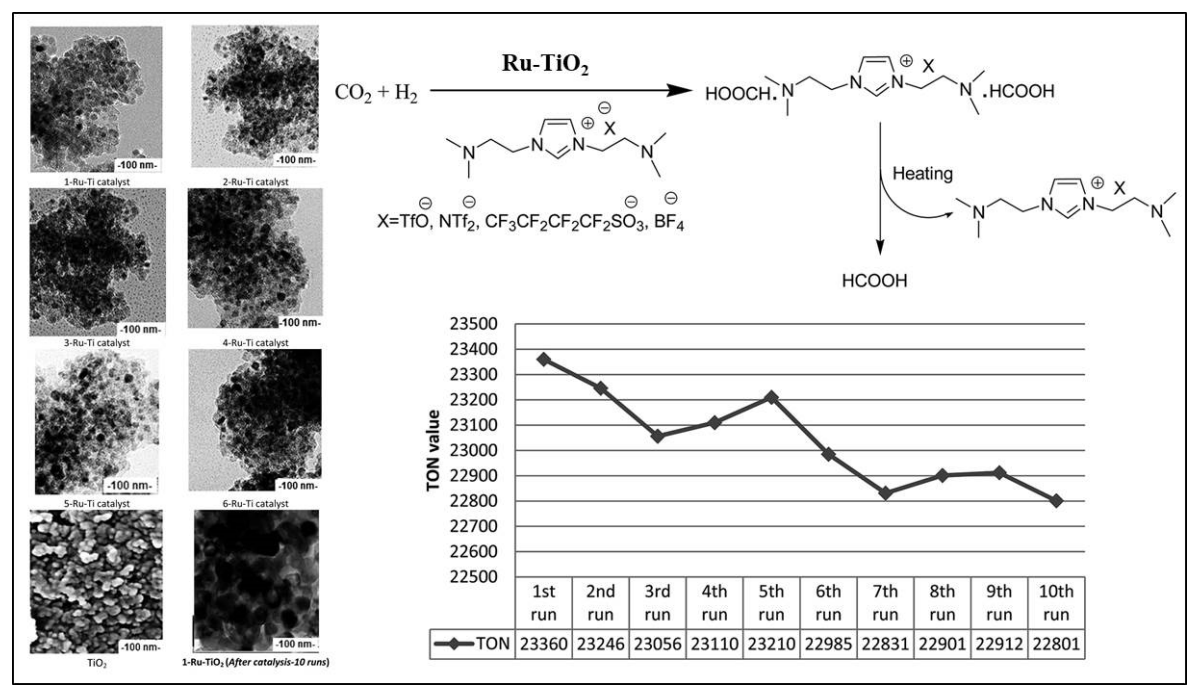


Figure 20. TEM images of the $\mathrm{Ru}-\mathrm{TiO}_{2}$ nanocatalysts for different $\mathrm{Ru}$ contents, catalytic scheme and recycling studies. Reprinted with permission from ref ${ }^{273}$. Copyright 2016 Royal Society of Chemistry.

Then, the same group reported data on the solubility of $\mathrm{CO}_{2}$ into various ILs. ${ }^{275}$ The previously cited IL, [DAMI] $\left[\mathrm{CF}_{3} \mathrm{CF}_{2} \mathrm{CF}_{2} \mathrm{CF}_{2} \mathrm{SO}_{3}\right]$, provided the best solubility thus confirming the high potential of this compound. For comparison purpose, three other ILs ([DAMI][TfO] where TfO= trifuoromethanesulfonate ; $\left[\right.$ mammim] $\left[\mathrm{CF}_{3} \mathrm{CF}_{2} \mathrm{CF}_{2} \mathrm{CF}_{2} \mathrm{SO}_{3}\right]$ with mammim $=1-(\mathrm{N}, \mathrm{N}-$ dimethylaminoethyl)-2,3-dimethylimidazolium and [DAMI][TfO]) were employed to prepare nanocatalysts from four different ruthenium precursors $\left(\left[\mathrm{RuCl}_{2}\left(\mathrm{C}_{6} \mathrm{H}_{6}\right)\right]_{2} ; \quad[\mathrm{Ru}(\mathrm{COD})(2-\right.$ methylallyl) $)_{2}$; $\left[\right.$ trans- $\left.\mathrm{RuCl}_{2}(\mathrm{DMSO})_{4}\right] ;\left[\mathrm{Ru}(\mathrm{COD}) \mathrm{Cl}_{2}\right]$; $\left.[\mathrm{Ru}(\mathrm{COD})(\mathrm{COT})]\right)$ by decomposing them under $\mathrm{H}_{2}$ (5 bar) at $323 \mathrm{~K}$ which led to Ru NPs in a size range of 7-14 nm. XPS data (from samples introduced under argon atmosphere) evidenced no $\mathrm{RuO}_{2}$ contamination. Small angleX-ray scattering (SAXS) and TEM data revealed that ionic interaction between cations and anions of the ILs plays an important role in the structural features of Ru NPs (stability, size, dispersion and agglomeration). Less coordinating ions $\left[\mathrm{CF}_{3} \mathrm{CF}_{2} \mathrm{CF}_{2} \mathrm{CF}_{2} \mathrm{SO}_{3}{ }^{-}\right]$prevent the separation of Ru NPs from IL better than [TfO-] and this effect was dropped while lowering the carbon chain $\left([\right.$ mammim $\left.]\left[\mathrm{CF}_{3} \mathrm{CF}_{2} \mathrm{CF}_{2} \mathrm{CF}_{2} \mathrm{SO}_{3}\right]\right)$. These IL-immobilized $\mathrm{Ru} \mathrm{NPs}$ were then investigated in $\mathrm{CO}_{2}$ hydrogenation in different reaction conditions (temperature: $303-373 \mathrm{~K}$; $\mathrm{CO}_{2} / \mathrm{H}_{2}$ total pressure: 20-50 bar, absence or presence of water, nature of IL, etc.). Although their results are not very clear, the authors claimed that the highest activity was observed with the Ru NPs immobilized into [DAMI][TfO]. They also claimed higher catalytic efficiency when using in situ formed [DAMI][TfO]-Ru NPs with TOF up to $3300 \mathrm{~h}^{-1}$ of FA obtained at $323 \mathrm{~K}$ and 50 bar in 8h. Finally a slow decrease in stability was observed after successive recycling. 
Dupont and coworkers reported on the selective hydrogenation of $\mathrm{CO}_{2}$ either to $\mathrm{FA}$ or to hydrocarbons catalysed by a colloidal catalytic system prepared by a single-step organometallic approach (hydrogen co-decomposition of $\left[\mathrm{Fe}(\mathrm{CO})_{5}\right]$ and $[\mathrm{Ru}(\mathrm{COD})(2-$ methylallyl) 2 ] into small RuFe NPs (ca. $1.7 \mathrm{~nm}$ ) dispersed in ILs (1-butyl-3-methyl-1H-imidazol3-ium acetate, BMi.OAc, or 1-butyl-3-methyl-1H-imidazol-3-ium bis((trifluoromethyl)sulfonyl)amide, BMi.NTf 2$)$ under mild reaction conditions $\left(\mathrm{DMSO} / \mathrm{H}_{2} \mathrm{O}\right.$; $333 \mathrm{~K} ; 30$ bar $\mathrm{H}_{2} / \mathrm{CO}_{2}=2 / 1$ ). The selectivity was observed to depend on the nature of the IL anion (Figure 21). ${ }^{256}$

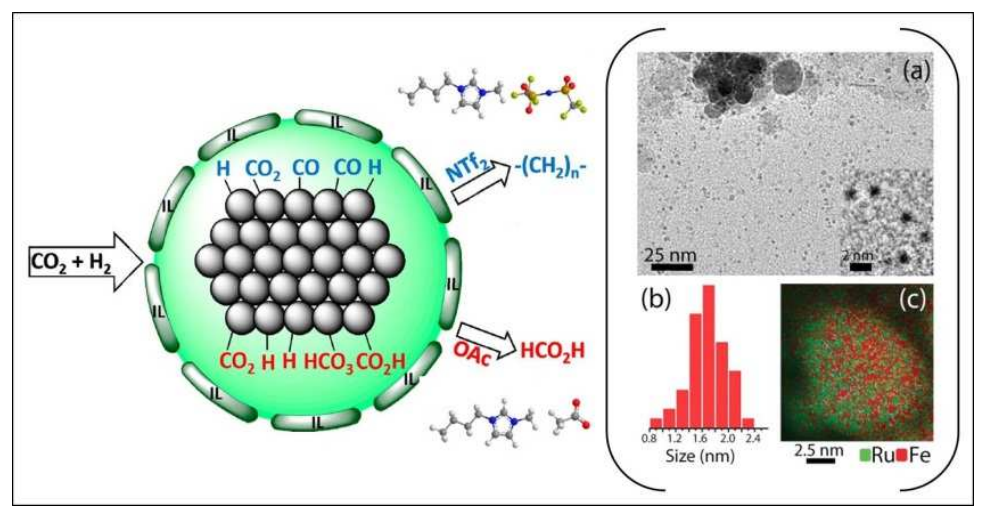

Figure 21. left : Schematic representation of the chemoselectivity observed in $\mathrm{CO}_{2}$ hydrogenation depending on the nature of the IL ; right: $(a, b)$ TEM image of RuFe NPs and size distibution, (c) EDS map, overlay of Ru-L and Fe-K of RuFe NPs in BMI-NTf 2 . Adapted with permission from ref ${ }^{256}$. Copyright 2018 American Chemical Society.

FA was more produced with ILs containing basic anions (BMi.OAc) with a TOF value of $23.5 \mathrm{~h}^{-}$ ${ }^{1}$ whereas heavy hydrocarbons (up to $C_{21}$ ) were more produced with non-basic anions (BMi.NTf 2 ). The composition of the metal alloy and the basicity/hydrophobicity of the IL ion pair (mainly imposed by the anion) appeared to be the key-points for the selective transformation of $\mathrm{CO}_{2}$. First, the IL forms a cage around the NPs that controls the diffusion/residence time of the substrates, intermediates and products. Second, compared to 
Ru and Fe monometallic NPs, the presence of Fe in RuFe NPs showed a dual effect: a positive metal dilution effect towards the formation of FA through the formation of bicarbonate species (Figure 22, route (I)) and a synergetic one for the formation of hydrocarbons through the conversion of $\mathrm{CO}_{2}$ to $\mathrm{CO}$ followed by chain propagation via FTS pathway (Figure 22, route (II)).

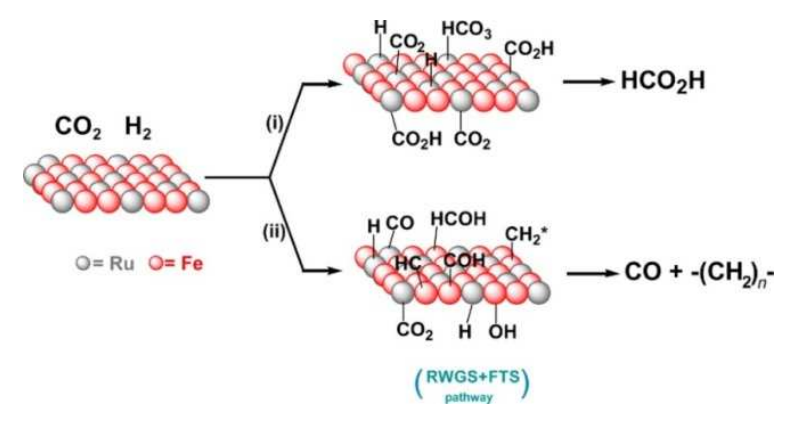

Figure 22. Representation of mechanistic route for the chemoselective hydrogenation of $\mathrm{CO}_{2}$ by RuFe NPs in ILs. Reprinted with permission from ref ${ }^{256}$. Copyright 2018 American Chemical Society.

This work clearly evidences that the precise design of a nanocatalyst (here a combination between metal alloy as active phase and IL as stabilizer) can lead to chemoselectivity in $\mathrm{CO}_{2}$ hydrogenation. Not only the ILs act as stabilizers for the NPs but also their chemical properties lead to a different interface between the metallic phase, the reactants, the intermediates and products that orientate the catalytic selectivity.

\subsubsection{Transformation of $\mathrm{CO}_{2}$ into $\mathrm{CO}, \mathrm{CH}_{4}$ or $\mathrm{C}_{2+}$ hydrocarbons}

Catalytic transformation of $\mathrm{CO}_{2}$ into hydrocarbons (like methane and superior alkanes $\left(\mathrm{C}_{2+}\right)$ or carbon monoxide) is a very attractive alternative to fossil fuels. The hydrogenation of $\mathrm{CO}_{2}$ to methane $\left(\mathrm{CO}_{2}+4 \mathrm{H}_{2} \rightarrow \mathrm{CH}_{4}+\mathrm{H}_{2} \mathrm{O} ;-114 \mathrm{~kJ} \mathrm{~mol}^{-1}\right)$ is well- known as $\mathrm{CO}_{2}$ methanation reaction or Sabatier's process. This reaction is usually performed at temperature $423-773 \mathrm{~K}$ and pressure 1-100 bar. ${ }^{264}$ Methane is more advantageous because it can be injected directly into already existing natural gas pipelines, and it can be used as a fuel or raw material for the 
production of other chemicals. In addition, $\mathrm{CO}_{2}$ methanation is a more simple reaction which can generate $\mathrm{CH}_{4}$ under atmospheric pressure (production of methanol and dimethylether from $\mathrm{CO}_{2}$ requires high pressures $\sim 5 \mathrm{MPa}$ and conversion is low in the case of $\mathrm{MeOH}$ ). Thus, the thermochemical conversion of $\mathrm{CO}_{2}$ to $\mathrm{CH}_{4}$ at low temperature has become an important breakthrough in the use of $\mathrm{CO}_{2}$ despite a low conversion. $\mathrm{CO}_{2}$ methanation remains an advantageous reaction with respect to thermodynamics, since it is faster than reactions leading to hydrocarbons or alcohols.

Both homogeneous and heterogeneous catalysts have been investigated to hydrogenate $\mathrm{CO}_{2}$ to methane. ${ }^{259}$ In heterogeneous condition, metals such as $\mathrm{Ru}, \mathrm{Rh}, \mathrm{Ni}, \mathrm{Co}, \mathrm{Fe}$ and so forth on various supports are recognized to be effective catalysts for this reaction. Noble metals proved to be efficient catalysts as the result of their high ability to dissociate $\mathrm{H}_{2}$, a required step in $\mathrm{CO}_{2}$ methanation. Note that for most catalysts in use, $\mathrm{CO}_{2}$ methanation is considered to be a linear combination of the reverse water-gas shift reaction ( $r W G S ; \mathrm{CO}_{2}+\mathrm{H}_{2} \rightarrow \mathrm{CO}+\mathrm{H}_{2} \mathrm{O}$ ) after which $\mathrm{CO}$ can lead to hydrocarbons via FTs pathways, and the direct hydrogenation of $\mathrm{CO}_{2}$ into methane $\left(\mathrm{CO}_{2}+3 \mathrm{H}_{2} \rightarrow \mathrm{CH}_{4}+\mathrm{H}_{2} \mathrm{O}\right)$. Given that, the choice of the catalyst is essential to get high conversion and selectivity, both varying with the active metal species, support, promoters and synthesis strategies. For the most significant catalysts, the trends of activity and selectivity can be summarized as follows: activity, $\mathrm{Ru}>\mathrm{Fe}>\mathrm{Ni}>\mathrm{Co}>\mathrm{Mo}$; selectivity $\mathrm{Ni}>$ $\mathrm{Co}>\mathrm{Fe}>\mathrm{Ru}$. Ruthenium is renowned as being the most active metal for the methanation of both $\mathrm{CO}$ and $\mathrm{CO}_{2}$ and to be quite stable when operating in a wide temperature range. However $\mathrm{Ru}$ is less selective while being more costly in comparison to non-noble metals. ${ }^{264}$ The catalytic activity can be greatly promoted at the metal/support interface due to synergistic interactions which can tune the reaction mechanism and in turn the selectivity of $\mathrm{CO}_{2}$ hydrogenation. Thus, when deposited onto oxide supports (such as $\mathrm{MgO}, \mathrm{SiO}_{2}, \mathrm{TiO}_{2}, \mathrm{Al}_{2} \mathrm{O}_{3}, \mathrm{ZrO}_{2}$ and $\mathrm{CeO}_{2}$ ), particles 
of $\mathrm{Ni}$ or $\mathrm{Ru}$ were reported to promote the formation of $\mathrm{CH}_{4}{ }^{276} \mathrm{CO}_{2}$ methanation via better defined heterogeneous Ru-based catalysts received more attention in recent years. ${ }^{277-279}$ The main objective is to obtain the best catalytic performance in terms of stability, selectivity, $\mathrm{CO}_{2}$ conversion, and $\mathrm{CH}_{4}$ production, especially aimed at mild reaction conditions (i.e. low reaction temperature). In these works, the Structure-performance relationships appeared to be a key for the development of highly performant catalysts.

A relevant example by Zeng and coworkers ${ }^{280}$ provides an elegant alternative to pure heterogeneous catalysts, by combining a solution synthesis approach and a sol gel approach in order to get a nanomaterial of Ru into a silica matrix. Selective hydrogenation of $\mathrm{CO}_{2}$ into CO was catalyzed by small Ru NPs (ca. 1-3 nm) encapsulated into silica nanowires (denoted as $\left.\mathrm{Ru} / \mathrm{mSiO}_{2}\right) .{ }^{239}$ Combining colloidal and heterogeneous approaches made this catalytic system closer to a nanocatalyst than to pure heterogeneous ones given the presence of better controlled Ru NPs. As shown on Figure 23, a colloidal suspension of Ru NPs was first prepared following a polyol-assisted method (decomposition of $\mathrm{RuCl}_{3}$ into ethylene glycol at $353 \mathrm{~K}$ in the presence of $\mathrm{NaOH}$ ) and then silica was grown around the Ru NPs by hydrolysis/condensation of TEOS (tetraethylorthosilicate) using ethylene glycol as a solvent instead of usual ethanol and an organic template (hexadecyltrimethylammonium chloride; CTACl). A calcination step at $573 \mathrm{~K}$ allowed to eliminate the organic template. Calcination in $\mathrm{N}_{2}$ led to $\mathrm{SiO}_{2}$-encapsulated Ru NPs of almost unchanged size (1-3 $\mathrm{nm}$ depending on the $\mathrm{Ru}$ content introduced) while calcination in air condition led to Ru NPs of larger sizes (5-30 nm) due to sintering. Comparatives studies in flow conditions inside a fix bed reactor (temperature: 473-673 K; $25 \mathrm{~mL}$. $\mathrm{min}^{-1}$ of $\mathrm{H}_{2} / \mathrm{CO}_{2}$ at ratio $4: 1$ ) revealed a selective transformation of $\mathrm{CO}_{2}$ into $\mathrm{CO}$ with $\mathrm{Ru} / \mathrm{mSiO}_{2}$ calcined in inert conditions and that contained small Ru NPs while the catalyst obtained in air condition and displaying large Ru NPs led preferentially to $\mathrm{CH}_{4}$. Fine 
surface studies (including temperature-programmed reduction (TPR) and temperatureprogrammed desorption (TPD), XPS and in-situ diffuse reflectance infrared Fourier transform spectroscopy (DRIFTS)), performed on the two catalysts $\left(1-3 \mathrm{~nm} \mathrm{Ru} / \mathrm{mSiO}_{2}\right.$ and $5-20 \mathrm{~nm}$ $\mathrm{Ru} / \mathrm{mSiO}_{2}$ ) after adsorption of $\mathrm{H}_{2}$ and $\mathrm{CO}_{2}$ revealed the formation of different reaction intermediates on catalyst surface: $\mathrm{CO}-\mathrm{Ru}_{\mathrm{n}}$ on $1-3 \mathrm{~nm} \mathrm{Ru} / \mathrm{mSiO}_{2}$ and formate species on 5-20 $\mathrm{nm} \mathrm{Ru} / \mathrm{mSiO}_{2}$, thus explaining the different selectivity observed as the result of different reaction pathways. The high selectivity of $\mathrm{CO}$ over $\mathrm{CH}_{4}$ is attributed to low affinity and hence coverage of atomic hydrogen on the surface of the 1-3 $\mathrm{nm}$ Ru NPs. DRIFTS, TPR and TPD experiments supported a surface redox mechanism for $\mathrm{CO}_{2}$ hydrogenation on 1-3 nm $\mathrm{Ru} / \mathrm{mSiO}_{2}$, where carbonyl species formed by dissociative adsorption of $\mathrm{CO}_{2}$ and desorbed directly to generate $\mathrm{CO}$. A formate route is established for $5-20 \mathrm{~nm} \mathrm{Ru} / \mathrm{mSiO}_{2}$ catalysts, where adsorbed atomic hydrogen associates with adsorbed $\mathrm{CO}_{2}$ to form formate species, which are further hydrogenated to $\mathrm{CH}_{4}$ with sufficient supply of surface hydrogen atoms due to the large metal surface. In addition, $1-3 \mathrm{~nm} \mathrm{Ru} / \mathrm{mSiO}_{2}$ nanocatalyst demonstrated to be stable in terms of activity and selectivity in extended reaction time up to $50 \mathrm{~h}$. This work provides an elegant way to maintain the advantage of small-sized Ru NPs while having them encapsulated into the pores of a silica support for a selective catalytic transformation of $\mathrm{CO}_{2}$ into $\mathrm{CO}$. 


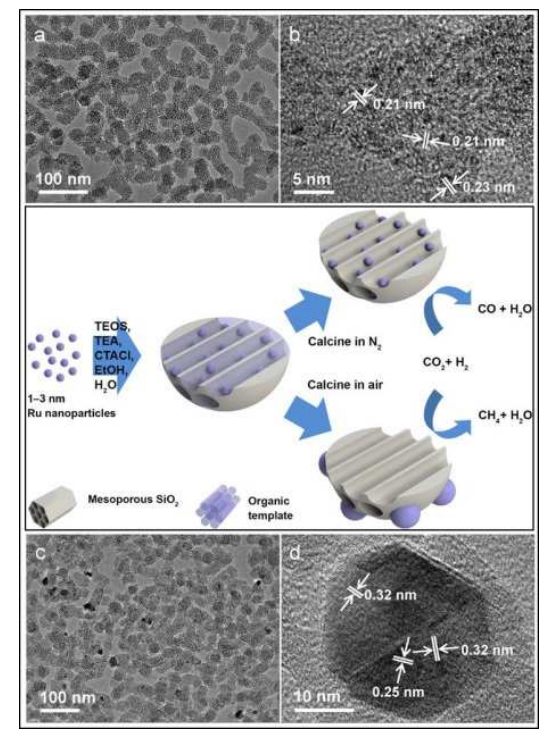

Figure 23. Schematic representation of the synthesis and TEM/HREM images of $\mathrm{Ru} / \mathrm{mSiO}_{2}$ nanocatalysts for selective reduction of $\mathrm{CO}_{2}$ to either $\mathrm{CO}$ (top) or $\mathrm{CH}_{4}$ (bottom). Adpated with permission from ref ${ }^{280}$. Copyright 2017 Elsevier.

Another relevant example by Chaudret and coworkers describes the use of nickel-coated iron carbide nanoparticles (ICNPs) prepared by the organometallic approach for the catalytic transformation of $\mathrm{CO}_{2}$ into $\mathrm{CO}$ and $\mathrm{CH}_{4}$ in a continuous-flow reactor under atmospheric pressure. $^{281}$ Interestingly, with this ICNP-based catalytic system, the heating arises from the magnetic properties of the iron cores that are induced after applying a magnetic field. This catalytic system was optimized by deposition onto an inorganic support previously impregnated with $1 \mathrm{wt} \% \mathrm{Ru}$ (also from an organometallic precursor). $\mathrm{CO}_{2}$ methanation with total selectivity and $93 \%$ yield was achieved in a model flow reactor. The presence of small Ru NPs in the alumina support (1 wt\%) greatly enhanced the catalytic performance of the system and allowed a highly efficient conversion of $\mathrm{CO}_{2}$ to $\mathrm{CH}_{4}$ in continuous flow (Figure 24). If not a pure Ru catalytic system however this work has the merit to show the synergy afforded by the proximity of Ru NPs onto the catalytic performance of a Ni-based nanocatalyst. 


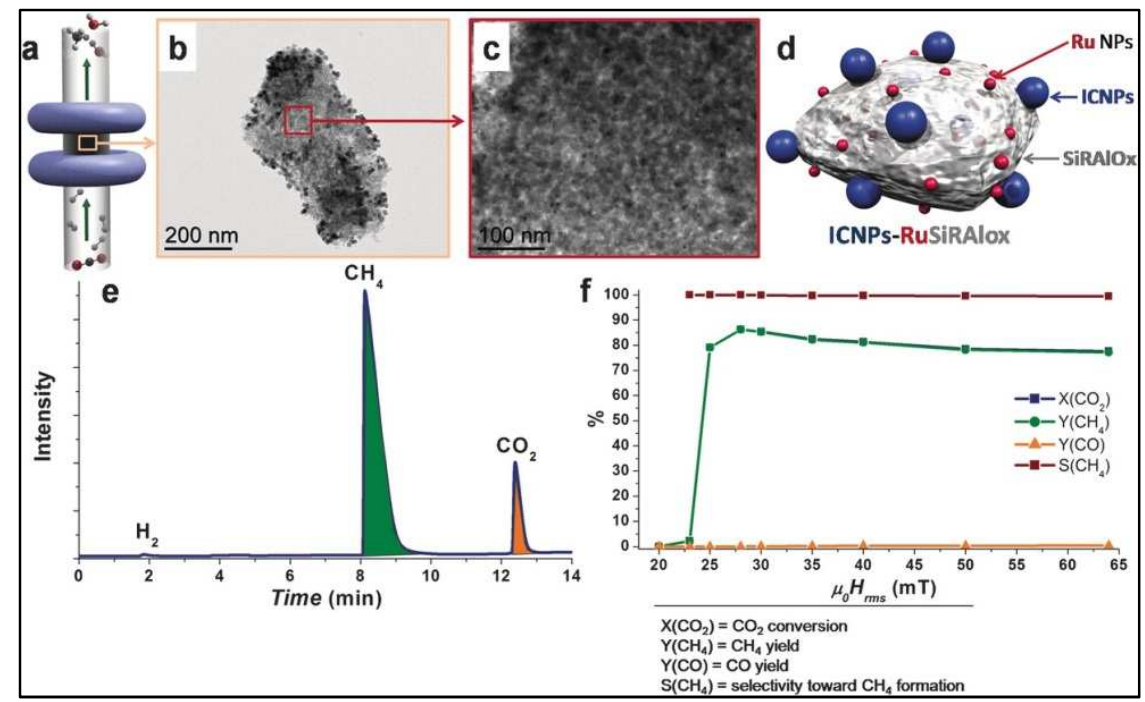

Figure 24. Magnetically induced Sabatier reaction in continuous-flow reactor using ICNPSRuSiRAIOx catalyst (ratio $\mathrm{H}_{2} / \mathrm{CO}_{2}=4 / 1,25$ mLmin@1, 18.3 Lh@1 g(Fe+Ru)@1 or 214.3 Lh@1 gRu@1, residence time t=0.00067 h, P atm). a) Schematic representation of the reactor, b) TEM of ICNPs and Ru NPs supported on a SiRAIOx particle, c) Zoom on small Ru NPs, scale bar=100 nm, d) schematic representation of the catalytic system, e) gas chromatogram obtained for $\mathrm{mOHrms}=28 \mathrm{mT}$, and f) catalytic results as a function of $\mathrm{mOHrms}$. Since the selectivity is total, $\mathrm{X}\left(\mathrm{CO}_{2}\right)$ and $\mathrm{Y}\left(\mathrm{CH}_{4}\right)$ are overlapping. Reprinted with permission from ref 281. Copyright 2016 Wiley.

Apart from these supported catalysts, Ru NPs dispersed into ILs also allowed the formation of $\mathrm{CO}, \mathrm{CH}_{4}$ or $\mathrm{C}_{2 x}$. A previously cited work by Dupont and coworkers, ${ }^{256}$ described the influence of the nature of the IL used as a stabilizer on the catalytic properties of bimetallic RuFe NPs during hydrogenation of $\mathrm{CO}_{2}$, more precisely on the selectivty ( $\mathrm{HCOOH}$ vs. $\mathrm{C}_{2+}$ ). In a very recent paper, the same group reported on the conversion of $\mathrm{CO}_{2}$ into $\mathrm{CO}$ or light hydrocarbons $\left(\mathrm{C}_{2}-\right.$ $\left.\mathrm{C}_{6}\right)$ under very mild conditions $\left(\mathrm{H}_{2} / \mathrm{CO}_{2}=4: 1,8.5\right.$ bar, $\left.423 \mathrm{~K}\right)$ by using bimetallic RuNi NPs deposited into ionic liquids. ${ }^{241}$ This nanocatalyst was easily prepared by co-decomposition of organometallic precursors $[\mathrm{Ni}(\mathrm{COD})]$ and $\left[\mathrm{Ru}(\mathrm{COD})(2 \text {-methylallyl })_{2}\right]$ under $\mathrm{H}_{2}$ atmosphere in an ionic liquid acting both as solvent and stabilizer. The so-obtained RuNi NPs presented a size 
of ca. 2-3 nm and a Ni-rich core with a Ru-rich shell whatever the synthetic conditions studied. But after the catalytic reactions, an enrichment of $\mathrm{Ni}$ in the shell was observed as the result of migration of $\mathrm{Ni}$ atoms towards the NP surface under catalytic conditions. In terms of catalytic performance, among the different RuNi compositions tested, $\mathrm{Ru}_{3} \mathrm{Ni}_{2} \mathrm{NPs}$ dispersed into an hydrophobic IL (BMI.NTf 2 (I-butyl-3-methyl-IH-imidazol-3-ium bis((tri- fluoromethyl) sulfonyl)amide)) offered the highest conversion (up to $30 \%$ ) and promoted the direct hydrogenation of $\mathrm{CO}_{2}$ into light hydrocarbons. The same $\mathrm{Ru}_{3} \mathrm{Ni}_{2} \mathrm{NPs}$ gave rise to $22 \%$ conversion into hydrophilic IL (1-n-butyl-3-methy I-IH-imidazol-3-ium tetrafluoborate) with CO as the main product (see table 14).

Table 14: Catalytic systems for the hydrogenation of $\mathrm{CO}_{2}$ to Hydrocarbons in ILs. ${ }^{\mathrm{a}}$ Reprinted with permission from ref ${ }^{282}$. Copyright 2019 Elsevier.

\begin{tabular}{|c|c|c|c|c|c|c|c|c|}
\hline \multirow[t]{2}{*}{ Entry } & \multirow[t]{2}{*}{ NPs } & \multirow[t]{2}{*}{ Time (h) } & \multirow[t]{2}{*}{ Conv. (\%) } & \multicolumn{5}{|c|}{ Selectivity (\%) } \\
\hline & & & & $\mathrm{CO}$ & $\mathrm{CH}_{4}$ & $\mathrm{C}_{2}-\mathrm{C}_{4}$ & $\mathrm{C}_{5}-\mathrm{C}_{6}$ & $\begin{array}{l}\text { Olefins }\left(C_{2^{-}}\right. \\
\left.C_{4}\right)\end{array}$ \\
\hline 1 & $\mathrm{Ru}_{1} \mathrm{Ni}_{2}$ & 20 & 20 & 26 & 1 & 65 & 8 & - \\
\hline 2 & $\mathrm{Ru}_{1} \mathrm{Ni}_{2}$ & 60 & 25 & 0 & 31 & 55 & 3 & 11 \\
\hline 3 & $\mathrm{Ru}_{4} \mathrm{Ni}_{3}$ & 60 & 24 & 0 & 14 & 59 & 19 & 8 \\
\hline 4 & $\mathrm{Ru}_{3} \mathrm{Ni}_{2}$ & 60 & 30 & 0 & 5 & 76 & 3 & 16 \\
\hline 5 & $\mathrm{Ru}_{3} \mathrm{Ni}_{2}{ }^{\mathrm{c}}$ & 60 & 22 & 47 & 7 & 7 & 35 & 4 \\
\hline 6 & RuNPs & 20 & 17 & 0 & 18 & 59 & 23 & - \\
\hline 7 & Ni NPs & 20 & 5 & 2 & 4 & 57 & 37 & - \\
\hline 8 & $\mathrm{Ru}_{1} \mathrm{Ni}_{2}{ }^{\mathrm{d}}$ & 20 & 2 & - & 100 & - & - & - \\
\hline 9 & - & 20 & - & - & - & - & - & - \\
\hline
\end{tabular}

a Reactions conditions: Catalyst $20 \mathrm{mg}$, IL $(0.5 \mathrm{~mL}), \mathrm{CO}_{2} / \mathrm{H}_{2}$ gas $(1: 4,8.5 \mathrm{bar}), 60 \mathrm{~h}$ and $423 \mathrm{~K}$.

${ }^{b}$ Selectivity of the products was calculated as equivalent amount of desired hydrocarbon with respect to the total number of hydrocarbons produced.

${ }^{c}$ Reaction was performed in BMI-BF4 hydrophilic IL.

d Without IL

Given the bimetallic RuNi NPs afforded higher efficiencies (up to $30 \%$ of conversion) than their 
monometallic counterparts ( $17 \%$ and $5 \%$ of conversion with Ru and Ni NPs, respectively), there is a strong synergy effect between $\mathrm{Ru}$ and $\mathrm{Ni}$ in this catalytic system. The presence of $\mathrm{Ni}$ yielded a more active rWGS catalyst while Ru increased the FTS towards the heavier hydrocarbons. In addition, as in their previous study with RuFe NPs, ${ }^{256}$ these obtained results showed that the nature of the IL (mainly, the choice of IL cations and anions) may orientate the selectivity of the reaction due to different geometric and electronic properties of the IL-supported metal NPs. Diffusion of reactants, intermediates, or products across the interface between ILs and the catalyst surface plays an important role in the final chemoselectivity. The hydrophobic IL (BMI.NTf $)_{2}$ influenced the hydrogenation of $\mathrm{CO}_{2}$ to heavier hydrocarbons by repelling the formed water from the active catalytic phase of RuNi NPs, hence increasing the water gas shift reaction and increasing the FTS reaction pathways. In the opposite, the dominance of CO pathway into hydrophilic IL $\left(\mathrm{BMI}_{\mathrm{B}} \mathrm{BF}_{4}\right)$ results from a higher solubility of the formed water which causes the reduction of FT catalytic active surface species (Figure 25).

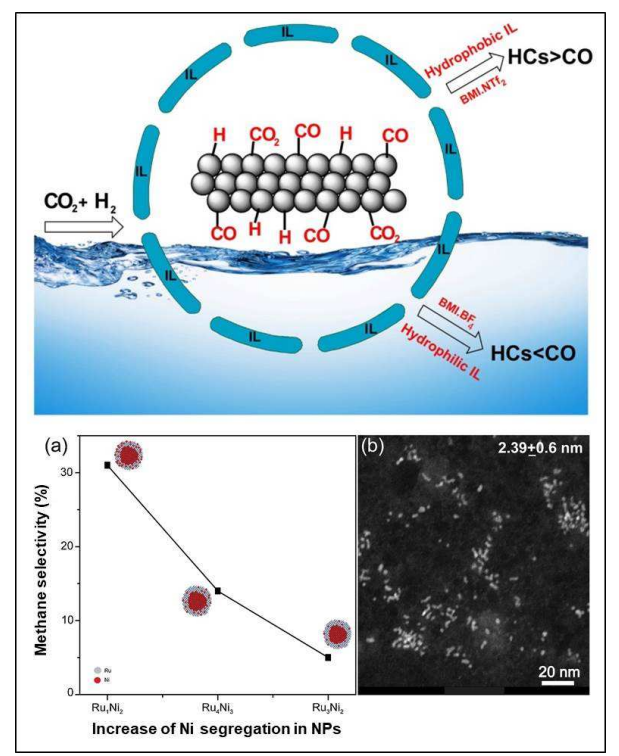

Figure 25. top : Schematic representation of the chemoselectivity observed in $\mathrm{CO}_{2}$ hydrogenation by RuNi NPs depending on the nature of the IL ; bottom : (a) Surface 
composition of $\mathrm{Ni}$ in RuNi NPs vs. methane selectivity and (b) STEM-HAADF analysis of $\mathrm{Ru}_{1} \mathrm{Ni}_{2}$

NPs after catalysis. Adapted with permission from ref ${ }^{282}$. Copyright 2019 Elsevier.

As a last example, Branco and coworkers described the hydrogenation of $\mathrm{CO}_{2}$ into methane using in situ formed IL-supported Ru NPs (Figure 26). ${ }^{283}$ The nanocatalyst was prepared in situ by mixing in an autoclave the $\left[\mathrm{Ru}(\mathrm{COD})(2 \text {-methylallyl) })_{2}\right]$ complex and an IL (1-butyl-3methylimidazolium bistrifluoromethanesulfonylimide, [bmim][NTf2], or 1-octyl-3methylimidazolium bistrifluoromethanesulfonylimide, [omim][NTf2]), followed by the application of hydrogen pressure and temperature $(313 \mathrm{~K})$ before introduction of $\mathrm{CO}_{2}$ (up to a total pressure of 80 bar) and increasing temperature (up to $423 \mathrm{~K}$ ) to perform the catalysis. TEM analysis of the black colloidal solution obtained after catalysis in [omim][NTf2] revealed the presence of Ru NPs of ca. $2.5 \mathrm{~nm}$.

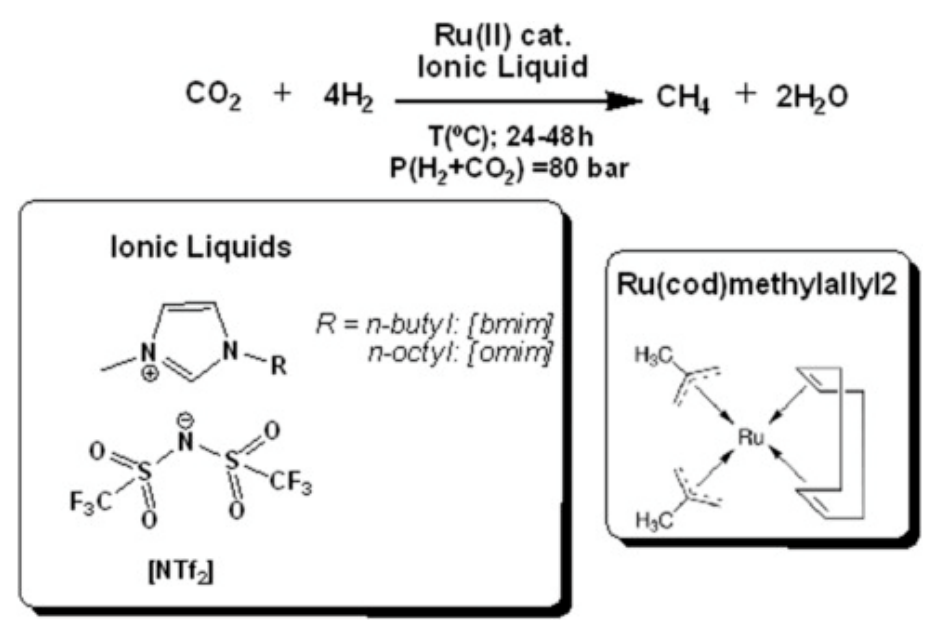

Figure 26. Hydrogenation of $\mathrm{CO}_{2}$ into $\mathrm{CH}_{4}$ catalyzed by Ru NPs dispersed into ionic liquids. Reprinted with permission from ref ${ }^{283}$. Copyright 2016 Wiley.

It is worth to mention that the presence of $\mathrm{PPh}_{3}$ in the reaction medium led to no substantial results, whereas methane and water were formed in its absence. Several reaction conditions were first tested using [bmim][NTf2] (amount of catalyst, hydrogen and $\mathrm{CO}_{2}$ pressures and ratio, reaction time and temperature). No methane was produced at 20 bar $\mathrm{H}_{2}$ whereas 40 or 60 bar led to the same quantity of methane (up to $4.7 \%$ yield, with TON (expressed as mol 
$\mathrm{CH} 4 / \mathrm{mol}$ cat) of 12 , after $24 \mathrm{~h}$ at $413 \mathrm{~K}$ with 60 bar $\mathrm{H}_{2}$ ). The change of the IL to [omim][NTf2], which is reported to better stabilize NPs, led in general to better performance for $\mathrm{CH}_{4}$ production. The best yield of methane (69\%) was achieved with 0.24 mol\% ruthenium catalyst, at 40 bar of $\mathrm{H}_{2}$ plus 40 bar of $\mathrm{CO}_{2}$, and at $423 \mathrm{~K}$ (see table 15 , entry 8 ).

Table 15. Hydrogenation of $\mathrm{CO}_{2}$ into methane with Ru NPs stabilized into [omim] $\left[\mathrm{NTf}_{2}\right]^{\text {a }}$ Reprinted with permission from ref ${ }^{283}$. Copyright 2016 Wiley.

\begin{tabular}{ccccccc}
\hline Entry & $\begin{array}{c}\text { Precursor } \\
{[\mu \mathrm{mol}]}\end{array}$ & $\mathrm{pH}_{2}[\mathrm{bar}]$ & $\boldsymbol{t}[\mathrm{h}]$ & $T[\mathrm{~K}]$ & Yield [\%] & TON $^{\mathbf{b}}$ \\
\hline 1 & 24 & 60 & 24 & 373 & - & - \\
2 & 25 & 60 & 24 & 413 & 4 & 30 \\
3 & 24 & 40 & 24 & 393 & 4 & 22 \\
4 & 28 & 40 & 24 & 413 & 10 & 47 \\
5 & 25 & 40 & 24 & 423 & 17 & 95 \\
6 & 77 & 40 & 48 & 413 & 30 & 51 \\
7 & 123 & 40 & 24 & 413 & 51 & 55 \\
8 & 125 & 40 & 24 & 423 & 69 & 72 \\
9 & 223 & 40 & 48 & 423 & 61 & 36 \\
\hline
\end{tabular}

${ }^{a}$ Reaction conditions: $\left[\mathrm{Ru}(\mathrm{COD})(2 \text {-methylallyl })_{2}\right.$ ] as precursor, $1 \mathrm{~mL}$ of IL, total pressure $=80$ bar at $313 \mathrm{~K} .{ }^{\mathrm{b}} \mathrm{mol} \mathrm{CH} / \mathrm{mol}_{4}$ Ru catalyst.

This work highlights that $\mathrm{CO}_{2}$ can be selectively hydrogenated to $\mathrm{CH}_{4}$ using a simply prepared nanocatalyst made of Ru NPs dispersed into an IL in reasonable reaction conditions. It also shows that the choice of the IL may change the catalytic performance. The better conversions reached with [omim][NTf2] compared to those observed in [bmim][NTf2] are attributed to a better solubility of $\mathrm{CO}_{2}$ (which contributes to a reduced viscosity of the IL and increases both miscibility of reagents in the IL) and also to a better stability of the Ru NPs given the longer alkylchain ( $\mathrm{C}_{8}$ against $\left.\mathrm{C} 4\right)$ beared by the of [omim][NTf2] IL. Catalysis investigation performed with preformed and isolated Ru NPs led to a reduction in $\mathrm{CH}_{4}$ production of (5\% of yield and 
$25 \%$ of TON), thus These comparative results pointing out that the conditions applied are the key point to achieve higher methane production performance. Moreover this catalytic system is very simple to implement.

\subsubsection{Conclusions on $\mathrm{CO}_{2}$ transformation}

The literature provides only a few works showing the potential of Ru-based nanocatalysts (both as monometallic and bimetallic systems) for the thermochemical hydrogenation of $\mathrm{CO}_{2}$. This probably derives from the present (and necessary) trend to use more abundant and less expensive metals for application in catalysis of industrial interest, which is not the case of ruthenium. Even if quite low values have been achieved in terms of activity compared to those reported for homogeneous ruthenium complexes, and even if not numerous today, the obtained results evidenced that the control of size and the nature of chemical environment around the particles are key-factors. These findings thus open some ways that merit being deeper explored in order to get more active Ru-based nanocatalysts. But apart from ILs that were shown to orientate the catalytic results by providing adequate chemical environment, to our knowledge, effects of capping ligands have not been studied. Moreover, when considering the needs in terms of mechanistic studies in order to better understand what occurs at the surface of metal NPs, ruthenium may provide nice opportunities because it allows the access to NMR spectroscopic techniques, tools that are usually applied for mechanistic studies with homogeneous catalysts. This possibility needs to be better exploited. Indeed such an approach is expected to provide insights at the atomic level on the surface state of metal nanoparticles as well as on intermediates formed, and thus it could greatly complement usual surface studies coming from heterogeneous catalysis. We believe it is a necessary step in order to define structure-activity relationships for in turn design better appropriate nanocatalysts for more efficient and more selective $\mathrm{CO}_{2}$ hydrogenation. Dupont 
and coworkers reported some data in this direction using ionic liquids. They observed by highpressure NMR (40 bar $\mathrm{H}_{2} / \mathrm{CO}_{2}$ at ratio $1 / 1$ ) the presence of $\mathrm{HCO}_{3}{ }^{-}$species on the surface of $\mathrm{Ru}$ NPs dispersed in ILs. ${ }^{271}$

\subsection{Dehydrogenation of amine boranes}

Hydrogen is considered as a clean energy carrier because it can be produced in a renewable way from various non-fossil feedstocks. Hydrogen has a much higher gravimetric energy density than petroleum (120 vs $44 \mathrm{~kJ} \mathrm{~g}^{-1}$ for hydrogen and petroleum, respectively) and can be readily used to operate high-energy-efficient fuel cells that produce water as the only waste, which makes it an ideal alternative energy vector. ${ }^{284}$ However, a main challenge relies with its storage in secure conditions while having an easy and fast release for an "on demand" usage. When employed as an energy carrier in portable electronic devices and vehicles, hydrogen fuel cells should have the highest possible energy content combined with the smallest possible volume and mass. As a consequence, numerous works focus on the development of strategies for efficient hydrogen storage with the objective to fulfil this criterion. Physical (compressed hydrogen gas, cryocompressed hydrogen storage, and hydrogen adsorbents) and chemical storage systems are studied (e.g. sorbent materials, metal hydrides, organic hydrides, borane-nitrogen (B-N) compounds, and aqueous solution of hydrazine), but no hydrogen storage methods are mature enough for industrial applications under mild conditions. ${ }^{284}$

Covalently bound hydrogen-containing materials, in either liquid or solid form, are very attractive for chemical hydrogen storage because of their generally high gravimetric hydrogen densities. Among them, amine boranes (B-N), with protic $\mathrm{N}-\mathrm{H}$ and hydridic $\mathrm{B}-\mathrm{H}$, have attracted much attention due to their high hydrogen contents and favorable kinetics of hydrogen 
release. ${ }^{285}$ Ammonia borane $\left(\mathrm{NH}_{3}-\mathrm{BH}_{3} ; \mathrm{AB}\right)$ which is the simplest $\mathrm{B}-\mathrm{N}$ compound represents a leading material given its high hydrogen density (19.6 wt\%), low molecular weight (30.7 g $\mathrm{mol}^{-1}$ ), solubility in polar solvents like water and methanol (vide infra), high stability under ambient conditions and environmental friendliness. ${ }^{286}$ Methylamine borane $\left(\mathrm{CH}_{3} \mathrm{NH}_{2}-\mathrm{BH}_{3}\right.$; hydrogen content of $17.86 \mathrm{wt} \%)$ and dimethylamine borane $\left(\left(\mathrm{CH}_{3}\right)_{2} \mathrm{NH}-\mathrm{BH}_{3}\right.$; hydrogen content of $17.1 \mathrm{wt} \%)$ or also hydrazine borane $\left(\mathrm{N}_{2} \mathrm{H}_{4}-\mathrm{BH}_{3}\right.$; hydrogen content of $\left.15.28 \mathrm{wt} \%\right)$ are other substrates of interest but they are less widely investigated, probably due to their lower hydrogen content and necessary conditions for the release. Hydrogen formation is generally quantified by volumetry and the reaction monitored by ${ }^{11} \mathrm{~B} N \mathrm{NR}$ to analyse the byproducts formed

A convenient method to release hydrogen from ammonia borane consists in its solvolysis using a protic solvent like water or methanol, namely hydrolysis (eq. 1) and methanolysis (eq.2), respectively.

$$
\begin{aligned}
& \mathrm{NH}_{3} \cdot \mathrm{BH}_{3}(\mathrm{aq})+2 \mathrm{H}_{2} \mathrm{O}(\mathrm{I}) \rightarrow \mathrm{NH}_{4} \cdot \mathrm{BO}_{2}(\mathrm{aq})+3 \mathrm{H}_{2}(\mathrm{~g}) \\
& \mathrm{NH}_{3} \cdot \mathrm{BH}_{3}(\mathrm{sol})+4 \mathrm{CH}_{3} \mathrm{OH}(\mathrm{I}) \rightarrow \mathrm{NH}_{4} \cdot \mathrm{B}\left(\mathrm{OCH}_{3}\right)_{4}(\mathrm{sol})+3 \mathrm{H}_{2}(\mathrm{~g})
\end{aligned}
$$

The use of a catalyst (homogeneous, heterogeneous or nanoparticulate) allows to make the solvolysis to occur at r.t., leading to the stoechiometric production of 3 equiv. $\mathrm{H}_{2}$.

Dehydrocoupling (eq. 3 and 4) is another way to liberate hydrogen from ammonia borane, using this time a non-protic solvent like tetrahydrofuran (THF) or toluene. Catalytic activation allows to drive this reaction at r.t., mainly using homogeneous species but heterogeneous species and nanoparticles are also developed.

$$
\begin{aligned}
& n \mathrm{NH}_{3} \cdot \mathrm{BH}_{3}(\mathrm{sol}) \rightarrow\left(\mathrm{NH}_{2} \mathrm{BH}_{2}\right)_{n}(\mathrm{~s} \text { or sol })+n \mathrm{H}_{2}(\mathrm{~g}) \\
& n \mathrm{NH}_{3} \cdot \mathrm{BH}_{3}(\mathrm{sol}) \rightarrow(\mathrm{NHBH})_{n}(\mathrm{~s} \text { or sol })+2 n \mathrm{H}_{2}(\mathrm{~g})
\end{aligned}
$$


As it will be seen hereafter, kinetic studies allow to quantify catalyst performance (in terms of turnover frequency (TOF), activation energy (Ea), activation enthalpy $\left(\Delta \mathrm{H}^{*}\right)$ and entropy $\left(\Delta \mathrm{S}^{*}\right)$ values). Other important parameters are the stability and the reusability/recycling of the catalysts, both being key-parameters for cost decrease and technology transfer.

Numerous metals are used for the dehydrogenation of amine boranes like noble metals and non-noble ones among which ruthenium is in the top list, either under the form of molecular complexes, heterogeneous catalysts or nanoparticles. The next parts of this section will provide recent results in the use of well-defined Ru NPs (mono-, bi- or trimetallic systems) for dehydrocoupling or solvolysis of amine boranes. Among the reported Ru-based catalytic systems many involve supported nanocatalysts while only a few articles describe Ru NPs in solution. The examples here presented correspond to catalysts made of Ru NPs prepared in mild conditions of wet chemistry allowing thus a good control of their characteristics.

\subsubsection{Dehydrogenation of amine boranes by dehydrocoupling}

Not a lot of examples describe the use of Ru nanocatalysts for the dehydrogenation of amine boranes in a non-protic solvent. It mainly concerns dimethylamine borane (DMAB) and THF as solvent as well as supported nanocatalysts. Nevertheless, a few unsupported systems have been reported, as follows.

The catalytic performance of 3-aminopropyltriethoxysilane-stabilized $\mathrm{Ru}$ nanoclusters (Ru/APTS) synthesized from the organometallic $[\mathrm{Ru}(\mathrm{COD})(\mathrm{COT})]$ complex (Figure 27) has been evaluated in the dehydrogenation of DMAB..$^{287-288} \mathrm{~A}$ size control operated by varying the $\mathrm{Ru} /$ ligand ratio allowed to study the influence of this parameter in catalysis (THF, $298 \mathrm{~K}$ ). Hydrogen evolution started immediately with an initial turnover frequency (TOF) of $53 \mathrm{~h}^{-1}$ for the best system (ca. $2.9 \mathrm{~nm}$ ) and continued until completion (1 equiv. $\mathrm{H}_{2}$ per mol DMAB released). Adding $\mathrm{Hg}(0)$ in the catalytic mixture led to suppression of the activity, thus 
evidencing heterogeneous catalysis (Figure 28). The initial TOF value of $53 \mathrm{~h}^{-1}$ attained with this system was comparable to that of the best heterogeneous rhodium catalyst known at that time $\left(\mathrm{TOF}=60 \mathrm{~h}^{-1}\right)$. Moreover, it was the first example of an isolable, bottleable and reusable transition metal nanocatalyst for the dehydrogenation of DMAB. APTS concentration increase significantly decreased the catalytic activity as a result of a higher coverage of metallic surface. This evidenced the necessary compromise between the NP mean size and the surface accessibility to get efficient catalytic behavior.

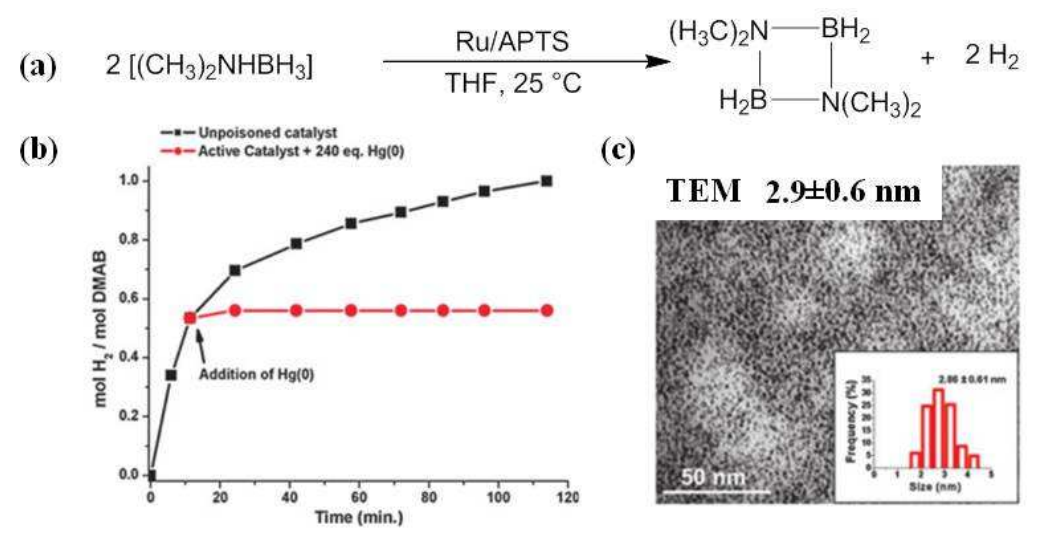

Figure 27. (a) Dehydrogenation of dimethylamine-borane catalyzed by Ru/APTS NPs in THF at r.t.(b) $\mathrm{mol} \mathrm{H}_{2} / \mathrm{mol} \mathrm{DMAB}$ vs. time graph ([Ru]= $2.24 \mathrm{mM}$; [DMAB] $=54 \mathrm{mM} ; 240$ eq. of $\mathrm{Hg}(0)$ after $\sim 50 \%$ conversion of DMAB), and (c) TEM image of Ru/APTS NPs ( $2.9 \mathrm{~nm})$ after the third catalytic run. Adapted with permission from ref ${ }^{288}$. Copyright 2012 Royal Society of Chemistry.
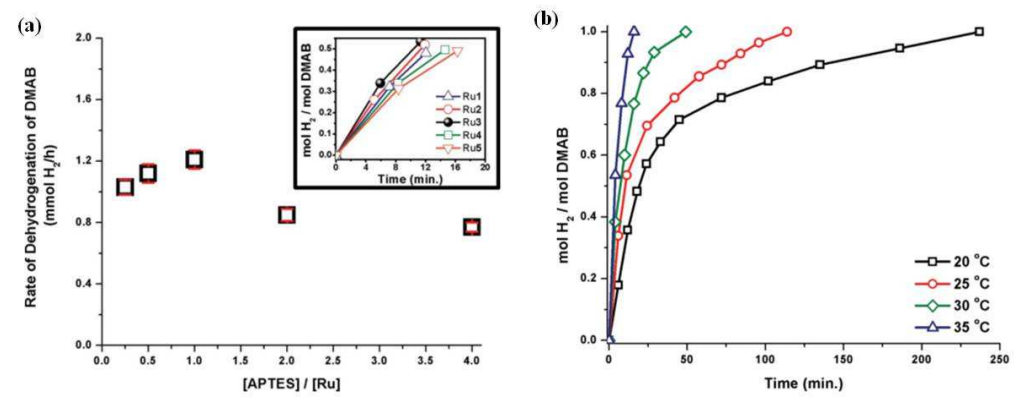

Figure 28 (a) Rate of dehydrogenation of $55 \mathrm{mM}$ DMAB vs. [APTS]/[Ru] ratio, using Ru/APTS NPs, (b) Plot of $\mathrm{mol} \mathrm{H}_{2}$ /mol DMAB vs. time for the dehydrogenation rxn ( 55 mM DMAB;.25 
mM Ru/APTS 3). Adapted with permission from ref ${ }^{288}$. Copyright 2012 Royal Society of

Chemistry.

The in situ generation of Ru NPs was also studied taking benefit of the catalysis reaction conditions for their formation, without adding extra stabilizer. ${ }^{289}[\operatorname{Ru}(\mathrm{COD}(\mathrm{COT})]$ easily decomposed during the dehydrogenation of DMAB in THF at $298 \mathrm{~K}$, forming Ru NPs as seen by TEM. NMR studies on the obtained Ru NPs showed their stabilization by B-N polymers resulting from DMAB decomposition. It was the first example of Ru nanocatalyst prepared in situ, displaying a TOF value of $35 \mathrm{~h}^{-1}$ together with a $\mathrm{H}_{2}$ production superior than 1.0 equiv. at the complete conversion of DMAB.

Oleylamine-stabilized Ru NPs were also used in the dehydrocoupling of DMAB by S. Ozkar's group. ${ }^{290}$ The nanocatalyst was generated in situ by reduction of $\mathrm{RuCl}_{3}$ at r.t. in toluene and in the presence of oleylamine as stabilizer and of DMAB as both reducing agent and catalysis substrate. This led to Ru/oleylamine NPs of ca. $1.8 \mathrm{~nm}$ that were reproducibly isolated and fully characterized. These Ru/oleylamine NPs proved to be a highly active catalyst in the dehydrogenation of DMAB, providing a release of $1 \mathrm{~mol} \mathrm{H}_{2}$ per mole of DMAB and an initial TOF value of $137 \mathrm{~h}^{-1}$ at $298 \mathrm{~K}$ and Ea value of $29 \pm 2 \mathrm{~kJ}^{\mathrm{mol}}{ }^{-1}$. The optimum ligand/Ru ratio to have active and stable NPs was found to be 3 . At this ratio, Ru/oleylamine NPs were shown stable and reusable giving rise to 20,660 total turnovers and preserving $75 \%$ of their initial activity after the $5^{\text {th }}$ catalytic run with the complete conversion of DMAB and the release of 1 equivalent $\mathrm{H}_{2}$. Although these oleylamine-stabilized Ru NPs have a mean size similar to that of APTS-stabilized Ru NPs previously described, their activity is almost the double. This can be explained by a difference in terms of available of active sites: oleylamine being less voluminous than APTS it probably leads to less-crowded metal surface and consequently to more accessible ruthenium atoms compared to APTS. 
In the very recent years, the group of F. Șen studied several ruthenium-containing catalytic systems in the dehydrocoupling of DMAB, including colloidal NPs. For example well-dispersed PVP-stabilized RuNi NPs were prepared by a facile sodium hydroxide-assisted aqueous reduction method under inert atmosphere, that consists in treating an aqueous solution of $\mathrm{RuCl}_{3}$ and $\mathrm{NiCl}_{2}$ by $\mathrm{NaBH}_{4}$ in the presence of $\mathrm{NaOH}$ and PVP as stabilizing agent. ${ }^{291}$ Optimum conditions in terms of Ru/Ni and PVP/metal ratios were found to be $1 / 1$ and 5/1, respectively. In these conditions, ca. $3.5 \pm 0.4 \mathrm{~nm}$ in size RuNi NPs, well-dispersed in the polymer matrix, stable, easily isolable and redispersable have been obtained and characterized as RuNi alloy. These NPs were investigated in the dehydrogenation of DMAB (eq. 5), an easy catalytic reaction to implement, just consisting in adding the DMAB substrate into a THF colloidal suspension of RuNi/PVP NPs.

$$
2\left(\mathrm{CH}_{3}\right)_{2} \mathrm{NH} . \mathrm{BH}_{3} \rightarrow\left(\left(\mathrm{CH}_{3}\right)_{2} \mathrm{~N} \cdot \mathrm{BH}\right)_{2}+2 \mathrm{H}_{2} \quad \text { (eq.5) }
$$

RuNi/PVP nanocatalyst allowed a complete release of $\mathrm{H}_{2}\left(1 \mathrm{~mol} \mathrm{H}_{2}\right.$ per mol of DMAB) at $298 \mathrm{~K}$ in a short time with no induction period. A comparative study performed with Ru/PVP NPs, Ni/PVP NPs and a physical mixture of both evidenced the superior performance of the RuNi/PVP nanocatalyst, attributed to its alloy character that provided a synergistic effect. A TOF value of $458.57 \mathrm{~h}^{-1}$ makes it to be among the best catalysts reported in the literature for dehydrocoupling of DMAB. This catalytic system also showed a low Ea value of $36.52 \pm 3$ $\mathrm{kJ} \cdot \mathrm{mol}^{-1}$, an activation enthalpy $\left(\Delta \mathrm{H}^{*}=34.02 \pm 2 \mathrm{~kJ} \cdot \mathrm{mol}^{-1}\right)$ and activation entropy $\left(\Delta \mathrm{S}^{*}\right)=-84.47$ J.mol-1). High negative values of activation entropy and small activation enthalpy value refer to an associate mechanism in the dehydrocoupling of DMAB. These RuNi/PVP NPs also appeared to be a reusable catalyst with $78 \%$ of initial activity preserved after four catalytic runs and no leaching observed. 
The same group also published the catalytic performances of alloyed PdRu/PVP NPs (ca. $3.8 \pm$ $1 \mathrm{~nm}$ ) in the dehydrocoupling of DMAB (THF, $298 \mathrm{~K}) \cdot{ }^{292}$ The synthesis of the NPs was performed by an ultrasonic double reduction technique (reduction of aqueous solution of $\mathrm{RuCl}_{3}$ and $\mathrm{K}_{2} \mathrm{PdCl}_{4}$ under ultrasounds at $363 \mathrm{~K}$ in the presence of PVP). Their catalytic behaviour was compared to those of Pd/PVP NPs, Ru/PVP NPs and a physical mixture of both in similar conditions. No induction time and complete DMAB conversion were observed. Kinetic parameters were found to be: TOF $=803.03 \mathrm{~h}^{-1}, \mathrm{Ea}=60.49 \pm 2 \mathrm{~kJ}^{\mathrm{mol}} \mathrm{m}^{-1}, \Delta \mathrm{H}^{*}=57.99 \pm 2 \mathrm{~kJ} . \mathrm{mol}^{-}$ ${ }^{1}$ and $\Delta \mathrm{S}^{*}=-53.17 \mathrm{~J}_{\mathrm{mol}}{ }^{-1}$. Reusability tests indicated ca. $80 \%$ of initial activity kept after four runs. Theoretical calculations by DFT using Pd/PVP, Ru/PVP and PdRu/PVP model clusters in optimized geometries were performed in order to determine adsorption energy of DMAB. The obtained theoretical results supported well the experimental results. The PdRu/PVP cluster presented a markedly lower chemical potential, adsorption energy and enthalpy values than those of Pd/PVP and Ru/PVP clusters. Also, higher chemical hardness and electronegativity values were observed for PdRu/PVP cluster compared to those of monometallic counterparts. All these differences may explain the outstanding efficiency of the PdRu/PVP NPs.

A summary of the catalytic properties of the previously described soluble Ru nanocatalysts is given in Table 16. The obtained results clearly evidence that colloidal ruthenium is a good metal for the dehydrogenation of DMAB. Interestingly, even if only a few ligands were tested, variation of capping ligand led to a variation in reactivity. Also, these results show the progress attained in terms of performance when associating a second metal like Ni or Pd to Ru. Similar studies with ligand-stabilized alloys could be of interest to perform.

Table 16. Comparison of kinetic data in dehydrocoupling of DMAB by soluble Ru NPs (298 K; THF except for Ru/oleylamine, toluene; total conversion). 


\begin{tabular}{|c|c|c|c|c|c|c|}
\hline Ru/APTS & $2.9 \pm 0.9$ & 53.1 & - & - & - & 288 \\
\hline Ru/B-N polymers & $2.9 \pm 0.9$ & 35.1 & & & & 289 \\
\hline Ru/oleylamine & $1.8 \pm 0.23$ & 137 & 29 & - & - & 290 \\
\hline RuNi/PVP & $3.5 \pm 0.4$ & 458.57 & 36.52 & 34.02 & -84.47 & 291 \\
\hline PdRu/PVP NPs & $3.8 \pm 1$ & 803.03 & 60.49 & 57.99 & -53.17 & 292 \\
\hline
\end{tabular}

F. Sen and coworkers also reported on the application of monometallic, bimetallic and even trimetallic Ru-based supported NPs in dehydrocoupling of DMAB (THF, $298 \mathrm{~K}) .{ }^{293-298}$ If these data are here cited it is because these catalysts were prepared in mild reaction conditions by reduction of the metal source(s) in the presence of the chosen support sometimes together with a polymer (PVP) or ligand (oleylamine), thus leading to controlled NPs. Graphite, ${ }^{293}$ graphene, ${ }^{298}$ functionnalized multiwalled carbon nanotubes (f-MWCNT), ${ }^{294,}{ }^{256}$ or graphene oxide (GO) were used as a support. ${ }^{295-297}$ The kinetic parameters measured for these catalysts are summarized in table 17. It can be seen that different values are obtained depending on the composition of the nanocatalyst both in terms of metal composition and nature of metalsupport interaction. Also, in Șen's group papers, comparisons with other catalysts reported in the literature are described highlighting the interest of Ru-based nanocatalysts for DMAB dehydrocoupling. However it is difficult to rationalize the observed effects since several parameters are different. In fact the works performed correspond more to trial-error works than real systematic comparison. More rationalization is thus required in order to define precisely the important parameters to master in order to get the best performance.

Table 17. Comparison of kinetic data in dehydrocoupling of DMAB (THF, $298 \mathrm{~K}$, total conversion) for diverse supported nanocatalysts studied by F. Șen and coworkers.

\begin{tabular}{ccccccc}
\hline Nanocatalyst & NP mean size $(\mathbf{n m})$ & TOF (h-1) & Ea (kJ.mol-1) & $\Delta$ H* $^{*}\left(\mathbf{k J . m o l} \mathbf{m}^{-1}\right)$ & $\Delta \mathbf{S}^{*}\left( \pm 2\right.$ J.mol $\left.{ }^{-1}\right)$ & Ref. \\
\hline Ru/oleylamine-graphite & $3.75 \pm 0.73$ & 281.5 & 13.82 & 11.33 & -220.68 & 293
\end{tabular}




\begin{tabular}{ccccccc} 
Ru/PVP-GO & $2.09 \pm 0.23$ & 896.54 & 11.45 & 8.96 & -194.02 & 298 \\
RuCo/f-MWCNT & $3.72 \pm 0.37$ & 775.28 & 13.72 & 11.2 & -173.53 & 294 \\
RuCu/r-GO & $3.86 \pm 0.47$ & 256.70 & 16.68 & 19.18 & -205.73 & 295 \\
RuPtNi/GO & $3.40 \pm 0.32$ & 727 & 49.43 & - & - & 296 \\
PdRuNi/GO & $3.78 \pm 0.43$ & 737.05 & 55.47 & 53.36 & -33.76 & 297 \\
\hline
\end{tabular}

\subsubsection{Dehydrogenation of amine boranes by methanolysis}

Only a few papers report on the dehydrogenation of amine boranes with nanoscale ruthenium using methanol as a solvent. Compared to hydrolysis (vide infra) the methanolysis presents a few merits such as a single gaseous product $\left(\mathrm{H}_{2}\right)$, recoverable by-products and the possibility of handling at low temperatures $(<273 \mathrm{~K}){ }^{299}$

H.-C. Zhou and coworkers described the synthesis of ultra-small fcc Ru NPs confined into the pores of a soluble and negatively charged porous coordination cage (PCC) of $4.2 \mathrm{~nm}$ in size that presents three different cavity diameters (ca. $2.5 \mathrm{~nm}$ and $1.4 \mathrm{~nm}$ for inner and intermolecular cavities, respectively). ${ }^{299}$ The preparation of this nanocatalyst consisted in the addition of $\mathrm{RuCl}_{3}$ to a DMF solution of PCC-2 $\left(\mathrm{Na}_{24}\left(\mathrm{Et}_{3} \mathrm{NH}\right)_{6}\left[\mathrm{Co}_{4}(\mu 4-\mathrm{OH}) \mathrm{V}_{6} \mathrm{~L}_{8}\right] 30-5 . \mathrm{MeOH} .10\right.$ $\mathrm{H}_{2} \mathrm{O}$ with $\mathrm{V}=$ phenolate groups and $\mathrm{L}=$ carboxylates) using a Ru/PCC- 2 molar ratio of $2 / 1$, followed by addition of $\mathrm{NaBH}_{4}$ also in DMF solution (Figure 29). This protocol led to a homogeneous colloidal dispersion containing PCC-2-stabilized Ru NPs with a narrow size distribution and a mean size of ca. $2.5 \mathrm{~nm}$ that corresponds well to the mean diameter of the inner cavities of the host. HREM analysis clearly showed that Ru/PCC-2 NPs have a truncated octahedral fcc structure, not usual for Ru NPs, which was also confirmed by powder XRD. XPS analysis indicated a major content of metallic $\mathrm{Ru}$. No precipitation from the colloidal suspension was observed up to 6 months in ambient air. The isolation of the NPs could be performed by addition of acetonitrile to the DMF suspension, which allowed the precipitation 
of a black solid redissolvable in DMF. These Ru/PCC-2 NPs were investigated in the dehydrogenation of ammonia borane by simply adding the DMF/MeOH colloidal suspension to solid AB. The catalysis was carried out at $298 \mathrm{~K}$. Reaction was completed after $4.5 \mathrm{~min}$ showing a TOF value of $304.4 \mathrm{~mol} \mathrm{H}_{2}$ per mol Ru per min, which appeared to be higher than the TOF value of $205 \mathrm{~min}^{-1}$ reported by $\mathrm{Xu}$ and coworkers using a PCC-stabilized Rh nanocatalyst for catalysing the same reaction. ${ }^{300}$ The catalytic performance of the Ru/PCC-2 nanocatalyst, being the best catalytic activity ever reported for the methanolysis of $A B$, was attributed to the small size and the fcc structure of the particles. Furthermore, the anionic and soluble PCC-2 played a critical role in encapsulating, stabilizing, homogenizing, and distributing the metal nanoclusters by regulating the size and the atomic arrangement of the encapsulated NPs. The soluble catalyst Ru/PCC-2 was also five times without a significant loss of activity.
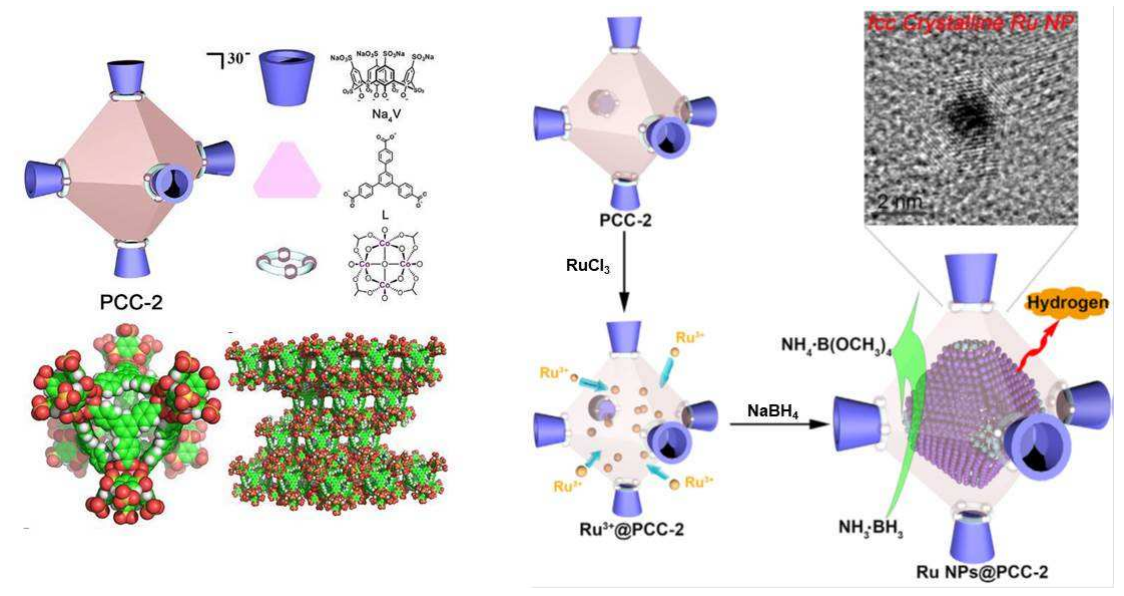

Figure 29. left : representation of the PCC-2 cage ; right : scheme of the synthesis of Ru/PCC2 NPs and their investigation as catalyst in dehydrogenation of AB. Adapted with permission from ref ${ }^{299}$. Copyright 2018 Elsevier.

The results of $\mathrm{F}$. Wang and coworkers are also among the best ones in methanolysis of $A B$. Their nanocatalyst was prepared by direct deposition of ultrafine Ru NPs onto tetrabutylammonium hydroxide-intercalated graphene as a support by the reduction of $\mathrm{RuCl}_{3}$ in water with $\mathrm{KBH}_{4}$ at $303 \mathrm{~K} .{ }^{301}$ The obtained $\mathrm{Ru} /$ graphene nanomaterial displayed well- 
dispersed Ru NPs onto the support with a mean size of ca. $1.6 \mathrm{~nm}$. This nanomaterial was investigated in the methanolysis of $A B$. Up to 35,600 total turnovers over a period of $300 \mathrm{~h}$ and a TOF value of $99.4 \mathrm{~min}^{-1}$ were obtained at $293 \mathrm{~K}$ before deactivation, and a Ea value of $54.1 \pm 22 \mathrm{~kJ} \cdot \mathrm{mol}^{-1}$. Additionally this nanocatalyst showed a satisfactory stability and retained $73.2 \%$ of its initial activity at the $15^{\text {th }}$ run.

\subsubsection{Dehydrogenation of amine boranes by hydrolysis}

Regarding hydrolytic dehydrogenation of $A B$, numerous studies are conducted on diverse monometallic and heterometallic nanocatalysts (mainly $\mathrm{Pt}, \mathrm{Ru}, \mathrm{Rh}, \mathrm{Ag}, \mathrm{Pd}$ ) that display high catalytic activity, among which numerous ones are Ru-based catalysts. Various stabilizers and supports are used in order to control the size, morphology and stability of the NPs. The addition of a second metal to ruthenium appeared to be positive to boost the catalysis.

As first example of soluble Ru NPs one can cite the metastable Ru NPs reported by O.A. Scherman and coworkers ${ }^{302}$ This work relates on a very facile catalytic system made of highly stable Ru NPs (up to 8 months) despite the absence of any extra stabilizer. In fact, the authors simply decomposed $\mathrm{RuCl}_{3}$ by $\mathrm{NaBH}_{4}$ in a $\mathrm{H}_{2} \mathrm{O} / \mathrm{EtOH}$ mixture (1/1) at r.t. (Figure 30).

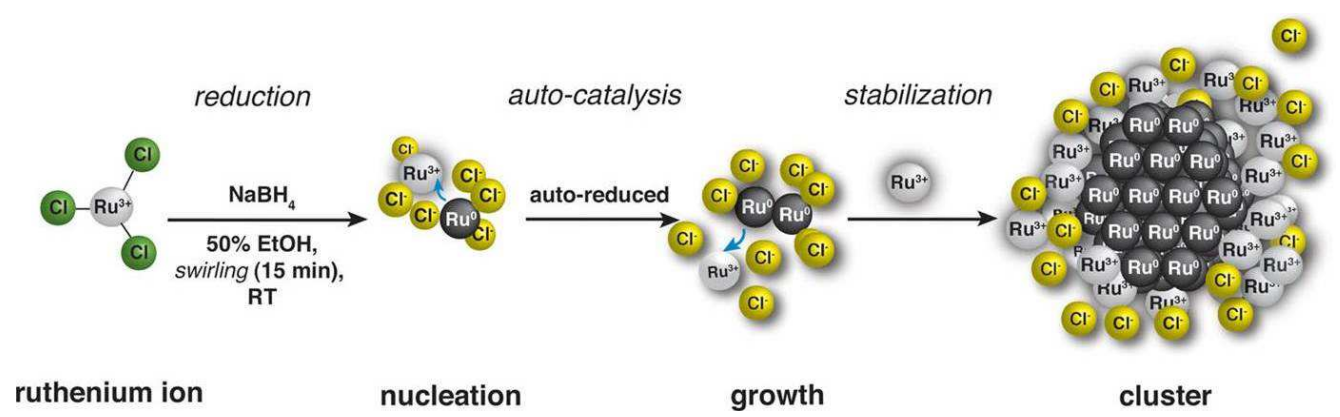

Figure 30. Synthesis of metastable Ru NPs. Reprinted with permission from ref ${ }^{302}$. Copyright 2014 Wiley.

The presence of monodisperse Ru NPs of ca. $2.2 \mathrm{~nm}$ was evidenced by HREM. The initial concentration of $\mathrm{RuCl}_{3}$ played a crucial role in the control of the NP size. A fcc structure was 
determined by HAADF-STEM and XPS showed a signal corresponding to Ru(0) for ca. $19.4 \%$ together with a signal attributed to remaining $\mathrm{RuCl}_{3}$, which probably acts as stabilizer for the Ru NPs. The $\%$ of Ru(0) species increased to over $75 \%$ after a complete catalytic cycle. These Ru NPs allowed the hydrolysis of AB yielding hydrogen gas with a TON of $21.8 \mathrm{~min}^{-1}$ at $298 \mathrm{~K}$. The high surface area available at Ru surface translated an Ea value of $27.5 \mathrm{~kJ}^{\mathrm{mol}}{ }^{-1}$, which was notably lower than that of other Ru NPs based catalysts.

As another example of AB hydrolysis with monometallic Ru NPs, by S. Ozkar, M. Zahmakiran and coworkers reported on the use of dihydrogenophosphate-stabilized Ru NPs. ${ }^{303}$ This catalytic system was prepared by reduction of an aqueous solution of $\mathrm{RuCl}_{3}$ and $\left(\left(\mathrm{C}_{4} \mathrm{H}_{9}\right)_{4} \mathrm{~N}\left[\mathrm{OP}(\mathrm{OH})_{2} \mathrm{O}\right]\right.$ with $\mathrm{DMAB}$ at r.t., leading to a stable colloidal dispersion of Ru NPs (ca. $2.9 \mathrm{~nm}$ ) with no precipitation after two days of storage. When investigated in the hydrolysis of $A B$ at r.t., this catalytic system presented an initial TOF value of $80 \mathrm{~min}^{-1}$. Moreover the high stability of these Ru NPs made them long-lived and reusable nanocatalyst for the hydrolysis of $A B$, providing 56,800 total turnovers over $36 \mathrm{~h}$ before deactivation, an initial TOF value of

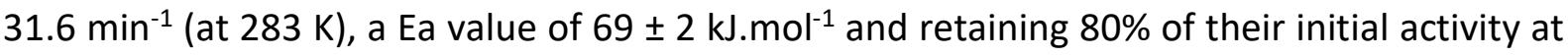
the $5^{\text {th }}$ catalytic run. These authors also published on the hydrolytic dehydrogenation of DMAB catalysed by similar $\left(\left(\mathrm{C}_{4} \mathrm{H}_{9}\right)_{4} \mathrm{~N}\left[\mathrm{OP}(\mathrm{OH})_{2} \mathrm{O}\right]\right.$-stabilized Ru NPs but synthesized in situ, i.e. in the catalysis medium, $(\mathrm{Ru} /$ stabilizer ratio $=1 / 20) \cdot{ }^{304} \mathrm{RuCl}_{3}$ was reduced by addition of $\mathrm{DMAB}$, being also the catalysis substrate, leading to the formation of Ru NPs of ca. $2.9 \mathrm{~nm}$ mean size. Kinetic studies revealed an initial TOF value of $500 \mathrm{~h}^{-1}$ at $298 \mathrm{~K}$ and stability studies an exceptional catalytic lifetime with 11600 total turnovers.

M. Rakap published the use of PVP-protected PtRu NPs for the hydrolysis of AB. ${ }^{305}$ This catalyst was synthesized by alcoholic reduction of $\mathrm{RuCl}_{3}$ and $\mathrm{PtCl}_{6}$ in the presence of PVP under mild conditions (EtOH; $363 \mathrm{~K} ; 2 \mathrm{~h}$ ). The obtained colloidal suspension was found stable for months 
at r.t. Isolation of the particles was performed by simple solvent evaporation. Characterization techniques (TEM-EDX, ICP, XRD, XPS) revealed ca. $3.2 \mathrm{~nm}$ in size alloyed PtRu NPs with a Pt/Ru composition of $1 / 1$ as well as the presence of $\mathrm{Pt}(0)$ and $\mathrm{Ru}(0)$ species but no higher oxidation states. The catalytic activity of PtRu/PVP NPs in the hydrolytic dehydrogenation of AB (at 298 K) was much higher than that reached with a physical mixture of monometallic Ru/PVP NPs (ca. $4.6 \mathrm{~nm}$ ) and Pt/PVP NPs (ca. $4.2 \mathrm{~nm}$ ) prepared in the same conditions, thus indicating a synergistic effect attributed to Pt-Ru interaction in the alloy although the reduced mean size of the PtRu/PVP NPs may also have an effect. It is worth to note that PtRu/PVP nanocatalyst led to complete hydrogen release $\left(3 \mathrm{~mol} \mathrm{H}_{2} \cdot \mathrm{mol} \mathrm{AB}^{-1}\right.$ ) for the hydrolysis of $0.100 \mathrm{MAB}$ solutions in $195 \mathrm{~s}$, corresponding to a record average TOF of $308 \mathrm{~min}^{-1}$ with a low Ea value of $53.3 \mathrm{~kJ} \cdot \mathrm{mol}^{-1}$. Recyclability tests showed a remaining activity of $72 \%$ after the $5^{\text {th }}$ catalytic cycle. The same author also reported on the hydrolysis of $A B$ using RuRh/PVP NPs. ${ }^{306}$ The nanocatalyst was prepared following the same synthesis method as described for RuPt/PVP one and the catalysis performed in the same conditions also. This catalyst was shown to be efficient and durable providing an average TOF value of $386 \mathrm{~min}^{-1}$ and Ea value of $47.4 \mathrm{~kJ}^{\mathrm{mol}}$ ${ }^{1}$ thus reflecting a higher efficiency than the previous PtRu system just by changing Pt by Rh in the alloy.

Similarly, F. Șen's group reported on the use of RuRh/PVP nanocatalyst for the hydrolysis of methylamineborane (MAB) at r.t. ${ }^{307}$ The NPs were also prepared by alcoholic reduction of a mixture of $\mathrm{RuCl}_{3}$ and $\mathrm{RhCl}_{3}$ in mild conditions $\left(\mathrm{H}_{2} \mathrm{O} / \mathrm{EtOH} ; 363 \mathrm{~K} ; 2 \mathrm{~h}\right)$ in the presence of PVP as stabilizer. HREM, XRD and EELS data indicated alloyed RuRh NPs of ca. 3.4 mean size and XPS data the presence of $\mathrm{Ru}(0)$ and $\mathrm{Rh}(0)$ species. Then this nanocatalyst was evaluated in hydrolysis of MAB at r.t., showing a high efficiency with an initial TOF value of $206.2 \mathrm{~min}^{-1}$, EA value of $43.5 \mathrm{~kJ} \cdot \mathrm{mol}^{-1}$ as well as $\Delta \mathrm{H}^{*}=41.18 \mathrm{~kJ} \cdot \mathrm{mol}^{-1}$ and $\Delta \mathrm{S}^{*}=-104.25 \pm 2 \mathrm{~J} \cdot \mathrm{mol}^{-1}$. Reusability 
tests indicated a $67 \%$ retaining of the initial catalytic activity after five cycles. All together, these characteristics place this nanocatalyst among the best for hydrolysis of MAB, a storage material which may lead to less volatile byproducts than $A B$. Indeed, the decomposition of $A B$ results in a distinct contamination of released $\mathrm{H}_{2}$ by $\mathrm{NH}_{3}$ and borazine which is a major problem for application in fuel cells.

All the results described above are summarized in table 18 . Here again it is difficult to rationalize these results given the different parameters used. Nevertheless, they prove the leader position of ruthenium for the hydrolysis of amine borane and the positive effect of the addition of a second metal like Rh or Pt.

Table 18. Comparison of kinetic data in hydrolysis of amineboranes at $298 \mathrm{~K}$.

\begin{tabular}{|c|c|c|c|c|c|c|}
\hline $\begin{array}{l}\text { Nanocatalyst } \\
\text { (substrate) }\end{array}$ & $\begin{array}{l}\text { NP mean size } \\
(\mathrm{nm})\end{array}$ & TOF $\left(\mathrm{min}^{-1}\right)$ & Ea (kJ.mol-1) & $\Delta H^{*}\left(\mathrm{~kJ} \cdot \mathrm{mol}^{-1}\right)$ & $\Delta \mathrm{S}^{*}\left( \pm 2{\left.\mathrm{~J} . \mathrm{mol}^{-1}\right)}^{-1}\right.$ & Ref. \\
\hline $\begin{array}{l}\text { Ru Metastable } \\
\text { (AB) }\end{array}$ & $2.2 \pm 0.5$ & 21.8 & 27.5 & - & - & 302 \\
\hline $\begin{array}{c}\mathrm{Ru} /\left(\left(\mathrm{C}_{4} \mathrm{H}_{9}\right)_{4} \mathrm{~N}\left[\mathrm{OP}(\mathrm{OH})_{2} \mathrm{O}\right]\right. \\
(\mathrm{AB})\end{array}$ & $2.1 \pm 0.9$ & 31.6 & 69 & - & - & 303 \\
\hline $\begin{array}{c}\mathrm{Ru} /\left(\left(\mathrm{C}_{4} \mathrm{H}_{9}\right)_{4} \mathrm{~N}\left[\mathrm{OP}(\mathrm{OH})_{2} \mathrm{O}\right]\right. \\
\text { (DMAB) }\end{array}$ & $2.9 \pm 0.9$ & 500 & - & - & - & 304 \\
\hline $\begin{array}{c}\text { PtRu/PVP } \\
\text { (AB) }\end{array}$ & $3.2 \pm 1.2$ & 308 & 53.3 & - & - & 305 \\
\hline $\begin{array}{l}\text { RuRh/PVP } \\
\text { (AB) }\end{array}$ & $3.4 \pm 0.4$ & 386 & 47.4 & - & - & 307 \\
\hline $\begin{array}{c}\text { RuRh/PVP } \\
\text { (MAB) }\end{array}$ & $3.4 \pm 0.3$ & 206.2 & 43.5 & 41.18 & -104.25 & 307 \\
\hline
\end{tabular}

As it will be described hereafter, a few papers describe the use of supported nanocatalysts that were pre-formed in solution in mild conditions. The preparation of these catalysts generally consists in two steps: 1) reduction of the Ru source to get the colloidal suspension 
and 2) impregnation of a given support from the colloidal suspension in order to deposit the NPs at the surface or in the pores of the material, followed by evaporation of the solvent. Control of Ru NPs is thus operated in solution before deposition on the support, and the influence of the support can be studied independently.

U.B Demirci and coworkers studied the catalytic performance of RuCo NPs and RuCu NPs with metal ratio $1 / 1$ prepared by the polyol process ([Ru(acac $\left.)_{3}\right],\left[\mathrm{Co}(\mathrm{acac})_{2}\right]$ and $\left[\mathrm{Cu}(\mathrm{acac})_{2}\right]$ with acetylacetonate (acac); ethylene glycol; $458 \mathrm{~K}$ ) in the absence of added stabilizer and then deposited onto $\mathrm{\gamma}-\mathrm{Al}_{2} \mathrm{O}_{3}$ as a support in the hydrolysis of $\mathrm{AB}(323-338 \mathrm{~K})$. A higher activity was observed for RuCo than for RuCu NPs, with activation energies of $47 \mathrm{~kJ} \cdot \mathrm{mol}^{-1}$ and $52 \mathrm{~kJ} \mathrm{~mol}^{-1}$, respectively. Moreover, the RuCu NPs presented a similar activity as Ru NPs prepared in the same conditions. The addition of Co thus had a positive effect on the catalytic behaviour of Ru that may result from synergistic interactions between Ru and Co atoms in the RuCo NPs.

G. Chen, D. Ma and coworkers prepared a series of NiRu/ligands alloy NPs at different metal ratios and deposited them onto a carbon black support for their evaluation in the hydrolysis of $A B .^{308}$ The NPs were prepared by reduction of a diphenylether solution of $\left[\mathrm{Ru}(\mathrm{acac})_{3}\right]$ and [Ni(acac $)_{2}$ ] complexes by triethyborohydride $\left(\mathrm{LiBEt}_{3} \mathrm{H}\right)$ in the presence of oleic acid and oleylamine as stabilizers at $523 \mathrm{~K}$. As confirmed by full characterization (HREM, XRD, XPS) such reaction conditions (strong reducing agent, high temperature) allowed to get alloyed NiRu NPs of ca. $9 \mathrm{~nm}$ mean size while Ru and $\mathrm{Ni}$ are immiscible in bulk form. The NPs were purified by precipitation with ethanol and redispersed in hexane for their further deposition onto the carbon support followed by solvent evaporation in order to get the final nanocatalysts. Catalysis was done in water at ca. $303 \mathrm{~K}$. A comparison with monometallic Ru NPs and Ni NPs as well as core-shell $\mathrm{Ni} / \mathrm{Ru}^{309}$ stabilized by the same ligand evidenced the superior catalytic activity of the NiRu alloy nanocatalysts (Figure 31). With a complete dehydrogenation of $A B$ in 
$12 \mathrm{~min}$, the best activity was obtained with the $\mathrm{Ni}$ richest nanocatalyst, namely $\mathrm{Ni}_{0.74} \mathrm{Ru}_{0.26}$ while Ni NPs were almost inactive and Ru NPs showed an intermediate activity. Moreover, the Ni@Ru NPs needed almost 3 times as long for a total conversion, thus showing the strong influence of the Ru-Ni interaction in the alloy. The determination of the activation energies, revealed a lower value for $\mathrm{NiRu}$ alloy nanocatalyst than for $\mathrm{Ni} / \mathrm{Ru}$ one. Thus, alloying $\mathrm{Ru}$ with $\mathrm{Ni}$ decreased the reaction activation energy and significantly enhanced the catalytic activity of Ru. A reusability test showed that the $\mathrm{Ni}_{0.74} \mathrm{Ru}_{0.26}$ still exhibited high catalytic activity after five catalytic cycles.

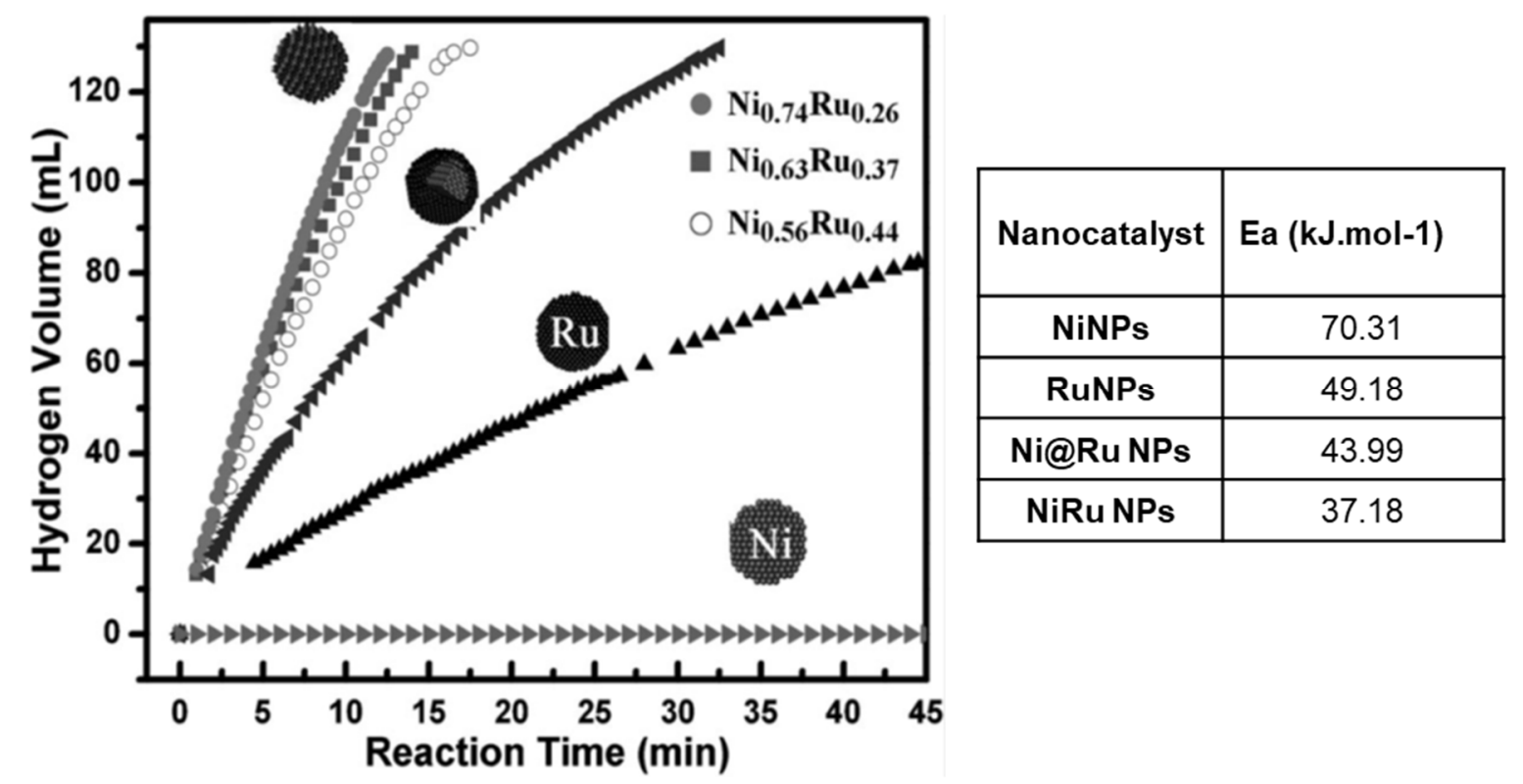

Figure 31. Comparison of catalytic activities (left) of activation energies (right) of monometallic $\mathrm{Ni}$, monometallic $\mathrm{Ru}, \mathrm{Ni} / \mathrm{Ru}$ core shell, and NiRu alloy NPs for AB hydrolysis at $30 \pm 1^{\circ} \mathrm{C}$. Adapted with permission from ref ${ }^{308}$. Copyright 2012 Wiley.

Recently, G. Chen and coworkers studied the effect of the size and of Ru crystal phase on the catalytic activity of $\mathrm{Ru} / \mathrm{PVP} / \gamma-\mathrm{Al}_{2} \mathrm{O}_{3}$ nanocatalyst in hydrolysis of $\mathrm{AB} \cdot{ }^{310}$ For this purpose, they prepared hcp Ru NPs and fcc Ru NPs exhibiting narrow size distributions and similar sizes (ca. $2.4 \mathrm{~nm})$. These Ru NPs were synthesized by decomposing $\left[\mathrm{Ru}(\mathrm{acac})_{3}\right]$ or $\mathrm{RuCl}_{3}$ at $473 \mathrm{~K}$ in triethyleneglycol (TEG) in the presence of PVP as a stabilizing agent. Ru NPs of different 
size/crystal phase were synthesized by adjusting the amount/nature of metal precursors, type of solvents and the amount of PVP. As demonstrated by characterization results, $\left[\mathrm{Ru}(\mathrm{acac})_{3}\right]$ led to fcc Ru NPs while $\mathrm{RuCl}_{3}$ provided hcp Ru NPs. The so-obtained Ru NPs were further deposited onto $\gamma-\mathrm{Al}_{2} \mathrm{O}_{3}$ by wet impregnation method before evaluating their catalytic performance in the hydrolysis of $A B$ at r.t. The hcp Ru NPs exhibited a higher activity than fcc Ru NPs at similar sizes. Also, with the size increase, the gap of activity became narrow. More interestingly, with the particle size change, an opposite variation of the activity trend for fcc and hcp structured $\mathrm{Ru} / \gamma-\mathrm{Al}_{2} \mathrm{O}_{3}$ was observed (Figure 32).

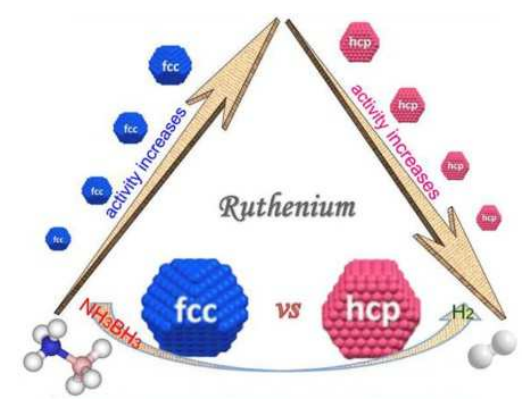

Figure 32. Schematic representation of the effect of Ru crystal structure (fcc vs hcp) on the hydrolysis of $A B$ by $\mathrm{Ru} / \mathrm{PVP} / \mathrm{Al}_{2} \mathrm{O}_{3}$ nanocatalysts. Reprinted with permission from ref

\section{${ }^{310}$. Copyright 2018 Elsevier.}

With the size increase, fcc Ru NPs presented an increased catalytic performance while hcp Ru NPs displayed a converse trend with a decreased performance at higher sizes. A reusability test showed that the fcc Ru NPs still exhibited high catalytic activity after four runs, although fcc Ru has a thermodynamically unstable structure. DFT calculations evidenced that fcc Ru NPs were easier to oxidize than hcp ones (values of adsorption energy of $\mathrm{O}_{2}$ onto (001) crystal plane of fcc and hcp Ru, were found to be $-2.17 \mathrm{eV}$ and $-1.81 \mathrm{eV}$, respectively). This difference in oxidation state could explain why hcp Ru NPs were more performant than fcc Ru NPs, without taking into account other parameters. Considering that the surface-to-volume ratio increases with the size decrease (so called "size effect") and that smaller NPs are more 
subjected to a higher oxidability than larger ones, the surface oxidation may play a dominant role on the fcc Ru NPs catalytic activity while the size effect may be responsible for the activity trend for hcp Ru NPs. Nevertheless other factors like the difference in step edges/step density between fcc and hcp Ru cannot be ruled out, but this requires more mechanism investigations. The results of this work are of particular interest because the influence of Ru crystal structure in Ru NPs is only recently studied while this parameter could have an important effect in the various possible catalytic applications of Ru NPs.

\subsubsection{Dehydrogenation of amine boranes by supported ruthenium nanocatalysts}

Despite the objective of this review is to highlight the interests of solution Ru NPs in catalysis, the high number of papers describing the use of supported-Ru NPs (mono- or heterometallic) for the dehydrogenation of amine boranes in the last decade makes that we cannot not mention it. ${ }^{284,311}$

The preparation of the nanocatalysts is generally done by decomposition of the Ru source (most often $\mathrm{RuCl}_{3}$ or $\left.\left[\mathrm{Ru}(\mathrm{acac})_{3}\right]\right)$ in the presence of a reducing agent $\left(\mathrm{NaBH}_{4}\right.$, polyol) and a chosen support (oxides - $\mathrm{Al}_{2} \mathrm{O}_{3}, \mathrm{SiO}_{2}, \mathrm{CeO}_{2}, \mathrm{TiO}_{2}-$, carbon-derivatives - $\mathrm{CNTs}$, $\mathrm{GO}$-, MOFs, etc. Among the recent papers, one can mention different works by S. Ozkar and coworkers who used nanohafnia, ${ }^{312}$ nanozirconia ${ }^{313}$ and silica coated $\mathrm{Fe}_{3} \mathrm{O}_{4}{ }^{314}$ as novel supports of Ru NPs and also that of L. Zhou and coworkers ${ }^{315}$ with a MOF support for the dehydrolytic dehydrogenation of $A B$ at r.t.

A second common preparation method is an in situ synthesis of the Ru NPs directly in the catalytic medium. The synthesis of the Ru NPs is carried out in the presence of a given support and using an amine borane as both reducing agent and catalysis substrate. In these conditions, the NP growth happens in parallel of the dehydrogenation of the amine borane and the catalysis is then pursued. For example G. Fan and coworkers investigated Ru NPs supported 
onto $\mathrm{TiO}_{2}$ nanotubes ${ }^{316}$ as well as $\mathrm{RuNi}^{317}$ and $\mathrm{RuCo}^{318}$ NPs deposited onto a graphene-like transition metal carbide $\left(\mathrm{Ti}_{3} \mathrm{C}_{2} \mathrm{X}_{2}\right.$; with $\mathrm{X}=\mathrm{OH}$ and/or $\left.\mathrm{F}\right)$. With $\mathrm{Ti}_{3} \mathrm{C}_{2} \mathrm{X}_{2}$ supporting material (hydrophilic surface), they observed a very good size control and dispersion of the NPs all over the support, and a good dispersion of the catalyst in the reaction medium, probably enhancing the contact between the metal surface and the substrate (AB). The so-obtained RuNi and RuCo nanocatalysts provided close catalytic performances, namely TOF/Ea values of $824.7 \mathrm{~mol}$ $\mathrm{H}_{2} .\left(\mathrm{mol}\right.$ metal.min $\left.{ }^{-1}\right) / 25.7 \mathrm{~kJ} . \mathrm{mol}^{-1}$ and $896.0 \mathrm{~mol} \mathrm{H}$. $\left(\mathrm{mol}\right.$ metal. $\left.\mathrm{min}^{-1}\right) / 31.1 \mathrm{~kJ} . \mathrm{mol}^{-1}$, respectively. Moreover, these two catalysts showed a good stability reaching $100 \%$ conversion of $A B$ after four catalytic cycles even if a decrease of velocity was observed. These catalytic performances are among the best ones claimed today for Ru-based nanocatalysts, as the result of enhanced contact between the metal surface and the substrate.

\subsubsection{Conclusions on amineborane dehydrogenation}

$\mathrm{Ru}$ is one of the most attractive catalysts in the dehydrogenation of amine boranes and most particularly of ammonia borane due to its high efficiency in accelerating the release of hydrogen from these substrates (either by dehydrocoupling or solvolysis). A high number of papers concern the hydrolytic dehydrogenation of ammonia borane because of its simplicity and green approach since it avoids the use of organic solvents as well as of its high efficiency. The preparation of better defined Ru NPs for this reaction has been extensively investigated using different stabilizers (mainly PVP as polymer and amines as ligands) to get stable colloidal solutions which were proven to be very active in this catalysis. But the influence of the stabilizing ligand is not studied yet in a systematic way, thus limiting the understanding of the ligand-activity relationships. Also a large panel of supports were tested to deposit the Ru NPs (either by wet impregnation or by direct synthesis of the nanoparticles in the presence of the support) and thus increase the stability of the catalysts as well as getting easier their 
separation from the reaction media for recycling concerns. Here also the support activity relationships are not well-studied. For economic purpose, some works provided promising results for the improvement of Ru activity and simultaneously minimize its use/cost by forming Ru-based bimetallic structures (RuCo, RuNi, PtRu, RuRh). If competitive results have been already obtained compared to those reached with nanocatalysts of other metals (in particular Rh ones), further research is still needed to improve synthesis methodologies to access more performant catalyst in terms of activity, lifetime and reusability. More rationalisation works are also needed because up to now it is very difficult to compare the numerous results described.

\subsection{Water splitting}

Fitting the green chemistry principles and known as the water splitting process, the production of hydrogen from water (Eq.6) is a very attractive route towards a clean energy vector and even more if envisaging its activation by sunlight. Besides the requirement in active, stable and if possible low-cost catalysts, the photo-activated water splitting needs to associate a light-harvester also called photosensitizer (PS) (organic, molecular complex or inorganic semiconductor material) for allowing the electron transfers.

The splitting of water is a redox process consisting in two successive half reactions, namely oxygen evolution reaction (OER) and hydrogen evolution reaction (HER). It starts by the oxidation of water to molecular oxygen at the anode (eq. (7a) and (7b) at neutral/acidic and basic $\mathrm{pH}$, respectively). Then the released electrons and protons produce molecular hydrogen at the cathode (Eq.(8a) and (8b) at neutral/acidic and basic $\mathrm{pH}$, respectively).

$$
\begin{aligned}
& 2 \mathrm{H}_{2} \mathrm{O} \rightarrow \mathrm{O}_{2}+2 \mathrm{H}_{2} \\
& 2 \mathrm{H}_{2} \mathrm{O} \rightarrow \mathrm{O}_{2}+4 \mathrm{H}^{+}+4 \mathrm{e}^{-}
\end{aligned}
$$




$$
\begin{aligned}
& 4 \mathrm{OH}^{-} \rightarrow \mathrm{O}_{2}+2 \mathrm{H}_{2} \mathrm{O}+4 \mathrm{e}^{-} \\
& 4 \mathrm{H}^{+}+4 \mathrm{e}^{-} \rightarrow 2 \mathrm{H}_{2} \\
& 4 \mathrm{H}_{2} \mathrm{O}+4 \mathrm{e}^{-} \rightarrow 2 \mathrm{H}_{2}+4 \mathrm{OH}^{-}
\end{aligned}
$$

These two key-steps are generally conducted into two different compartments separated by a proton exchange membrane of a (photo)electrochemical cell. They are kinetically slow because of their mechanistic complexity, especially for the oxidation half reaction, and the difficulty of evolving gases from a liquid phase. It is therefore of upmost importance to find suitable catalysts able to accelerate them. A main difficulty is having efficient catalysts with compatible kinetics in order to enable the complete splitting process to occur and so the total conversion of $\mathrm{H}_{2} \mathrm{O}$ into $\mathrm{O}_{2}$ and $\mathrm{H}_{2}$. Another issue is the stability of the catalysts given the harsh necessary conditions (acidic or basic $\mathrm{pH}$ ). For these reasons, numerous studies aim at evaluating the catalyst performances by studying only one part of the splitting process (either OER or HER).

Intensive research activity has been devoted to the use of molecular catalysts among which polypyridyl ruthenium complexes showed to be very active for OER. ${ }^{2,} 319$ Among heterogeneous catalysts, iridium oxide $\left(\mathrm{IrO}_{2}\right)$ anodes display excellent electroactivity for the OER. ${ }^{320}$ However, heterogeneous $\mathrm{RuO}_{2}$ also showed significant activity in the OER. ${ }^{321}$ Concerning the HER, in the solid phase, the most active metal in reducing protons and especially in acidic conditions is platinum. Nanomaterials have also received high attention among which Ru-based nanocatalysts emerged as true potential substitutes for the state-ofthe-art platinum and iridium oxide catalysts for OER and HER, under the form of oxide Ru or metal $\mathrm{Ru}$ species, respectively. As the application of $\mathrm{RuO}_{2} \mathrm{NPs}$ and $\mathrm{Ru} N P s$ as (photo)electrocatalysts for the water-splitting process has been reviewed very recently, ${ }^{322}$ we will not provide here a complete description of these nanocatalysts. Interestingly, among the 
Ru-based nanocatalysts evaluated in water splitting, only scarce examples describe controlled Ru NPs synthesized in mild conditions of wet chemistry for the HER. Because they correspond well to the objectives of the present review, these works will be hereafter briefly presented.

\subsubsection{Ru NPs as electrocatalysts for HER}

The use of Ru-based nanocatalysts for the HER is recent but fast evolving (most of the relevant literature was published in the period 2016-2019). This derives from advantageous characteristics of Ru compared to Pt, the state-of-the-art metal for this reaction. First, in HER the $\mathrm{M}-\mathrm{H}$ bond energy strongly affects proton reduction catalysis given that a high $\mathrm{M}-\mathrm{H}$ binding energy favours the adsorption of protons (but hardens the $\mathrm{H}_{2}$ desorption), while a low $\mathrm{M}-\mathrm{H}$ binding energy results in a contrary effect. With an optimum $\mathrm{M}-\mathrm{H}$ binding energy (neither too low nor too high), platinum stands at the center of the volcano plot for proton reduction catalysts. ${ }^{323-324}$ In comparison to $\mathrm{Pt}$, Ru displays a slightly weaker $\mathrm{M}-\mathrm{H}$ bond which hardly decreases the HER catalytic efficiency, both according to experimental results and DFT calculations. ${ }^{12}$ Furthermore, Ru showed to be stable both under acidic and basic conditions while Pt is not optimally stable at basic pH. Finally, the Ru cost is lower than that of Pt. All together these characteristics have boosted the attractivity of Ru metal as HER electrocatalyst in the last three years.

Even if some photocatalytic examples exist, most of the described systems consist in Ru NPs deposited or supported/embedded onto conductive C-based (or even metallic) materials that are electrochemically triggered. However, a few papers report on non-supported systems prepared ex situ through various methods (thermal decomposition/calcination of anhydrous $\mathrm{RuO}_{2}$, Ru salt, or a Ru complex; electroreduction of a Ru salt, Ru perovskite-type precursor, or Ru complex) and then deposited onto the electrode for catalytic evaluation. But the tailored synthesis and rational catalytic fine-tuning of non-supported Ru-based NPs for water splitting 
is not a simple matter. First, the use of a stabilizer, typically a coordinating solvent, ligand, or the surface of a material, is mandatory to maintain nanoscale systems, preventing the formation of thermodynamically favoured bulk species. Also, the metal oxidation state at the NP surface may evolve and even reversibly switch (typically between metallic Ru and Ru (IV) in $\mathrm{RuO}_{2}$ ) in contact with air and/or under (electro)catalytic turnover conditions. So, as for all catalysis, disposing of an effective way to have model Ru-based NPs (with controlled size, shape, oxidation state, and surface composition) for the splitting of water is of utmost interest for performing fundamental studies in order to develop more efficient catalysts. In this regard, the use of an organometallic complex as precursor recently allowed getting interesting results. The decomposition of the $[\mathrm{Ru}(\mathrm{COD}) \mathrm{COT})]$ complex under hydrogen, in a MeOH/THF mixture without any stabilizer, allowed to get significantly active Ru NPs when deposited onto glassy carbon (GC) electrodes (Figure 33). ${ }^{325}$ Thus, the $21.4 \mathrm{~nm}$ porous Ru NPs in $0.5 \mathrm{M} \mathrm{H}_{2} \mathrm{SO}_{4}$ led values of $\eta_{0} \approx 0 \mathrm{mV}, \eta_{10}=83 \mathrm{mV}, b=46 \mathrm{mVdec}^{-1}, \mathrm{TOF}_{100 \mathrm{mV}}=0.87 \mathrm{~s}^{-1}$, a Faradaic efficiency of $97 \%$, and excellent durability for up to $12 \mathrm{~h}$ (Figure 33).

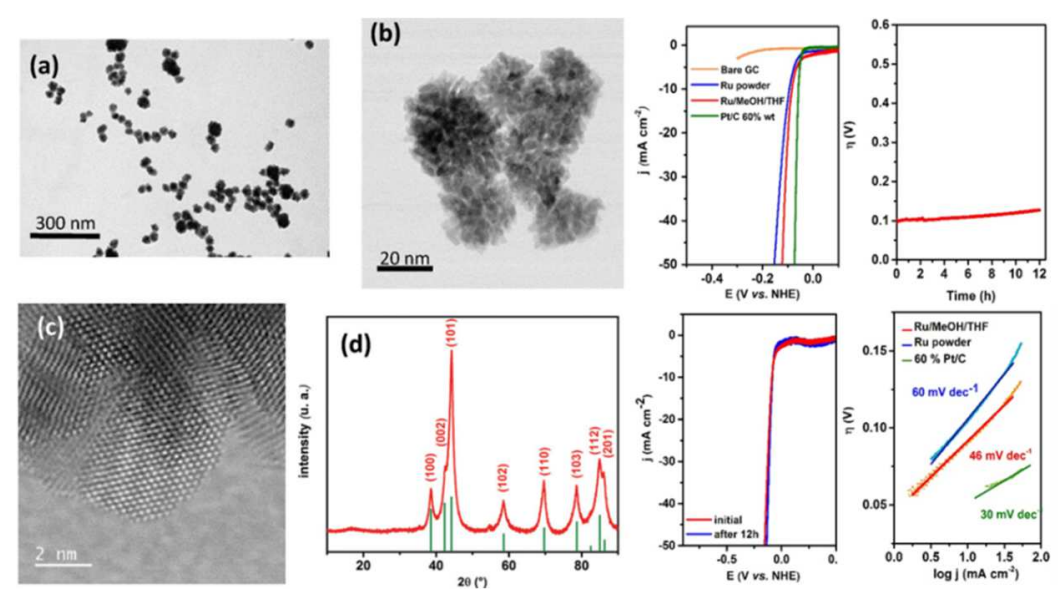

Figure 33. left : Tem/HREM images and powder-XRD diagram of MeOH/THF stabilized Ru NPs ; right : (a) LSV curves of the Ru/MeOH/THF nanomaterial (red), Ru powder (blue) and $\mathrm{Pt} / \mathrm{C}$ (green) in $0.5 \mathrm{M} \mathrm{H} 2 \mathrm{SO} 4$ solution at $10 \mathrm{mV} . \mathrm{s}^{-1}$. The LSV curve of a bare GC electrode (orange). (b) Galvanostatic experiment of the Ru/ MeOH/THF nanomaterial at a current 
density of $10 \mathrm{~mA} \cdot \mathrm{cm}^{-2}$ in $0.5 \mathrm{M} \mathrm{H}_{2} \mathrm{SO}_{4}$, without ohmic drop compensation (c) LSV curves of the initial $\mathrm{Ru} / \mathrm{MeOH} / \mathrm{THF}$ nanomaterial (red) and after $12 \mathrm{~h}$ of galvanostatic experiment (blue) in $0.5 \mathrm{M} \mathrm{H}_{2} \mathrm{SO}_{4}$ solution at $10 \mathrm{mV}^{-1}{ }^{-1}$. (d) Tafel plots of the Ru/MeOH/THF nanomaterial (red), Ru powder (blue) and $\mathrm{Pt} / \mathrm{C}$ (green) in $0.5 \mathrm{MH}_{2} \mathrm{SO}_{4}$ solution. Adapted with permission from ref ${ }^{325}$. Copyright 2017 Royal Society of Chemistry Also, the electrochemical analysis of 4-phenylpyridine (PP)-capped Ru NPs (mean size ca. 1.5 $\mathrm{nm}$ ) synthesized from the same complex and then drop-casted onto a GC electrode (PP-RuGC) together with their thoroughly characterization in air and under HER turnover conditions (in both acidic and basic electrolytes), evidenced the influence of the coordinated PP ligand on the catalytic performance. The surface of these Ru NPs spontaneously oxidized to $\mathrm{RuO}_{2}$ upon exposure to air, yielding a mixed $\mathrm{Ru} / \mathrm{RuO}_{2}$ system in which the PP ligand was still present. Although this mixed $\mathrm{Ru} / \mathrm{RuO}_{2}$ system was less active towards the HER compared with that of pure Ru NPs, it was converted into the metallic Ru form under reductive conditions (20 min bulk electrolysis at $-10 \mathrm{~mA} \cdot \mathrm{cm}^{-2}$ ) at acidic $\mathrm{pH}$ (Figure 34). ${ }^{326-327}$ Thus, the recovered PP-Ru-GC system exhibited values of $\eta_{0} \approx 0 \mathrm{mV}, \eta_{10}=20 \mathrm{mV}, b=29 \mathrm{mVdec}^{-1}$, and a TOF as high as $17.4 \mathrm{~s}^{-1}$ at $\eta=100 \mathrm{mV}$ in $1 \mathrm{M} \mathrm{H}_{2} \mathrm{SO}_{4}$, with complete stability after $12 \mathrm{~h}$ of continuous operation. In contrast, in $1 \mathrm{M} \mathrm{NaOH}$, the only stable form of the PP-Ru-GC system was a $\mathrm{Ru} / \mathrm{RuO}_{2}$ mixture, yielding a slightly less active and stable catalytic system, although still outperforming the performance and stability of commercial Pt/C. The presence of the PP capping agent is believed to induce a good mechanical stability; thus allowing the nanostructured character of the material to be maintained, even after a long run. This hypothesis is supported by DFT calculations, which showed the coordination of $11 \mathrm{PP}$ molecules onto the surface of a $\mathrm{Ru}_{55} \mathrm{H}_{53}$ NP both through $\mathrm{N}-\sigma$ and $\pi$-coordination modes; the latter was more stable and preferentially took place on the edges of the NP. Furthermore, the d-band energy levels of the surface Ru 
atoms were significantly modified by the presence of hydride ligands, which have a stabilizing effect, whereas these energy levels were not significantly altered by the PP capping ligands; thus indicating a moderate adsorption strength of the latter onto the NP surface. As a consequence, a larger number of hydride ligands were present on the NP surface compared with those of PP (53 vs. 11); thus accounting for the enhanced $\mathrm{H}_{2}$ evolution behavior. These results clearly show that a capping ligand like a phenylpyridine can tune the properties of a Ru nanocatalyst for the HER. Nevertheless, the real effect of the ligand needs to be deeper studied and comparative studies with other ligands need to be performed.
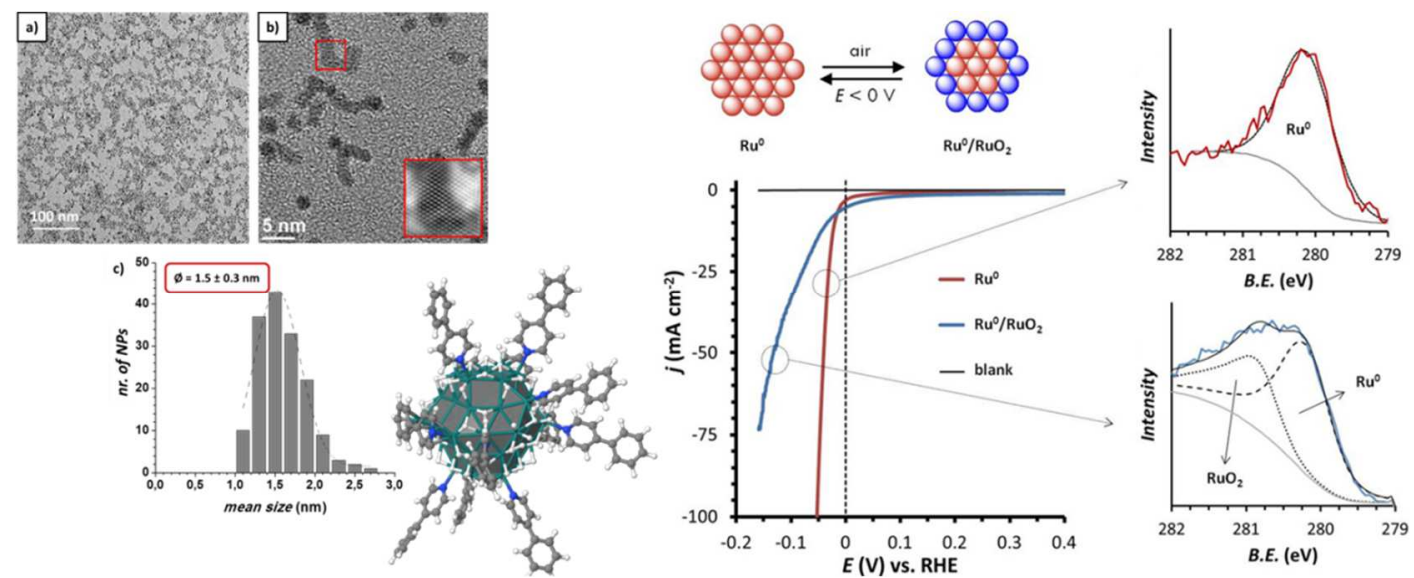

Figure 34. Left: TEM images of Ru-PP NPs at low (a) and high (b) magnification and size histogram ; DFT model of PP-protected $1 \mathrm{~nm}$ RuNP $\left(\mathrm{Ru}_{55} \mathrm{H}_{53} \sigma \mathrm{PP}{ }_{9} \pi \mathrm{PP}_{2}\right)$. Right : polarization curves in $1 \mathrm{~m} \mathrm{H}_{2} \mathrm{SO}_{4}$ at $10 \mathrm{mVs} 1$ and XPS data for metallic PP-Ru NPs and their Ru/RuO surface-passivated counterpart, which formed upon exposure to air. Adapted with permission from ref ${ }^{326}$ and ref ${ }^{322}$. Copyright 2018 American Chemical Society and Copyright

$$
2019 \text { Wiley. }
$$

Supported Ru-based nanomaterials prepared in more drastic conditions have been also reported as active species for the HER showing high influence of the nature of the support on the catalytic performance. The effect of the crystal structure of the Ru phase has also been demonstrated. Moreover, the interaction of metallic Ru with other metal/semimetal-based 
nanostructures in mixed catalysts was shown to increase the HER catalytic activity compared with that of the respective separated systems, as a result of the synergistic effect between metals, which improves the electron conductivity and lowers the $\mathrm{H}$ adsorption energy.

\subsubsection{Ru NPs as (photo)catalysts for HER}

Concerning the inclusion of Ru NPs in HER photocatalytic systems, it is not an easy task given the inherent difficulties in properly transferring electrons from a photosensitive molecule or material to the nanocatalyst, while avoiding undesired back-electron transfer processes. Indeed, the electron-transfer process between Ru NPs and the widely employed molecular PS $\left[\mathrm{Ru}(\mathrm{bpy})_{3}\right]^{2+}$ is generally not optimal. ${ }^{328}$ Thus, together with a sacrificial electron-donor (SED; e.g., reduced nicotinamide adenine dinucleotide $(N A D H))$ supplying the necessary electrons in half-cell systems, the use of an electron mediator (e.g., methyl viologen) is generally required. Only PSs with sufficient and long-lived charge-separated states after photoexcitation are able to inject electrons into the HER electrocatalyst without the need to use an electron mediator; thus making the systems less complex and more efficient. In this regard, Fukuzumi and coworkers reported on the use of a molecular dyad that acts both as a PS and as an efficient electron supplier for Ru NPs, namely the 2-phenyl-4-(1-naphthyl)quinolinium ion (QuPh+-NA; Figure 35). ${ }^{329}$ Using PVP-stabilized Ru NPs with QuPh+-NA PS in alkaline solution, they found optimal conditions for the photocatalytic HER. No increase in the photocatalytic activity above a certain optimal catalyst concentration (presumably due to light dispersion and opacity if more nanomaterial present in the reaction medium), and an activity-size dependency of the tested NPs were observed. Small NPs displayed a higher negative charge density, which eased the proton reduction process, but hindered the hydrogen-atom association step because of low density of hydrogen atoms on a single particle. Larger NPs eased the hydrogen-atom association step due to the presence of more hydrogen atoms on their surface, but hindered 
the previous proton reduction process because the negative charge density of the surface was initially lower. As a consequence, the best results were obtained with NPs of intermediate size, namely, $4.1 \mathrm{~nm} .{ }^{329}$ Finally, the deposition of the Ru NPs and QuPh+-NA onto oxide-based materials $\left(\mathrm{SiO}_{2}, \mathrm{TiO}_{2}, \mathrm{CeO}_{2}\right.$, etc.) led to less agglomeration under $\mathrm{HER}$ turnover conditions and enhanced photocatalytic stability with regard to the corresponding non-supported systems. ${ }^{328}$ Apart from the QuPh+-NA ion, only the dye Eosin $\mathrm{Y}^{330}$ and the combination of $\left[\mathrm{Ru}(\mathrm{bpy})_{3}\right]^{2+}$ with 9-phenyl-10-methylacridinium derivatives as electron mediators ${ }^{331}$ have led to relative success in the photocatalytic HER with Ru-based NPs.

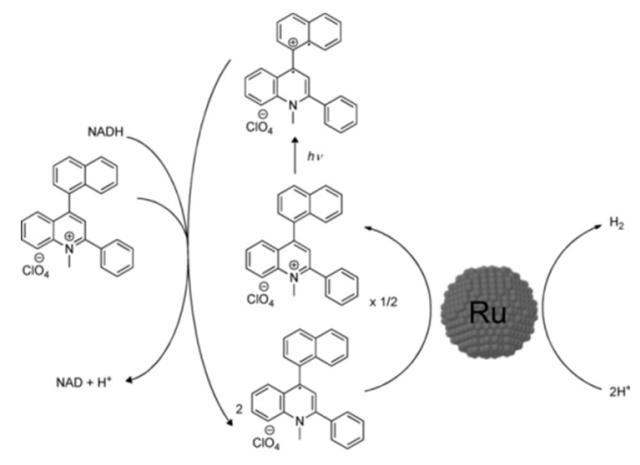

Figure 35. Electron-transfer processes involved in photocatalytic HER promoted by Ru NPs in the presence of the QuPh+-NA organic donor-acceptor photoabsorber decribed by Fukuzumi and coworkers. Adapted with permission from ref ${ }^{322}$. Copyright 2019 Wiley.

\subsubsection{Conclusions on water splitting}

Very recently, Ru NPs have received a renewed interest for their application as catalysts in the water splitting process. Available data on non-supported systems indicate amorphous $\mathrm{RuO}_{2}-$ based NPs and highly crystalline Ru NPs as the species of choice for attaining highperformance HER NP electrocatalysts. Remarkably, the mild conditions of solution chemistry provided interesting catalytic systems to conduct fundamental studies where an effect of capping ligand was observed. The catalytic performances achieved evidenced that Ru NPs may be a potential substitute of $\mathrm{Pt}$ which is still the most active metal for this reaction. Concerning 
the photoactivated version of the HER, even if still in their infancy in terms of development, tandem particle-based photocatalysts proved to be promising candidates.

\section{CONCLUDING REMARKS AND OUTLOOK}

In this review, we gathered main recent advances in the use of Ru-based NPs as catalysts in relevant catalytic reactions such as reduction, oxidation, Fischer-Tropsch, $\mathrm{C}-\mathrm{H}$ activation, $\mathrm{CO}_{2}$ transformation, dehydrogenation of amine boranes and water splitting. All together the research data here assembled clearly evidence the significance of Ru metal at the nanoscale for these reactions. If from the point of view of industrial applications and thus at large scale and for a long term, the use of noble metals like Ru in catalytic conversions is certainly not realistic due to economic reasons, Ru systems can allow developing fundamental researches in order to better apprehend the prerequisites for rendering a given catalysis more effective. Recent progress in solution nanochemistry allowed having at disposal better controlled Ru NPs (in terms of size, dispersion, shape, composition and surface state, etc.), all these characteristics influencing strongly their surface properties. Even if not always satisfying, this led to progress in the understanding of the relationships between their structure and their potential in catalysis (in terms of both reactivity and selectivity). Most particularly, the surface chemistry of Ru NPs starts to be better understood which gives a strong basis to better apprehend catalytic processes on the metal surface as well as how these can be affected by the presence of stabilizing molecules or by the crystallographic structure of the ruthenium cores, eventually by taking benefit of these parameters. However, this is only in its infancy and numerous studies are trial-error or screening works and the rationalization of the catalysis findings with the NP structural features is not often done. Such a rationalization is not possible from published works given synthesis conditions and parameters change from one study to 
another one. More efforts are thus required in order to bridge this gap. This is fundamental if one want to be able one day to anticipate about the needed Ru NP structure for making a target catalysis highly performant and also highly selective. But this is not true only for ruthenium, because such studies are generally missing in nanocatalysis whatever the metals used. For instance, regarding the influence of ligand, this is not an easy task because this requires to have pre-formed NPs that enable a complete ligand exchange or have a synthesis method that provides always the same size of particles whatever the stabilizing ligand added in the reaction mixture. To our best knowledge such means are not accessible yet. Concluding remarks and perspectives are hereafter given more specifically for the catalytic reactions described above.

Ru NPs are very versatile catalysts for reduction reactions. As reviewed above this versatility is illustrated with the large range of reduction reactions, including the hydrogenation of $\mathrm{C}=\mathrm{C}$, $\mathrm{C}=\mathrm{O},-\mathrm{NO}_{2}$ motives using several reducing agents. Due to the straightforward implementation of some of these reactions, for instance reduction of styrene by $\mathrm{H}_{2}$ or reduction of $-\mathrm{NO}_{2}$ groups by $\mathrm{NaBH}_{4}$, and the facility to compare the obtained results to other reported works, these reactions are often used as an indirect characterization way to get information on the surface properties of the nanocatalysts. Ru-based nanocatalysts for reduction reactions underwent important evolution in the last years. If first they were only stabilized with simple molecules, ruthenium nanocatalysts are now more complex because their design has strongly benefited from the development of nanochemistry tools. Such evolution is visible either by the use of new and sometimes sophisticated ligands that have been deliberately designed to obtain a desired property or by introducing a second (or more) metal, or by using a more reactive fcc structure. Water-soluble ligands or polymers, stabilizers containing long carbon chains, ligands with a specific electronic property are among examples that have been successfully explored. 
It is important to note that Ru NPs systems able to induce chirality are only elusive, even if some efforts have been done in this topic. All the knowledge obtained in these model reactions is currently been used to explore the applicability of Ru NPs in challenging reduction reactions such as hydrodeoxygenation together with $\mathrm{C}-\mathrm{O}$ cleavage of biomass derivatives. Bimetallic Ru-based systems proved to be very efficient catalysts as the result of the subtle balance of the properties of the metals used, their combination leading to synergistic effects. In contrast, unsupported Ru NPs as catalysts for oxidation reactions are scarce, and are essentially devoted to the oxidation of CO. The catalysts of this reaction are principally bimetallic systems with a specific tuning of the NPs, or the metal ratio, or the Ru structure, or both. Ru NPs with a fcc structure have proven to be highly reactive for this reaction. FischerTropsch reaction was demonstrated to be also sensitive to the crystalline structure of the Ru NPs, giving highly active catalysts when adopting the fcc structure. Also, the reaction is sensitive to the size of the Ru NPs which can be related to the CO energy adsorption in different surface positions. The ability of Ru NPs to activate $\mathrm{C}-\mathrm{H}$ bonds reported in the past has been recently exploited to produce labelled organic compounds in a highly selective manner. A general weakness of the Ru NPs colloidal based catalysis is the lack of knowledge on the catalytic active species that is operating. Characterization of the spent catalyst, recycling test, hot filtration, among other procedures, are far to be systematically performed, and when carried out they are not always done in the appropriate manner (a typical example is to carry out recycling tests at $100 \%$ conversion). In situ or in operando characterization techniques are, by now, scarce for these catalysts.

The chemical transformation of $\mathrm{CO}_{2}$ has not been investigated into detail over well-defined heterogeneous catalysts including nanoparticle-containing ones. This topic remains a challenging but of high interest task given the advantages provided by heterogeneous 
catalysts compared to homogeneous ones for industrial applications. State-of-the-art data revealed substantial limitations but no clear insights at the molecular level have been reported, hindering concrete progress. In particular, there is a clear lack of understanding of structure-reactivity correlations and of catalyst designing principles for this catalysis. As described above, recent results involving Ru-based nanocatalysts have shown that efforts performed for the precise design of solution and supported nanocatalysts can lead to the chemoselective $\mathrm{CO}_{2}$ hydrogenation into $\mathrm{HCOOH}, \mathrm{CO}, \mathrm{CH}_{4}$ or other hydrocarbons. Such studies make a paralell with those reported on Ru molecular complexes. Recent knowledge and knowhow in nanotechnology and nanocatalysis should lead to novel strategies in the design of efficient and more stable nanocatalysts for $\mathrm{CO}_{2}$ transformation. Prospective studies with a molecular approach may allow tuning more finely the catalytic properties of nanocatalysts. Mechanistic details being critical to the development of improved nanocatalysts, more investigations in this direction are also required in order to achieve higher catalytic performances. Even if catalytic activities are not elevated with this metal, Ru based nanocatalysts may offer the possibility to access spectroscopic NMR studies which can be very complementary to infrared studies in order to get mechanistic insights. Associate another metal ( $\mathrm{Pd}, \mathrm{Ni}$ or $\mathrm{Fe})$ to $\mathrm{Ru}$ is certainly a strategy to explore more in order to increase the catalytic performance (both reactivity and selectivity). Also separately optimize the metal active sites and the support may provide benefit. Finally, it is also needed to keep in mind that harmonization is necessary to ensure a constant and dynamic balance of all things to be considered, for a sustainable and green chemistry. The use of $\mathrm{H}_{2}$ issued from green sources like water also appears as a great solution to reach a closed nature's carbon cycle.

Concerning the $\mathrm{H}_{2}$ production by dehydrogenation of amine boranes, Ru-based nanocatalysts are highly efficient and stand at the top list. If extensive research efforts focused on the 
dehydrogenation of ammonia borane by hydrolysis (due to its simplicity and green character as well as efficiency), interesting results were also obtained by methanolysis or dehydrocoupling. These last approaches merit more efforts, at least at the fundamental level, in order to get mechanism insights, enable the development of more performant catalytic systems and improve hydrogen productivity. If numerous kinetics parameters are available and allow comparing the efficiency of the Ru nanocatalysts reported for the dehydrogenation of amine boranes in water, there is no clear insight explaining the high activity generally observed. What about the real effect of particle size, Ru crystal structure, surface area, stabilizer and/or support nature on the catalytic performances? Answers to these questions remain to be found in most cases. Moreover, the catalytic lifetime parameter has received a quite low attention until now, whereas NPs are not thermodynamically stable entities and can be readily deactivated, which may harm their long-term performance. If $A B$ solvolytic dehydrogenation is a promising hydrogen generation system (in particular for cases that require a convenient and reliable hydrogen source) the decomposition of $A B$ results in $a$ contamination of released $\mathrm{H}_{2}$ by $\mathrm{NH}_{3}$ and borazine which is a major problem for application in fuel cells. Thus further efforts are required in order to solve pending issues like breaking the strong $\mathrm{B}-\mathrm{O}$ bonds in byproducts of $\mathrm{AB}$ solvolysis and reducing $\mathrm{NH}_{3}$ release. Other important issues are the storage irreversibility and cost factor. Regeneration of $A B$ from byproducts of solvolysis, especially hydrolysis, is cost-ineffective as undesired byproducts of the recycling process cannot be converted to the main reactants. ${ }^{243}$ So, other hydrogen storage materials need to be studied in order to have less volatile byproducts than with AB. Only a few papers deal with $A M B$ and $D M A B$ that are alternative substrates, thus showing that more efforts have to be done in this direction. 
Ru-based NPs have clearly emerged as promising (electro)catalytic systems for the two halfcell reactions in water splitting and potential substitutes of standard Pt and $\operatorname{IrO} \mathrm{S}_{x}$ species used for catalyzing the HER and OER, respectively, in commercial electrolyzers. Most particularly, the development of Ru-based NPs as catalysts for the HER was highly dynamic in the last three years. Reports on non-supported catalytic systems showed that the active sites of the Ru NPs can be tuned with ease and the surface chemistry resembles that of molecular complexes. In this regard, the organometallic synthesis of nanostructures opens up numerous possibilities through the inexhaustible ligand pool of NP stabilizers. The combination of electrochemical analysis, detailed structural and surface characterization, and DFT modeling of the reaction pathways involved can lead to structure--activity/stability relationships; thus allowing the subsequent rational improvement of the electrocatalytic HER systems.

To conclude, even if less expensive than other noble metals, the high price and limited abundance of Ru probably hinder the practical applications of Ru NPs-based catalysts for industrial purposes. But studied systems are of high interest at the fundamental level because they allow doing nice breakthroughs and getting precious insights on the catalytic properties of Ru NPs. As a non-exhaustive example, $R u$ is a $4 \mathrm{~d}$ transition metal that in the bulk adopts an hcp structure at all temperatures, but thanks to the development of effective tools, Ru NPs with a crystallographic fcc structure could be prepared although they are thermodynamically unstable, thus highlighting the interest of modern nanochemistry. By this way, the crystal phase effect of Ru could be explored towards a few catalytic reactions (like CO oxidation, nitrophenol reduction, hydrolysis of ammoniaborane, oxygen evolution reaction), allowing to observe differences compared to hcp Ru NPs. These advances underline that not only the size of the NPs is of paramount importance if one wants to tune finely their catalytic performance but also how important is the control of their other characteristics such as their crystalline 
structure and their composition/surface state. Indeed, catalytic properties are closely correlated with the catalyst surface geometric and electronic structures and an optimal compromise among reactant adsorption rate, adsorbate-surface interaction and product desorption is necessary to promote catalytic activity. This is true whatever the target catalytic reaction. It thus requires to develop effective synthesis tools in order to have at disposal model NPs with an atomic precision level to be able to conduct precise comparative studies. Besides the synthesis aspects, in operando techniques could bring very useful information of the surface state of the NPs in catalysis conditions (IRFT, NMR, XPS, Environmental-HREM, EXAFS, etc.). Such approaches are still rare in the papers describing the interests of welldefined Ru NPs in catalysis. Interestingly, Ru is a metal which permits to take benefit of NMR techniques to access a fine mapping of the surface state of the NPs, as it is generally done for metal active centers in molecular catalysts. Moreover, in parallel of experimental techniques, theoretical studies can afford a better understanding of the influencing parameters of a given catalysis within the aim to develop more performant nanocatalysts in terms of activity and selectivity. Efficient theoretical tools are now accessible that allow getting an overview of a nanoscale surface with a resolution close to that usually got for molecular catalysts or extended metal surfaces. As a final message, we thus do believe that future developments crossing experimentally well-defined model metal nanoparticles together with theoretically close simulated nanoclusters will enable nice breakthroughs for the development of more performant nanocatalysts and that Ru is a highly interesting metal to do so.

\section{ACKNOWLEDGMENTS}


The authors acknowledge the Laboratory of Coordination Chemistry (LCC-UPR8241), the Centre National de la Recherche (CNRS) and the University de Toulouse - Université Paul Sabatier for financial support.

\section{Biographies}

Karine Philippot is research director at CNRS, at the Laboratory of Coordination Chemistry of Toulouse, where she is the head of the team "Engineering of Metal Nanoparticles". Being involved in different projects, her current research interests cover the design of metal nanoparticles and composite nanomaterials by using molecular chemistry concepts and their applications, mainly in colloidal or supported catalysis and for energy production $\left(\mathrm{CO}_{2}\right.$ valorisation, water-splitting, fuel cells). She is co-author of 175 peer reviewed papers (including 7 reviews, 9 book chapters, 6 patents) and over 200 presentations at national and international conferences. She also co-edited a special issue devoted to "Catalysis in solution by defined nanoparticles" (Topics in Catalysis, 2013) and the book "Nanomaterials in Catalysis" (Wiley, 2013).

M. Rosa Axet did her PhD in Tarragona with a thesis on chiral catalysis and nanocatalysis (Prof. Claver and Prof. Castillón). After a postdoctoral fellowship in Trieste (Prof. Milani), Toulouse (Dr. Chaudret and Dr. Philippot), and Paris (Dr. Amouri) she joined CNRS - France as an associate researcher at the Laboratoire de Chimie de Coordination in Toulouse, where she started her research activities focusing on nanocatalysis. Her current research activities include organometallic and nanomaterials chemistry areas, mainly for applications in catalysis. She is interested in the study of the structure-properties relationships in several 
nanomaterials including bimetallic, supported or shape-controlled nano-objects, with special attention to the effects of the stabilizing ligands of the nanoparticles on their properties.

\section{REFERENCES}

(1) Johnson Matthey. Pgm Market Report. http://www.platinum.matthey.com/services/market-

\section{$\underline{\text { research/pgm-market-reports. }}$}

(2) Matheu, R.; Ertem, M. Z.; Gimbert-Suriñach, C.; Sala, X.; Llobet, A., Seven Coordinated Molecular Ruthenium-Water Oxidation Catalysts: A Coordination Chemistry Journey. Chem. Rev. 2019, $119,3453-3471$.

(3) Rathore, N.; Panwar, N. L.; Yettou, F.; Gama, A., A Comprehensive Review of Different Types of Solar Photovoltaic Cells and their Applications. Int. J. Ambient Energy 2019, 1-18.

(4) Qian, Q.; Zhang, J.; Cui, M.; Han, B., Synthesis of Acetic Acid via Methanol Hydrocarboxylation with $\mathrm{CO}_{2}$ and $\mathrm{H}_{2}$. Nat. Commun. 2016, 7, 11481 .

(5) Naota, T.; Takaya, H.; Murahashi, S.-I., Ruthenium-Catalyzed Reactions for Organic Synthesis. Chem. Rev. 1998, 98, 2599-2660.

(6) Sordakis, K.; Tang, C.; Vogt, L. K.; Junge, H.; Dyson, P. J.; Beller, M.; Laurenczy, G., Homogeneous Catalysis for Sustainable Hydrogen Storage in Formic Acid and Alcohols. Chem. Rev. 2018, 118, 372433.

(7) Griffith, W. P.; Editor, Ruthenium Oxidation Complexes: Their Uses as Homogeneous Organic Catalysis. Kluwer: 2010.

(8) Muhler, M.; Rosowski, F.; Hinrichsen, O.; Hornung, A.; Ertl, G., Ruthenium as Catalyst for Ammonia Synthesis. Stud. Surf. Sci. Catal. 1996, 101, 317-326.

(9) Seddon, E. A.; Seddon, K. R.; Clark, R. J. H., The Chemistry of Ruthenium. Elsevier Science: 2013.

(10) CLAL, C. Prix de l'or et cours des métaux précieux https://www.cookson-clal.com/cours/. 
(11) Zhao, M.; Chen, Z.; Lyu, Z.; Hood, Z. D.; Xie, M.; Vara, M.; Chi, M.; Xia, Y., Ru Octahedral Nanocrystals with a Face-Centered Cubic Structure, $\{111\}$ Facets, Thermal Stability up to $400{ }^{\circ} \mathrm{C}$, and Enhanced Catalytic Activity. J. Am. Chem. Soc. 2019, 141, 7028-7036.

(12) Zheng, Y.; Jiao, Y.; Zhu, Y.; Li, L. H.; Han, Y.; Chen, Y.; Jaroniec, M.; Qiao, S.-Z., High Electrocatalytic Hydrogen Evolution Activity of an Anomalous Ruthenium Catalyst. J. Am. Chem. Soc. 2016, 138, 16174-16181.

(13) Kusada, K.; Kobayashi, H.; Yamamoto, T.; Matsumura, S.; Sumi, N.; Sato, K.; Nagaoka, K.; Kubota, Y.; Kitagawa, H., Discovery of Face-Centered-Cubic Ruthenium Nanoparticles: Facile SizeControlled Synthesis Using the Chemical Reduction Method. J. Am. Chem. Soc. 2013, 135, 5493-5496.

(14) Fievet, F.; Ammar-Merah, S.; Brayner, R.; Chau, F.; Giraud, M.; Mammeri, F.; Peron, J.; Piquemal, J. Y.; Sicard, L.; Viau, G., The Polyol Process: a Unique Method for Easy Access to Metal Nanoparticles with Tailored Sizes, Shapes and Compositions. Chem. Soc. Rev. 2018, 47, 5187-5233.

(15) France, S. C. d. Ruthénium. http://www.societechimiquedefrance.fr/rhutenium.html.

(16) Graf, C.; Dembski, S.; Hofmann, A.; Ruehl, E., A General Method for the Controlled Embedding of Nanoparticles in Silica Colloids. Langmuir 2006, 22, 5604-5610.

(17) Ruthenium Catalysts [Special issue]. In Catalytic Materials, Demonceau, A.; Dragutan, I.; Dragutan, V., Eds. Catalysts: 2017.

(18) Over, H., Surface Chemistry of Ruthenium Dioxide in Heterogeneous Catalysis and Electrocatalysis: From Fundamental to Applied Research. Chem. Rev. 2012, 112, 3356-3426.

(19) Astruc, D., Organometallic Chemistry and Catalysis. Springer Berlin Heidelberg: 2007.

(20) Serp, P.; Philippot, K.; Editors, Nanomaterials in Catalysis. Wiley-VCH Verlag GmbH \& Co. KGaA: 2013.

(21) Jin, R.; Zeng, C.; Zhou, M.; Chen, Y., Atomically Precise Colloidal Metal Nanoclusters and Nanoparticles: Fundamentals and Opportunities. Chem. Rev. 2016, 116, 10346-10413.

(22) Jin, R.; Pei, Y.; Tsukuda, T., Controlling Nanoparticles with Atomic Precision. Acc. Chem. Res. 2019, 52, 1-1. 
(23) Schmid, G.; Editor, Nanoparticles: From Theory to Application, Second Edition. Wiley-Blackwell: 2010.

(24) Talapin, D. V.; Shevchenko, E. V., Introduction: Nanoparticle Chemistry. Chem. Rev. 2016, 116, 10343-10345.

(25) Wu, L.; Mendoza-Garcia, A.; Li, Q.; Sun, S., Organic Phase Syntheses of Magnetic Nanoparticles and Their Applications. Chem. Rev. 2016, 116, 10473-10512.

(26) Gilroy, K. D.; Ruditskiy, A.; Peng, H.-C.; Qin, D.; Xia, Y., Bimetallic Nanocrystals: Syntheses, Properties, and Applications. Chem. Rev. 2016, 116, 10414-10472.

(27) Zhou, B.; Han, S.; Raja, R.; Somorjai, G. A.; Eds., Nanotechnology in Catalysis. Springer, New York: 2003.

(28) Heiz, U.; Landman, U.; Eds., Nanocatalysis. Springer, Berlin, Heidelberg: 2007.

(29) Roucoux, A.; Philippot, K., Homogeneous Hydrogenation: Colloids - Hydrogenation with Noble Metal Nanoparticles. In The Handbook of Homogeneous Hydrogenation, Vries, J. G. d.; Elsevier, C. J., Eds. WILEY-VCH, : Weinheim, 2007.

(30) Astruc, D.; Editor, Nanoparticles and Catalysis. WILEY INTERSCIENCE: New York, 2008.

(31) Corain, B.; Schmid, G.; Toshima, N.; Eds., Metal Nanoclusters in Catalysis and Materials Science: The Issue of Size Control. Elsevier Science: Amsterdam, The Netherland, 2008.

(32) R. Richards, R. K., K. Klabunde, L. Erickson ; Eds., Nanoscale Materials in Chemistry: Environmental Applications, . ACS Publications: Washington D.C., 2011.

(33) Philippot, K.; Serp, P.; Eds., Concepts in Nanocatalysis. Wiley-VCH: Weinheim, 2013.

(34) Polshettiwar, V.; Asefa, T.; EDs., Nanocatalysis: Synthesis and Applications. Wiley: 2013.

(35) Tao, T.; Eds., Metal Nanoparticles for Catalysis: Advances and Applications RSC: 2014.

(36) Prechtl, M. H. G.; Eds., Nanocatalysis in Ionic Liquids. Wiley: 2016.

(37) Voorde, M. V. d.; Sels, B.; Eds., Nanotechnology in Catalysis: Applications in the Chemical Industry, Energy Development, and Environment Protection. Wiley: 2017. 
(38) Tao, A. R.; Habas, S.; Yang, P., Shape Control of Colloidal Metal Nanocrystals. Small 2008, 4, 310-325.

(39) Xia, Y.; Xia, X.; Peng, H.-C., Shape-Controlled Synthesis of Colloidal Metal Nanocrystals: Thermodynamic versus Kinetic Products. J. Am. Chem. Soc. 2015, 137, 7947-7966.

(40) Chen, G.; Zhang, J.; Gupta, A.; Rosei, F.; Ma, D., Shape-Controlled Synthesis of Ruthenium Nanocrystals and their Catalytic Applications. New J. Chem. 2014, 38, 1827-1833.

(41) Chen, T.; Rodionov, V. O., Controllable Catalysis with Nanoparticles: Bimetallic Alloy Systems and Surface Adsorbates. ACS Catal. 2016, 6, 4025-4033.

(42) Zhukhovitskiy, A. V.; MacLeod, M. J.; Johnson, J. A., Carbene Ligands in Surface Chemistry: From Stabilization of Discrete Elemental Allotropes to Modification of Nanoscale and Bulk Substrates. Chem. Rev. 2015, 115, 11503-11532.

(43) Heuer-Jungemann, A.; Feliu, N.; Bakaimi, I.; Hamaly, M.; Alkilany, A.; Chakraborty, I.; Masood, A.; Casula, M. F.; Kostopoulou, A.; Oh, E.; Susumu, K.; Stewart, M. H.; Medintz, I. L.; Stratakis, E.; Parak, W. J.; Kanaras, A. G., The Role of Ligands in the Chemical Synthesis and Applications of Inorganic Nanoparticles. Chem. Rev. 2019, 119, 4819-4880.

(44) Yuan, Y.; Yan, N.; Dyson, P. J., Advances in the Rational Design of Rhodium Nanoparticle Catalysts: Control via Manipulation of the Nanoparticle Core and Stabilizer. ACS Catal. 2012, 2, 10571069.

(45) Zhou, K.; Li, Y., Catalysis Based on Nanocrystals with Well-Defined Facets. Angew. Chem., Int. Ed. 2012, 51, 602-613.

(46) Dykeman, R. R.; Yan, N.; Scopelliti, R.; Dyson, P. J., Enhanced Rate of Arene Hydrogenation with Imidazolium Functionalized Bipyridine Stabilized Rhodium Nanoparticle Catalysts. Inorg. Chem. 2011, $50,717-719$.

(47) Gonzalez-Galvez, D.; Nolis, P.; Philippot, K.; Chaudret, B.; van Leeuwen, P. W. N. M., PhosphineStabilized Ruthenium Nanoparticles: The Effect of the Nature of the Ligand in Catalysis. ACS Catal. 2012, 2, 317-321. 
(48) Stratton, S. A.; Luska, K. L.; Moores, A., Rhodium Nanoparticles Stabilized with Phosphine Functionalized Imidazolium Ionic Liquids as Recyclable Arene Hydrogenation Catalysts. Catal. Today 2012, 183, 96-100.

(49) Baker, L. R.; Kennedy, G.; Krier, J. M.; Van Spronsen, M.; Onorato, R. M.; Somorjai, G. A., The Role of an Organic Cap in Nanoparticle Catalysis: Reversible Restructuring of Carbonaceous Material Controls Catalytic Activity of Platinum Nanoparticles for Ethylene Hydrogenation and Methanol Oxidation. Catal. Lett. 2012, 142, 1286-1294.

(50) Axet, M. R.; Conejero, S.; Gerber, I. C., Ligand Effects on the Selective Hydrogenation of Nitrobenzene to Cyclohexylamine Using Ruthenium Nanoparticles as Catalysts. ACS Appl. Nano Mater. $2018,1,5885-5894$.

(51) Costa, N. J. S.; Rossi, L. M., Synthesis of Supported Metal Nanoparticle Catalysts using Ligand Assisted Methods. Nanoscale 2012, 4, 5826-5834.

(52) Janiak, C., CHAPTER 11 Metal Nanoparticle Synthesis in Ionic Liquids. In Catalysis in Ionic Liquids: From Catalyst Synthesis to Application, Hardacre, C.; Parvulescu, V., Eds. The Royal Society of Chemistry: 2014, 537-577.

(53) Claus, P.; Schwab, F., CHAPTER 6 Modification of Supports and Heterogeneous Catalysts by Ionic Liquids: SILP and SCILL Systems. In Catalysis in Ionic Liquids: From Catalyst Synthesis to Application, Hardacre, C.; Parvulescu, V., Eds. The Royal Society of Chemistry: 2014, 391-409.

(54) An, K.; Alayoglu, S.; Ewers, T.; Somorjai, G. A., Colloid Chemistry of Nanocatalysts: A Molecular View. J. Colloid Interface Sci. 2012, 373, 1-13.

(55) Somorjai, G. A.; Li, Y.-M., Major Successes of Theory-and-Experiment-Combined Studies in Surface Chemistry and Heterogeneous Catalysis. Top. Catal. 2010, 53, 311-325.

(56) Freund, H.-J.; Somorjai, G. A., The Frontiers of Catalysis Science and Future Challenges. Catal. Lett. 2015, 145, 1-2.

(57) Bond, G. C.; Louis, C.; Thompson, D. T., Catalysis by Gold. World Scientific: 2006. 
(58) Louis, C.; Pluchery, O., Gold Nanoparticles for Physics, Chemistry and Biology. World Scientific: 2012.

(59) Saldan, I.; Semenyuk, Y.; Marchuk, I.; Reshetnyak, O., Chemical Synthesis and Application of Palladium Nanoparticles. J. Mater. Sci. 2015, 50, 2337-2354.

(60) Chen, A.; Ostrom, C., Palladium-Based Nanomaterials: Synthesis and Electrochemical Applications. Chem. Rev. 2015, 115, 11999-12044.

(61) Cusinato, L.; Martinez-Prieto, L. M.; Chaudret, B.; del Rosal, I.; Poteau, R., Theoretical Characterization of the Surface Composition of Ruthenium Nanoparticles in Equilibrium with Syngas. Nanoscale 2016, 8, 10974-10992.

(62) Cushing, B. L.; Kolesnichenko, V. L.; O'Connor, C. J., Recent Advances in the Liquid-Phase Syntheses of Inorganic Nanoparticles. Chem. Rev. 2004, 104, 3893-3946.

(63) Amiens, C.; Ciuculescu-Pradines, D.; Philippot, K., Controlled Metal Nanostructures: Fertile Ground for Coordination Chemists. Coord. Chem. Rev. 2016, 308, 409-432.

(64) Denicourt-Nowicki, A.; Roucoux, A., Odyssey in Polyphasic Catalysis by Metal Nanoparticles. Chem. Rec. 2016, 16, 2127-2141.

(65) Toshima, N.; Yonezawa, T., Bimetallic Nanoparticles - Novel Materials for Chemical and Physical Applications. New J. Chem. 1998, 22, 1179-1201.

(66) Yu, W.; Liu, M.; Liu, H.; Ma, X.; Liu, Z., Preparation, Characterization, and Catalytic Properties of Polymer-Stabilized Ruthenium Colloids. J. Colloid Interface Sci. 1998, 208, 439-444.

(67) Boennemann, H.; Braun, G.; Brijoux, G. B.; Brinkman, R.; Tilling, A. S.; Seevogel, K.; Siepen, K., Nanoscale Colloidal Metals and Alloys Stabilized by Solvents and Surfactants. Preparation and Use as Catalyst Precursors. J. Organomet. Chem. 1996, 520, 143-162.

(68) Yan, X.; Liu, H.; Liew, K. Y., Size Control of Polymer-Stabilized Ruthenium Nanoparticles by Polyol Reduction. J. Mater. Chem. 2001, 11, 3387-3391. 
(69) Harpeness, R.; Peng, Z.; Liu, X.; Pol, V. G.; Koltypin, Y.; Gedanken, A., Controlling the Agglomeration of Anisotropic Ru Nanoparticles by the Microwave-Polyol Process. J. Colloid Interface Sci. 2005, 287, 678-684.

(70) Viau, G.; Brayner, R.; Poul, L.; Chakroune, N.; Lacaze, E.; Fievet-Vincent, F.; Fievet, F., Ruthenium Nanoparticles: Size, Shape, and Self-Assemblies. Chem. Mater. 2003, 15, 486-494.

(71) Wang, Y.; Ren, J.; Deng, K.; Gui, L.; Tang, Y., Preparation of Tractable Platinum, Rhodium, and Ruthenium Nanoclusters with Small Particle Size in Organic Media. Chem. Mater. 2000, 12, 1622-1627. (72) Joo, S. H.; Park, J. Y.; Renzas, J. R.; Butcher, D. R.; Huang, W.; Somorjai, G. A., Size Effect of Ruthenium Nanoparticles in Catalytic Carbon Monoxide Oxidation. Nano Lett 2010, 10, 2709-2713.

(73) Ye, H.; Wang, Q.; Catalano, M.; Lu, N.; Vermeylen, J.; Kim, M. J.; Liu, Y.; Sun, Y.; Xia, X., Ru Nanoframes with an fcc Structure and Enhanced Catalytic Properties. Nano Lett. 2016, 16, 2812-2817. (74) Zhao, M.; Xu, L.; Vara, M.; Elnabawy, A. O.; Gilroy, K. D.; Hood, Z. D.; Zhou, S.; Figueroa-Cosme, L.; Chi, M.; Mavrikakis, M.; Xia, Y., Synthesis of Ru Icosahedral Nanocages with a Face-Centered-Cubic Structure and Evaluation of Their Catalytic Properties. ACS Catal. 2018, 8, 6948-6960.

(75) Bradley, J. S.; Hill, E.; Leonowicz, M. E.; Witzke, H., Clusters, Colloids and Catalysis. J. Mol. Catal. $1987,41,59-74$.

(76) Bradley, J. S.; Hill, E. W.; Chaudret, B.; Duteil, A., Surface Chemistry on Colloidal Metals. Reversible Adsorbate-Induced Surface Composition Changes in Colloidal Palladium-Copper Alloys. Langmuir 1995, 11, 693-695.

(77) Bradley, J. S.; Millar, J. M.; Hill, E. W.; Behal, S.; Chaudret, B.; Duteil, A., Surface Chemistry on Colloidal Metals: Spectroscopic Study of Adsorption of Small Molecules. Faraday Discuss. 1992, 92, 255-268.

(78) Duteil, A.; Queau, R.; Chaudret, B.; Mazel, R.; Roucau, C.; Bradley, J. S., Preparation of Organic Solutions or Solid Films of Small Particles of Ruthenium, Palladium, and Platinum from Organometallic Precursors in the Presence of Cellulose Derivatives. Chem. Mater. 1993, 5, 341-347. 
(79) Amiens, C.; Chaudret, B.; Ciuculescu-Pradines, D.; Colliere, V.; Fajerwerg, K.; Fau, P.; Kahn, M.; Maisonnat, A.; Soulantica, K.; Philippot, K., Organometallic Approach for the Synthesis of Nanostructures. New J. Chem. 2013, 37, 3374-3401.

(80) Lignier, P.; Bellabarba, R.; Tooze, R. P.; Su, Z.; Landon, P.; Menard, H.; Zhou, W., Facile Synthesis of Branched Ruthenium Nanocrystals and Their Use in Catalysis. Cryst. Growth Des. 2012, 12, 939-942.

(81) Dixneuf, P. H.; Bruneau, C., Ruthenium in Catalysis Volume 48 de Topics in Organometallic Chemistry. Springer International Publishing: 2014.

(82) Lara, P.; Philippot, K.; Chaudret, B., Organometallic Ruthenium Nanoparticles: A Comparative Study of the Influence of the Stabilizer on their Characteristics and Reactivity. ChemCatChem 2013, 5, 28-45.

(83) Salas, G.; Campbell, P. S.; Santini, C. C.; Philippot, K.; Costa Gomes, M. F.; Padua, A. A. H., Ligand Effect on the Catalytic activity of Ruthenium Nanoparticles in lonic Liquids. Dalton Trans. 2012, 41, 13919-13926.

(84) Chacon, G.; Dupont, J., Arene Hydrogenation by Metal Nanoparticles in Ionic Liquids. Chem CatChem 2019, 11, 333-341.

(85) Taglang, C.; Martinez-Prieto, L. M.; del Rosal, I.; Maron, L.; Poteau, R.; Philippot, K.; Chaudret, B.; Perato, S.; Sam Lone, A.; Puente, C.; Dugave, C.; Rousseau, B.; Pieters, G., Enantiospecific C-H Activation using Ruthenium Nanocatalysts. Angew. Chem., Int. Ed. 2015, 54, 10474-10477.

(86) Debouttiere, P.-J.; Martinez, V.; Philippot, K.; Chaudret, B., An Organometallic Approach for the Synthesis of Water-Soluble Ruthenium and Platinum Nanoparticles. Dalton Trans. 2009, 1017210174.

(87) Guerrero, M.; Roucoux, A.; Denicourt-Nowicki, A.; Bricout, H.; Monflier, E.; Colliere, V.; Fajerwerg, K.; Philippot, K., Alkyl Sulfonated Diphosphines-Stabilized Ruthenium Nanoparticles as Efficient Nanocatalysts in Hydrogenation Reactions in Biphasic Media. Catal. Today 2012, 183, 34-41. (88) Guerrero, M.; Coppel, Y.; Chau, N. T. T.; Roucoux, A.; Denicourt-Nowicki, A.; Monflier, E.; Bricout, H.; Lecante, P.; Philippot, K., Efficient Ruthenium Nanocatalysts in Liquid-Liquid Biphasic 
Hydrogenation Catalysis: Towards a Supramolecular Control Through a Sulfonated DiphosphineCyclodextrin Smart Combination. Chem CatChem 2013, 5, 3802-3811.

(89) Martinez-Prieto, L. M.; Baquero, E. A.; Pieters, G.; Flores, J. C.; de Jesus, E.; Nayral, C.; Delpech, F.; van Leeuwen, P. W. N. M.; Lippens, G.; Chaudret, B., Monitoring of Nanoparticle Reactivity in Solution: Interaction of L-Lysine and Ru Nanoparticles Probed by Chemical Shift Perturbation Parallels Regioselective H/D Exchange. Chem. Commun. 2017, 53, 5850-5853.

(90) Debouttiere, P.-J.; Coppel, Y.; Denicourt-Nowicki, A.; Roucoux, A.; Chaudret, B.; Philippot, K., PTA-Stabilized Ruthenium and Platinum Nanoparticles: Characterization and Investigation in Aqueous Biphasic Hydrogenation Catalysis. Eur. J. Inorg. Chem. 2012, 2012, 1229-1236.

(91) Martinez-Prieto, L. M.; Chaudret, B., Organometallic Ruthenium Nanoparticles: Synthesis, Surface Chemistry, and Insights into Ligand Coordination. Acc. Chem. Res. 2018, 51, 376-384.

(92) Gonzalez-Gomez, R.; Cusinato, L.; Bijani, C.; Coppel, Y.; Lecante, P.; Amiens, C.; del Rosal, I.; Philippot, K.; Poteau, R., Carboxylic Acid-Capped Ruthenium Nanoparticles: Experimental and Theoretical Case Study with Ethanoic Acid. Nanoscale 2019, 11, 9392-9409.

(93) Pery, T.; Pelzer, K.; Buntkowsky, G.; Philippot, K.; Limbach, H.-H.; Chaudret, B., Direct NMR Evidence for the Presence of Mobile Surface Hydrides on Ruthenium Nanoparticles. ChemPhysChem $2005,6,605-607$.

(94) Rothermel, N.; Roether, T.; Ayvali, T.; Martinez-Prieto, L. M.; Philippot, K.; Limbach, H.-H.; Chaudret, B.; Gutmann, T.; Buntkowsky, G., Reactions of $D_{2}$ with 1,4-Bis(diphenylphosphino)butaneStabilized Metal Nanoparticles-A Combined Gas-phase NMR, GC-MS and Solid-state NMR Study. Chem CatChem 2019, 11, 1465-1471.

(95) Gutmann, T.; Bonnefille, E.; Breitzke, H.; Debouttiere, P.-J.; Philippot, K.; Poteau, R.; Buntkowsky, G.; Chaudret, B., Investigation of the Surface Chemistry of Phosphine-Stabilized Ruthenium Nanoparticles - an Advanced Solid-State NMR Study. Phys. Chem. Chem. Phys. 2013, 15, 17383-17394. 
(96) Lara, P.; Rivada-Wheelaghan, O.; Conejero, S.; Poteau, R.; Philippot, K.; Chaudret, B., Ruthenium Nanoparticles Stabilized by N-Heterocyclic Carbenes: Ligand Location and Influence on Reactivity. Angew. Chem., Int. Ed. 2011, 50, 12080-12084.

(97) Novio, F.; Monahan, D.; Coppel, Y.; Antorrena, G.; Lecante, P.; Philippot, K.; Chaudret, B., Surface Chemistry on Small Ruthenium Nanoparticles: Evidence for Site Selective Reactions and Influence of Ligands. Chem. - Eur. J. 2014, 20, 1287-1297.

(98) Martinez-Prieto, L. M.; Carenco, S.; Wu, C. H.; Bonnefille, E.; Axnanda, S.; Liu, Z.; Fazzini, P. F.; Philippot, K.; Salmeron, M.; Chaudret, B., Organometallic Ruthenium Nanoparticles as Model Catalysts for CO Hydrogenation: A Nuclear Magnetic Resonance and Ambient-Pressure X-ray Photoelectron Spectroscopy Study. ACS Catal. 2014, 4, 3160-3168.

(99) Kinayyigit, S.; Philippot, K., CHAPTER 4 Organometallic Approach for the Synthesis of Noble Metal Nanoparticles: Towards Application in Colloidal and Supported Nanocatalysis. In Metal Nanoparticles for Catalysis: Advances and Applications, The Royal Society of Chemistry: 2014, 47-82. (100) van Leeuwen, P. W. N. M., Homogeneous Catalysis: Understanding the Art. Springer: 2004.

(101) Axet, M. R.; Durand, J.; Gouygou, M.; Serp, P., Chapter Two - Surface coordination chemistry on graphene and two-dimensional carbon materials for well-defined single atom supported catalysts. In Advances in Organometallic Chemistry, Pérez, P. J., Ed. Academic Press: 2019, 53-174.

(102) Zhang, J.; Teo, J.; Chen, X.; Asakura, H.; Tanaka, T.; Teramura, K.; Yan, N., A Series of NiM (M = $\mathrm{Ru}, \mathrm{Rh}$, and Pd) Bimetallic Catalysts for Effective Lignin Hydrogenolysis in Water. ACS Catal. 2014, 4, 1574-1583.

(103) Mondal, J.; Kundu, S. K.; Hung Ng, W. K.; Singuru, R.; Borah, P.; Hirao, H.; Zhao, Y.; Bhaumik, A., Fabrication of Ruthenium Nanoparticles in Porous Organic Polymers: Towards Advanced Heterogeneous Catalytic Nanoreactors. Chem. - Eur. J. 2015, 21, 19016-19027.

(104) Wang, C.; Ciganda, R.; Salmon, L.; Gregurec, D.; Irigoyen, J.; Moya, S.; Ruiz, J.; Astruc, D., Highly Efficient Transition Metal Nanoparticle Catalysts in Aqueous Solutions. Angew. Chem., Int. Ed. 2016, 55, 3091-3095. 
(105) Sato, K.; Tomonaga, H.; Yamamoto, T.; Matsumura, S.; Zulkifli, N. D. B.; Ishimoto, T.; Koyama, M.; Kusada, K.; Kobayashi, H.; Kitagawa, H.; Nagaoka, K., A Synthetic Pseudo-Rh: NOx Reduction Activity and Electronic Structure of Pd-Ru Solid-solution Alloy Nanoparticles. Sci. Rep. 2016, 6, 28265.

(106) Zhao, Y.; Luo, Y.; Yang, X.; Yang, Y.; Song, Q., Tunable Preparation of Ruthenium Nanoparticles with Superior Size-Dependent Catalytic Hydrogenation Properties. J. Hazard. Mater. 2017, 332, 124131.

(107) Hou, S.; Xie, C.; Yu, F.; Yuan, B.; Yu, S., Selective Hydrogenation of $\alpha$-Pinene to cis-Pinane over Ru Nanocatalysts in Aqueous Micellar Nanoreactors. RSC Adv. 2016, 6, 54806-54811.

(108) Weilhard, A.; Abarca, G.; Viscardi, J.; Prechtl, M. H. G.; Scholten, J. D.; Bernardi, F.; Baptista, D. L.; Dupont, J., Challenging Thermodynamics: Hydrogenation of Benzene to 1,3-Cyclohexadiene by Ru@Pt Nanoparticles. ChemCatChem 2017, 9, 204-211.

(109) Hou, S.; Wang, X.; Huang, C.; Xie, C.; Yu, S., Highly Selective Hydrogenation of $\alpha$-Pinene Catalyzed by Ru Nanoparticles in Aqueous Micellar Microreactors. Catal. Lett. 2016, 146, 580-586.

(110) Easterday, R.; Sanchez-Felix, O.; Losovyj, Y.; Pink, M.; Stein, B. D.; Morgan, D. G.; Rakitin, M.; Doluda, V. Y.; Sulman, M. G.; Mahmoud, W. E.; Al-Ghamdi, A. A.; Bronstein, L. M., Design of Ruthenium/Iron Oxide Nanoparticle Mixtures for Hydrogenation of Nitrobenzene. Catal. Sci. Technol. $2015,5,1902-1910$.

(111) Zhao, Y.; Luo, Y.; Zhu, Y.; Sun, Y.; Cui, L.; Song, Q., Sensitive Colorimetric Assay of $\mathrm{H}_{2} \mathrm{~S}$ Depending on the High-Efficient Inhibition of Catalytic Performance of Ru Nanoparticles. ACS Sustainable Chem. Eng. 2017, 5, 7912-7919.

(112) Breso-Femenia, E.; Chaudret, B.; Castillon, S., Selective Catalytic Hydrogenation of Polycyclic Aromatic Hydrocarbons Promoted by Ruthenium Nanoparticles. Catal. Sci. Technol. 2015, 5, 27412751.

(113) Bonnefille, E.; Novio, F.; Gutmann, T.; Poteau, R.; Lecante, P.; Jumas, J.-C.; Philippot, K.; Chaudret, B., Tin-Decorated Ruthenium Nanoparticles: a Way to Tune Selectivity in Hydrogenation Reaction. Nanoscale 2014, 6, 9806-9816. 
(114) Gual, A.; Axet, M. R.; Philippot, K.; Chaudret, B.; Denicourt-Nowicki, A.; Roucoux, A.; Castillon,

S.; Claver, C., Diphosphite Ligands Derived from Carbohydrates as Stabilizers for Ruthenium Nanoparticles: Promising Catalytic Systems in Arene Hydrogenation. Chem. Commun. 2008, 27592761.

(115) Gual, A.; Godard, C.; Philippot, K.; Chaudret, B.; Denicourt-Nowicki, A.; Roucoux, A.; Castillon,

S.; Claver, C., Carbohydrate-Derived 1,3-Diphosphite Ligands as Chiral Nanoparticle Stabilizers: Promising Catalytic Systems for Asymmetric Hydrogenation. ChemSusChem 2009, 2, 769-779.

(116) Llop Castelbou, J.; Breso-Femenia, E.; Blondeau, P.; Chaudret, B.; Castillon, S.; Claver, C.; Godard, C., Tuning the Selectivity in the Hydrogenation of Aromatic Ketones Catalyzed by Similar Ruthenium and Rhodium Nanoparticles. ChemCatChem 2014, 6, 3160-3168.

(117) Qi, X.; Axet, M. R.; Philippot, K.; Lecante, P.; Serp, P., Seed-Mediated Synthesis of Bimetallic Ruthenium-Platinum Nanoparticles Efficient in Cinnamaldehyde Selective Hydrogenation. Dalton Trans. 2014, 43, 9283-9295.

(118) Kelsen, V.; Meffre, A.; Fazzini, P.-F.; Lecante, P.; Chaudret, B., How to Modulate Catalytic Properties in Nanosystems: The Case of Iron-Ruthenium Nanoparticles. ChemCatChem 2014, 6, 17141720.

(119) Offner-Marko, L.; Bordet, A.; Moos, G.; Tricard, S.; Rengshausen, S.; Chaudret, B.; Luska, K. L.; Leitner, W., Bimetallic Nanoparticles in Supported Ionic Liquid Phases as Multifunctional Catalysts for the Selective Hydrodeoxygenation of Aromatic Substrates. Angew. Chem., Int. Ed. 2018, 57, 1272112726.

(120) Scott, M.; Deuss, P. J.; de Vries, J. G.; Prechtl, M. H. G.; Barta, K., New Insights into the Catalytic Cleavage of the Lignin $\beta-0-4$ Linkage in Multifunctional Ionic Liquid Media. Catal. Sci. Technol. 2016, 6, $1882-1891$.

(121) Wu, Z.; Jiang, H., Efficient Palladium and Ruthenium Nanocatalysts Stabilized by Phosphine Functionalized Ionic Liquid for Selective Hydrogenation. RSC Adv. 2015, 5, 34622-34629. 
(122) Jiang, H.-Y.; Zheng, X.-X., Tuning the Chemoselective Hydrogenation of Aromatic Ketones, Aromatic Aldehydes and Quinolines Catalyzed by Phosphine Functionalized Ionic Liquid Stabilized Ruthenium Nanoparticles. Catal. Sci. Technol. 2015, 5, 3728-3734.

(123) Campbell, P. S.; Prechtl, M. H. G.; Santini, C. C.; Haumesser, P.-H., Ruthenium Nanoparticles in Ionic Liquids - a Saga. Curr. Org. Chem. 2013, 17, 414-429.

(124) Winterle, S. M. Synthesis of Ruthenium Nanoparticles in Functionalized Ionic Liquids as Multifunctional Catalyst Systems for the Conversion of Biomass. 2012.

(125) Andanson, J.-M.; Marx, S.; Baiker, A., Selective Hydrogenation of Cyclohexenone on IronRuthenium Nanoparticles Suspended in Ionic Liquids and $\mathrm{CO}_{2}$-Expanded lonic Liquids. Catal. Sci. Technol. 2012, 2, 1403-1409.

(126) Salas, G.; Santini, C. C.; Philippot, K.; Colliere, V.; Chaudret, B.; Fenet, B.; Fazzini, P. F., Influence of Amines on the Size Control of in situ Synthesized Ruthenium Nanoparticles in Imidazolium Ionic Liquids. Dalton Trans. 2011, 40, 4660-4668.

(127) Prechtl, M. H. G.; Scholten, J. D.; Dupont, J., Tuning the Selectivity of Ruthenium Nanoscale Catalysts with Functionalized Ionic Liquids: Hydrogenation of Nitriles. J. Mol. Catal. A: Chem. 2009, 313, 74-78.

(128) Prechtl, M. H. G.; Scariot, M.; Scholten, J. D.; Machado, G.; Teixeira, S. R.; Dupont, J., Nanoscale $\mathrm{Ru}(0)$ Particles: Arene Hydrogenation Catalysts in Imidazolium Ionic Liquids. Inorg. Chem. 2008, 47, 8995-9001.

(129) Silveira, E. T.; Umpierre, A. P.; Rossi, L. M.; Machado, G.; Morais, J.; Soares, G. V.; Baumvol, I. J. R.; Teixeira, S. R.; Fichtner, P. F. P.; Dupont, J., The Partial Hydrogenation of Benzene to Cyclohexene by Nanoscale Ruthenium Catalysts in Imidazolium Ionic Liquids. Chem. - Eur. J. 2004, 10, 3734-3740.

(130) Chen, L.; Xin, J.; Ni, L.; Dong, H.; Yan, D.; Lu, X.; Zhang, S., Conversion of Lignin Model Compounds under Mild Conditions in Pseudo-Homogeneous Systems. Green Chem. 2016, 18, 23412352. 
(131) Luska, K. L.; Bordet, A.; Tricard, S.; Sinev, I.; Gruenert, W.; Chaudret, B.; Leitner, W., Enhancing the Catalytic Properties of Ruthenium Nanoparticle-SILP Catalysts by Dilution with Iron. ACS Catal. 2016, 6, 3719-3726.

(132) Gonzalez-Galvez, D.; Lara, P.; Rivada-Wheelaghan, O.; Conejero, S.; Chaudret, B.; Philippot, K.; van Leeuwen, P. W. N. M., NHC-Stabilized Ruthenium Nanoparticles as New Catalysts for the Hydrogenation of Aromatics. Catal. Sci. Technol. 2013, 3, 99-105.

(133) Martinez-Prieto, L. M.; Ferry, A.; Lara, P.; Richter, C.; Philippot, K.; Glorius, F.; Chaudret, B., New Route to Stabilize Ruthenium Nanoparticles with Non-Isolable Chiral N-Heterocyclic Carbenes. Chem. - Eur. J. 2015, 21, 17495-17502.

(134) Lara, P.; Martinez-Prieto, L. M.; Rosello-Merino, M.; Richter, C.; Glorius, F.; Conejero, S.; Philippot, K.; Chaudret, B., NHC-Stabilized Ru Nanoparticles: Synthesis and Surface Studies. NanoStruct. Nano-Objects 2016, 6, 39-45.

(135) Martinez-Prieto, L. M.; Ferry, A.; Rakers, L.; Richter, C.; Lecante, P.; Philippot, K.; Chaudret, B.; Glorius, F., Long-Chain NHC-Stabilized RuNPs as Versatile Catalysts for One-Pot Oxidation/Hydrogenation Reactions. Chem. Commun. 2016, 52, 4768-4771.

(136) Tay, B. Y.; Wang, C.; Phua, P. H.; Stubbs, L. P.; Huynh, H. V., Selective Hydrogenation of Levulinic Acid to $\mathrm{y}$-Valerolactone Using in situ Generated Ruthenium Nanoparticles Derived from Ru-NHC Complexes. Dalton Trans. 2016, 45, 3558-3563.

(137) Martinez-Espinar, F.; Blondeau, P.; Nolis, P.; Chaudret, B.; Claver, C.; Castillon, S.; Godard, C., NHC-Stabilised Rh Nanoparticles: Surface Study and Application in the Catalytic Hydrogenation of Aromatic Substrates. J. Catal. 2017, 354, 113-127.

(138) Rakers, L.; Martinez-Prieto, L. M.; Lopez-Vinasco, A. M.; Philippot, K.; van Leeuwen, P. W. N. M.; Chaudret, B.; Glorius, F., Ruthenium Nanoparticles Ligated by Cholesterol-Derived NHCs and their Application in the Hydrogenation of Arenes. Chem. Commun. 2018, 54, 7070-7073. 
(139) Mourdikoudis, S.; Pallares, R. M.; Thanh, N. T. K., Characterization Techniques for Nanoparticles: Comparison and Complementarity upon Studying Nanoparticle Properties. Nanoscale 2018, 10, 12871-12934.

(140) Zhang, F.; Fang, J.; Huang, L.; Sun, W.; Lin, Z.; Shi, Z.; Kang, X.; Chen, S., Alkyne-Functionalized Ruthenium Nanoparticles: Impact of Metal-Ligand Interfacial Bonding Interactions on the Selective Hydrogenation of Styrene. ACS Catal. 2019, 9, 98-104.

(141) Morioka, Y.; Matsuoka, A.; Binder, K.; Knappett, B. R.; Wheatley, A. E. H.; Naka, H., Selective Hydrogenation of Arenes to Cyclohexanes in Water Catalyzed by Chitin-Supported Ruthenium Nanoparticles. Catal. Sci. Technol. 2016, 6, 5801-5805.

(142) Leng, F.; Gerber, I. C.; Lecante, P.; Bentaleb, A.; Munoz, A.; Illescas, B. M.; Martin, N.; Melinte, G.; Ersen, O.; Martinez, H.; Axet, M. R.; Serp, P., Hexakis [60]Fullerene Adduct-Mediated Covalent Assembly of Ruthenium Nanoparticles and Their Catalytic Properties. Chem. - Eur. J. 2017, 23, 1337913386

(143) Leng, F.; Gerber, I. C.; Axet, M. R.; Serp, P., Selectivity Shifts in Hydrogenation of Cinnamaldehyde on Electron-Deficient Ruthenium Nanoparticles. C. R. Chim. 2018, 21, 346-353.

(144) Chen, M.; Dong, Q.; Ni, W.; Zhao, X.; Gu, Q.; Tang, G.; Li, D.; Ma, W.; Hou, Z., CyclodextrinBased Polymer-Assisted Ru Nanoparticles for the Aqueous Hydrogenation of Biomass-Derived Platform Molecules. ChemistrySelect 2017, 2, 10537-10545.

(145) Noel, S.; Bourbiaux, D.; Tabary, N.; Ponchel, A.; Martel, B.; Monflier, E.; Leger, B., Acid-tolerant Cyclodextrin-Based Ruthenium Nanoparticles for the Hydrogenation of Unsaturated Compounds in Water. Catal. Sci. Technol. 2017, 7, 5982-5992.

(146) Karakhanov, E. A.; Maksimov, A. L.; Zolotukhina, A. V.; Kardashev, S. V., Preparation of nanostructured dendrimer-based catalytic systems and their catalytic activity in hydrogenation: synthesis of ruthenium nanoparticles immobilized on dendrimer network. Neftekhimiya 2010, 50, 303310. 
(147) Antonels, N. C.; Meijboom, R., Preparation of Well-Defined Dendrimer Encapsulated Ruthenium Nanoparticles and Their Evaluation in the Reduction of 4 Nitrophenol According to the Langmuir-Hinshelwood Approach. Langmuir 2013, 29, 13433-13442.

(148) Murugan, E.; Pakrudheen, I., Efficient Amphiphilic Poly(propylene imine) Dendrimer Encapsulated Ruthenium Nanoparticles for Sensing and Catalysis Applications. Sci. Adv. Mater. 2015, 7, 891-901.

(149) Wu, D.; Kusada, K.; Kitagawa, H., Recent Progress in the Structure Control of Pd-Ru Bimetallic Nanomaterials. Sci. Technol. Adv. Mater. 2016, 17, 583-596.

(150) Kunz, S., Supported, Ligand-Functionalized Nanoparticles: An Attempt to Rationalize the Application and Potential of Ligands in Heterogeneous Catalysis. Top. Catal. 2016, 59, 1671-1685.

(151) De, S.; Zhang, J.; Luque, R.; Yan, N., Ni-Based Bimetallic Heterogeneous Catalysts for Energy and Environmental Applications. Energy Environ. Sci. 2016, 9, 3314-3347.

(152) Lara, P.; Philippot, K.; Lacroix, L.-M.; Lachaize, S.; Liakakos, N.; Soulantica, K.; Chaudret, B. In Organometallic Nanoparticles, John Wiley \& Sons, Inc.: 2014; 421-436.

(153) Sahoo, A.; Tripathy, S. K.; Dehury, N.; Patra, S., A Porous Trimetallic Au@Pd@Ru Nanoparticle System: Synthesis, Characterization and Efficient Dye Degradation and Removal. J. Mater. Chem. A 2015, 3, 19376-19383.

(154) Yao, Y.; He, D. S.; Lin, Y.; Feng, X.; Wang, X.; Yin, P.; Hong, X.; Zhou, G.; Wu, Y.; Li, Y., Modulating fcc and hcp Ruthenium on the Surface of Palladium-Copper Alloy through Tunable Lattice Mismatch. Angew. Chem., Int. Ed. 2016, 55, 5501-5505.

(155) Ito, Y.; Ohta, H.; Yamada, Y. M. A.; Enoki, T.; Uozumi, Y., Transfer Hydrogenation of Alkenes using $\mathrm{Ni} / \mathrm{Ru} / \mathrm{Pt} / \mathrm{Au}$ Heteroquatermetallic Nanoparticle Catalysts: Sequential Cooperation of Multiple Nano-Metal Species. Chem. Commun. 2014, 50, 12123-12126.

(156) Leng, F.; Gerber, I. C.; Lecante, P.; Bacsa, W.; Miller, J.; Gallagher, J. R.; Moldovan, S.; Girleanu, M.; Axet, M. R.; Serp, P., Synthesis and structure of ruthenium-fullerides. RSC Adv. 2016, 6, 6913569148. 
(157) Gmeiner, J.; Behrens, S.; Spliethoff, B.; Trapp, O., Ruthenium Nanoparticles in High-Throughput Studies of Chemoselective Carbonyl Hydrogenation Reactions. ChemCatChem 2016, 8, 571-576.

(158) Aguilera, J.; Favier, I.; Sans, M.; Mor, A.; Alvarez-Larena, A.; Illa, O.; Gomez, M.; Ortuno, R. M., Synthesis of Chiral Functionalised Cyclobutylpyrrolidines and Cyclobutylamino Alcohols from (-)-(S)Verbenone - Applications in the Stabilisation of Ruthenium Nanocatalysts. Eur. J. Org. Chem. 2015, 2015, 810-819.

(159) Wang, X.; Yu, F.; Xie, C.; Yu, S., Highly Selective Hydrogenation of $\alpha$-Pinene in Aqueous Medium using PVA-Stabilized Ru Nanoparticles. Mol. Catal. 2018, 444, 62-69.

(160) Qu, L.; Yu, H.; Yu, F.; Yuan, B.; Xie, C.; Yu, S., Catalytic Reduction of $\alpha$-Pinene using Ru Nanoparticles Stabilized by Modified Carboxymethyl Cellulose. Appl. Surf. Sci. 2018, 453, 271-279.

(161) Liu, Y.; Li, L.; Liu, S.; Xie, C.; Yu, S., Magnetically Recyclable Ru Immobilized on AmineFunctionalized Magnetite Nanoparticles and its High Selectivity to Prepare cis-Pinane. J. Mol. Catal. A: Chem. 2016, 424, 269-275.

(162) Hou, S.; Xie, C.; Zhong, H.; Yu, S., Mild Water-Promoted Ruthenium Nanoparticles as an Efficient Catalyst for the Preparation of cis-Rich Pinane. RSC Adv. 2015, 5, 89552-89558.

(163) Upadhyay, P.; Srivastava, V., Ruthenium Nanoparticle-Intercalated Montmorillonite Clay for Solvent-Free Alkene Hydrogenation Reaction. RSC Adv. 2015, 5, 740-745.

(164) Leng, F.; Gerber, I. C.; Lecante, P.; Moldovan, S.; Girleanu, M.; Axet, M. R.; Serp, P., Controlled and Chemoselective Hydrogenation of Nitrobenzene over Ru@ C $_{60}$ Catalysts. ACS Catal. 2016, 6, 60186024.

(165) Rambabu, D.; Pradeep, C. P.; Dhir, A., New Self-Assembled Material Based on Ru Nanoparticles and 4-Sulfocalix[4]arene as an Efficient and Recyclable Catalyst for Reduction of Brilliant Yellow Azo Dye in Water: a New Model Catalytic Reaction. J. Nanopart. Res. 2016, 18, 1-10.

(166) Song, J.; Huang, Z.-F.; Pan, L.; Li, K.; Zhang, X.; Wang, L.; Zou, J.-J., Review on Selective Hydrogenation of Nitroarene by Catalytic, Photocatalytic and Electrocatalytic Reactions. Appl. Catal., B 2018, 227, 386-408. 
(167) Serna, P.; Corma, A., Transforming Nano Metal Nonselective Particulates into Chemoselective Catalysts for Hydrogenation of Substituted Nitrobenzenes. ACS Catal. 2015, 5, 7114-7121.

(168) Gelder, E. A.; Jackson, S. D.; Lok, C. M., The Hydrogenation of Nitrobenzene to Aniline: a New Mechanism. Chem. Commun. 2005, 522-524.

(169) Kahl, T.; Schröder, K.-W.; Lawrence, F. R.; Marshall, W. J.; Höke, H.; Jäckh, R., Aniline. In Ullmann's Encyclopedia of Industrial Chemistry, Wiley-VCH Verlag GmbH \& Co. KGaA: 2011, 465-478.

(170) Roose, P.; Eller, K.; Henkes, E.; Rossbacher, R.; Höke, H., Amines, Aliphatic. In Ullmann's Encyclopedia of Industrial Chemistry, Wiley-VCH Verlag GmbH \& Co. KGaA: 2015, 1-55.

(171) Tomkins, P.; Gebauer-Henke, E.; Leitner, W.; Mueller, T. E., Concurrent Hydrogenation of Aromatic and Nitro Groups over Carbon-Supported Ruthenium Catalysts. ACS Catal. 2015, 5, 203-209. (172) Mao, J.; Chen, W.; Sun, W.; Chen, Z.; Pei, J.; He, D.; Lv, C.; Wang, D.; Li, Y., Rational Control of the Selectivity of a Ruthenium Catalyst for Hydrogenation of 4-Nitrostyrene by Strain Regulation. Angew. Chem., Int. Ed. 2017, 56, 11971-11975.

(173) Zhang, Z.; Liu, Y.; Chen, B.; Gong, Y.; Gu, L.; Fan, Z.; Yang, N.; Lai, Z.; Chen, Y.; Wang, J.; Huang, Y.; Sindoro, M.; Niu, W.; Li, B.; Zong, Y.; Yang, Y.; Huang, X.; Huo, F.; Huang, W.; Zhang, H., Submonolayered Ru Deposited on Ultrathin Pd Nanosheets used for Enhanced Catalytic Applications. Adv. Mater. 2016, 28, 10282-10286.

(174) Kim, S.; Kwon, E. E.; Kim, Y. T.; Jung, S.; Kim, H. J.; Huber, G. W.; Lee, J., Recent Advances in Hydrodeoxygenation of Biomass-Derived Oxygenates over Heterogeneous Catalysts. Green Chem. 2019, 21, 3715-3743.

(175) Jin, W.; Pastor-Perez, L.; Shen, D.; Sepulveda-Escribano, A.; Gu, S.; Ramirez Reina, T., Catalytic Upgrading of Biomass Model Compounds: Novel Approaches and Lessons Learnt from Traditional Hydrodeoxygenation - a Review. ChemCatChem 2019, 11, 924-960.

(176) Besson, M.; Gallezot, P.; Pinel, C., Conversion of Biomass into Chemicals over Metal Catalysts. Chem. Rev. 2014, 114, 1827-1870. 
(177) Mondal, S.; Singuru, R.; Chandra Shit, S.; Hayashi, T.; Irle, S.; Hijikata, Y.; Mondal, J.; Bhaumik, A., Ruthenium Nanoparticle-Decorated Porous Organic Network for Direct Hydrodeoxygenation of Long-Chain Fatty Acids to Alkanes. ACS Sustainable Chem. Eng. 2018, 6, 1610-1619.

(178) Bulut, S.; Siankevich, S.; van Muyden, A. P.; Alexander, D. T. L.; Savoglidis, G.; Zhang, J.; Hatzimanikatis, V.; Yan, N.; Dyson, P. J., Efficient Cleavage of Aryl Ether C-O Linkages by Rh-Ni and RuNi Nanoscale Catalysts Operating in Water. Chem. Sci. 2018, 9, 5530-5535.

(179) Luska, K. L.; Migowski, P.; El Sayed, S.; Leitner, W., Bifunctional Ruthenium Nanoparticle-SILP Catalysts (RuNPs@SILP) for the Hydrodeoxygenation of Eucalyptol under Batch and Continuous Flow Conditions. ACS Sustainable Chem. Eng. 2016, 4, 6186-6192.

(180) Yan, N.; Zhao, C.; Luo, C.; Dyson, P. J.; Liu, H.; Kou, Y., One-Step Conversion of Cellobiose to C $^{-}$ Alcohols Using a Ruthenium Nanocluster Catalyst. J. Am. Chem. Soc. 2006, 128, 8714-8715.

(181) Luo, C.; Wang, S.; Liu, H., Cellulose Conversion into Polyols Catalyzed by Reversibly Formed Acids and Supported Ruthenium Clusters in Hot Water. Angew. Chem., Int. Ed. 2007, 46, 7636-7639.

(182) Kobayashi, H.; Matsuhashi, H.; Komanoya, T.; Hara, K.; Fukuoka, A., Transfer Hydrogenation of Cellulose to Sugar Alcohols over Supported Ruthenium Catalysts. Chem. Commun. 2011, 47, 23662368.

(183) Negoi, A.; Triantafyllidis, K.; Parvulescu, V. I.; Coman, S. M., The Hydrolytic Hydrogenation of Cellulose to Sorbitol over M (Ru, Ir, Pd, Rh)-BEA-Zeolite Catalysts. Catal. Today 2014, 223, 122-128.

(184) Lazaridis, P. A.; Karakoulia, S. A.; Teodorescu, C.; Apostol, N.; Macovei, D.; Panteli, A.; Delimitis, A.; Coman, S. M.; Parvulescu, V. I.; Triantafyllidis, K. S., High Hexitols Selectivity in Cellulose Hydrolytic Hydrogenation over Platinum (Pt) vs. Ruthenium (Ru) Catalysts Supported on Micro/Mesoporous Carbon. Appl. Catal., B 2017, 214, 1-14.

(185) Adsuar-Garcia, M. D.; Flores-Lasluisa, J. X.; Azar, F. Z.; Roman-Martinez, M. C., Carbon-BlackSupported Ru Catalysts for the Valorization of Cellulose through Hydrolytic Hydrogenation. Catalysts 2018, 8, 572/1-572/14. 
(186) Huang, L.; Arndt, M.; Goossen, K.; Heydt, H.; Goossen, L. J., Late Transition Metal-Catalyzed Hydroamination and Hydroamidation. Chem. Rev. 2015, 115, 2596-2697.

(187) Kalck, P.; Urrutigoity, M., Tandem Hydroaminomethylation Reaction to Synthesize Amines from Alkenes. Chem. Rev. 2018, 118, 3833-3861.

(188) Elangovan, S.; Neumann, J.; Sortais, J.-B.; Junge, K.; Darcel, C.; Beller, M., Efficient and selective $\mathrm{N}$-alkylation of amines with alcohols catalyzed by manganese pincer complexes. Nat. Commun. 2016, 7, 12641.

(189) Liang, G.; Wang, A.; Li, L.; Xu, G.; Yan, N.; Zhang, T., Production of Primary Amines by Reductive Amination of Biomass-Derived Aldehydes/Ketones. Angew. Chem., Int. Ed. 2017, 56, 3050-3054.

(190) Gallardo-Donaire, J.; Ernst, M.; Trapp, O.; Schaub, T., Direct Synthesis of Primary Amines via Ruthenium-Catalyzed Amination of Ketones with Ammonia and Hydrogen. Adv. Synth. Catal. 2016, $358,358-363$.

(191) Liang, G.; Zhou, Y.; Zhao, J.; Khodakov, A. Y.; Ordomsky, V. V., Structure-Sensitive and Insensitive Reactions in Alcohol Amination over Nonsupported Ru Nanoparticles. ACS Catal. 2018, 8, 11226-11234.

(192) Chandra, D.; Inoue, Y.; Sasase, M.; Kitano, M.; Bhaumik, A.; Kamata, K.; Hosono, H.; Hara, M., A High Performance Catalyst of Shape-Specific Ruthenium Nanoparticles for Production of Primary Amines by Reductive Amination of Carbonyl Compounds. Chem. Sci. 2018, 9, 5949-5956.

(193) Deng, W.; Wang, Y.; Zhang, S.; Gupta, K. M.; Hulsey, M. J.; Asakura, H.; Liu, L.; Han, Y.; Karp, E. M.; Beckham, G. T.; Dyson, P. J.; Jiang, J.; Tanaka, T.; Wang, Y.; Yan, N., Catalytic Amino Acid Production from Biomass-Derived Intermediates. Proc. Natl. Acad. Sci. 2018, 115, 5093-5098.

(194) Ruiz, D.; Aho, A.; Saloranta, T.; Eranen, K.; Warna, J.; Leino, R.; Murzin, D. Y., Direct Amination of Dodecanol with $\mathrm{NH}_{3}$ over Heterogeneous Catalysts. Catalyst Screening and Kinetic Modelling. Chem. Eng. J. 2017, 307, 739-749. 
(195) Jagadeesh, R. V.; Murugesan, K.; Alshammari, A. S.; Neumann, H.; Pohl, M.-M.; Radnik, J.; Beller, M., MOF-Derived Cobalt Nanoparticles Catalyze a General Synthesis of Amines. Science 2017, $358,326-332$

(196) Tomer, A.; Wyrwalski, F.; Przybylski, C.; Paul, J.-F.; Monflier, E.; Pera-Titus, M.; Ponchel, A., Facile Preparation of $\mathrm{Ni} / \mathrm{Al}_{2} \mathrm{O}_{3}$ Catalytic Formulations with the Aid of Cyclodextrin Complexes: Towards Highly Active and Robust Catalysts for the Direct Amination of Alcohols. J. Catal. 2017, 356, 111-124. (197) Shimizu, K.-i.; Imaiida, N.; Kon, K.; Hakim Siddiki, S. M. A.; Satsuma, A., Heterogeneous Ni Catalysts for N-Alkylation of Amines with Alcohols. ACS Catal. 2013, 3, 998-1005.

(198) Leung, A. Y. K.; Hellgardt, K.; Hii, K. K. M., Catalysis in Flow: Nickel-Catalyzed Synthesis of Primary Amines from Alcohols and $\mathrm{NH}_{3}$. ACS Sustainable Chem. Eng. 2018, 6, 5479-5484.

(199) Komanoya, T.; Kinemura, T.; Kita, Y.; Kamata, K.; Hara, M., Electronic Effect of Ruthenium Nanoparticles on Efficient Reductive Amination of Carbonyl Compounds. J. Am. Chem. Soc. 2017, 139, 11493-11499.

(200) Shimizu, K.-i.; Kon, K.; Onodera, W.; Yamazaki, H.; Kondo, J. N., Heterogeneous Ni Catalyst for Direct Synthesis of Primary Amines from Alcohols and Ammonia. ACS Catal. 2013, 3, 112-117.

(201) He, J.; Kim, J. W.; Yamaguchi, K.; Mizuno, N., Efficient Catalytic Synthesis of Tertiary and Secondary Amines from Alcohols and Urea. Angew. Chem., Int. Ed. 2009, 48, 9888-9891.

(202) Uehara, K. Preparation of Amines from Alicyclic Alcohols. JP05148191A, 1993.

(203) Nishimura, S.; Mizuhori, K.; Ebitani, K., Reductive Amination of Furfural toward Furfurylamine with Aqueous Ammonia under Hydrogen over Ru-Supported Catalyst. Res. Chem. Intermed. 2016, 42, $19-30$.

(204) Dong, B.; Guo, X.; Zhang, B.; Chen, X.; Guan, J.; Qi, Y.; Han, S.; Mu, X., Heterogeneous Ru-Based Catalysts for One-Pot Synthesis of Primary Amines from Aldehydes and Ammonia. Catalysts 2015, 5, 2258-2270.

(205) Bodis, J.; Lefferts, L.; Mueller, T. E.; Pestman, R.; Lercher, J. A., Activity and Selectivity Control in Reductive Amination of Butyraldehyde over Noble Metal Catalysts. Catal. Lett. 2005, 104, 23-28. 
(206) Gomez, S.; Peters, J. A.; van der Waal, J. C.; Zhou, W.; Maschmeyer, T., Preparation of Benzylamine by Highly Selective Reductive Amination of Benzaldehyde over Ru on an Acidic Activated Carbon Support as the Catalyst. Catal. Lett. 2002, 84, 1-5.

(207) Li, B.; Liu, S.; Lin, Q.; Shao, Y.; Peng, S.; Li, Y., Ruthenium Nanoparticle Catalyzed Selective Reductive Amination of Imine with Aldehyde to Access Tertiary Amines. Chem. Commun. 2018, 54, 9214-9217.

(208) Song, S.; Wang, Y.; Yan, N., A Remarkable Solvent Effect on Reductive Amination of Ketones. Mol. Catal. 2018, 454, 87-93.

(209) Touchy, A. S.; Hakim Siddiki, S. M. A.; Kon, K.; Shimizu, K.-i., Heterogeneous Pt Catalysts for Reductive Amination of Levulinic Acid to Pyrrolidones. ACS Catal. 2014, 4, 3045-3050.

(210) Du, X.-L.; He, L.; Zhao, S.; Liu, Y.-M.; Cao, Y.; He, H.-Y.; Fan, K.-N., Hydrogen-Independent Reductive Transformation of Carbohydrate Biomass into $\psi$-Valerolactone and Pyrrolidone Derivatives with Supported Gold Catalysts. Angew. Chem., Int. Ed. 2011, 50, 7815-7819.

(211) Winans, C. F., Hydrogenation of Aldehydes in the Presence of Ammonia. J. Am. Chem. Soc. $1939,61,3566-3567$.

(212) Schafer, C.; Nisanci, B.; Bere, M. P.; Dastan, A.; Torok, B., Heterogeneous Catalytic Reductive Amination of Carbonyl Compounds with Ni-Al Alloy in Water as Solvent and Hydrogen Source. Synthesis 2016, 48, 3127-3133.

(213) Chary, K. V. R.; Seela, K. K.; Naresh, D.; Ramakanth, P., Characterization and Reductive Amination of Cyclohexanol and Cyclohexanone over $\mathrm{Cu} / \mathrm{ZrO}_{2}$ Catalysts. Catal. Commun. 2007, 9, 7581.

(214) Heinen, A. W.; Peters, J. A.; Van Bekkum, H., The Reductive Amination of Benzaldehyde over Pd/C Catalysts: Mechanism and Effect of Carbon Modifications on the Selectivity. Eur. J. Org. Chem. 2000, 2501-2506. 
(215) Chatterjee, M.; Ishizaka, T.; Kawanami, H., Reductive Amination of Furfural to Furfurylamine Using Aqueous Ammonia Solution and Molecular Hydrogen: an Environmentally Friendly Approach. Green Chem. 2016, 18, 487-496.

(216) Qi, F.; Hu, L.; Lu, S.; Cao, X.; Gu, H., Selective Synthesis of Secondary Amines by Pt Nanowire Catalyzed Reductive Amination of Aldehydes and Ketones with Ammonia. Chem. Commun. 2012, 48, 9631-9633.

(217) Nakamura, Y.; Kon, K.; Touchy, A. S.; Shimizu, K.-i.; Ueda, W., Selective Synthesis of Primary Amines by Reductive Amination of Ketones with Ammonia over Supported Pt catalysts. ChemCatChem 2015, 7, 921-924.

(218) Hudson, R.; Chazelle, V.; Bateman, M.; Roy, R.; Li, C.-J.; Moores, A., Sustainable Synthesis of Magnetic Ruthenium-Coated Iron Nanoparticles and Application in the Catalytic Transfer Hydrogenation of Ketones. ACS Sustainable Chem. Eng. 2015, 3, 814-820.

(219) Rauchdi, M.; Ait Ali, M.; Roucoux, A.; Denicourt-Nowicki, A., Novel Access to Verbenone via Ruthenium Nanoparticles-Catalyzed Oxidation of $\alpha$-Pinene in Neat Water. Appl. Catal., A 2018, 550, 266-273.

(220) Cao, G.-J.; Jiang, X.; Zhang, H.; Croley, T. R.; Yin, J.-J., Mimicking Horseradish Peroxidase and Oxidase using Ruthenium Nanomaterials. RSC Adv. 2017, 7, 52210-52217.

(221) Peng, S.; Liu, J.; Li, Q.; Zhang, J.; Niu, Q., PVP-Stabilized Ru Colloidal Nanoparticles by Solvothermal Synthesis: Preparation, Characterization, and Catalytic Properties. Integr. Ferroelectr. 2016, 170, 83-91.

(222) Ertl, G., Reactions at surfaces: from atoms to complexity (Nobel lecture). Angew. Chem., Int. Ed. 2008, 47, 3524-3535.

(223) Freund, H.-J.; Meijer, G.; Scheffler, M.; Schloegl, R.; Wolf, M., CO Oxidation as a Prototypical Reaction for Heterogeneous Processes. Angew. Chem., Int. Ed. 2011, 50, 10064-10094. 
(224) Song, C.; Sakata, O.; Kumara, L. S. R.; Kohara, S.; Yang, A.; Kusada, K.; Kobayashi, H.; Kitagawa, H., Size Dependence of Structural Parameters in fcc and hcp Ru Nanoparticles, Revealed by Rietveld Refinement Analysis of High-Energy X-ray Diffraction Data. Sci. Rep. 2016, 6, 31400.

(225) Sreedhala, S.; Vinod, C. P., Surfactant Assisted Formation of Ruthenium Nanochains under Mild Conditions and their Catalytic CO Oxidation Activity. Chem. Commun. 2015, 51, 10178-10181.

(226) Kusada, K.; Kobayashi, H.; Ikeda, R.; Kubota, Y.; Takata, M.; Toh, S.; Yamamoto, T.; Matsumura, S.; Sumi, N.; Sato, K.; Nagaoka, K.; Kitagawa, H., Solid Solution Alloy Nanoparticles of Immiscible Pd and Ru Elements Neighboring on Rh: Changeover of the Thermodynamic Behavior for Hydrogen Storage and Enhanced CO-Oxidizing Ability. J. Am. Chem. Soc. 2014, 136, 1864-1871.

(227) Huang, B.; Kobayashi, H.; Yamamoto, T.; Matsumura, S.; Nishida, Y.; Sato, K.; Nagaoka, K.; Kawaguchi, S.; Kubota, Y.; Kitagawa, H., Solid-Solution Alloying of Immiscible Ru and Cu with Enhanced CO Oxidation Activity. J. Am. Chem. Soc. 2017, 139, 4643-4646.

(228) Huang, B.; Kobayashi, H.; Yamamoto, T.; Toriyama, T.; Matsumura, S.; Nishida, Y.; Sato, K.; Nagaoka, K.; Haneda, M.; Xie, W.; Nanba, Y.; Koyama, M.; Wang, F.; Kawaguchi, S.; Kubota, Y.; Kitagawa, H., A CO Adsorption Site Change Induced by Copper Substitution in a Ruthenium Catalyst for Enhanced CO Oxidation Activity. Angew. Chem., Int. Ed. 2019, 58, 2230-2235.

(229) Wang, C.; Liu, S.; Wang, D.; Chen, Q., Interface Engineering of $\mathrm{Ru}-\mathrm{Co}_{3} \mathrm{O}_{4}$ Nanocomposites for Enhancing CO Oxidation. J. Mater. Chem. A 2018, 6, 11037-11043.

(230) Chen, W.; Lin, T.; Dai, Y.; An, Y.; Yu, F.; Zhong, L.; Li, S.; Sun, Y., Recent advances in the investigation of nanoeffects of Fischer-Tropsch catalysts. Catal. Today 2018, 311, 8-22.

(231) Xiao, C.-x.; Cai, Z.-p.; Wang, T.; Kou, Y.; Yan, N., Aqueous-Phase Fischer-Tropsch Synthesis with a Ruthenium Nanocluster Catalyst. Angew. Chem., Int. Ed. 2008, 47, 746-749.

(232) Yu, J.-W.; Li, W.-Z.; Zhang, T.; Ma, D.; Zhang, Y.-W., Ruthenium Nanoclusters Dispersed on Titania Nanorods and Nanoparticles as High-Performance Catalysts for Aqueous-Phase Fischer-Tropsch Synthesis. Catal. Sci. Technol. 2016, 6, 8355-8363. 
(233) Eslava, J. L.; Sun, X.; Gascon, J.; Kapteijn, F.; Rodriguez-Ramos, I., Ruthenium Particle Size and Cesium Promotion Effects in Fischer-Tropsch Synthesis over High-Surface-Area Graphite Supported Catalysts. Catal. Sci. Technol. 2017, 7, 1235-1244.

(234) Foppa, L.; Coperet, C.; Comas-Vives, A., Increased Back-Bonding Explains Step-Edge Reactivity and Particle Size Effect for CO Activation on Ru Nanoparticles. J. Am. Chem. Soc. 2016, 138, 1665516668

(235) Quek, X.-Y.; Filot, I. A. W.; Pestman, R.; van Santen, R. A.; Petkov, V.; Hensen, E. J. M., Correlating Fischer-Tropsch Activity to Ru Nanoparticle Surface Structure as Probed by High-Energy Xray Diffraction. Chem. Commun. 2014, 50, 6005-6008.

(236) Li, W.-Z.; Liu, J.-X.; Gu, J.; Zhou, W.; Yao, S.-Y.; Si, R.; Guo, Y.; Su, H.-Y.; Yan, C.-H.; Li, W.-X.; Zhang, Y.-W.; Ma, D., Chemical Insights into the Design and Development of Face-Centered Cubic Ruthenium Catalysts for Fischer-Tropsch Synthesis. J. Am. Chem. Soc. 2017, 139, 2267-2276.

(237) Quek, X.-Y.; Pestman, R.; van Santen, R. A.; Hensen, E. J. M., Structure Sensitivity in the Ruthenium Nanoparticle Catalyzed Aqueous-Phase Fischer-Tropsch Reaction. Catal. Sci. Technol. 2014, 4, 3510-3523.

(238) Filot, I. A. W.; Zijlstra, B.; Broos, R. J. P.; Chen, W.; Pestman, R.; Hensen, E. J. M., Kinetic Aspects of Chain Growth in Fischer-Tropsch Synthesis. Faraday Discuss. 2017, 197, 153-164.

(239) Filot, I. A. W.; van Santen, R. A.; Hensen, E. J. M., Quantum Chemistry of the Fischer-Tropsch Reaction Catalyzed by a Stepped Ruthenium Surface. Catal. Sci. Technol. 2014, 4, 3129-3140.

(240) Filot, I. A. W.; van Santen, R. A.; Hensen, E. J. M., The Optimally Performing Fischer-Tropsch Catalyst. Angew. Chem., Int. Ed. 2014, 53, 12746-12750.

(241) Ralston, W. T.; Liu, W.-C.; Alayoglu, S.; Melaet, G., Bimetallic Cobalt Nanoparticles (Co-M): Synthesis, Characterization, and Application in the Fischer-Tropsch Process. Top. Catal. 2018, 61, 10021015.

(242) Palazzolo, A.; Feuillastre, S.; Pfeifer, V.; Garcia-Argote, S.; Bouzouita, D.; Tricard, S.; Chollet, C.; Marcon, E.; Buisson, D.-A.; Cholet, S.; Fenaille, F.; Lippens, G.; Chaudret, B.; Pieters, G., Efficient Access 
to Deuterated and Tritiated Nucleobase Pharmaceuticals and Oligonucleotides using HydrogenIsotope Exchange. Angew. Chem., Int. Ed. 2019, 58, 4891-4895.

(243) Pieters, G.; Taglang, C.; Bonnefille, E.; Gutmann, T.; Puente, C.; Berthet, J.-C.; Dugave, C.; Chaudret, B.; Rousseau, B., Regioselective and Stereospecific Deuteration of Bioactive Aza Compounds by the Use of Ruthenium Nanoparticles. Angew. Chem., Int. Ed. 2014, 53, 230-234.

(244) Rothermel, N.; Bouzouita, D.; Roether, T.; de Rosal, I.; Tricard, S.; Poteau, R.; Gutmann, T.; Chaudret, B.; Limbach, H.-H.; Buntkowsky, G., Surprising Differences of Alkane C-H Activation Catalyzed by Ruthenium Nanoparticles: Complex Surface-Substrate Recognition? ChemCatChem 2018, 10, 42434247.

(245) Lin, M.; Kang, L.; Gu, J.; Dai, L.; Tang, S.; Zhang, T.; Wang, Y.; Li, L.; Zheng, X.; Zhu, W.; Si, R.; Fu, X.; Sun, L.; Zhang, Y.; Yan, C., Heterogeneous Synergistic Catalysis by Ru-RuOx Nanoparticles for Se-Se Bond Activation. Nano Res. 2017, 10, 922-932.

(246) Lin, M.; Dai, L.-X.; Gu, J.; Kang, L.-Q.; Wang, Y.-H.; Si, R.; Zhao, Z.-Q.; Liu, W.-C.; Fu, X.; Sun, L.D.; Zhang, Y.-W.; Yan, C.-H., Moderate Oxidation Levels of Ru Nanoparticles Enhance Molecular Oxygen Activation for Cross-Dehydrogenative-Coupling Reactions via Single Electron Transfer. RSC Adv. 2017, 7, 33078-33085.

(247) Gao, L.; Perato, S.; Garcia-Argote, S.; Taglang, C.; Martinez-Prieto, L. M.; Chollet, C.; Buisson, D.-A.; Dauvois, V.; Lesot, P.; Chaudret, B.; Rousseau, B.; Feuillastre, S.; Pieters, G., Ruthenium-Catalyzed Hydrogen Isotope Exchange of $\mathrm{C}\left(\mathrm{sp}^{3}\right)$-H Bonds Directed by a Sulfur Atom. Chem. Commun. 2018, 54, 2986-2989.

(248) Breso-Femenia, E.; Godard, C.; Claver, C.; Chaudret, B.; Castillon, S., Selective Catalytic Deuteration of Phosphorus Ligands using Ruthenium Nanoparticles: a New Approach to Gain Information on Ligand Coordination. Chem. Commun. 2015, 51, 16342-16345.

(249) Srivastava, V., Active Ruthenium (0) Nanoparticles Catalyzed Wittig-Type Olefination Reaction. Catal. Lett. 2017, 147, 693-703. 
(250) Higman, C. S.; Lanterna, A. E.; Marin, M. L.; Scaiano, J. C.; Fogg, D. E., Catalyst Decomposition during Olefin Metathesis Yields Isomerization-Active Ruthenium Nanoparticles. ChemCatChem 2016, 8, 2446-2449.

(251) Ganji, P.; van Leeuwen, P. W. N. M., Phosphine Supported Ruthenium Nanoparticle Catalyzed Synthesis of Substituted Pyrazines and Imidazoles from $\alpha$-Diketones. J. Org. Chem. 2017, 82, 17681774.

(252) Sakakura, T.; Choi, J.-C.; Yasuda, H., Transformation of Carbon Dioxide. Chem. Rev. 2007, 107, 2365-2387.

(253) Yan, N.; Philippot, K., Transformation of $\mathrm{CO}_{2}$ by Using Nanoscale Metal Catalysts: Cases Studies on the Formation of Formic Acid and Dimethylether. Curr. Opin. Chem. Eng. 2018, 20, 86-92.

(254) Senftle, T. P.; Carter, E. A., The Holy Grail: Chemistry Enabling an Economically Viable $\mathrm{CO}_{2}$ Capture, Utilization, and Storage Strategy. Acc. Chem. Res. 2017, 50, 472-475.

(255) Chauvier, C.; Cantat, T., A Viewpoint on Chemical Reductions of Carbon-Oxygen Bonds in Renewable Feedstocks Including $\mathrm{CO}_{2}$ and Biomass. ACS Catal. 2017, 7, 2107-2115.

(256) Qadir, M. I.; Weilhard, A.; Fernandes, J. A.; de Pedro, I.; Vieira, B. J. C.; Waerenborgh, J. C.; Dupont, J., Selective Carbon Dioxide Hydrogenation Driven by Ferromagnetic RuFe Nanoparticles in Ionic Liquids. ACS Catal. 2018, 8, 1621-1627.

(257) Jessop, P. G.; Joo, F.; Tai, C.-C., Recent Advances in the Homogeneous Hydrogenation of Carbon Dioxide. Coord. Chem. Rev. 2004, 248, 2425-2442.

(258) Dong, K.; Razzaq, R.; Hu, Y.; Ding, K., Homogeneous Reduction of Carbon Dioxide with Hydrogen. Top. Curr. Chem. 2017, 375, 1-26.

(259) Wang, W.; Wang, S.; Ma, X.; Gong, J., Recent Advances in Catalytic Hydrogenation of Carbon Dioxide. Chem. Soc. Rev. 2011, 40, 3703-3727.

(260) Alvarez, A.; Bansode, A.; Urakawa, A.; Bavykina, A. V.; Wezendonk, T. A.; Makkee, M.; Gascon, J.; Kapteijn, F., Challenges in the Greener Production of Formates/Formic Acid, Methanol, and DME by Heterogeneously Processes. Chem. Rev. 2017, 117, 9804-9838. 
(261) Aziz, M. A. A.; Jalil, A. A.; Triwahyono, S.; Ahmad, A., $\mathrm{CO}_{2}$ Methanation over Heterogeneous Catalysts: Recent Progress and Future Prospects. Green Chem. 2015, 17, 2647-2663.

(262) Aresta, M.; Dibenedetto, A.; Angelini, A., Catalysis for the Valorization of Exhaust Carbon: from $\mathrm{CO}_{2}$ to Chemicals, Materials, and Fuels. Technological Use of $\mathrm{CO}_{2}$. Chem. Rev. 2014, 114, 1709-1742.

(263) Müller, K.; Brooks, K.; Autrey, T., Hydrogen Storage in Formic Acid: A Comparison of Process Options. Energy \& Fuels 2017, 31, 12603-12611.

(264) Artz, J.; Müller, T. E.; Thenert, K.; Kleinekorte, J.; Meys, R.; Sternberg, A.; Bardow, A.; Leitner, W., Sustainable Conversion of Carbon Dioxide: An Integrated Review of Catalysis and Life Cycle Assessment. Chem. Rev. 2018, 118, 434-504.

(265) Wang, W.-H.; Himeda, Y.; Muckerman, J. T.; Manbeck, G. F.; Fujita, E., $\mathrm{CO}_{2}$ Hydrogenation to Formate and Methanol as an Alternative to Photo- and Electrochemical $\mathrm{CO}_{2}$ Reduction. Chem. Rev. 2015, 115, 12936-12973.

(266) Gunasekar, G. H.; Park, K.; Jung, K.-D.; Yoon, S., Recent Developments in the Catalytic Hydrogenation of $\mathrm{CO}_{2}$ to Formic Acid/Formate using Heterogeneous Catalysts. Inorg. Chem. Front. 2016, 3, 882-895.

(267) Bredig, G.; Carter, S. R., Katalytische Synthese der Ameisensäure unter Druck. Ber. Dtsch. Chem. Ges. 1914, 47, 541-545.

(268) Farlow, M. W.; Adkins, H., Hydrogenation of Carbon Dioxide and a Correction of the Reported Synthesis of Urethans. J. Am. Chem. Soc. 1935, 57, 2222-2223.

(269) Mori, K.; Taga, T.; Yamashita, H., Isolated Single-Atomic Ru Catalyst Bound on a Layered Double Hydroxide for Hydrogenation of $\mathrm{CO}_{2}$ to Formic Acid. ACS Catal. 2017, 7, 3147-3151.

(270) Hao, C.; Wang, S.; Li, M.; Kang, L.; Ma, X., Hydrogenation of $\mathrm{CO}_{2}$ to Formic Acid on Supported Ruthenium Catalysts. Catal. Today 2011, 160, 184-190.

(271) Weilhard, A.; Qadir, M. I.; Sans, V.; Dupont, J., Selective $\mathrm{CO}_{2}$ Hydrogenation to Formic Acid with Multifunctional Ionic Liquids. ACS Catal. 2018, 1628-1634. 
(272) Umegaki, T.; Enomoto, Y.; Kojima, Y., Metallic Ruthenium Nanoparticles for Hydrogenation of Supercritical Carbon Dioxide. Catal. Sci. Technol. 2016, 6, 409-412.

(273) Upadhyay, P. R.; Srivastava, V., Selective Hydrogenation of $\mathrm{CO}_{2}$ Gas to Formic Acid over Nanostructured Ru-TiO 2 Catalysts. RSC Adv. 2016, 6, 42297-42306.

(274) Lei, Z.; Dai, C.; Chen, B., Gas Solubility in Ionic Liquids. Chem. Rev. 2014, 114, 1289-1326.

(275) Upadhyay, P. R.; Srivastava, V., Ionic Liquid Mediated In Situ Synthesis of Ru Nanoparticles for $\mathrm{CO}_{2}$ Hydrogenation Reaction. Catal. Lett. 2017, 147, 1051-1060.

(276) Kattel, S.; Liu, P.; Chen, J. G., Tuning Selectivity of $\mathrm{CO}_{2}$ Hydrogenation Reactions at the Metal/Oxide Interface. J. Am. Chem. Soc. 2017, 139, 9739-9754.

(277) Kim, A.; Debecker, D. P.; Devred, F.; Dubois, V.; Sanchez, C.; Sassoye, C., $\mathrm{CO}_{2}$ methanation on $\mathrm{Ru} / \mathrm{TiO}_{2}$ catalysts: On the effect of mixing anatase and rutile $\mathrm{TiO}_{2}$ supports. Appl. Catal., B 2018, 220, 615-625.

(278) Guo, Y.; Mei, S.; Yuan, K.; Wang, D.-J.; Liu, H.-C.; Yan, C.-H.; Zhang, Y.-W., Low-Temperature $\mathrm{CO}_{2}$ Methanation over $\mathrm{CeO}_{2}$-Supported $\mathrm{Ru}$ Single Atoms, Nanoclusters, and Nanoparticles Competitively Tuned by Strong Metal-Support Interactions and H-Spillover Effect. ACS Catal. 2018, 8, 6203-6215.

(279) Navarro-Jaen, S.; Navarro, J. C.; Bobadilla, L. F.; Centeno, M. A.; Laguna, O. H.; Odriozola, J. A., Size-Tailored Ru Nanoparticles Deposited over $\mathrm{Y}^{-} \mathrm{Al}_{2} \mathrm{O}_{3}$ for the $\mathrm{CO}_{2}$ Methanation Reaction. Appl. Surf. Sci. 2019, 483, 750-761.

(280) Dou, J.; Sheng, Y.; Choong, C.; Chen, L.; Zeng, H. C., Silica nanowires encapsulated Ru nanoparticles as stable nanocatalysts for selective hydrogenation of $\mathrm{CO}_{2}$ to $\mathrm{CO}$. Appl. Catal., B 2017, $219,580-591$

(281) Bordet, A.; Lacroix, L.-M.; Fazzini, P.-F.; Carrey, J.; Soulantica, K.; Chaudret, B., Magnetically Induced Continuous $\mathrm{CO}_{2}$ Hydrogenation Using Composite Iron Carbide Nanoparticles of Exceptionally High Heating Power. Angew. Chem., Int. Ed. 2016, 55, 15894-15898. 
(282) Qadir, M. I.; Bernardi, F.; Scholten, J. D.; Baptista, D. L.; Dupont, J., Synergistic $\mathrm{CO}_{2}$ Hydrogenation over Bimetallic Ru/Ni Nanoparticles in Ionic Liquids. Appl. Catal., B 2019, 252, 10-17.

(283) Melo, C. I.; Szczepanska, A.; Bogel-Lukasik, E.; Nunes da Ponte, M.; Branco, L. C., Hydrogenation of Carbon Dioxide to Methane by Ruthenium Nanoparticles in Ionic Liquid. ChemSusChem 2016, 9, $1081-1084$

(284) Zhan, W.-W.; Zhu, Q.-L.; Xu, Q., Dehydrogenation of Ammonia Borane by Metal Nanoparticle Catalysts. ACS Catal. 2016, 6, 6892-6905.

(285) Hamilton, C. W.; Baker, R. T.; Staubitz, A.; Manners, I., B-N Compounds for Chemical Hydrogen Storage. Chem. Soc. Rev. 2009, 38, 279-293.

(286) Cao, N.; Su, J.; Hong, X.; Luo, W.; Cheng, G., In Situ Facile Synthesis of Ru-Based Core-Shell Nanoparticles Supported on Carbon Black and Their High Catalytic Activity in the Dehydrogenation of Amine-Boranes. Chem. - Asian J. 2014, 9, 562-571.

(287) Zahmakiran, M.; Tristany, M.; Philippot, K.; Fajerwerg, K.; Oezkar, S.; Chaudret, B., Aminopropyltriethoxysilane Stabilized Ruthenium(0) Nanoclusters as an Isolable and Reusable Heterogeneous Catalyst for the Dehydrogenation of Dimethylamine-Borane. Chem. Commun. 2010, $46,2938-2940$.

(288) Zahmakiran, M.; Philippot, K.; Oezkar, S.; Chaudret, B., Size-Controllable APTS Stabilized Ruthenium(0) Nanoparticles Catalyst for the Dehydrogenation of Dimethylamine-Borane at Room Temperature. Dalton Trans. 2012, 41, 590-598.

(289) Zahmakiran, M.; Ayval, T.; Philippot, K., In Situ Formed Catalytically Active Ruthenium Nanocatalyst in Room Temperature Dehydrogenation/Dehydrocoupling of Ammonia-Borane from $\mathrm{Ru}(\mathrm{cod})$ (cot) Precatalyst. Langmuir 2012, 28, 4908-4914.

(290) Duman, S.; Ozkar, S., Oleylamine-Stabilized Ruthenium(0) Nanoparticles Catalyst in Dehydrogenation of Dimethylamine-Borane. Int. J. Hydrogen Energy 2013, 38, 10000-10011. 
(291) Sen, B.; Kuyuldar, E.; Demirkan, B.; Onal Okyay, T.; Savk, A.; Sen, F., Highly Efficient Polymer Supported Monodisperse Ruthenium-Nickel Nanocomposites for Dehydrocoupling of Dimethylamine Borane. J. Colloid Interface Sci. 2018, 526, 480-486.

(292) Sen, B.; Aygun, A.; Ferdi Fellah, M.; Harbi Calimli, M.; Sen, F., Highly Monodispersed PalladiumRuthenium Alloy Nanoparticles Assembled on Poly(N-vinyl-pyrrolidone) for Dehydrocoupling of Dimethylamine-Borane: An Experimental and Density Functional Theory Study. J. Colloid Interface Sci. 2019, 546, 83-91.

(293) Sen, B.; Demirkan, B.; Savk, A.; Kartop, R.; Nas, M. S.; Alma, M. H.; Surdem, S.; Sen, F., HighPerformance Graphite-Supported Ruthenium Nanocatalyst for Hydrogen Evolution Reaction. J. Mol. Liq. 2018, 268, 807-812.

(294) Sen, B.; Kuzu, S.; Demir, E.; Akocak, S.; Sen, F., Highly Monodisperse RuCo Nanoparticles Decorated on Functionalized Multiwalled Carbon Nanotube with the Highest Observed Catalytic Activity in the Dehydrogenation of Dimethylamine-borane. Int. J. Hydrogen Energy 2017, 42, 2329223298.

(295) Sen, B.; Kuyuldar, E.; Şavk, A.; Calimli, H.; Duman, S.; Sen, F., Monodisperse Ruthenium-Copper Alloy Nanoparticles Decorated on Reduced Graphene Oxide for Dehydrogenation of DMAB. Int. J. Hydrogen Energy 2019, 44, 10744-10751.

(296) Sen, B.; Kuzu, S.; Demir, E.; Onal Okyay, T.; Sen, F., Hydrogen Liberation from Dehydrocoupling of Dimethylamine-Borane at Room Temperature by Using Novel and Highly Monodispersed RuPtNi Nanocatalysts Decorated with Graphene Oxide. Int. J. Hydrogen Energy 2017, 42, 23299-23306.

(297) Sen, B.; Demirkan, B.; Savk, A.; Karahan Gulbay, S.; Sen, F., Trimetallic PdRuNi Nanocomposites Decorated on Graphene Oxide: A Superior Catalyst for the Hydrogen Evolution Reaction. Int. J. Hydrogen Energy 2018, 43, 17984-17992.

(298) Sen, B.; Aygun, A.; Savk, A.; Duman, S.; Calimli, M. H.; Bulut, E.; Sen, F., Polymer-Graphene Hybrid Stabilized Ruthenium Nanocatalysts for the Dimethylamine-Borane Dehydrogenation at Ambient Conditions. J. Mol. Liq. 2019, 279, 578-583. 
(299) Fang, Y.; Li, J. L.; Togo, T.; Jin, F. Y.; Xiao, Z. F.; Liu, L. J.; Drake, H.; Lian, X. Z.; Zhou, H.-C., UltraSmall Face-Centered-Cubic Ru Nanoparticles Confined within a Porous Coordination Cage for Dehydrogenation. Chem 2018, 4, 555-563.

(300) Sun, J.-K.; Zhan, W.-W.; Akita, T.; Xu, Q., Toward Homogenization of Heterogeneous Metal Nanoparticle Catalysts with Enhanced Catalytic Performance: Soluble Porous Organic Cage as a Stabilizer and Homogenizer. J. Am. Chem. Soc. 2015, 137, 7063-7066.

(301) Peng, S.; Liu, J.; Zhang, J.; Wang, F., An Improved Preparation of Graphene Supported Ultrafine Ruthenium (0) NPs: Very Active and Durable Catalysts for $\mathrm{H}_{2}$ Generation from Methanolysis of Ammonia Borane. Int. J. Hydrogen Energy 2015, 40, 10856-10866.

(302) Abo-Hamed, E. K.; Pennycook, T.; Vaynzof, Y.; Toprakcioglu, C.; Koutsioubas, A.; Scherman, O. A., Highly Active Metastable Ruthenium Nanoparticles for Hydrogen Production through the Catalytic Hydrolysis of Ammonia Borane. Small 2014, 10, 3145-3152.

(303) Durap, F.; Caliskan, S.; Ozkar, S.; Karakas, K.; Zahmakiran, M., Dihydrogen Phosphate Stabilized Ruthenium(0) Nanoparticles: Efficient Nanocatalyst for the Hydrolysis of Ammonia-Borane at Room Temperature. Materials 2015, 8, 4226.

(304) Caliskan, S.; Zahmakiran, M.; Durap, F.; Oezkar, S., Hydrogen Liberation from the Hydrolytic Dehydrogenation of Dimethylamine-Borane at Room Temperature by Using a Novel Ruthenium Nanocatalyst. Dalton Trans. 2012, 41, 4976-4984.

(305) Rakap, M., Hydrogen Generation from Hydrolysis of Ammonia Borane in the Presence of Highly Efficient Poly(N-vinyl-2-pyrrolidone)-Protected Platinum-Ruthenium Nanoparticles. Appl. Catal., A 2014, 478, 15-20.

(306) Rakap, M., PVP-Stabilized Ru-Rh Nanoparticles as Highly Efficient Catalysts for Hydrogen Generation from Hydrolysis of Ammonia Borane. J. Alloys Compd. 2015, 649, 1025-1030.

(307) Tacyildiz, S.; Demirkan, B.; Karatas, Y.; Gulcan, M.; Sen, F., Monodisperse Ru-Rh Bimetallic Nanocatalyst as Highly Efficient Catalysts for Hydrogen Generation from Hydrolytic Dehydrogenation of Methylamine-Borane. J. Mol. Liq. 2019, 285, 1-8. 
(308) Chen, G.; Desinan, S.; Rosei, R.; Rosei, F.; Ma, D., Synthesis of Ni-Ru Alloy Nanoparticles and Their High Catalytic Activity in Dehydrogenation of Ammonia Borane. Chem. - Eur. J. 2012, 18, 79257930.

(309) Chen, G.; Desinan, S.; Nechache, R.; Rosei, R.; Rosei, F.; Ma, D., Bifunctional Catalytic/Magnetic Ni@Ru Core-Shell Nanoparticles. Chem. Commun. 2011, 47, 6308-6310.

(310) Chen, G.; Wang, R.; Zhao, W.; Kang, B.; Gao, D.; Li, C.; Lee, J. Y., Effect of Ru Crystal Phase on the Catalytic Activity of Hydrolytic Dehydrogenation of Ammonia Borane. J. Power Sources 2018, 396, 148-154.

(311) Akbayrak, S.; Ozkar, S., Hydrogen Generation from the Hydrolysis of Ammonia Borane Using Transition Metal Nanoparticles as Catalyst. In Hydrogen Production Technologies Sankir, M.; Sankir, N. D., Eds. Wiley-VCH Verlag GmbH \& Co. KGaA: 2017, 207-230.

(312) Kalkan, E. B.; Akbayrak, S.; Ozkar, S., Ruthenium(0) Nanoparticles Supported on Nanohafnia: A Highly Active and Long-Lived Catalyst in Hydrolytic Dehydrogenation of Ammonia Borane. J. Mol. Catal. A: Chem. 2017, 430, 29-35.

(313) Tonbul, Y.; Akbayrak, S.; Ozkar, S., Nano-Zirconia Supported Ruthenium(0) Nanoparticles: Highly Active and Reusable Catalyst in Hydrolytic Dehydrogenation of Ammonia Borane. J. Colloid Interface Sci. 2018, 513, 287-294.

(314) Sarca, E.; Akbayrak, S.; Ozkar, S., Ruthenium(0) Nanoparticles Supported on Silica Coated $\mathrm{Fe}_{3} \mathrm{O}_{4}$ as Magnetically Separable Catalysts for Hydrolytic Dehydrogenation of Ammonia Borane. Int. J. Hydrogen Energy 2018, 43, 15124-15134.

(315) Zhang, S.; Zhou, L.; Chen, M., Amine-Functionalized MIL-53(Al) with Embedded Ruthenium Nanoparticles as a Highly Efficient Catalyst for the Hydrolytic Dehydrogenation of Ammonia Borane. RSC Adv. 2018, 8, 12282-12291.

(316) Ma, Y.; Li, X.; Zhang, Y.; Chen, L.; Wu, J.; Gao, D.; Bi, J.; Fan, G., Ruthenium Nanoparticles Supported on TiO2 (B) Nanotubes: Effective Catalysts in Hydrogen Evolution from the Hydrolysis of Ammonia Borane. J. Alloys Compd. 2017, 708, 270-277. 
Catalyzed by Highly Efficient Bimetallic RuNi Nanoparticles Stabilized on $\mathrm{Ti}_{3} \mathrm{C}_{2} \mathrm{X}_{2}$ (X $\mathrm{XH}$ and/or F). Int. J. Hydrogen Energy 2015, 40, 3883-3891.

Li, X.; Zeng, C.; Fan, G., Magnetic RuCo Nanoparticles Supported on Two-Dimensional Titanium Carbide as Highly Active Catalysts for the Hydrolysis of Ammonia Borane. Int. J. Hydrogen Energy 2015, 40, 9217-9224.

(319) Garrido-Barros, P.; Gimbert-Surinach, C.; Matheu, R.; Sala, X.; Llobet, A., How to Make an Efficient and Robust Molecular Catalyst for Water Oxidation. Chem. Soc. Rev. 2017, 46, 6088-6098.

(320) Murphy, C. J.; Buriak, J. M., Best Practices for the Reporting of Colloidal Inorganic Nanomaterials. Chem. Mater. 2015, 27, 4911-4913.

(321) McCrory, C. C. L.; Jung, S.; Peters, J. C.; Jaramillo, T. F., Benchmarking Heterogeneous Electrocatalysts for the Oygen Evolution Reaction. J. Am. Chem. Soc. 2013, 135, 16977-16987.

(322) Creus, J.; De Tovar, J.; Romero, N.; Garcia-Anton, J.; Philippot, K.; Bofill, R.; Sala, X., Ruthenium Nanoparticles for Catalytic Water Splitting. ChemSusChem 2019, 12, 2493-2514.

(323) Matheu, R.; Francas, L.; Chernev, P.; Ertem, M. Z.; Batista, V.; Haumann, M.; Sala, X.; Llobet, A., Behavior of the Ru-bda Water Oxidation Catalyst Covalently Anchored on Glassy Carbon Electrodes. ACS Catal. 2015, 5, 3422-3429.

(324) Norskov, J. K.; Bligaard, T.; Logadottir, A.; Kitchin, J. R.; Chen, J. G.; Pandelov, S.; Stimming, U., Trends in the Exchange Current for Hydrogen Evolution. J. Electrochem. Soc. 2005, 152, J23-J26.

(325) Drouet, S.; Creus, J.; Colliere, V.; Amiens, C.; Garcia-Anton, J.; Sala, X.; Philippot, K., A Porous Ru Nanomaterial as an Efficient Electrocatalyst for the Hydrogen Evolution Reaction under Acidic and Neutral Conditions. Chem. Commun. 2017, 53, 11713-11716.

(326) Creus, J.; Drouet, S.; Surinach, S.; Lecante, P.; Colliere, V.; Poteau, R.; Philippot, K.; GarciaAnton, J.; Sala, X., Ligand-Capped Ru Nanoparticles as Efficient Electrocatalyst for the Hydrogen Evolution Reaction. ACS Catal. 2018, 8, 11094-11102. 
(327) Creus, J.; Mallon, L.; Romero, N.; Bofill, R.; Moya, A.; Fierro, J. L. G.; Mas-Balleste, R.; Sala, X.; Philippot, K.; Garcia-Anton, J., Ruthenium Nanoparticles Supported on Carbon Microfibers for Hydrogen Evolution Electrocatalysis. Eur. J. Inorg. Chem. 2019, 2019, 2071-2077.

(328) Yamada, Y.; Shikano, S.; Fukuzumi, S., Robustness of $\mathrm{Ru} / \mathrm{SiO}_{2}$ as a Hydrogen-Evolution Catalyst in a Photocatalytic System Using an Organic Photocatalyst. J. Phys. Chem. C 2013, 117, 13143-13152. (329) Yamada, Y.; Miyahigashi, T.; Kotani, H.; Ohkubo, K.; Fukuzumi, S.-I., Photocatalytic Hydrogen Evolution under Highly Basic Conditions by Using Ru Nanoparticles and 2-Phenyl-4-(1naphthyl)quinolinium Ion. J. Am. Chem. Soc. 2011, 133, 16136-16145.

(330) Kong, C.; Li, Z.; Lu, G., The Dual Functional Roles of Ru as Co-Catalyst and Stabilizer of Dye for Photocatalytic Hydrogen Evolution. Int. J. Hydrogen Energy 2015, 40, 5824-5830.

(331) Yamada, Y.; Yano, K.; Fukuzumi, S., Photocatalytic Hydrogen Evolution Using 9-Phenyl-10methyl-acridinium Ion Derivatives as Efficient Electron Mediators and Ru-Based Catalysts. Aust. J. Chem. 2012, 65, 1573-1581. 
